\title{
Modeled sulfur dioxide exposure from a proposed coal fired power plant, using geographic information systems and air dispersion modeling
}

\author{
Steven Jason Hutchens \\ West Virginia University
}

Follow this and additional works at: https://researchrepository.wvu.edu/etd

\section{Recommended Citation}

Hutchens, Steven Jason, "Modeled sulfur dioxide exposure from a proposed coal fired power plant, using geographic information systems and air dispersion modeling" (2004). Graduate Theses, Dissertations, and Problem Reports. 1971.

https://researchrepository.wvu.edu/etd/1971

This Thesis is protected by copyright and/or related rights. It has been brought to you by the The Research Repository @ WVU with permission from the rights-holder(s). You are free to use this Thesis in any way that is permitted by the copyright and related rights legislation that applies to your use. For other uses you must obtain permission from the rights-holder(s) directly, unless additional rights are indicated by a Creative Commons license in the record and/ or on the work itself. This Thesis has been accepted for inclusion in WVU Graduate Theses, Dissertations, and Problem Reports collection by an authorized administrator of The Research Repository @ WVU. For more information, please contact researchrepository@mail.wvu.edu. 


\title{
Modeled Sulfur Dioxide Exposure from a Proposed Coal Fired Power Plant, using Geographic Information Systems and Air Dispersion Modeling
}

\author{
Steven Jason Hutchens
}

Thesis submitted to the College of Engineering and Mineral Resources at West Virginia University in partial fulfillment of the requirements for the degree of

\author{
Master of Science \\ in \\ Safety Management \\ Area of Emphasis: Environmental Management
}

\author{
Gary Winn, Ph.D. (Chair) \\ David Whaley, Ph.D. \\ Michael Klishis, Ph.D. \\ Michael McCawley, Ph.D. \\ Michael Strager, Ph.D. \\ Department of Industrial and Management Systems Engineering \\ Morgantown, WV 2004
}

Keywords:

Geographic Information Systems, Air Dispersion Modeling, Sulfur Dioxide, Air Pollution, Sensitive Receptors 


\begin{abstract}
Modeled Sulfur Dioxide Exposure from a Proposed Coal Fired Power Plant, using Geographic Information Systems and Air Dispersion Modeling
\end{abstract}

\title{
Steven Jason Hutchens
}

This study models the contribution of sulfur dioxide $\left(\mathrm{SO}_{2}\right)$ from a proposed coal fired power plant (CFPP) above existing ambient levels. Most vulnerable to $\mathrm{SO}_{2}$ exposure appear to be the elderly, young, and diseased, here identified as sensitive receptors (SR). Epidemiologic studies suggest $260 \mu \mathrm{g} / \mathrm{m}^{3}$ as the lowest toxic threshold for SR exposure. It was hypothesized that added $\mathrm{SO}_{2}$ concentrations to existing ambient levels at regional sensitive receptors, under worst case scenario, would not exceed $260 \mu \mathrm{g} / \mathrm{m}^{3}$.

The methods used identify and quantify density locations of localized SR using geographic information systems. Modeled worst case air dispersion concentration exposure to localized SR was conducted using AERMOD. A kriged surface of 1145 modeled concentration points was generated to interpolate contour intervals of concentration contribution. Results show an increased exposure to $1.82 \mu \mathrm{g} / \mathrm{m}^{3} \mathrm{SO}_{2}$, well within $260 \mu \mathrm{g} / \mathrm{m}^{3}$. A higher density of young SR were observed than for the elderly and diseased. 


\section{Acknowledgments}

I would like to express my gratitude to, Dr. David Whaley, whose expertise, understanding, and patience added considerably to my graduate experience. I appreciate his vast knowledge and skill in many areas and his assistance in completing this thesis and my master's degree. I would also like to thank the other members of my committee, Dr. Gary Winn, Dr.Michael Klishis, Dr. Michael McCawley, and Dr. Michael Strager for the assistance they provided at all levels of my research. Each committee member provided me with sound knowledge and advice towards completing this thesis. Dr. Michael Strager has been considerably informative with all my GIS decisions, as well as Dr. Michael McCawley with the air dispersion modeling.

I thank my family for the support they provided me through my entire life and academic career, especially my parents, Lisa, and Travis. I would have not made it this far without their support, patience, and encouragement. Lastly, I extend my dearest appreciation to Jessica, without whose love, persisting encouragement, and understanding, I would not have finished this thesis. 


\section{Table of Contents}

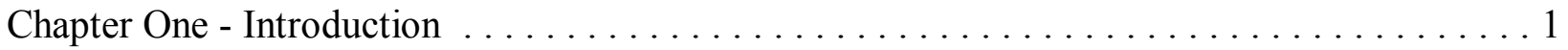

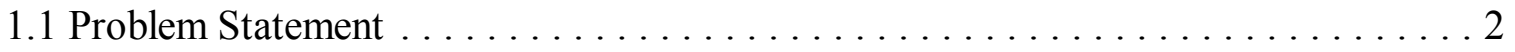

Chapter Two - Overview of Literature $\ldots \ldots \ldots \ldots \ldots \ldots \ldots \ldots \ldots \ldots \ldots \ldots$

$2.1 \quad$ Health concerns surrounding $\mathrm{SO}_{2} \ldots \ldots \ldots \ldots \ldots \ldots \ldots \ldots \ldots$

2.2 Air Quality Standards on $\mathrm{SO}_{2}$ attainment, and Air Quality of Surrounding Region

2.3 Air Pollution Meteorology: Effects of Temperature Inversions and Wind Velocity on Pollutant Dispersion . . . . . . . . . . . . . . . . . . . 13

2.4 Comparison of Air Dispersion Modeling Approaches $\ldots \ldots \ldots \ldots \ldots \ldots \ldots$

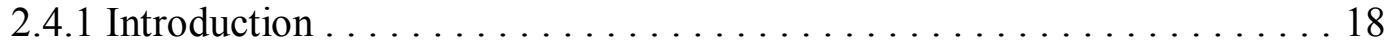

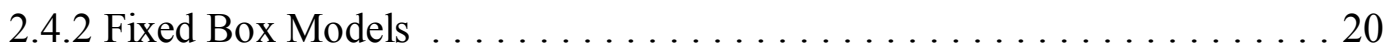

2.4.3 Multiple Cell Models . . . . . . . . . . . . . . . . . . . 21

2.4.4 Plume Dispersion Models . . . . . . . . . . . . . . . . . 22

2.4.4.1 Effect of Atmospheric Stability on Plume . . . . . . . . . 30

2.4.4.2 Modeling in Complex Terrain . . . . . . . . . . . . . . 31

2.4.4.3 United States Compliance Modeling . . . . . . . . . . . . . 31

2.5 Geographic Information Systems Applicability . . . . . . . . . . . . . . 34

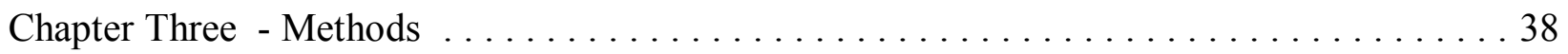

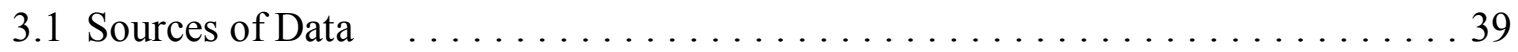

3.1.1 Geographic Information System (GIS) Data . . . . . . . . . . . . . . . 39

3.1.2 Proposed Coal Fired Power Plant (CFPP) Data . . . . . . . . . . . . . 40

3.1.3 Air Dispersion Modeling Data . . . . . . . . . . . . . . . . 41

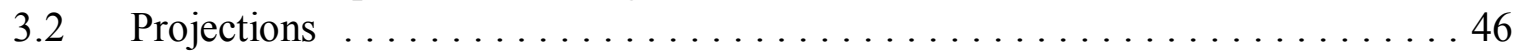

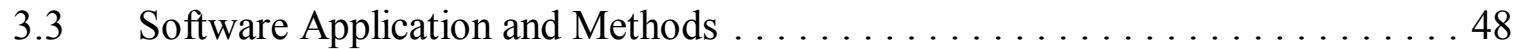

3.3.1 Method 1, Sensitive Receptors . . . . . . . . . . . . . . . . . . . . . . . . . . . . . . . .

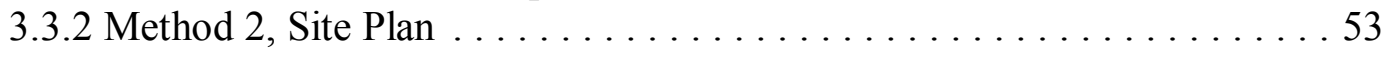

3.3.3 Method 3, Concentration Exposure Modeling . . . . . . . . . . . 55

Chapter 4 - Results . . . . . . . . . . . . . . . . . . . . . . . 62

4.1 Geographic Information Systems Spatial Analysis $\ldots \ldots \ldots \ldots \ldots \ldots \ldots \ldots$

4.2 Plot Plan Drawing Results for Potential Building Downwash . . . . . . . . . . 80

4.3 Concentration Exposure Modeling Results $\ldots \ldots \ldots \ldots \ldots \ldots \ldots$

Chapter 5 - Discussion and Summary . . . . . . . . . . . . . . . . . . . . 104

5.1 Summary of Categorized Sensitive Receptors Locations . . . . . . . . . . . . . . 105

5.2 Summary and Discussion of Worst Case Modeled $\mathrm{SO}_{2}$ Contribution Exposure . . 109

5.3 Discussion of Limitations . . . . . . . . . . . . . . . . . . 114

5.3.1 Categorized Sensitive Receptor Location Identification . . . . . . . . . . 114

5.3.2 Modeled Worst Case $\mathrm{SO}_{2}$ Exposure . . . . . . . . . . . . . . 116 


\section{Table of Contents \\ (continued)}

5.3.2.1 Modeled Provisional Maximum Ambient Air Concentration and

Prevention of Significant Deterioration Consumption . . . . . . 117

5.3.2.2 Gaussian Distribution Equation Limitations . . . . . . . . . . . . 121

5.3.2.3 Potential Stack Parameter Limitations . . . . . . . . . . . . . . . . . . . . . 123

5.3.2.4 Kriging Interpolation Limitations . . . . . . . . . . . . 123

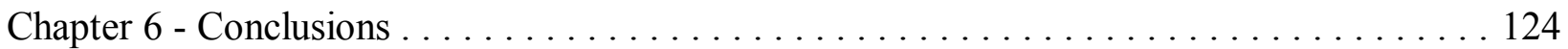

Chapter 7 - Recommendations . . . . . . . . . . . . . . . . . 127

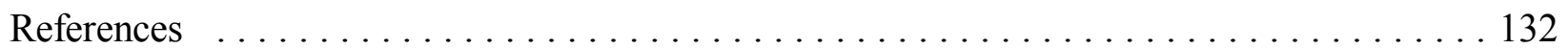

Appendix A - GIS Data Used . . . . . . . . . . . . . . . . . . . . . . . 139

Appendix B - Complete List of Yellowpages per Sensitive Receptor Category Matched to

Populated Places Tables . . . . . . . . . . . . . . . . . . . . . . . . . . 141

Appendix C - Complete List of Facilities per Category of Sensitive Receptors within Study Area

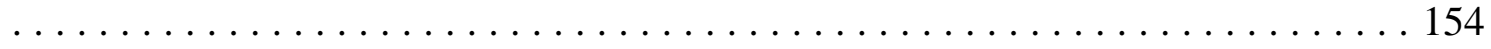




\section{List of Tables}

Table 2.1 - National Ambient Air Quality Standards for $\mathrm{SO} 2 \ldots \ldots \ldots \ldots \ldots$

Table 2.2 - Prevention of Significant Deterioration Increments Levels for $\mathrm{SO}_{2}$ for All Class II Air

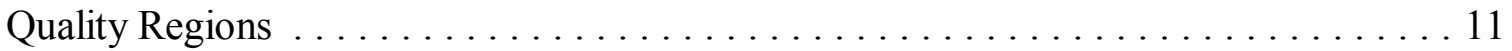

Table 2.3 - Pasquill and Gillford Stability Categories $\ldots \ldots \ldots \ldots \ldots \ldots \ldots$

Table 2.4 - Comparison of AERMOD and ISC Compliance Plume Models . . . . . . . . . 33

Table 3.1 - Longview PC Boiler Location and Stack Parameters . . . . . . . . . . . . 41

Table 3.2 - Surface Roughness Categories and Length $(\mathrm{m}) \ldots \ldots \ldots \ldots \ldots \ldots$

Table 3.3 - Monitored $\mathrm{SO}_{2}\left(\mu \mathrm{g} / \mathrm{m}^{3}\right)$ for $2000 \ldots \ldots \ldots \ldots \ldots \ldots \ldots \ldots \ldots \ldots \ldots \ldots \ldots \ldots \ldots$

Table 4.1 - Names of Populated Places Containing Sensitive Receptor Categories Used . . . . 65

Table 4.2 - Example of Tabular Data Matched between Yellowpages.com and the Populated

Places Database File Table ......................... 66

Table 4.3 - Database File Table: Sensitive Receptors at Populated Areas, Distance to Stack

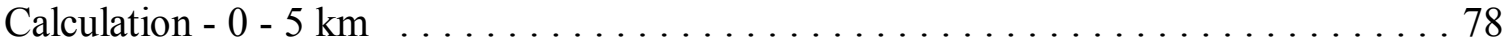

Table 4.4 - Database File Table: Sensitive Receptors at Populated Areas, Distance to Stack

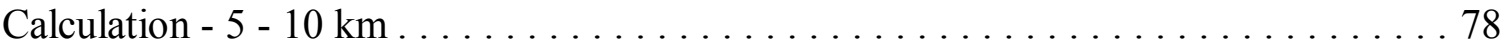

Table 4.5 - Database File Table: Sensitive Receptors at Populated Areas, Distance to Stack

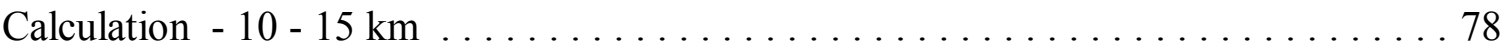

Table 4.6 - Database File Table: Sensitive Receptors at Populated Areas, Distance to Stack

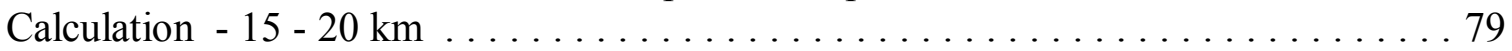

Table 4.7 - Database File Table: Sensitive Receptors at Populated Areas, Distance to Stack

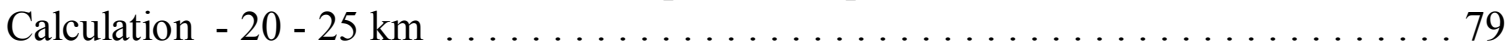

Table 4.8 - Database File Table: Sensitive Receptors at Populated Areas, Distance to Stack Calculation $-25-30 \mathrm{~km} \ldots \ldots \ldots \ldots \ldots \ldots \ldots \ldots$

Table 4.9 - Top 25 Maximum, 24 Hour Averaging $\mathrm{SO}_{2}$ Concentrations $\left(\mu \mathrm{g} / \mathrm{m}^{3}\right)$, for $2000 \ldots 84$

Table 4.10 - Top 25, 24 Hour $\mathrm{SO}_{2}$ Concentration $\left(\mu \mathrm{g} / \mathrm{m}^{3}\right)$ for June $11,2000 \ldots \ldots$. . . . 86 


\section{List of Tables \\ (continued)}

Table 4.11 - Top 25,24 Hour $\mathrm{SO}_{2}$ Concentration $\left(\mu \mathrm{g} / \mathrm{m}^{3}\right)$ for June $19,2000 \ldots \ldots \ldots$

Table 4.12 - Top 25,24 Hour $\mathrm{SO}_{2}$ Concentration $\left(\mu \mathrm{g} / \mathrm{m}^{3}\right)$ for June $16,2000 \ldots \ldots$. . . 87

Table 4.13 - Top 25, 24 Hour $\mathrm{SO}_{2}$ Concentration $\left(\mu \mathrm{g} / \mathrm{m}^{3}\right)$ for July $23,2000 \ldots \ldots 7$

Table 4.14 - Top 25, 24 Hour $\mathrm{SO}_{2}$ Concentration $\left(\mu \mathrm{g} / \mathrm{m}^{3}\right)$ for May, $312000 \ldots \ldots 8$

Tables 4.15 - June 11, 2000 Populated Place $\mathrm{SO}_{2}$ Concentration Contribution Calculations

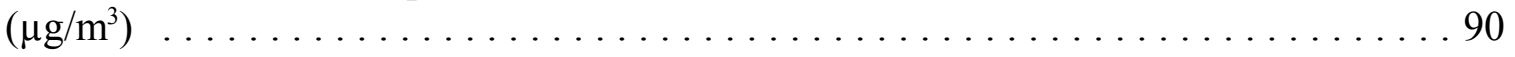

Tables 4.16 - June 19, 2000 Populated Place $\mathrm{SO}_{2}$ Concentration Contribution Calculations

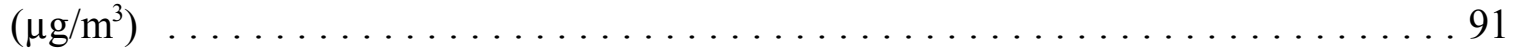

Tables 4.17 - July 23, 2000 Populated Place $\mathrm{SO}_{2}$ Concentration Contribution Calculations

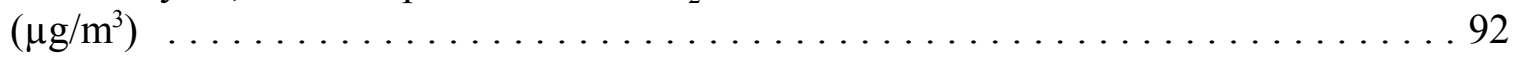

Tables 4.18 - June 16, 2000 Populated Place $\mathrm{SO}_{2}$ Concentration Contribution Calculations

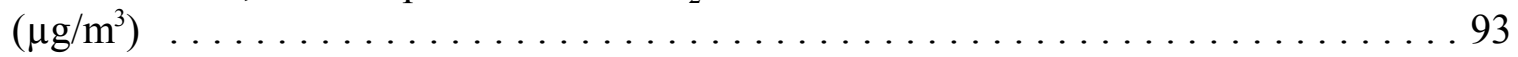

Tables 4.19 - May 31, 2000 Populated Place $\mathrm{SO}_{2}$ Concentration Contribution Calculations

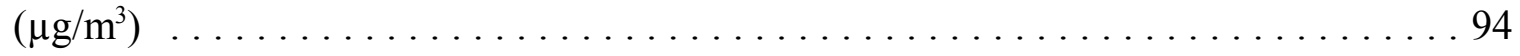

Table 4.20 - June 11, 2000 Krigning Cross Validation Results . . . . . . . . . . . . 101

Table 4.21 - June 19, 2000 Krigning Cross Validation Results . . . . . . . . . . . . . . 101

Table 4.22 - July 23, 2000 Krigning Cross Validation Results . . . . . . . . . . . . . 101

Table 4.23 - June 16, 2000 Krigning Cross Validation Results . . . . . . . . . . . . . . 101

Table 4.24 - May 31, 2000 Krigning Cross Validation Results . . . . . . . . . . . . . 101 


\section{List of Figures}

Figure 1 - Stagnation Index for May $2000 . \ldots \ldots \ldots \ldots \ldots \ldots \ldots \ldots \ldots \ldots \ldots \ldots \ldots \ldots \ldots$

Figure 2 - Stagnation Index for September $2000 \ldots \ldots \ldots \ldots \ldots \ldots \ldots \ldots \ldots \ldots \ldots$

Figure 3 - Gaussian plume distribution equation $\ldots \ldots \ldots \ldots \ldots \ldots \ldots \ldots \ldots$

Figure 4 - Gaussian plume distribution 3 dimensional coordinate system $\ldots \ldots \ldots \ldots$

Figure 5 - Horizontal dispersion coefficients for Pasquill and Gillford stability categories . . . . 28

Figure 6 - Vertical dispersion coefficients for Pasquill and Gillford stability categories . . . . . 29

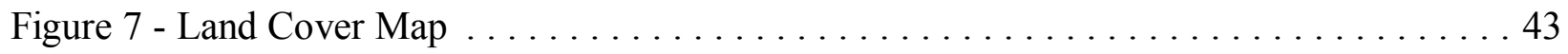

Figure 8 - US Census Bureau's Zip Code Tabulation Area Map . . . . . . . . . . . . . . 51

Figure 9 - 51 populated places with sensitive receptor categories, $30 \mathrm{~km}$ from source stack. . . 64

Figure 10 - Increment of annular distance to stack calculation. $\ldots \ldots \ldots \ldots \ldots \ldots$

Figure 11 - Counties and locations of sensitive receptor categories used within distance to stack

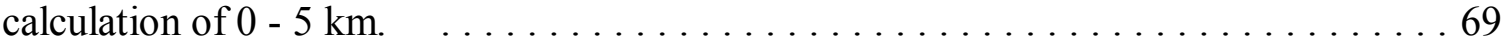

Figure 12 - Counties and locations of sensitive receptor categories used within distance to stack

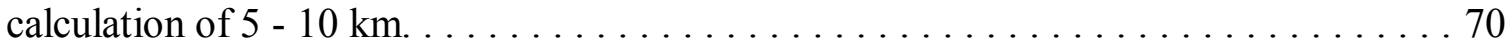

Figure 13 - Counties and locations of sensitive receptor categories used within distance to stack

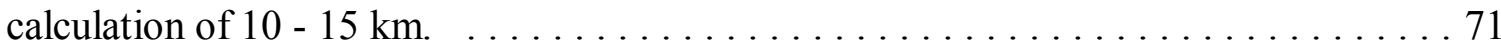

Figure 14 - Counties and locations of sensitive receptor categories used within distance to stack

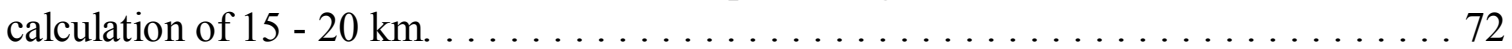

Figure 15 - Counties and locations of sensitive receptor categories used within distance to stack

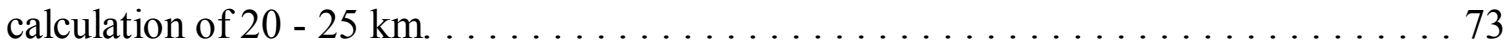

Figure 16 - Southwest Counties and locations of sensitive receptor categories used within distance to stack calculation of $25-30 \mathrm{~km} . \ldots \ldots \ldots \ldots \ldots \ldots \ldots \ldots$

Figure 17 - Southeast Counties and locations of sensitive receptor categories used within distance

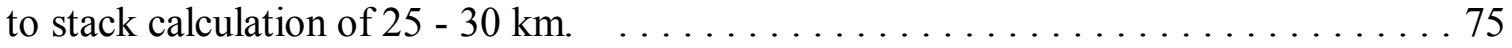




\section{List of Figures \\ (continued)}

Figure 18 - Northeast Counties and locations of sensitive receptor categories used within distance

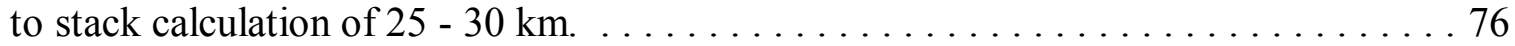

Figure 19 - Northwest Counties and locations of sensitive receptor categories used within

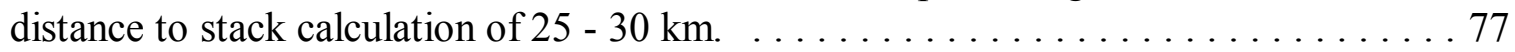

Figure 21 - Plot plan dimensions of proposed coal fired power plant $\ldots \ldots \ldots \ldots$. . . . 81

Figure 20 - 2 dimensional drawing of proposed coal fired power plant plot plan. . . . . . 81

Figure 22 - 3 dimensional modeling in the air dispersion modeling software, AERMOD. . . . 83

Figure 23 - June 11, 2000 concentration contribution contours from kriging $\left(\mu \mathrm{g} / \mathrm{m}^{3}\right)$ - highest 24

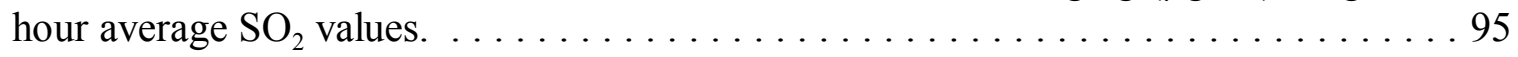

Figure 24 - June 19, 2000 concentration contribution contours from kriging $\left(\mu \mathrm{g} / \mathrm{m}^{3}\right)$ - highest 24

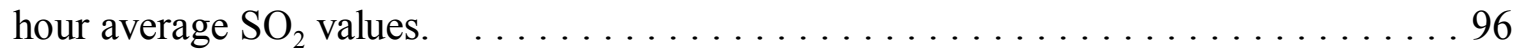

Figure 25 - July 23, 2000 concentration contribution contours from kriging $\left(\mu \mathrm{g} / \mathrm{m}^{3}\right)$ - highest 24

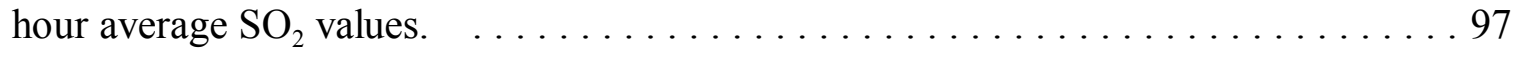

Figure 26 - June 16, 2000 concentration contribution contours from kriging $\left(\mu \mathrm{g} / \mathrm{m}^{3}\right)$ - highest 24

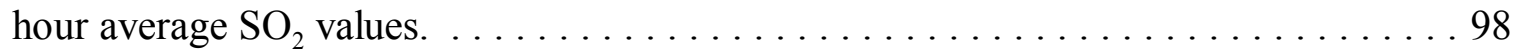

Figure 27 - May 31, 2000 concentration contribution contours from kriging $\left(\mu \mathrm{g} / \mathrm{m}^{3}\right)$ - highest 24

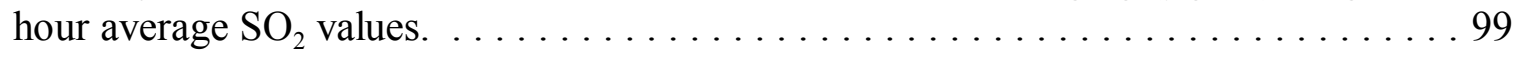

Figure 28 - Morgantown, West Virginia windrose for the year 2000 . . . . . . . . . . 102

Figure 29 - Quantity of sensitive receptor categories within $30 \mathrm{~km}$ of stack. $\ldots \ldots \ldots 6$

Figure 30 - Density of sensitive receptors within distance to stack range . . . . . . . 108

Figure 31 - Modeled increment consumption of prevention of significant deterioration, $91 \mu \mathrm{g} / \mathrm{m}^{3}$

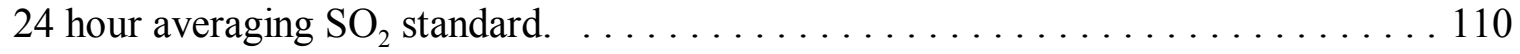

Figure 32 -Modeled increment consumption of prevention of significant deterioration, $91 \mu \mathrm{g} / \mathrm{m}^{3}$ 24 hour averaging $\mathrm{SO}_{2}$ standard by West Virginia Air Pollution Control Commission . 120 


\section{List of Figures \\ (continued)}

Figure 33: Modeled increment consumption of prevention of significant deterioration, $91 \mu \mathrm{g} / \mathrm{m}^{3}$

24 hour averaging $\mathrm{SO}_{2}$ standard by West Virginia Department of Air Quality . . . . . 121

Figure 34 - Inverse relationship between wind speed and $\mathrm{SO}_{2}$ calculated concentrations. . . . 122 


\section{List of Acronyms}

2D - 2 Dimensional

3D - 3 Dimensional

AERMAP - American Meteorological Society/Environmental Protection Regulatory Terrain Preprocessor

AERMET - American Meteorological Society/Environmental Protection Regulatory Meteorology Preprocessor

AERMOD - American Meteorological Society/Environmental Protection Regulatory Model

ANS - Autonomic Nervous System

ATSDR - Agency for Toxic Substance and Disease Registry

CAA - Clean Air Act

CAD - Computer Assisted Drafting

CFPP - Coal Fired Power Plant

CFR - Code of Federal Regulations

COPD - Chronic Obstructive Pulmonary Disease

DBF - Database File

DEM - Digital Elevation Model

ESRI - Environmental Research Institute

FAA - Federal Aviation Administration

FIPS - Federal Information Providing Service

GCS - Geographic Coordinate System

GEP - Good Engineering Practices

GIS - Geographic Information Systems

ISC - Industrial Source Complex Model

LIDAR - Light Detection and Ranging

NAAQS - National Ambient Air Quality Standards

NAD - North American Datum

NAMS - National Air Monitoring System

$\mathrm{NO}_{\mathrm{X}}$ - Nitrous Oxides

PASDA - Pennsylvania Spatial Data Access

PBL - Planetary Boundary Layer

PSD - Prevention of Significant Deterioration

SBL - Stable Boundary Layer

SLAMS - State Local Air Monitoring System

$\mathrm{SO}_{2}$ - Sulfur Dioxide

TRI - Toxic Release Inventory

UCS - User Coordinate System

US EPA - United States Environmental Protection Agency

USGS - United States Geological Survey

UTM - Universal Transverse Mercador

VOC - Volatile Organic Compounds

WCS - World Coordinate System 


\section{List of Acronyms \\ (continued)}

WV DAQ - West Virginia Division of Air Quality

WV DEP - West Virginia Department of Environmental Protection

WV NRAC - West Virginia Natural Resources Analysis Center

WVU - West Virginia University

ZCTA - Zip Code Tabulation Area 


\section{Chapter One - Introduction}

Today, there is an ongoing debate regarding the health effects of coal fired power plant (CFPP) emissions, especially on vulnerable populations of society, particularly the elderly, sick, and young. Sulfur Dioxide $\left(\mathrm{SO}_{2}\right)$ is a major pollutant of concern. Industrial smog occurs when carbon and oxygen come together to form carbon dioxide and carbon monoxide, or when sulfur compounds come together with oxygen, forming $\mathrm{SO}_{2}$. State air monitoring systems throughout the country are currently collecting and analyzing concentrations of $\mathrm{SO}_{2} \cdot \mathrm{SO}_{2}$ emissions are a result of fossil fuel combustion. The goal of this thesis was to estimate from GIS spatial analysis and dispersion modeling the contribution of $\mathrm{SO}_{2}$, from a proposed new coal-fired electricity generating plant under review for construction, to potential human exposure. This new plant is to be located near the Monongahela River valley in Monongalia County West Virginia. Two existing CFPP are currently located within the valley, in the same county along the same river.

This thesis hypothesizes that the added $\mathrm{SO}_{2}$ concentration contribution from the new CFPP to existing ambient levels of $\mathrm{SO}_{2}$ at regional sensitive receptors, under worst case scenario, will not exceed the provisional maximum ambient $\mathrm{SO}_{2}$ concentration for this study, or other applicable air quality standards. The direct contribution of $\mathrm{SO}_{2}$ from the proposed power plant to sensitive receptors, under worst case scenario, was analyzed through dispersion modeling and spatial analysis. Worst case scenario, is to be defined in this study, as the highest modeled 24 hour average pollutant contribution concentrations. In designing this research, it was assumed that through dispersion of it's $\mathrm{SO}_{2}$ concentrations under such circumstances, ambient air concentrations will show an increase of the pollutant at prioritized sensitive receptors, contributed by the new CFPP. A discussion of the provisional maximum ambient $\mathrm{SO}_{2}$ concentration for this 
study and air quality standards are to follow.

\subsection{Problem Statement}

Throughout the past decade, health concerns surrounding air pollution has increased.

Evidence of such concerns has mounted, through extensive research conducted, both on smalland large-scale areas, by government, the private sector, and universities. Research on $\mathrm{SO}_{2}$ has been shown to have respiratory impacts on all living organisms tested. Among humans, the elderly, sick, and young are of greatest concern because they are more vulnerable to health damage from industrial $\operatorname{smog}^{1,11,12,15,17,19,23,32,38}$

The study area of this thesis, outward from the proposed CFPP to a 30 kilometer radius, includes the city of greater Morgantown. The enhanced $\mathrm{SO}_{2}$ exposure modeled for the local air quality region was added to ambient monitored background concentrations for $\mathrm{SO}_{2}$ (a criteria pollutant)for the same year. ${ }^{62}$ The local air quality region, including greater Morgantown, is currently within primary National Ambient Air Quality Standards (NAAQS) attainment for $\mathrm{SO}_{2}$. The overall goal of this thesis was to assess the proposed new CFPP $\mathrm{SO}_{2}$ contribution to exposure of sensitive populations in the area, seeing if these proposed emissions are likely to advance the study area into an un-healthy, non-attainment region for $\mathrm{SO}_{2}$, as discussed in the following section. Therefore, I modeled the transport and dispersion of $\mathrm{SO}_{2}$ emissions from the proposed CFPP to local prioritized sensitive receptor locations, which were identified using Geographic Information Systems (GIS).

The volume of spatial research regarding exposure of sensitive populations to air polluting sources is vastly expanding across the world ${ }^{10,11,38,43,45,51}$ showing a cause for concern. Like most of the Mid-Atlantic and Northeast regions of the United States, Morgantown and the surrounding 
area are characteristically subjected to coal fired power plant (CFPP) emissions. Coal production and coal produced electricity are major industries in the region, producing emissions which are complex to model, due to the complex meteorology conditions associated with surrounding mountainous topology (as discussed below).

Compliance type modeling of regional air pollution, as defined by the Clean Air Act (CAA) and it regulations has been the only type of air dispersion modeling conducted within the region recently. There has been very limited air pollution modeling conducted on the surrounding region at West Virginia University or by other entities. For this reason, I decided that allowing the addition of another CFPP in the region warranted a review of its direct contribution to already existing air pollution concentrations, as well as review of sensitive population exposures in the area. Air dispersion modeling is continually evolving in technology and use, due to the increased pressure of concern for health threat from air pollution. Scientist's, epidemiologist's, air dispersion modelers, public health authorities, Geographic Information Systems (GIS) professionals, the federal government, and academic communities are all contributing to this body

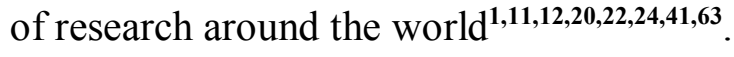




\section{Chapter Two - Overview of Literature}

\subsection{Health concerns surrounding $\mathrm{SO}_{2}$}

Sulfur dioxide is formed mostly during combustion of fossil fuels containing sulfur, but can form from other industrial processes as well. The literature contains substantial data, as evidence for the relationship between monitored ambient levels or experimentally defined exposure levels and associated health effects of sulfur dioxide. Recent monitoring and health studies have implicated that high concentrations of $\mathrm{SO}_{2}$ aggravate lung and cardiovascular diseases, and may disrupt respiratory defenses and the nervous system. ${ }^{11,12,15,22,23,32,47,52}$ Evidence has also been published that $\mathrm{SO}_{2}$, present at high enough concentrations, can disrupt the breathing of healthy individuals. ${ }^{11,17,33,42,45,47,54,55,60}$

Clinical studies have demonstrated that in adolescents and senior citizens, susceptibility to $\mathrm{SO}_{2}$ is determined primarily by respiratory health, not by age alone. ${ }^{72}$ The minimal risk level for sulfur dioxide, according to the Agency for Toxic Substances and Disease Registry (ATSDR) is $260 \mu \mathrm{g} / \mathrm{m}^{3} .{ }^{72}$ This is the lowest level at which increased bronchioconstriction of humans has been recognized in epidemiological studies and is set to be the provisionally maximum ambient air concentration of this study. Due to such literature evidence, the United States Environmental Protection Agency (EPA) and West Virginia Division Air Quality consider $\mathrm{SO}_{2}$ a harmful pollutant to public health. Therefore EPA has promulgated an ambient primary standard for $\mathrm{SO}_{2}$ to protect public health, as a criteria air pollutant NAAQS, requiring regular ambient monitoring by states.

Health problems associated with air pollution are not new information. The public health effects of air pollution have been a concern for quite some time., ${ }^{2,11,19,41,45,46,60}$ Citizens demands 
for cleaner air and subsequent legislation began in the late 1940's when it became apparent that air pollution episodes were effecting public health. One such event occurred in October of 1948, within the same river valley as the proposed power plant being evaluated in this thesis. During late October of that year, a six day, increased air pollution episode in the Monongahela River Valley, in Donora, Pennsylvania, resulted in several deaths and thousands of residents suffering additional adverse health effects. ${ }^{46}$ Around the same time period, other episodes were starting to be noticed throughout the world, gaining more attention from scientists and the public, stimulating the passage of new clean air legislation. ${ }^{17}$ Since then massive research has been devoted toward the association of air pollution with health deterioration.

Many laboratory animal and epidemiological studies have been conducted on the health effects of different criteria air pollutants, including sulfur dioxide. Scientists have emphasized the need to establish a biological plausible link between the health effects and air pollution, as described in many epidemiological reports..$^{12,22,28,33,41,46,47,52,53,54,55,65}$ One animal study involved administration of sulfur dioxide by inhalation to healthy adult mice that resulted in oxidative damage to stomachs and intestines. ${ }^{28}$ This study concluded that $\mathrm{SO}_{2}$ can also be a toxic agent to stomach and intestines of mammals, in addition to its toxicity to the respiratory system. ${ }^{28}$

Another recent study observed heart rate variability in non-exercising asthmatic adult humans undergoing $\mathrm{SO}_{2}$ pollutant exposure. ${ }^{54}$ This study found that the autonomic nervous system (ANS) may be influenced by $\mathrm{SO}_{2}$ at concentrations frequently encountered during air pollution episodes. ${ }^{54}$ The ANS is the part of nervous system that regulates vegetative organs of the body, such as the functions of heart, stomach, intestines, and other smooth muscle. ANS functions are reflexive and involuntary, controlling heart beat, blood pressure, iris in the eye, 
urinary and gall bladders, among other tissues and organs. The research on effects of exposure of $\mathrm{SO}_{2}$ on the ANS has recently expanded. ${ }^{22,54}$

It is well established that $\mathrm{SO}_{2}$ is a strong respiratory irritant to both humans and animals. $\mathrm{SO}_{2}$ exposure has different consequences depending on the health and age of an individual human or animal, and on concentration and duration of exposure. Recent studies suggest larger concentrations of $\mathrm{SO}_{2}$ create more severe health effects, a dose/response effect. ${ }^{\mathbf{2 8 , 4 7 , 5 2}}$ Large concentrations of $\mathrm{SO}_{2}$ are now thought to cause premature death in individuals with pre-existing heart and lung disease and also to aggravate asthma and other lung diseases in individuals of all ages. Research is showing that active asthmatics, the elderly, and very young are more susceptible to $\mathrm{SO}_{2}$ because of pre-existing medical condition and weaker immune systems, as is the case with most other criteria pollutants. ${ }^{62}$ The human immune system deteriorates from aging, and may be further weakened by disease, improving the likelihood for infection. Immune systems in infants and young children are still developing. Exposing these infants and young children to $\mathrm{SO}_{2}$ levels alone appear to intensify existing illness. A group of panel studies have been conducted on humans diagnosed with chronic obstructive pulmonary disease (COPD), which includes asthma, chronic bronchitis, bronchiectasis and emphysema. ${ }^{33}$ During maximum $\mathrm{SO}_{2}$ exposure in these studies, $4200 \mu \mathrm{g} / \mathrm{m}^{3}$ for 3 minutes, wheezing on the same day was observed, as well as at 24 hours and up to 48 hours later. ${ }^{33}$

As one can see, evidence is very strong that adverse health consequences are clearly associated with the inhalation of sulfur dioxide environmental air pollution. As mentioned above, epidemiologic studies have drawn such association. The body of such causality studies continues to grow. Causality studies, in this context, are those in which human volunteers are the study and 
control samples of the population, giving us more accurate insight towards the detrimental effects of particular exposure concentrations and durations on humans for a particular pollutant of concern. Causality studies give scientists a firmer estimate of risk to humans than those results extrapolated across species from studying rats and other laboratory animal models. Sufficient data are now available to support the need to assess public health risks associated with $\mathrm{SO}_{2}$, among other criteria pollutants.

Various epidemiologic studies have been conducted internationally. In summary, such studies continue to find disproportionately high respiratory diseases in children in urban areas throughout the United States and in other countries. ${ }^{\mathbf{1 2 , 3 8}}$ Epidemiologic studies involve drawing correlations between exposure estimates, air monitoring, biological samples, questionnaire responses, functional studies, and other, medical outcomes. In some types of epidemiologic study design, where possible, the effects on samples of exposed groups of individuals are compared with samples of unexposed groups.

\subsection{Air Quality Standards on $\mathrm{SO}_{2}$ attainment, and Air Quality of Surrounding Region}

Recognition that high levels of air pollution induce or aggravate certain respiratory illnesses as well as strong lobbying of Congress by citizen's groups, led to the establishment of the Clean Air Act in 1970. ${ }^{19,62}$ The goal of the act was to set and achieve National Ambient Air Quality Standards (NAAQS). Primary versus secondary standards are discussed below. Later amendments to the Act required prevention of significant deterioration (PSD) of areas with pristine air quality and those populated non-pristine regions already in attainment with NAAQS. The CAA Amendments of 1977 established the requirement that US EPA designate maximum 
PSD increments, classified per region, for all criteria pollutants. There are three PSD classifications. Class I areas include those regions with pristine air quality, like wilderness areas, and other national parks. Class II areas are non-pristine areas that are well within NAAQS attainment. Class III are those regions not in attainment with NAAQS and must strive for Class II advancement.

Currently the State of West Virginia, Department of Environmental Protection (DEP) Division of Air Quality (DAQ) monitors ambient air compliance in the air quality regions within the state to ensure NAAQS attainments are maintained. Using both continuous and periodic monitoring systems strategically located throughout the state, the air monitoring division of WV DAQ collects, analyzes and reports on air monitored concentrations; these data are available to the public. The US EPA requires each state to develop a State Implementation Plan (SIP), acceptable to the EPA, for attaining NAAQS compliance in non-attainment air quality regions and to maintain compliance. Currently the West Virginia State Implementation Plan (SIP) requirement for ambient air monitoring for criteria pollutants meets guidelines set forth by the EPA. As stated in 40 CFR $51.166,{ }^{6}$ all SIP shall contain emission limitations and such other measures as may be necessary to prevent significant deterioration of air quality that is in attainment to NAAQS.

PSD increments for pollutants within attainment are established in the WV SIP in order to prevent existing ambient air pollution from deteriorating, by maintaining attainment levels of all NAAQS criteria pollutants, including $\mathrm{SO}_{2}$. One PSD increment allotted for all contributing sources, including the proposed CFPP, is a maximum of $91 \mu \mathrm{g} / \mathrm{m}^{3}$ of $\mathrm{SO}_{2}$ in an averaging period of 24 hours. ${ }^{57}$ This is an amount that all regional air polluting facilities will be able to emit 
without causing a significant deterioration in air quality which would further push the area significantly toward non-attainment, for that PSD increment. The last major PSD increment consuming source addition was the Beehurst Power Plant in Morgantown at the shore of the Monongahela River in 1989. This addition, together with all other increment consuming sources in 1988, modeled an increment consumption that nearly consumed the entire $91 \mu \mathrm{g} / \mathrm{m}^{3}$ of $\mathrm{SO}_{2}$ in an averaging period of 24 hours, PSD increment. ${ }^{70}$ This is addressed, in detail, in chapter 5.

Whereas the PSD increment allowed by the US EPA for all Class II regions is fitted at $91 \mu \mathrm{g} / \mathrm{m}^{3}$, the proportion of this increment actually used by regional sources, as 24 -hour averages over a year, will vary from year to year. This work has assumed that the totality (or number) of all other contributing sources has not varied, with the naturally varying PSD increment consumption from year to year, in the time span since Beechurst Power Plant. Any contribution from the new CFPP source would be the only source potentially causing the region to exceed the allowed leftover PSD increment.

The PSD increment level of $91 \mu \mathrm{g} / \mathrm{m}^{3}$ of $\mathrm{SO}_{2}$ in an averaging period of 24 hours is going to be the chosen air quality standard level for interpreting the exposure contribution modeled from the proposed CFPP in this thesis. Any contribution exposure levels modeled to exceed $91 \mu \mathrm{g} / \mathrm{m}^{3}$ in a 24 hour averaging period at spatially analyzed and prioritized sensitive receptors will be assumed to exceed the standard, therefore potentially creating levels harmful to human health. Relative to the usual range of emission rates from nearby CFPP sources, and other air polluting sources, this permitted PSD increment is huge, that is, very generous to regional air polluting businesses given today's Best Available Control Technologies (BACT). While development of the primary NAAQS is based on protecting human health and property (primary and secondary 
pollutants), the PSD is based on what emission control is achievable, using BACT available at the time a PSD increment consumption is determined by the SIP modeling requirements and US EPA.

As described above, $\mathrm{SO}_{2}$ aggravates lung and cardiovascular diseases, and may disrupt respiratory defenses and the autonomic nervous system. $\mathrm{SO}_{2}$ is a criteria pollutant to which both primary and secondary NAAQS apply. The Clean Air Act mandates EPA to establish the more strict primary ambient air standards to protect public health, including the health of sensitive groups. A margin of safety that includes consideration of uncertainties in knowledge is also mandated, which leads to continual research and review of ambient air standards. In addition, the EPA must establish a secondary NAAQS for all criteria pollutants, including SO2, which is a less strict, higher concentration, in order to protect property from damage (Table 2.1).

Below are tables from EPA and the PSD Permit Application for the proposed CFPP, indicating NAAQS standards and PSD Increment levels, of SO. ${ }^{57,60}$ These NAAQS values represent thresholds for non-attainment. Each CFPP and other air emitters within the state share the combined amount of on-site air releases, designated by the EPA and WV DAQ in increment levels for each site, as not to exceed the NAAQS threshold. Currently WV DEP models for compliance, all emission sources contributing to PSD increment levels.

Table 2.1 NAAQS for SO2

\begin{tabular}{|c|c|c|}
\hline Averaging Period & Standard Value & Standard Type \\
\hline Annual Arithmetic Mean & $80 \mu \mathrm{g} / \mathrm{m}^{3}$ & Primary \\
\hline 24-hour Average & $365 \mu \mathrm{g} / \mathrm{m}^{3}$ & Primary \\
\hline 3-hour Average & $1300 \mu \mathrm{g} / \mathrm{m}^{3}$ & Secondary \\
\hline
\end{tabular}


Table 2.2 PSD Increments Level s for $\mathrm{SO}_{2}$ for All Class II Air Quality Regions

\begin{tabular}{|c|c|}
\hline Averaging Period & PSD Increment \\
\hline Annual Arithmetic Mean & $20 \mu \mathrm{g} / \mathrm{m}^{3}$ \\
\hline 24-hour Average & $91 \mu \mathrm{g} / \mathrm{m}^{3}$ \\
\hline 3-hour Average & $521 \mu \mathrm{g} / \mathrm{m}^{3}$ \\
\hline
\end{tabular}

Given the population size and industries of northern West Virginia and the surrounding region, ambient air standard attainment is met for most of the year., $2,25,37,64$ The proposed study area, explained in more detail in the following chapter, is going to be within a $30 \mathrm{~km}$ radius of the proposed new stack location. This reaches far into Pennsylvania, and West Virginia. Beyond the proposed study area, the consensus from the literature is that coal fired power plants are one of the most significant $\mathrm{SO}_{2}$ polluters within this Northern Appalachian region. ${ }^{2,11,59}$ It is important to note, that if industries in this region continue to grow, $\mathrm{SO}_{2}$ ambient air standard attainment may be lost. Greater Morgantown is steadily growing and has recently been assigned metropolitan status by the US Census Bureau, based on the 2000 Census.

The study area is within one of the primary bituminous coal-producing regions of the U.S., so naturally all nearby electric power plants are fueled by bituminous coal, which is known to produce higher amounts of $\mathrm{SO}_{2}$ than other grades of coal. The proposed power plant emissions could locally affect northern West Virginia and nearby states as well. As stated earlier, the proposed site is roughly 2 miles, straight line distance, south of the Pennsylvania state line and the prevailing wind for area ridge tops, where the proposed CFPP is to be constructed, are directed toward the east-northeast. It is important to note however, that prevailing wind direction changes inside valleys compared to surrounding ridge tops. Both states are currently meeting NAAQS 
attainment for $\mathrm{SO}_{2}$ withing the region. ${ }^{25,37,65}$

For West Virginia and Pennsylvania, this area contains various air polluting industries. ${ }^{\mathbf{2 5 9}}$ The Toxic Release Inventories (TRI) for various years, for each of these states, cite CFPPs as the largest stationary source contributors of on-site releases in pounds of $\mathrm{SO}_{2}$ for air pollution. Allegheny Energy Inc., Fort Martin Power Station, Maidsville, West Virginia was third, on the top ten list of facilities, cited per pound of emissions, on the EPA TRI Fact Sheet for 2000 in West Virginia. The site location for the proposed plant is located on the hillside above Fort Martin, less than 2 miles straight line distance to the south-southwest. Four out of the top ten CFPP emitters in West Virginia, cited air pounds of $\mathrm{SO}_{2}$ emissions per year, in this Fact Sheet are the counties within the proposed study area. Allegheny Energy Inc., Hatfield Power Station, Masontown, Pennsylvania, was third on the top ten facilities list for Pennsylvania. ${ }^{59}$ Hartfield power plant is along the same Monongahela River valley as Fort Martin. Fort Martin is northwest in this valley but at an altitude substantially lower than the proposed CFPP location.

As discussed above, the surrounding region already contains a significant amount of CFPP emissions being emitted to local ambient air, which are among the largest CFPP emissions within each of these states. The State TRI's for this area cite some of the largest $\mathrm{SO}_{2}$ emissions from other industry sectors as well. ${ }^{59}$ Weather patterns, topological features, and changing seasons govern the dispersion of air pollution. Topological features can play a significant role in the dispersal CFPP emissions. Mountainous regions such as in this Appalachian area often prevent adequate dispersion of air pollution from industrial stack emissions. The established pollution situation, within the study area, in place prior to the construction of the proposed CFPP, could lead to further air pollution modeling research following this thesis. 


\subsection{Air Pollution Meteorology: Effects of Temperature Inversions and Wind Velocity on Pollutant Dispersion}

As stated earlier, Donora, PA sits within a river valley that is in the proposed study region, where a severe upper air subsidence inversion associated with a stagnant high pressure system, together with low layer air radiation inversion episode caused 20 deaths and injured several thousand in October of $1948 .^{13,21,42,46}$

Microscale meteorology dictates weather behavior in the layer closest to the surface of the earth. Macroscale meteorology usually dictates weather in the atmospheric layers above the surface layer. An example of macroscale meteorology are those conditions covering large regions, like the huge stagnant prevailing high pressure system that extended over a greater portion of the entire eastern half of the United States during the Donora episode. ${ }^{46}$ These high pressure systems normally produce sunny, dry warm days with calm winds. High pressure systems are those of a huge warming descending air mass, producing what is called an upper air subsidence inversion.

Within the descending high pressure system, air pressure increases with descent, causing the temperature of the upper air mass to increase as it subsides. This subsidence usually settles above a much smaller, cooler surface air mass (altitude where the to air masses meet). The normal decease in temperature observed usually with an increase in altitude from the ground surface up, is interrupted, or inverted, thus the term subsidence inversion. The stable boundary layer between the smaller, cooler, lower air mass serves as a barrier to vertical dispersion of air pollution. Under such conditions, this stable boundary layer, preventing vertical dispersion of the plume, determines the plume mixing height.

Microscale meteorology refers to those conditions controlled by local factors, in shallow 
layers of surface air, such as the radiative cooling of surface air, at night, sometimes referred to as nocturnal radiation inversion. Nocturnal radiation inversions can also produce fog if the shallow surface layer is more moist than the layer above and it cools to it's established dew point (which was the case at Donora). The dew point is the temperature at which moisture in a give parcel of air will condense. Wind and increased air temperature serve to disperse fog. At Donora, daytime sunlight was not reaching the earth's surface due to fog formation, so the air directly above the surface, in the Monongahela River Valley, remained cool and foggy during those October days in 1948. ${ }^{46}$ The high fog and pollutant concentration, together called smog, prevented the sun's radiating heat from penetrating to the valley floor, which would normally erode the surface layers radiation inversion during the day. As a result of calm winds and the decoupling meteorology conditions between these two air masses, the pollution concentrations in the valley increased to fatal levels. ${ }^{46,50}$

When macroscale and Microscale meteorology are coupled, or in sync, conditions are such that vertical motion is induced in both layers and adequate vertical mixing and dispersion of pollutants occurs. Wind can also be an important driving factor of pollutant dispersion in both the upper air masses and surface air masses, when they are coupled. But in the case of Denora, winds were negligible as the two air mass systems remained stable and uncoupled.

This Donora episode helped motivate the clean air movement which lead to the enactment of the original precursors of the Clean Air Act (CAA) in 1970. The Monongahela River valley generally has steep hills on both sides. During this episode, pollutant emissions to the air, that were normally dispersed by the prevailing westerly winds, became trapped within stagnant air. ${ }^{13,21,42,46}$ Air pollution episodes as strong as the one in Donora, October 1948, are encouraged 
by meteorological processes discussed above, and even more complex processes not fully understood by scientists, both on large and small scales. Such weather episodes are a result of more complex macroscale and Microscale meteorological processes than what is fully understood by scientist's of upper air subsidence inversions and radiation inversions, within two different atmospheric layers.

As occurred in Denora, PA, radiation inversions in a river valley with industrial areas can result in extreme human exposure to toxic air pollutants. This thesis's study area, as well as most of Appalachia, experience radiation inversion episodes occurring throughout different times of the year depending on cloud cover and wind speed during the night. ${ }^{4,46,49,50}$ Episodes of extreme stagnate high pressure systems associated with a subsidence inversion occur more frequently during certain spring and fall months, in Appalachia valleys; April - June and September October. See Figures1 and 2 below. The combination of theses two types of inversions, radiation and subsidence, occurring at the same time, become a problem in urban areas. Under inversion conditions, pollutants from industry can become trapped near the ground in urban areas, potentially harming those breathing that air, instead of dispersing out of the area due to natural wind current and vertical turbulent mixing. ${ }^{19,30,46}$ Human activities, releasing pollutants, including industry, cause the problem not the naturally occurring phenomena. The build up of air pollution to harmful levels depends on a number of factors including the specific local pollutants, the length of time of the inversion episode(s), and the location of people during an episode(s). Air inversions break up when either a strong, cooler, frontal system moves in to replace the stagnant high pressure system, or when the sun radiates through to the earths surface or valley floor, heating the surface and surrounding layers of air causing them to rise. Cold air aloft then subsides 
replacing the warm rising air that was acting as a lid, so that the air near the ground is no longer trapped. ${ }^{30,45,50}$

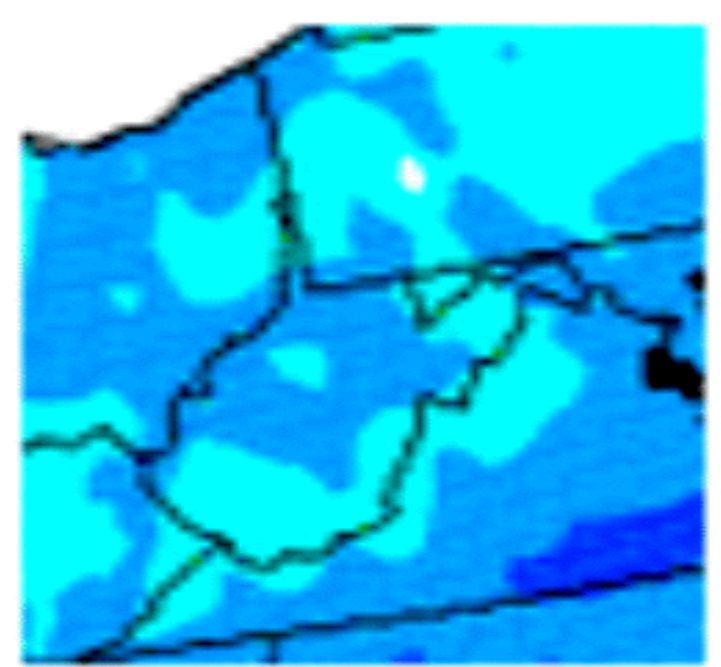

Figure 1 : Stagnation Index for May 2000. This image depicts the percentage of days air stagnation occurred in West Virginia and surrounding states during that month, 2000.

\section{Legend}

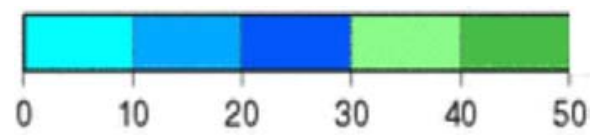

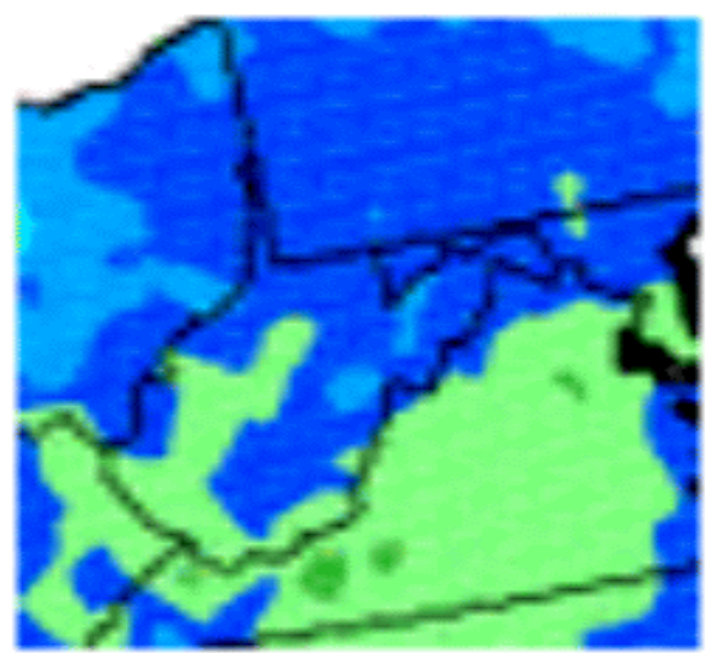

Figure 2 : Stagnation Index for September 2000. This image depicts the percentage of days air stagnation occurred in West Virginia and surrounding states during that month, 2000. 
The complexity of various types of atmospheric inversions has only been briefly discussed. Much is yet to be understood about the many variables required for accurately predicting extreme pollution episodes. EPA recognizes inversion trapped polluted air as unhealthy to breathe ${ }^{60}$ and is currently funding research to model for inversion episodes in mountainous terrain in order to establish areas most susceptible to inversion pollution episodes.

Figures 1 and 2 show some maps provided by the National Oceanic Atmospheric Administration depicting percentage of days air stagnation occurs in West Virginia and surrounding regions during the months of May and September 2000. Stagnations are associated with slow moving high pressure systems with light winds in a stable lower atmosphere. Light winds and a stable lower atmosphere prevent to dispersion of pollutants. Maps of these same months are available from 1973 through 2002. Similar maps for radiation inversion and subsidence inversion frequencies have not been located.

As has been established, radiation inversions and air stagnation episodes play a major role in the failure of dispersion of air pollution. Such conditions were assumed in this thesis to be contributory to modeled worst case scenarios for human exposure. The geography and climatology of Morgantown meet criteria required for occurrence of both radiation caused thermal inversions and simultaneous upper air subsidence inversions associated with stagnations.

Another prime meteorological condition assumed in this thesis be contributory to modeled worst case scenarios for human exposure is extremely high wind velocity, inducing conditions know as stack tip or direction specific building downwash. Stack tip downwash is a result of a streamline of wind becoming interrupted by the stack and as a result, eddies (swirling motions of air) form in lee of stack, causing the plume to bend downward eliminating vertical 
mixing and dispersion. ${ }^{19}$ Direction-specific building downwash occurs when a streamline of wind is interrupted by a building, or series of buildings, causing eddies to form on the lee side of the building(s), forming a wake which travels over the building, recirculating eddies on the lee side called the cavity. ${ }^{13}$ Emissions released at, or close to the same elevations of surrounding buildings can disperse into the wake and "lee" cavity of a building. In building downwash conditions, pollutant concentrations have the potential to become trapped and accumulate in the cavity on the lee side. If the condition persists, the accumulating pollutant mass on the lee side of the building will increase resulting in higher ground level concentrations in the cavity, called fumigation from source. These conditions, are of great concern and can be very dangerous to workers, or nearby sensitive receptor populations, of any facility emitting emissions through a source stack. A much higher stack can greatly reduce this likelihood of dangerous cavity fumigation.

\subsection{Comparison of Air Dispersion Modeling Approaches}

\subsubsection{Introduction}

Models are used in science to produce simplified pictures of reality. As is the case in air dispersion modeling, the advancement of knowledge surrounding the science and the respective theories being questioned or applied, often contain less features than those systems occurring in nature. Although it is much more complex, in simple terms, pollutants emitted into the air are mostly transported by wind and turbulence, becoming mixed with the ambient air over time. This mixing either increases or dilutes the emitted pollutant(s) concentration depending on the preexisting concentration of pollutant(s) in the ambient air. Features accounted for in the most modern computer simulated models included emission rates, site characteristics, topology (terrain 
elevation change), background concentrations, and available recorded weather data.

The preceding explanation of air pollution concentration modeling is a simplified introduction. Realistically modeling the transport of pollutants through the atmosphere is rather more complex. Many variables, not always necessarily available, need to be accounted for to accurately portray actual air pollution movement in the atmosphere. The mathematical calculations used to predict the transported concentrations of pollutants in today's latest models remain restrictive because of the tremendous meteorological effects operating on air pollutants that are yet to be completely understood. Instantaneous micro-meteorological effects, operating on pollutants continually change. Current technology is unable to account for these ever changing conditions, unless very costly detailed monitoring data can be recorded. The most common air pollution concentration modeling method for receptors near the source is described by a Gaussian distribution, which attempts to overcome the changing micro-meteorological conditions by averaging out the changes over time. Researchers, weather measuring instruments, and the mathematical computer simulations used to model the transport of air pollution concentrations are continually improving, as discussed in the following section of the thesis.

Model complexity varies, depending on the type of air pollution source(s) being modeled. Three most common types of sources include point sources, line sources and area sources. Point sources are identified as being industrial stacks, or chimneys, from chemical plants, other manufacturing plants, or a power plant, such as the proposed power plant being evaluated in this thesis. Examples of other sources, although not being evaluated in this thesis, include mobile source emissions (on- or off-roadway), and industrial storage or refuse pile emissions, often referred to in air pollution literature as line or area sources. ${ }^{14,16,19}$ 
Three common types of air pollution concentration modeling found in literature, beginning from the simplest to the most complex, are fixed box-models, dispersion models, and multiple cell models. ${ }^{31}$ Each type of model becomes more detailed, accounting for more natural features and source types. The more natural features and sources accounted for in a model, the more digital data gathering, labor and computer power are needed to run the model. In return, however, models accounting for more natural features are more complex and are assumed to be more accurate with actual scenarios.

\subsubsection{Fixed Box Models}

As stated earlier, fixed box-models are over simplified and depict the most unrealistic concentration values. Applying a general balance equation, such models involve constructing a box over an entire city and calculating flows in and out of the box to obtain a concentration value inside the box ${ }^{31}$. The sides of the box border both sides of the city, usually in the $\mathrm{x}$ direction, and are parallel with predominant wind direction. The city rests on the base/floor of the box while the top face of the box is established as the mixing height, in the $\mathrm{z}$ direction. Finally enclosing the system are the upwind and downwind faces adjacent to the parallel sides in the y direction, on both ends of the city.

Flows into a fixed-box model include emissions from the city through the base/floor, and wind from the upwind face of the box. Flows out of the box include emissions and upwind air currents added to the system through the upwind face. By subtracting the flows out from the flows in (a general balance equation) an average concentration above the city may be calculated. Values calculated using this method are extremely high, over exaggerating the ambient air pollution concentration within the box. The reason for this is because of the over simplified 
assumptions made while constructing the model. As stated by Never, "several of the assumptions made using the fixed-box model are quit contrary to what is observed in nature."31 Wind velocity and direction is assumed to be the same at all elevations in the box. In nature, wind velocity increases with an increase in elevation and continually changes direction at all elevations. Also, various types of emissions, from point and mobile sources, are combined into one uniform value for the city. Realistically, these emissions are emitted at different locations and elevations, initially subject to different surface micro-meteorology conditions (horizontal and vertical mixing parameters).

Complex micro- meteorology, effects the vertical and horizontal mixing of emissions at their sources, and are usually not taken into consideration in the fixed-box type of model. For example, wind velocity is often the only meteorological parameter considered in a fixed-box model. Temperature profile and atmospheric stability classifications, along with wind velocity and direction, are considered in other model designs, leading to more realistic calculated exposure values.

\subsubsection{Multiple Cell Models}

The most realistic model calculations can be obtained through multiple cell models, or an airshed model. As described by Never, ${ }^{31}$ these models consist of the airspace over an entire city or region divided into multiple cells, with each cell calculated separately from the others. These models contain uniform grid sizes, normally 2 to $5 \mathrm{~km}$ in the $\mathrm{x}$ and $\mathrm{y}$ direction, with half the stacked layers above the mixing height and the other half below, in the $\mathrm{z}$ direction. Flows, from all sources, in and out of each cell are calculated much like that in the preceding box model discussion. Each cell concentration calculated takes into account the different micro- 
meteorological conditions, (temperature profile and stability, wind velocity, direction, etc.) that occurred throughout different times of the day within that particular cell. Light Detection and Ranging (LIDAR) ${ }^{1}$ systems may be used to provide the type of weather data needed in each cell, measuring wind velocity, elevation, and chemical composition within. ${ }^{29}$

Depending on the size of the city, these models may range anywhere from 100 to a 1000 or more cells. The chemical composition of each cell must be calculated, pollutant sources determined, and each cell's individual pollutant concentration summed, to receive total concentration per pollutant in multiple cell models. Given the size of data input into a multiple cell model, it requires large computer systems, expensive software, expensive weather measuring equipment, and many data collection and modeling hours. Currently, these models are only being used to model reactive atmospheric pollutants, such as conversion of Nitrous Oxide (NOx) and Volatile Organic Compounds (VOC) to ground level $\mathrm{O}_{3}$. Both NOx and VOC serve as precursors to the formation of ground level ozone. These air pollutants, together with $\mathrm{O}_{2}$, in the presence of high heat form ground level $\mathrm{O}_{3}$ during summer months.

\subsubsection{Plume Dispersion Models}

Given current levels of air pollution concentration modeling technology, the most common modeling approach is through the dispersion, sometime referred to as the diffusion, model process. Throughout air pollution literature the word diffusion and dispersion are used interchangeably. ${ }^{31,35,63}$ Diffusion is often associated with molecular diffusion. Molecular diffusion is the mixing of substances through random molecular motion. Here, different substances are

\footnotetext{
${ }^{1}$ LIDAR instruments transmit and receive electromagnetic radiation at high a frequency (ultraviolet, visible and infrared region of the electromagnetic spectrum). Different types of physical processes and chemical composition in the atmosphere are related to different types of light scattering. Choosing and evaluating for different types of scattering processes allows atmospheric composition, temperature, and wind to be measured.
} 
mixed together as a result of each substance's molecules and ions being under constant random motion. ${ }^{27}$ That simply is not the case with these types of air pollution concentration models. Molecular diffusion obviously occurs with emitted pollutants, however, it is not the principal mechanism described, and discussed below, by some of these types of models. ${ }^{31}$

Dispersion models attempt to calculate the average emission concentration flow directly from their source, using the well known Gaussian plume methods, or other Non-Gaussian plume methods. ${ }^{6,7}$ In this thesis, I used calculated results from the Gaussian plume method, only. NonGaussian plume methods include different probability functions, and are used to predict dispersion under atmospheric instability ${ }^{6}$. This thesis is only concerned with downwind dispersion of plume concentration during atomospheric stability (also extremely high wind velocities), in which the Gaussian model does have limited calculating abilities under such stable conditions (See Chapter 5), but is used by leading modeling software for such conditions. When such a stable air mass condition occurs, the likelihood of ground level plume concentration impact on receptors is the increased.

Gaussian models have been widely used to model the advection along the plume centerline and lateral and vertical diffusion of stack plumes. ${ }^{31,35,56,63}$ These models incorporate the Gaussian distribution curve at which time averaged atmospheric conditions are used to calculate diffusion as a normal distribution, in the $\mathrm{y}$ and $\mathrm{z}$ direction, of plume concentration from plume centerline. Because the Gaussian distribution equation (Figure 3) uses time-averaged atmospheric conditions, an instantaneous picture of the plume can not be calculated using this method. Rather the advection, or large scale linear motion along centerline, and progressive broadening of the plume with progressing distance from source, are calculated. The plume calculation is 
superimposed over the natural snake-like twisting and turning observed in nature, as smoke is

emitted and dispersed downwind from a stack. ${ }^{31,56}$ See Figure 4, taken from Turner's Workbook of Atmospheric Dispersion Estimates, below.

$$
\begin{aligned}
X= & \frac{Q}{u} \bullet \frac{f}{\sigma_{y} \sqrt{2 \pi}} \cdot \frac{g^{1}+g^{2}}{\sigma_{z} \sqrt{2 \pi}} \\
X= & \text { ground level pollutantconcentration } \\
u= & \text { wind speed } \\
\mathrm{y}= & \text { distancein horizontaldirection } \\
\mathrm{z}= & \text { distancein vertical direction } \\
\mathrm{H}= & \text { effectivestack height } \\
\mathrm{Q}= & \text { mass emittedper unit time } \\
\sigma_{y}= & \text { standarddeviationof plumepollutantconcentraion } \\
& \text { in y }(\text { horizontal }) \text { direction } \\
\sigma_{z}= & \text { standarddeviationof plumepollutantconcentration } \\
& \text { in } \mathrm{z}(\text { vertical }) \text { direction } \\
f= & \exp \left[-\mathrm{y}^{2} /\left(2 \sigma_{y}^{2}\right)\right] \\
g^{1}= & \exp \left[-(\mathrm{z}-\mathrm{H})^{2} /\left(2 \sigma_{z}^{2}\right)\right] \\
g^{2}= & \exp \left[-(\mathrm{z}+\mathrm{H})^{2} /\left(2 \sigma_{z}^{2}\right)\right]
\end{aligned}
$$

Figure 3: Gaussian plume distribution equation. Gaussian models incorporate the Gaussian distribution curve at which time averaged atmospheric conditions are used to calculate diffusion as a normal distribution, in the $y$ and $z$ direction, of plume concentration from plume centerline.

Source: Workbook of Atmospheric Dispersion Estimate 


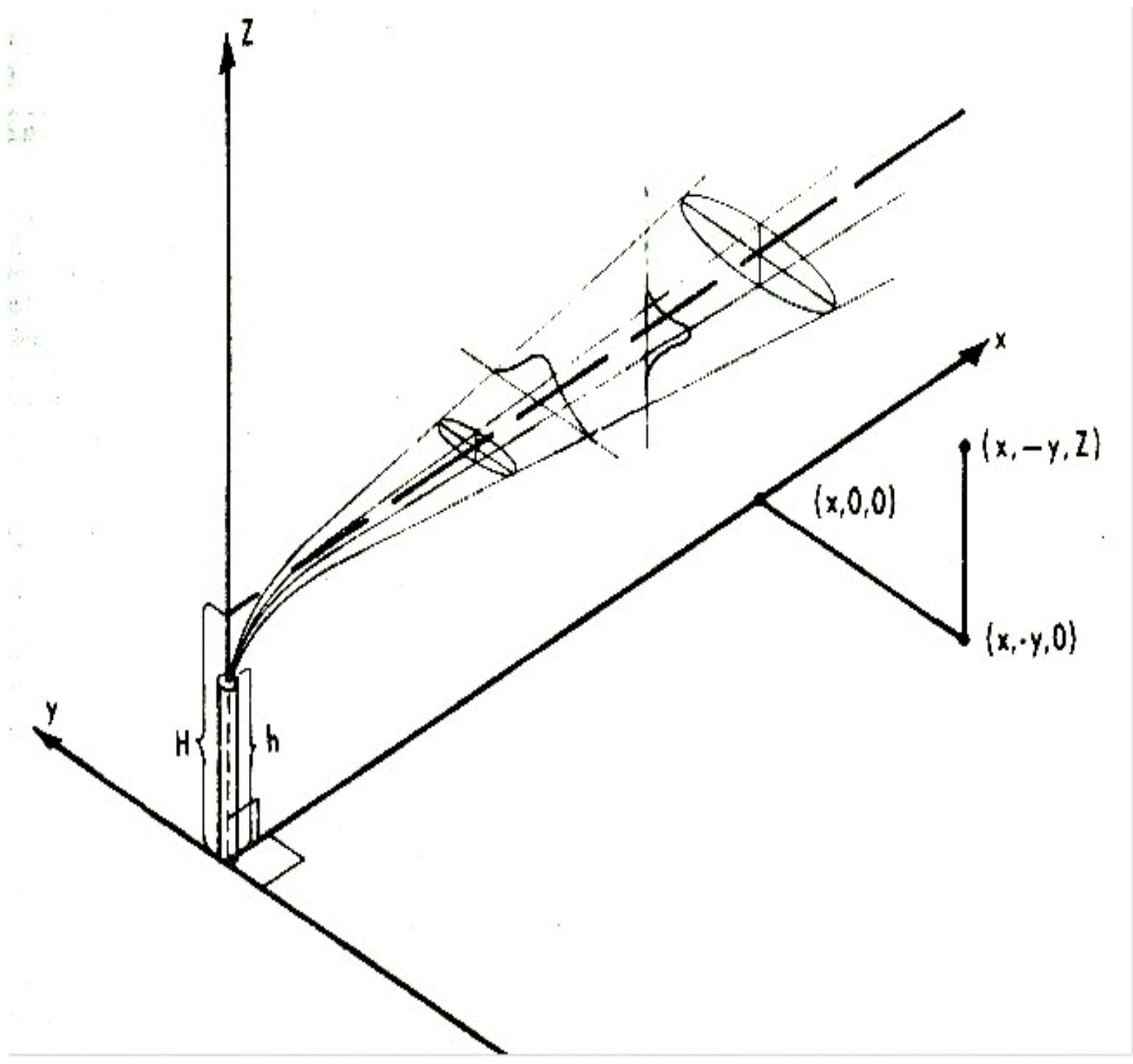

Figure 4: Gaussian plume distribution 3 dimensional coordinate system. Because the Gaussian distribution equation (Figure 3) uses time-averaged atmospheric conditions, an instantaneous picture of the plume can not be calculated. The advection, or large scale linear motion along centerline, and progressive broadening of the plume with progressing distance from source, is what is calculated.

Source: Workbook of Atmospheric Dispersion Estimate 
As stated by D.B. Turner, ${ }^{56}$ the Gaussian distribution equation uses relatively simple calculations requiring only two diffusive dispersion parameters, $\sigma_{z}$ and $\sigma_{y}$, to identify the variation of pollutant concentrations away from the center of the plume; where $\sigma$ 's represent standard deviations under normal distribution of pollutant concentration at different atmospheric conditions. Dispersion coefficients $\left(\sigma_{z}\right.$ and $\left.\sigma_{y}\right)$ representing variances from centerline plume concentration, for each atmospheric stability category, have been established from experimental research conducted by Pasquill and Gillford, ${ }^{35}$ and correlated with work conducted by Turner, ${ }^{\mathbf{5 6}}$ for use in the Gaussian plume distribution equation from the Eulearian viewpoint. Stability categories have been developed to represent various atmospheric conditions. The different stability categories, developed by Pasquill and Gillford are listed in Table 2.3. ${ }^{\mathbf{5 6}}$ Dispersion coefficients, extrapolated for distances greater than $1 \mathrm{~km}$, in the form of plots of $\log \sigma_{\mathrm{y}}$ and $\log \sigma_{\mathrm{z}}$ versus $\log \mathrm{x}$ are represented in Figures 5 - 6, and were taken from Turners "Workbook of Atmospheric Dispersion Estimates". $31,35,56$ The two dispersion parameters and stability categories like those discussed above, together with other variables listed in Figure 3 above, are required by the Gaussian plume distribution equation to calculate from source, the downwind concentration of emissions, away from plume centerline, at receptor locations. 
Table 2.3 Pasquill and Gillford (PG) Stability Categories

\begin{tabular}{|c|c|c|c|c|c|}
\hline & Day & $\begin{array}{c}\text { Day (Incoming } \\
\text { solar radiation) }\end{array}$ & Day & Night & Night \\
\hline $\begin{array}{c}\text { Surface wind } \\
\text { speed at 10m } \\
(\mathrm{m} / \mathrm{sec})\end{array}$ & strong & moderate & slight & $\begin{array}{c}\text { Thinly overcast or } \\
>4 / 8 \text { cloud cover }\end{array}$ & $\begin{array}{c}\text { Clear or }<3 / 8 \\
\text { cloud cover }\end{array}$ \\
\hline$<2$ & A & A - B & B & ----- & ----- \\
\hline $2-3$ & A - B & B & C & E & F \\
\hline $3-5$ & B & B - C & C & D & E \\
\hline $5-6$ & C & C- D & D & D & D \\
\hline$>6$ & C & D & D & D \\
\hline
\end{tabular}

Source: Workbook of Atmospheric Dispersion Estimate 


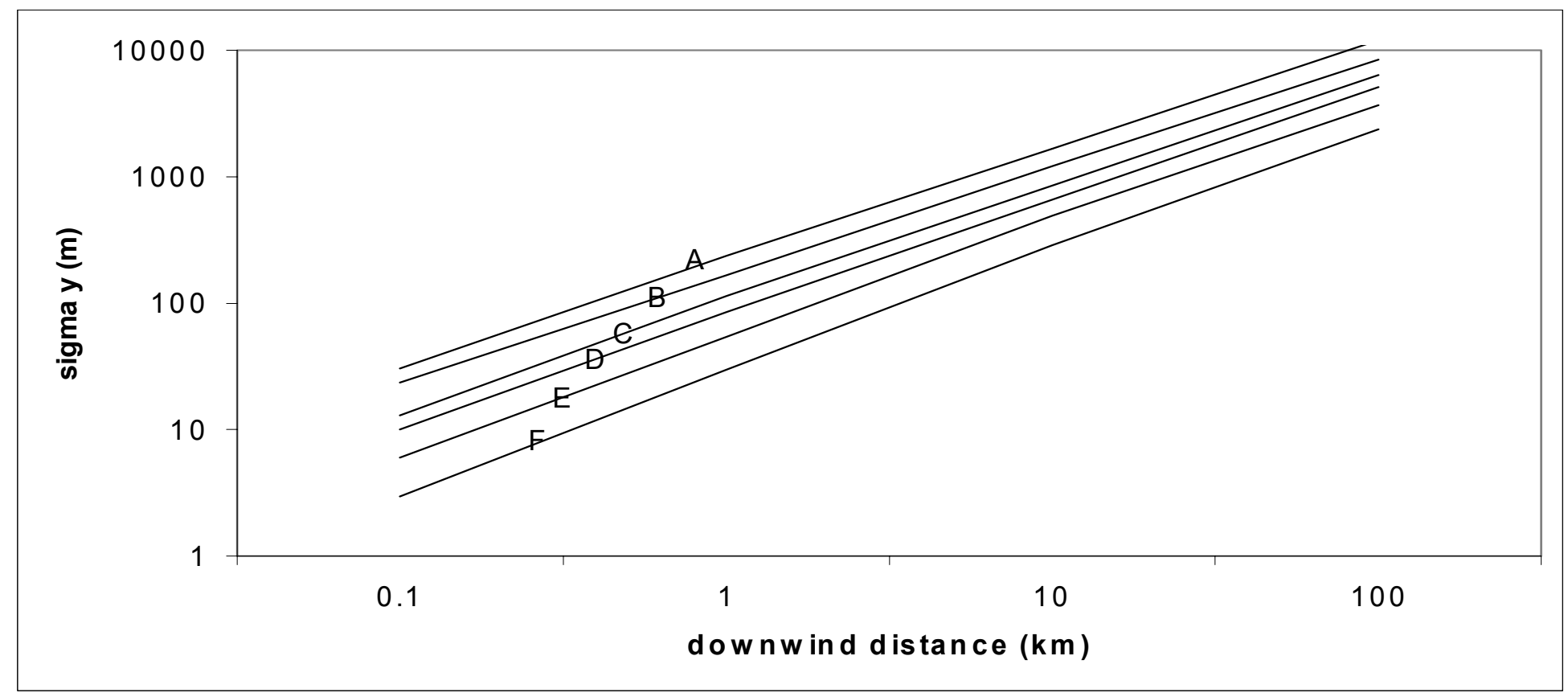

Figure 5: Horizontal dispersion coefficients for PG stability categories. See Table 2.3. Dispersion coefficients $\left(\sigma_{y}\right)$ representing variances from centerline plume concentration, for each atmospheric stability category.

Source: Workbook of Atmospheric Dispersion Estimate 


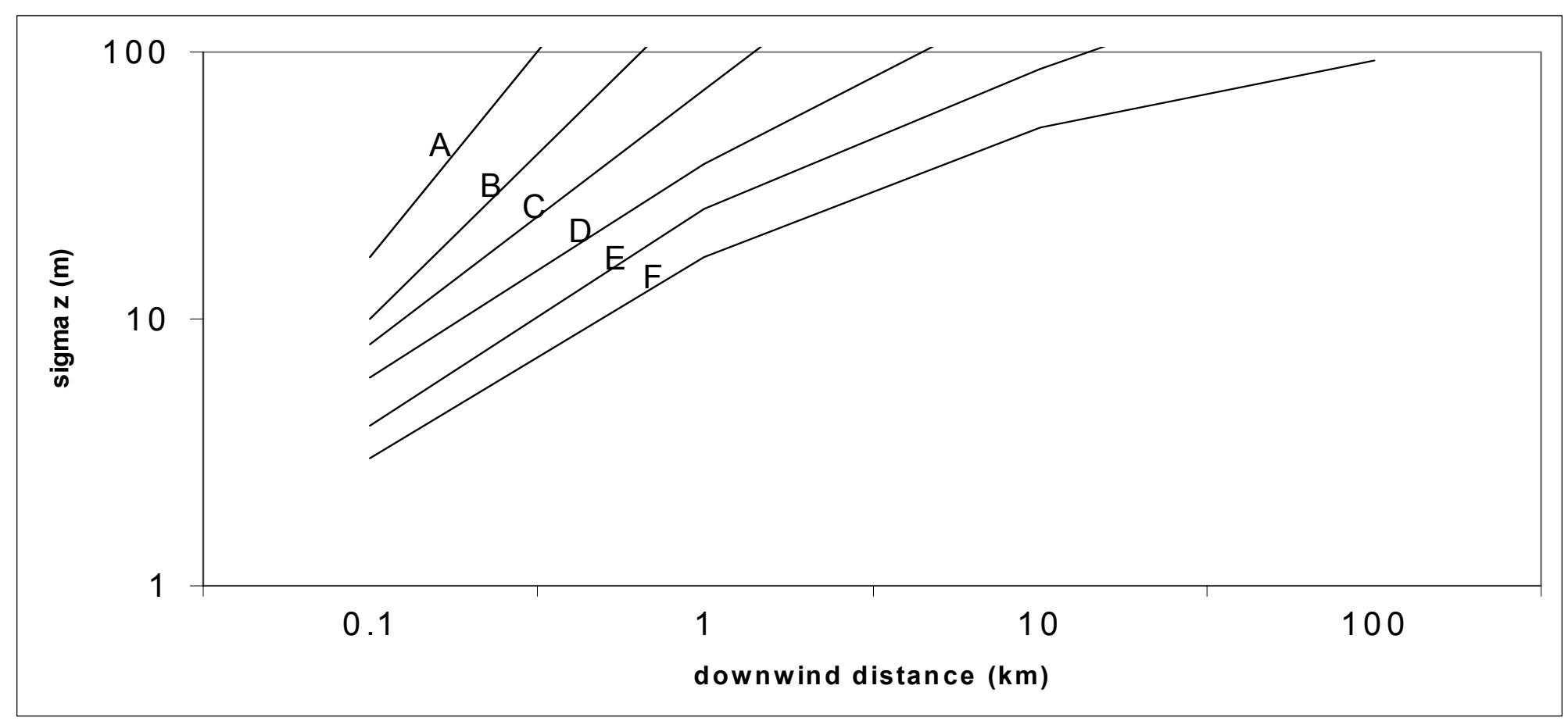

Figure 6 : Vertical dispersion coefficients for PG stability categories. See Table 2.3. Dispersion coefficients $\left(\sigma_{z}\right)$ representing variances from centerline plume concentration, for each atmospheric stability category.

Source: Workbook of Atmospheric Dispersion Estimates 
As stated earlier, the calculated concentration, at a fixed downwind distance X, represents the Eulearian viewpoint. ${ }^{31}$ The Langrangian viewpoint is another form (or derivative) of the Gaussian plume distribution, that may be used to calculate plume concentrations at point $\mathrm{X}$ within the middle of the moving puff of plume as apposed to a fixed point represented by $\mathrm{X} .{ }^{31}$ This thesis is evaluating the Gaussian distribution equation from the Eulearian viewpiont only, using a polar coordinate grid system within the computer simulated air dispersion model. ${ }^{6}$ In the model, downwind distance $\mathrm{X}$ is represented by multiple radii/radius intersections with incremental ring distances from source on a polar grid, as well as other manually added prioritized sensitive receptor points, used in running the computer simulated dispersion model. Therefore, various plume concentrations, can be calculated as caused by wind changes, moving in different directions, and impacting different elevations.

\subsubsection{Effect of Atmospheric Stability on Plume}

Current modeling software use the same Gaussian plume distribution equation discussed above to calculate different directed plume concentrations under stable atmospheric conditions, however they have the ability to recognize more atmospheric conditions than what is listed in Pasquill and Gillford table. Using recorded weather soundings extracted for use within its own software, computer simulated models develop and use more sophisticated (or in-depth) stability categories and dispersion coefficients, derived from more comprehensive meteorological data. ${ }^{7}$ Other variables listed with Gaussian plume distribution equation, Figure 3, and for terrain elevation, are entered into the model run as well. 


\subsubsection{Modeling in Complex Terrain}

Where plume computations are conducted, during stable conditions, for locations of complex terrain, computer simulated models use the dividing streamline approach, demonstrated in laboratory experiments conducted by Synder., ${ }^{7,48}$ This theoretical concept assumes that a dividing layer forms during stable conditions in which air flow in the upper layer rises over the terrain while air flow in the lower layer remains horizontal, deflecting, or splitting to flow around high obstacles. During unstable conditions, such a dividing stream line disappears, and all flows rise up and over the elevated terrain. ${ }^{48}$ Detailed wind and turbulence data, and vertical profiles of temperature, are needed for computer models to construct the elevation of dividing stream lines. ${ }^{44,48}$ Depending on the elevation of the plume, it will either go over a hill or be forced to go around the hill (often up or down the valley if the plume is emitted within the valley). Higher stacks can prevent plumes from becoming embedded under dividing stream lines, forcing plume movement over the hill rather than laterally around the hill.

\subsubsection{United States Compliance Modeling}

Understanding current levels of technology and labor intensities involved with accurately predicting air pollution transport and mixing in the atmosphere, EPA establishes preferred/chosen computer simulating models for compliance use. Different computer simulated models are required for different types of sources being modeled. EPA's preferred models are continually reviewed as science and technology surrounding air pollution modeling software advances. The fixed box models are overly simplified and rarely used for compliance evaluation. Given the current level of computer technology and atmospheric science, multiple cell models are extremely labor intensive, but are increasing in use for reactive atmospheric pollutants. ${ }^{31}$ For many years the 
preferred dispersion model for a continuous steady-state point source has been the Industrial Source Complex (ISC). AERMOD, another dispersion model was used in this thesis, and is currently under EPA review for becoming the preferred continuous steady-state model for compliance. A more in depth discussion of AERMOD is to follow in Chapter 3.

Both AERMOD and ISC are dispersion models that use the Gaussian plume distribution equation when modeling under stable atmospheric conditions. AERMOD however comprises the latest in Planetary Boundary Layer (PBL) parameterization, accounting for technological advancements ISC otherwise does not posses. The goal of EPA regulatory concentration models is to design or improve modeling capabilities as the science and technology surrounding air pollution modeling advances. Table 2.4, adapted form one of EPA's detailed comparison reviews of AERMOD and ISC, compares and contrasts some of the major differences between ISC and AERMOD capabilities. ${ }^{40}$ 
Table 2.4 Comparison of AERMOD and ISC Compliance Plume Models

\begin{tabular}{|l|l|}
\hline \multicolumn{1}{|c|}{ ISC } & \multicolumn{1}{c|}{ AERMOD } \\
\hline $\begin{array}{l}\text { Only wind speed is profiled using profiling } \\
\text { meteorological data }\end{array}$ & $\begin{array}{l}\text { AERMOD creates profiles of } \\
\text { wind, temperature, and } \\
\text { turbulence, using all available } \\
\text { measurement levels of meteorological data }\end{array}$ \\
\hline $\begin{array}{l}\text { Stack-top meteorological variables for all } \\
\text { downwind distances }\end{array}$ & $\begin{array}{l}\text { Meteorological variables measured throughout } \\
\text { the plume depth (averaged from } \\
\text { plume centerline; changes with } \\
\text { downwind distance) }\end{array}$ \\
\hline $\begin{array}{l}\text { Gaussian treatment in horizontal } \\
\text { and vertical }\end{array}$ & $\begin{array}{l}\text { Gaussian treatment in horizontal } \\
\text { and in vertical for stable } \\
\text { conditions; non-Gaussian } \\
\text { probability density function in } \\
\text { vertical for unstable conditions }\end{array}$ \\
\hline $\begin{array}{l}\text { Interpolates mixing height based upon } \\
\text { maximum afternoon mixing } \\
\text { height }\end{array}$ & $\begin{array}{l}\text { Interpolates convective and mechanical mixing heights } \\
\text { and their fluctuations throughout the day }\end{array}$ \\
\hline
\end{tabular}

Source: Comparison of Regulatory Design Concentration Modeling 
AERMOD obviously incorporates advancements in air dispersion modeling technology. As stated earlier, the more variables that can be accounted for in a model, the more accurate portrayal of real world conditions. AERMOD has become the chosen model for this thesis due to it's availability and advancements in technology. It is important to note, however, that both ISC and AERMOD use the same Gaussian treatment under stable atmospheric conditions, which as stated earlier, may contribute to modeled worst case scenario in this thesis.

\subsection{Geographic Information Systems Applicability}

The use of Geographic Information Systems (GIS) to solve environmental problems is increasing rapidly. ${ }^{34}$ GIS is an information system that is designed to work with digitized data referenced by spatial or geographic coordinates. ${ }^{\mathbf{6 1}}$ GIS has also been referred to as a collection or system of computer hardware, software, geographic data and personnel expertise integrated to efficiently capture, store, update, manipulate, analyze, and display all forms of geographically referenced information. ${ }^{\mathbf{5 1}}$ The power of GIS lies in the production of its visual images, and spatial analysis of them, as compared to any other computer based information system. GIS allows various types of maps, all with different surfaces and features, to be laid over one another in layers to produce a preferred map of interest. It allows one to visualize such spatial information changes in air pollution concentrations, land cover, population density, watershed and stream location, road and building location, elevation, and many other sets of data, by statistically analyzing the geographically referenced spatial data, layered over one another, to produce a map. These maps may undergo further manipulation, to help one understand a particular environmental problem. Today, GIS is used by a wide range of disciplines and 
entities. Government agencies, private industry, and universities all use GIS to understand relationships that cause and solve spatial problems in our natural environment.

Recent developments of GIS have provided environmental epidemiologist's with new tools to study associations between environmental exposures and disease. ${ }^{11}$ Various geographically referenced data, including population census data, are being spatially analyzed through GIS by different public health and environmental pollution researchers . A particular focus area of this thesis is the geographical point locations of sensitive receptor populations to the proposed stack. GIS spatial analysis application allows for the identification of the real world point locations of sensitive receptor populations at certain straight line distances from the proposed stack, to modeled air pollution concentration from the stack. Such concentrations represent pollution that could contribute to health effects discussed in section 2.1 , at locations identified using GIS techniques.

GIS spatial analysis application to sensitive receptor point locations, alone, cannot determine public environmental health threats associated with the one proposed CFPP air pollution source. Therefore, so air dispersion modeling was pursued as well. GIS spatial analysis does, however, provide unique additional information for this study. One literature study involved evaluating the magnitude of outdoor exposure to particulate matter potentially experienced by the population of Mexico City. ${ }^{10}$ Circero-Fernandez used GIS software, to link population groups in Mexico City to particulate matter concentrations that exceeded air quality standards during certain days throughout a period of one year. Other studies have included pollution exposure to minority or otherwise underprivileged individuals and populations. ${ }^{\mathbf{5 , 1 0 , 4 3}}$ Rushton ${ }^{43}$ stated that "recent advances in the analysis of disease maps (produced using 
GIS) have been influenced by and benefitted from the adoption of new practices for georeferencing health data and new ways of linking such data geographically to potential sources of environmental exposures, the locations of health resources and the geodemographic characteristics of populations.

Another GIS technique applied in this thesis was kriging, a geostatistical method. As defined in Using ArcGIS Geostatistical Analyst book, "kriging a statistical interpolation method that uses data from a single data type to predict values of that same data type at unsampled locations."Geostatisitcs is actually a much broader term to include kriging, spatial statistics common to geography and geology, as well as other mathematical interpolation techniques known as deterministic technique. ${ }^{69}$ See chapter 3 , section 3.3 .3 for a more detailed discussion on kriging and geostatistical analysis.

Precipitation measurements and predictions, groundwater hydrology, oil exploration or spills, water and air pollution all use geostatistics, to create and illustrate their boundary location or phenomenon. More current applications of kriging air pollution include those on monitored concentrations of air pollution. Such programs include analysis of ozone concentrations in California (EPA monitoring), and studies of particulate pollution in British Columbia and hydrogen sulfide in Nebraska. ${ }^{\mathbf{6 7}, 689}$ Under all three cases, kriging was used to interpolate exposure estimates, producing prediction maps, using monitoring data from strategically georeferenced locations. In this study, I conducted the same type of exposure estimates, not from monitored concentration data, but rather from calculated concentration estimates determined from air dispersion modeling.

This thesis combines GIS spatial analysis application, resembling studies discussed 
above, with air dispersion modeling to geographically identify at point locations of sensitive population groups to concentration contributions of air pollution from the proposed CFPP source. After the air dispersion modeling, further analysis was conducted, using GIS geostatistical analysis to produce prediction maps of exposure to the entire study area $(30 \mathrm{~km}$ radius), including those sensitive population locations. 


\section{Chapter Three - Methods}

The previous chapter makes it clear that modeling the exposure of air pollution from a single source involve large amounts of many different types of digital data, including weather, demographic, geographic, and mechanical data. This data stems from an array of different sciences and techniques that must be linked together, in organized fashion, in order to attempt to model and graphically present that which might be occurring in nature. For example, the study area is defined to be a 30 kilometer radius surrounding the proposed CFPP stack. Although it is expected that, under worst case scenario, the lateral distribution of the CFPP emissions will not disperse that far, the software modeling distance (discussed below) is validated up to a 50 kilometer radius of the stack. It is most accurate up to 30 kilometers ${ }^{7}$ which is the distance chosen for this study. The region within the 30 kilometer radius is mostly deciduous forest, with urban areas scattered intermittently throughout the entire study area. The Monongahela and Cheat Rivers are the lowest elevations in the area. Moderate to rolling hills are to the west, while higher mountains predominate eastward, southeast of the proposed stack, starting with the Chestnut Ridge anticline. Emission rates from the proposed CFPP, in combination with certain local climate situations, locations of sensitive populations, and the geologic topography of the area could present and environmental public health threat. This thesis quantifies this possible threat.

This chapter is intended to lay out the sources of data, projections, software used and how the data was compiled, organized and used for GIS, AutoCAD and air dispersion modeling. Many organizations contributed the needed data for either GIS application, AutoCAD, dispersion modeling, or for all three. 


\subsection{Sources of Data}

Where possible, proposed CFPP emissions, meteorological, and sensitive receptors was for the year 2000, or as close to that as possible. This information was provided by various federal and state departments, universities, non-profit organizations, as well as a private company. Organizations providing data and information include the West Virginia (WV) Division of Air Quality (DAQ), West Virginia University (WVU) Natural Resource Analysis Center (NRAC), GenPower LLC of Newton, MA, US Geological Survey, Pennsylvania Spatial Data Access (PASDA), the Yellow Pages, and WV Geographical Information System (GIS) Technical Center at West Virginia University, US Environmental Protection Agency, US Census Bureau, and Trinity Consultants. I used this information together with various software and devices, and resources made available through books and courses taken here at West Virginia University as well as training in air pollutant dispersion modeling received from Trinity Consultants. A more in - depth discussion is to follow in this chapter. See Appendix A for a brief discussion of the types of data used and the organizations previously mentioned.

\subsubsection{Geographic Information System (GIS) Data}

In order to use GIS, to run the models, proper digitized tabular, and georeferenced spatial data were needed and collected from various data sources. See Appendix A for the data resource locations and sites. Tabular data were then organized into spreadsheet formats using Microsoft Excel $2002^{2}$. Some of these files were then transformed, within Excel, to Database III files, with extension DBF, to be used by the GIS software. GIS applications were conducted using ArcGIS

\footnotetext{
${ }^{2}$ Microsoft excel is a standard spreadsheet software program allowing users to organize and analyze data in tabular form.
} 
8.3 by $\mathrm{ESRI}^{3}$, which only recognizes spreadsheet files with data-base file (DBF) extensions.

The scale of the georeferenced spatial data and maps were determined next. The scale is the ratio of distance on a map to it's corresponding real world distance. The established scale for this study ranged from 1:24k meters to $1: 100 \mathrm{k}$ meters. The various data sources listed above provided maps at different scales, therefore analysis was only as good as the worst or smallest scale, i.e. $1: 100 \mathrm{k}$. An important factor in determining the proper scale for maps created in this thesis was the chosen resolution size of the study area. Resolution, as it pertains to this study, was the ability to see the difference, or discriminate on the study area maps, between locations on the earth's surface at a set aerial distance. For example, one point location represents an area that may contain more than one sensitive receptors, but receives the same calculated $\mathrm{SO}_{2}$ concentration, to be discussed in section 3.3.3. Maps produced on a county-wide scale, as apposed to state-wide, were portrayed at 1:24k meter resolution. The majority of data was collected at a scale of $1: 24 \mathrm{k}$.

\subsubsection{Proposed Coal Fired Power Plant (CFPP) Data}

Data on the proposed CFPP was provided through GenPower, LLC's PSD permit application that was reviewed by West Virginia Department of Air Quality. The Clean Air Act and it's respective NAAQS and PSD criteria, require both dispersion modeling of proposed emissions to be modeled to prove a prevention of significant deterioration of air quality as well as an emissions inventory to be kept by the proposed CFPP facility, once built and operating. Dispersion modeling, required for applying for a permit to operate, within PSD criteria, was not

\footnotetext{
3،ESRI is the largest research and development organization dedicated to GIS development software. ESRI's ArcGIS is a scalable system for geographic data creation, management, integration, analysis, and dissemination for every organization, from an individual to a globally distributed network of people." ${ }^{\text {26 }}$
} 
the goal of this thesis. Rather, the goal was to model contribution exposure to sensitive receptors during worst case scenario - using as the air quality PSD standard for this study, 24 hour $\mathrm{SO}_{2}$ PSD Increment allotted by the US EPA. Source (stack) data parameters obtained for the proposed CFPP include emissions, all listed in Table 3.1, were: georeferenced coordinates of the stack, internal stack diameter at stack mouth, stack emission temperature, exit velocity, and stack height (above grade). WV DAQ also provided digitized engineering drawings of the proposed CFPP site plan. This CFPP information was organized and manipulated into various different types of spreadsheets, and compatible software files, to fit GIS import requirements, an AutoCAD drawing of the site in UTM projection, and for import into the dispersion model.

\section{Table 3.1 Longview PC Boiler (main) Location and Stack Parameters}

\begin{tabular}{|l|l|l|l|l|l|l|}
\hline Coordinates & $\begin{array}{l}\text { Stack } \\
\text { Height }\end{array}$ & $\begin{array}{l}\text { Emission } \\
\text { Temperature }\end{array}$ & $\begin{array}{l}\text { Emission } \\
\text { Rate }\end{array}$ & $\begin{array}{l}\text { Stack } \\
\text { internal } \\
\text { diameter }\end{array}$ & $\begin{array}{l}\text { Exit } \\
\text { velocity }\end{array}$ & Elevation \\
\hline $\begin{array}{l}\text { Longitude: } \\
79 \text { Deg 57 } \\
\text { Min 23 Sec } \\
\text { Latitude: 39 } \\
\text { Deg 42 Min } \\
\text { 21 Sec }\end{array}$ & $554 \mathrm{ft}$ & $\begin{array}{l}56.85^{\circ} \mathrm{C}= \\
135^{\circ} \mathrm{F}\end{array}$ & $\begin{array}{l}13.866 \\
\mathrm{~g} / \mathrm{s}\end{array}$ & $\begin{array}{l}5.94 \mathrm{~m}= \\
19.5 \mathrm{ft}\end{array}$ & $\begin{array}{l}26 \mathrm{~m} / \mathrm{s} \\
=86 \mathrm{fps}\end{array}$ & $\begin{array}{l}\sim 335.28 \\
\mathrm{~m}= \\
1100 \mathrm{ft}\end{array}$ \\
\hline
\end{tabular}

\subsubsection{Air Dispersion Modeling Data}

Ground level pollution concentrations are controlled by the weather and surface roughness of the surrounding topology. As discussed in the previous chapter, wind direction and speed (transport distance), vertical mixing and turbulence are the main meteorological elements that determine plume dispersion. The boundary layer that the plume height rises to is its mixing height. Atmosphere stability and mixing height are a function of atmospheric turbulence. During 
upper air inversions, the thermal stratification between layers in the atmosphere resists vertical movement of a plume. Depending on plume momentum on emissions, concentrations, and buoyancy, plumes can sometimes penetrate these inversions. Although based on the same thermal stratification concept, the mixing height during a radiation inversion is often the height of the mountains on either side of the valley, or is, sometimes, the level of the bottom layer of an upper air subsidence inversion. The combination of these two inversion conditions was discussed in chapter 2. Surface roughness, in units of length, is determined by topographical features such as buildings and vegetation. Both the height and spacing between surface roughness features effect wind turbulence and thus vertical mixing of the plume. Below is Table 3.2, showing surface roughness length for surface type categories. ${ }^{32}$

Table 3.2 Surface Roughness Categories and Length (m)

\begin{tabular}{|c|c|}
\hline Urban & $1.0-3.0$ \\
\hline Deciduous Forest & 2.2 \\
\hline Coniferous Forest & 1.3 \\
\hline Cultivated land (summer) & 0.2 \\
\hline Cultivated land (winter) & 0.1 \\
\hline Grassland (summer) & 0.1 \\
\hline Grassland (winter) & 0.001 \\
\hline Water & 0.001 \\
\hline
\end{tabular}

Atmospheric Dispersion Modeling Compliance Guide, 1999

The USGS provides nationwide land cover maps from their "National Map Viewer" website. Land cover maps provided by USGS, were used to establish the predominant surface roughness of the study area, to be used in the air dispersion model. See Figure 7. 


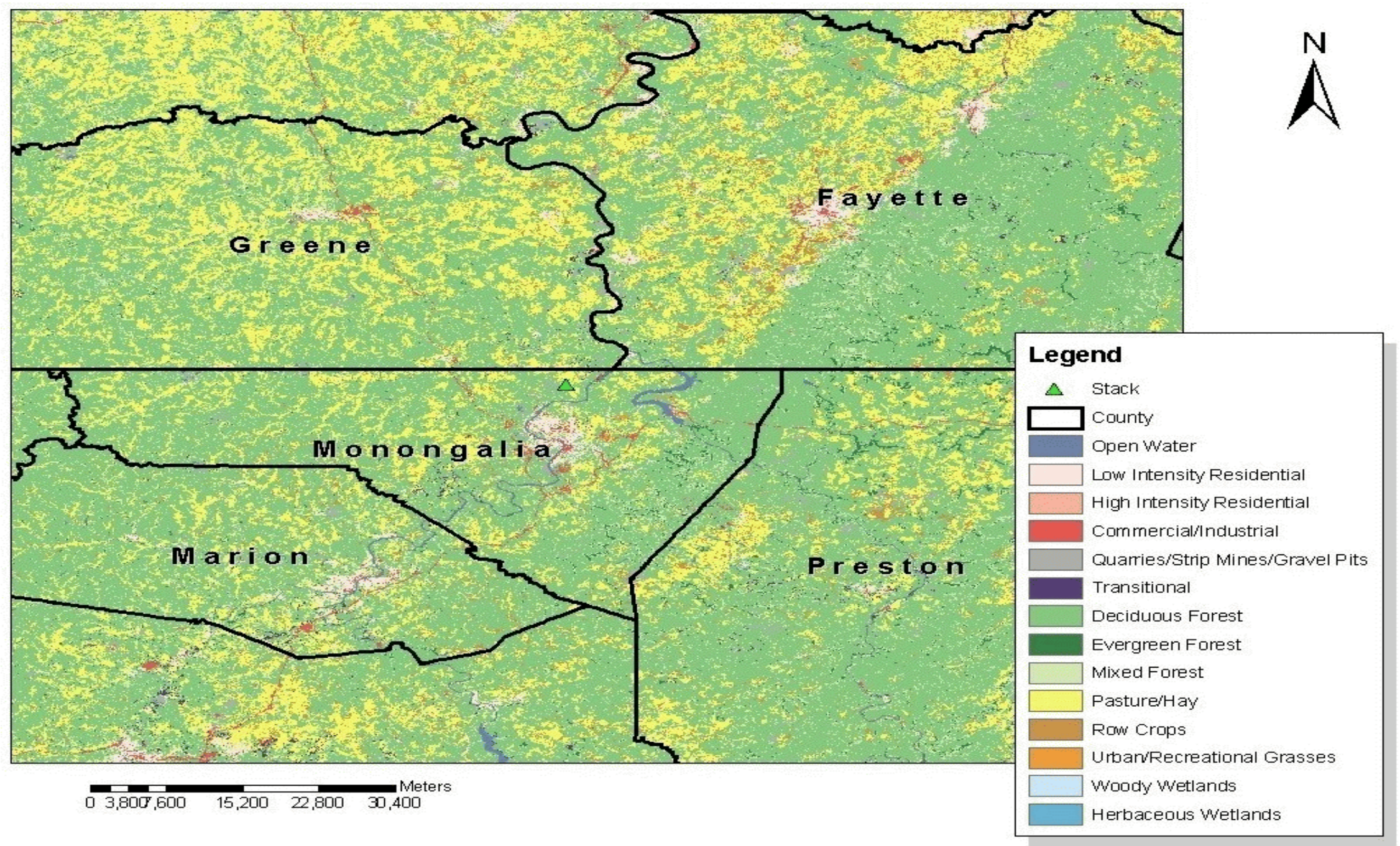

Figure 7: Land Cover Map. The land cover map and legend was used to identify major surface roughness categories and lengths (m) within the study area. Table 7 lists surface roughness categories and lengths (m) used by the air dispersion model. Surface roughness of surrounding topology induce wind turbulence which in return effects vertical mixing of ground level pollution, discussed in chapter 2. Deciduous forest was the chosen predominant land cover there by the surface roughness category chosen for use in the air dispersion model. 
Three different types of meteorological data needed for the air dispersion model meteorological preprocessor, AERMET ${ }^{4}$, include National Weather Service (NWS) hourly surface observations, NWS upper air soundings, and on-site measurements. NWS hourly surface observations and upper air soundings are ultimately retrieved from the National Climatic Data Center (NCDC) of the National Oceanic Atmospheric Administration (NOAA) in compact formats and extracted to usable formats by AERMET. Local meteorological towers, measuring wind (speed and direction) and temperature, provide on-site data for AERMET. Trinity Consultants, designer of a AERMET with their "Breeze" Graphical User Interface (GUI), organized meteorological data formats for us to run these models. Trinity is located in Houston, Texas.

Elevation data were converted from the US Geological Survey ordinance survey format to digital elevation model (DEM), using the program crlf.exe to the format necessary for the AERMAP $^{5}$ terrain preprocessor module of the Breeze AERMOD Suite of dispersion modeling applications. Data are identified by unique "quads," each quad consisting of a rectangle, one degree latitude by one degree longitude. Each quad is subdivided into 64 equal squares, each 7.5 minutes a side, as follows. Each quad is divided into 8 columns, each 7.5 minutes wide, sequentially numbered 1 through 8 from the SE toward the SW corner of the quad. Each quad is

\footnotetext{
${ }^{4}$ AERMET is the meteorological preprocessor for the AERMOD. Input data can come from surface meteorological observations, hourly cloud cover observations, and twice-a-day upper air observations. Output includes surface meteorological observation parameters and vertical profiles of several atmosheric parameters.

${ }^{5}$ AERMAP is a terrain preprocessor used to simplify and standardize the input of terrain data for use in AERMOD. Input data includes receptor terrain elevation data. It may be in the form of digital terrain data, available from the U.S. Geological Survey. Output for each receptor includes, location and height scale, which are elevations that are then used for the computation of air flow around hills.
} 
also divided into 8 rows, each 7.5 minutes high, sequentially lettered a through $\mathrm{h}$ from the SE to the NE corners of the quad. Each square within the quad is then uniquely identified by a column number and a row letter. The quads to be used by AERMOD must be "stitched" together, so the program sees them as a continuous array of digital elevation measurements. The lateral resolution of these measurements, at the latitude of Morgantown is about + or - 30 meters in both N-S and E-W directions.

Background concentrations of existing air pollution are monitored by WV DAQ and the US EPA, as required by NAAQS, through State and Local Air Monitoring Stations (SLAMS) and National Air Monitoring Stations (NAMS) strategically scattered throughout the nation. ${ }^{\mathbf{2 , 6 4}}$ This recorded background concentration of air pollution data is public information, and is made available through EPA's AirData web-site at www.epa.gov/air/data/geosel.html. The study area $\mathrm{SO}_{2}$ concentrations for the year 2000 were obtained from AirData and are presented in a simplified format, in Table 3.3 below. Theses $\mathrm{SO}_{2}$ concentrations are assumed to be representative concentrations of existing $\mathrm{SO}_{2}$, contributed from all air pollution sources in the region as well as from farther west, moving eastward into the study area with the movement of weather patterns. Modeled $\mathrm{SO}_{2}$ concentrations from the proposed CFPP were to be added to monitored $\mathrm{SO}_{2}$ concentrations reported by WV DAQ and EPA. This gives a generalized estimate of what the highest $\mathrm{SO}_{2}$ concentration would have been if the proposed CFPP had been constructed and running for the year 2000. As mentioned, year 2000 emissions and weather have been used in order to correspond to US Census data on population and sensitive receptor distribution across the study area. 
Table 3.3 Monitored SO2 $\left(\mu \mathrm{g} / \mathrm{m}^{3}\right)$ for 2000

\begin{tabular}{|c|c|c|c|c|}
\cline { 1 - 2 } $\begin{array}{c}\text { 24-Hour } \\
\text { Values }\end{array}$ & \multicolumn{5}{|c|}{ County } & State \\
\hline 1st Max & $\begin{array}{c}\text { Number of } \\
\text { Site } \\
\text { Monitors }\end{array}$ & Site Location & Monongalia Co & WV \\
\hline 0.723 & 1 & Knapp Hall, WVU, Morgantown & Monongalia Co & WV \\
\hline 0.542 & 1 & Morgantown Airport Us 119\&Airport Blvd. & Monongalia Co & WV \\
\hline 0.747 & 1 & WVU Law School, Morgantown & Greene Co & PA \\
\hline 0.277 & 1 & 4.8 Km SE Of Holbrook & & \\
\hline
\end{tabular}

\subsection{Projections}

When gathering geographic data from different sources, the projection of the data must be the same to be able to graphically present the data, layered together, in the form of maps. All data and maps in this thesis are georeferenced in the spherical geographic coordinate system (GCS) as opposed to the two-dimensional cartesian coordinate system. These locations are then projected into UTM flat dimensional cartesian coordinate system, as explained below. The theory behind GCS projections enables for a more precise determination of real world point locations. The GCS uses latitude/longitude lines to locate points lined across the $\mathrm{x}$ and $\mathrm{y}$ axes grided over the entire, approximately spherical, surface of the earth. The angles of these lines are measured from the center of the earth to a location on the earth's surface resulting in rad or degree units with the equator being zero degrees lattitude (x-axis) and the prime meridian (through Greenwich, England) being zero degrees longitude (y-axis). Although more accurate than the cartesian coordinate system, a coordinate system such as this results in spherical surface curved maps which need to be projected back to a flat map in order to be analyzed on paper or in 
GIS by ESRI, AutoCAD by Autodesk ${ }^{6}$, or AERMOD by Trinity. Projecting a map converts a curved map to a flat surface while somewhat holding coordinate grid accuracy.

Map projections are important when analyzing smaller, more local geographical areas. Since the poles are somewhat flattened and the equatorial region expanded due to the centrifugal effect, the earth's surface is not precisely spherical. Therefore, for greater accuracy, an ellipsoid correction, or datum, is used for projecting a quasi-spheroid surface into a flat surface map. The converted quasi-sphere of the earth is called a geoid. Some of the more common projections used in the region of the U.S. are NAD83 and NAD27. NAD83 is the projection chosen for this thesis. It is an Earth-centered datum, using the Geodetic Reference System 1980 (GRS 80) ellipsoid and its reference point is the center of the earth. NAD27 uses the Geodetic Reference System but its reference point is on the surface of the earth. ${ }^{36,39}$ Using recent measurements with modern geodetic, gravimetric, astrodynamic, and astronomic instruments, the GRS 80 ellipsoid has proven to best fit the worldwide geoid. ${ }^{36,39}$ A lot of GIS Data is either NAD27 or NAD83, and these projections onto a flat, two-dimensional sphere, are only slightly different. Having all the data and maps produced in this thesis in the same projection is very important. The position of a point based between these two different datums will result in a deviation between what should be the same location on the earth's surface, meaning that the georeferenced points will not match.

Also, it is important to point out that a difference in coordinate system terminology sometimes exists between civil and environmental engineers, and other scientists that work strictly with geographic data. Most engineers, that make use of AutoCAD software technology and

\footnotetext{
${ }^{6}$ Autodesk is a software and digital content company. They offer business solutions through technology products and services. AutoCAD is a registered trademark of Autodesk.
} 
various surveying technology for use in their project design, are familiar with what is referred to as the user coordinate system (UCS). They often use the simple X and Y coordinate system, with the $0,0(\mathrm{X}, \mathrm{Y})$ located in the lower left hand corner of their grid for project designs. AutoCAD does however contain another coordinate system design option, referred to as the world coordinate system (WCS), which is more compatible for use with other geographic data. The WCS is a spherical coordinate system that has been projected back to a flat surface for use in AutoCAD. The WCS enable engineers to design projects directly over real world coordinate points, like that of the GCS. This option, however, requires engineers to conform to, recognize and work with much larger $\mathrm{X}, \mathrm{Y}$ figures than what is otherwise used in AutoCAD, when designing over the simplified UCS.

\subsection{Software Application and Methods}

The following section gives detailed description of software and methods used to identify sensitive population exposure to $\mathrm{SO}_{2}$ contributions from the proposed CFPP under worst case weather scenarios. GIS applications were approached first, using ArcGIS 8.3. This established the identification, locations of, and number of categorized sensitive receptor populations which are located within the study area, centered at the proposed CFPP location. After the GIS work was completed, AutoCAD applications were focused on next. Here, I constructed a digital drawing compatible for use in the air dispersion modeling software using the site plan drawings of the proposed CFPP provided by WV DAQ. Air dispersion modeling was conducted last, using some of the results obtained from the previous software applications. Breeze AERMOD Pro Prime version 4.0.13 was used for air dispersion modeling. 


\subsubsection{Method 1, Sensitive Receptors}

I have separated sensitive receptors into two classes. GIS was used to establish the category and location of institutional sensitive receptors surrounding the proposed site plan, out to a radius of $30 \mathrm{~km}$. The first class of sensitive receptors are comprised of sites containing people of limited mobility, here represented by nursing homes, and hospitals. The second class of sensitive receptors are those where large numbers of people congregate intermittently, so that a serious air pollution episode affecting such a site could have catastrophic consequences. For this thesis, child day care facilities and grade schools will represent the second class of sensitive receptors. As previously mentioned, the elderly, sick and young are the especially vulnerable sectors of the population. A similar study could, however, add more categories of sensitive receptors, in each of these two classes. For example, shopping malls, stadiums and churches may be added for areas where a number of people gather intermittently, while prisons, and homes for the disabled may added for those of limited mobility. Based on the literature review and discussion of $\mathrm{SO}_{2}$ health effects, it was decided that these aforementioned categories of sensitive receptors lack the population size and frequency of visits of those categories used as representative of these two classes in this thesis, which are most especially vulnerable to air pollution episodes.

GIS analysis with mapping was conducted using ArcGIS 8.3, from the Environmental Systems and Research Institute (ESRI). Yellowpages.com, and the US Census Bureau's Zip Code Tabulation Area (ZCTA) map files from TIGER geographic database provided a way to gather a representative sample of the institutional sensitive receptors within the study area. The Bureau provides access to these GIS friendly ZCTA files. Such ZCTA files were used in this study to 
develop a Zip Code Boundary Map (Figure 8 below) of the study area, per county, to be used in conjunction with the Yellowpages.com search per classification per zip code of sensitive receptors. ZCTA was developed by the US Census Bureau to overcome difficulties in precisely defining the land area covered by each ZIP Code when tabulating census data. ${ }^{\mathbf{5 8}}$ Addresses and name of the sensitive receptors, returned form the Yellowpages.com searches, were matched with the georeferenced populated place points. 


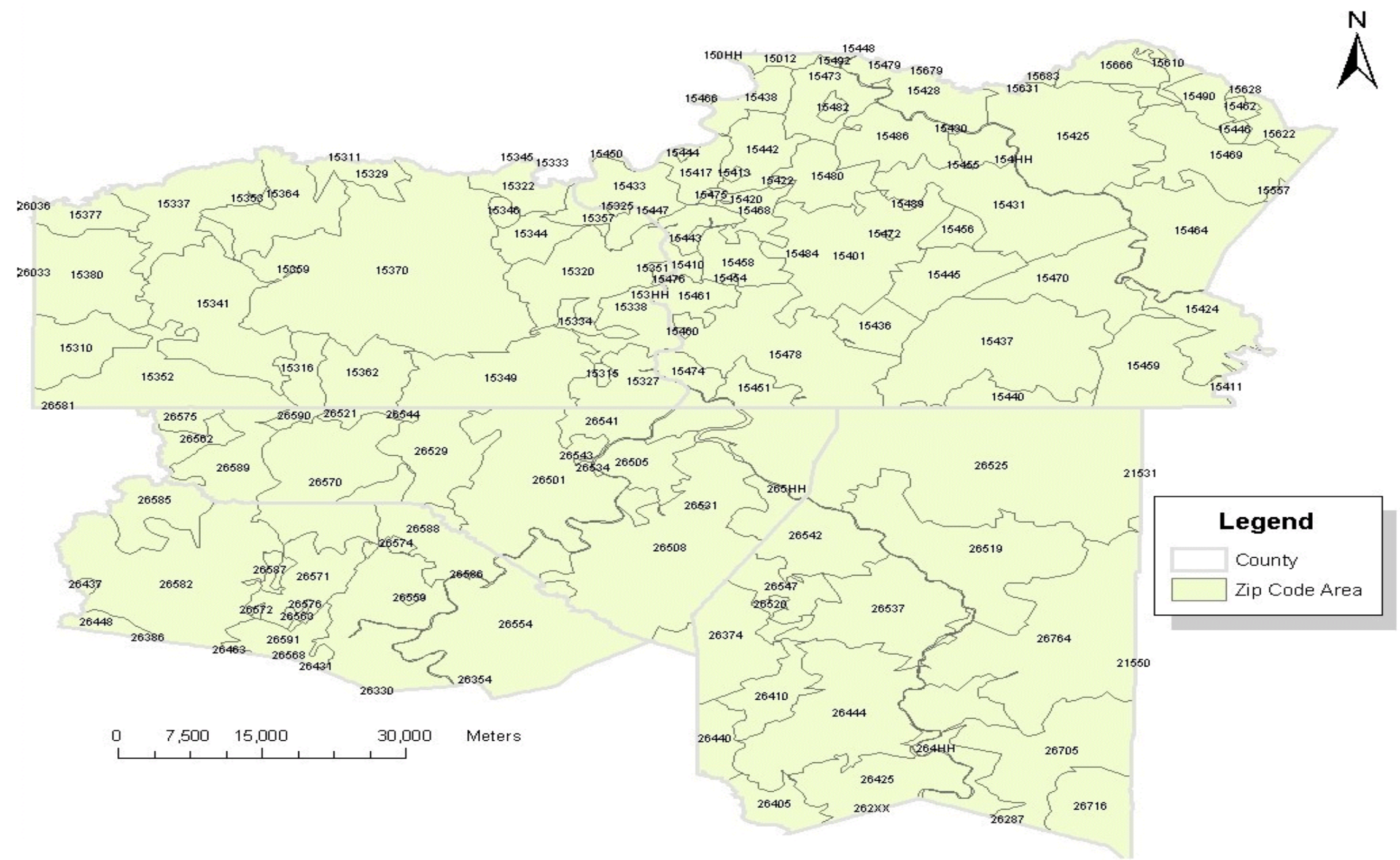

Figure 8: US Census Bureau's Zip Code Tabulation Area (ZCTA) Map. The ZCTA map of the study area was used to match georeferenced populated place points with names and addresses from Yellowpages.com sensitive receptor search. A Yellowpages.com sensitive receptor search was conducted per zip code, per county. See appendix B for a complete list of Yellowpages.com search results discussed in chapter 4. 
Extensions to ArcGIS are included within the 8.3 version are Spatial Analyst, such as StreetMap USA, ArcPress, 3D Analyst, Ecological Management Decision Support, Extension, and Geostatistical Analyst. These essential tools within the software enable users to question, analyze, discover, visualize, navigate, and solve spatial problems. The ArcGIS extensions used in this thesis was the Spatial Analyst and Geostatistical Analyst. The Spatial Analyst was used to measure distances from the proposed coal fired power plant to regional prioritized sensitive receptors.

Using the Spatial Analyst extension allows spatial analysis of data being studied in ArcGIS. You can provide answers to simple spatial questions, such as "How far is this location to another?" or "What direction is this location facing?", or more complex spatial questions, like "Where is the best location to build a new building?" or "What is the least-cost path from point A to B?"26 Least cost path refers to the travel path with the fewest obstacles (fewest impedances) to movement from one location to another - helpful in locations with irregular topography. A large part of this thesis was to identify the straight line distances from the proposed source stack to prioritized sensitive receptor locations.

Calculating the distance of sensitive receptors from the new stack's location was done using the analysis mask and raster calculator tools within the Spatial Analyst extension. The analysis mask was used, establishing georeferenced boundaries, among other features, to the new map layer being created. The raster calculator was used next to statistically analyze spatial data inputs, producing a continuous interpolated map surface that can be used to visualize, analyze, and answer spatial questions. In this distance to stack calculation, a new color-coded radial distance surface layer from source stack was produced, depicting distance, moving away from 
stack. Each color of the new surface layer theoretically corresponds to a given distance, changing as you get further away from a stack or sensitive receptor location, as shown when overlaying the two different map layers.

ArcGIS extension tools were crucial software for fulfilling the goals of this thesis. Developing maps using the techniques discussed above enabled the creation and overlay of various map layers, allowing me to determine city/community/area containing sensitive receptors, and the stack to straight line distances to those city/community/area containing sensitive receptors. For example, I was able to produce map layers of populated place at $5 \mathrm{~km}$ radius increments, out to a maximum of $30 \mathrm{~km}$, from the distance to stack map calculation. This broke the volume of populated place containing sensitive receptors, into annular segments, minimizing the volume to be evaluated and presented at any one time. Real world coordinates of each city/community/area with sensitive receptors were also established using GIS tabular data. That, combined with sensitive receptors location per $5 \mathrm{~km}$ increment level, facilitated identification of sensitive receptors, in the receptor grid designed later for use in air dispersion modeling. A more detailed description of the receptor grid design is to follow in section 3.3.3.

\subsubsection{Method 2, Site Plan}

The AutoCAD application in this type of study is smaller than use of GIS and air dispersion modeling, but is crucial to improving the quality of air dispersion modeling. Local site characteristics, especially height and width of stacks and buildings, of any CFPP have the ability to greatly effect plume dispersal. A 2 dimensional (2D) AutoCAD drawing, file extension DXF, of the proposed stack and building(s) provided in feet, had to be re-created in meters and imported for use in the air dispersion modeling software. 
This study is only concerned with ground level concentration impacts outside of the proposed CFPP boundaries. Stack-tip and direction-specific building downwash are only briefly discussed above because of the relatively smaller residential population density that would be directly surrounding the proposed CFPP. However, because of the possibility, and the magnitude of the impact outside plant boundaries being so great, if it were to occur, such conditions warrant an evaluation within the air dispersion modeling process.

AutoCAD is the leading software used by engineers and architects to construct digital drawings of their design projects. AutoCAD is a computer program that may be used to manipulate $\mathrm{CAD}$ drawings of buildings, bridges, roads, among other engineering drawings. AutoCAD was only to be used in this thesis for proposed site plan drawings, to be used in AERMOD for modeling. Many engineering disciplines make use of this software, including civil, environmental, mechanical, as well as others. Architects find AutoCAD a great resource when designing buildings. This study made use of AutoCAD, to construct a $2 \mathrm{D}$ drawing of the proposed plant.

Four different buildings, the main stack, and the site boundary were digitally drawn, using the proposed site plan provided by WV DAQ. The file provided to me by WV DAQ was rather detailed, and of unfamiliar coordinates. It contained more information than necessary for air dispersion modeling, however features of interest were readily extractable. Plant coordinates, discussed above, appeared to be in the WCS, but did not match that of any coordinates found in West Virginia. As mentioned earlier, real world coordinates are often irrelevant during the first steps of drawing a project design. Coordinates may be repositioned in AutoCAD, to real world coordinates, anytime throughout the process. To do this, a unit conversion may be required, if 
the project design was originally drawn from a grid in Imperial (or English) units, as apposed to Metric. Geographic projections discussed in section 3.2 are all measured in Metric units, and as it turns out, the file provided to me by WV DAQ was in Imperial units. A unit conversion was required in order to import the correct type of .DBF file and run the air dispersion model. The 2D drawing, developed for use in the model was drawn in feet and needed to be converted to meters. This was done in AutoCAD by re-setting the drawing to the UCS, re-scaling the drawing, converting the grid size to meters, and re-setting the drawing to the correct world coordinates.

A 3 dimensional (3D) drawing file could not be imported into the air dispersion model. Only the 2D drawing needs to be imported into AERMOD plus dat on the heights of the stack and individual buildings. 3D capabilities do exist in AutoCAD, however, the air dispersion modeling software reserves the right to add the third dimension (height) from the 2D. This is due to it's direction specific building and stack tip downwash algorithms, and the importing of terrain elevations. Importing elevation data allows for the additional heights of building and stack features, above grade, to be considered in the modeling. Constructing the third dimension in the air dispersion model, decreases the quantity of input data required from the modeler, by adding these important terrain elevations and site characteristics to the model all at once. Doing so correctly, empowers the model to incorporate possible building and stack tip downwash incidents, during any model run.

\subsubsection{Method 3, Concentration Exposure Modeling}

The transport and dispersion of $\mathrm{SO}_{2}$ from the proposed CFPP was modeled in this study using the U.S. EPA model AERMOD, accessed through the graphical user interface (GUI), Breeze version of AERMOD from Trinity Consultants. Breeze AERMOD makes use of various 
weather conditions, plume rise (emission momentum and bouncy induced dispersion), stack-tip downwash, direction-specific building downwash, buoyancy-induced and lateral dispersion. Special non-gaussian methods are used by AERMOD, constructing a convective boundary layer (CBL), when modeling under atmospheric instability. This goal of this thesis is to model downwind dispersion under worst case scenario. For this study then, AERMOD uses the more basic Gaussian method discussed in chapter 2, when modeling under stable boundary layer (SBL) conditions. Upon completion of air dispersion modeling, calculated concentration estimates were used to produce concentration maps further depicting calculated contribution exposure of the entire study area (30km radius).

Again, factors most likely to influence dispersion include plume contents and concentration, hourly wind velocity and direction, location and height (above grade) of the stack relevant to site characteristics, stack exit velocity of emissions determining emission momentum, topology and surface roughness (such as effects of vegetation, and water bodies), and internal diameter of the stack at it's outlet. AERMOD can account for all these factors, combining the equations for continuous plume mass flow with diffusion Guassian dispersion in the y (lateral) direction and $\mathrm{z}$ (vertical) direction form plume centerline.

AERMIC (American Meteorological Society/Environmental Protection Agency Regulatory Model Improvement Committee), introduced this state-of-the-art modeling concept into the EPA's air quality models. As described, AERMOD requires the concurrent use of a meteorological preprocessor and terrain preprocessor, respectively U.S. EPA models AERMET and AERMAP used here in the Breeze GUI version. As stated earlier, it is validated up to a radius of $50 \mathrm{~km}$ from the source stack, although greatest accuracy is probably limited to a radius 
of $30 \mathrm{~km}$, which defines the study area of interest in this thesis.

AERMOD can model an unlimited number of point sources (stacks), source groups, receptors, regularly spaced receptor grids, and short- and long-term averages, and can store up to 200 pollutant emission rates in a modeling project. AERMOD is the second, updated, major U.S. EPA model (following ISC), for dispersion from industrial source points, flares, lines, areas, or volumes which can accommodate irregular terrain (ISC accommodates irregular terrain as well), as is necessary in Appalachia. AERMOD can model ambient concentrations due to emissions, separately, by hour of day, month, and season, seasonal and hourly combined, and preprocessed meteorological data. ${ }^{6}$ An unlimited amount of receptor concentrations can be calculated at all elevations in one model run.

Picking the correct averaging times to run in AERMOD was crucial. Designing a modeling scenario that would incorporate AERMOD's maximum capabilities becomes very labor intensive for the modeler(s) (often more than one modeler is necessary), maximizing computer memory capabilities, as well.

Air dispersion modeling conducted for this thesis was rather simple compared to what AERMOD is capable of modeling. However, the goal here was to review model results under stable atmospheric conditions. The air dispersion modeling steps, roughly followed, are listed in below:

1. Stack coordinate location, height (above grade), exit velocity, emission rate, internal diameter, and exit temperature were entered.

2. Imported the .dxf drawing of the proposed site plan, converting buildings to $3 \mathrm{D}$, and adding discrete receptors along the plant boundary.

3. Designed the polar grid receptor, and entered discrete receptors at real world coordinates established by GIS within the receptor grid. 
4. Imported weather data for the 2000, extracted for use by AERMET.

5. Imported terrain elevation data, extracted for use by AERMAP.

6. Run Building Downwash Profile Input Program (BPIP) establishing dimensions necessary to model direction-specific building downwash.

7. Run model for desired time frame, and averaging periods

These same steps were roughly followed in consecutive model runs. Selected features discussed throughout this chapter were entered into the model and runs, first for the entire year for 2000, and for consecutive model runs.

This study is much less complex, mostly due to much simpler source parameters (than full model capability) and computer RAM and speed limitations. This modeling scenario, incorporates the worst 24 hour average modeled emission concentrations at receptor locations from the proposed CFPP main stack emissions, for the year 2000. These modeled contributions were then added to monitored background concentrations for the same year. The combined concentrations were then compared to the provisional maximum ambient $\mathrm{SO}_{2}$ concentration for this study, as well as the US EPA PSD $91 \mu \mathrm{g} / \mathrm{m}^{3} 24$ hour averaging standard.

Higher concentrations are theoretically calculated when stable atmospheric conditions occurred, and those are the days on which I have focused. The first model run, for the entire year for 2000, was conducted to establish which day the highest modeled plume concentrations occurred. The output file of this modeling software is programed to list the coordinate locations and date of maximum concentrations, per averaging period chosen. I chose to have the model list the locations and date of the 25 maximum high concentrations at a 24 hour averaging period in the first model run. I then broke subsequent model runs down into the top five highest 24 average 
concentration dates modeled, running the same model run criteria for all 5 dates, for the year 2000. After modeling the 5 subsequent days, and for the entire year, a detailed evaluation of results on high concentration modeled days was conducted. The location of populated places with sensitive receptors, relative to high concentration locations modeled, were key variables evaluated.

Geostatistical analyst, has the ability to interpolate a continuous surface using calculated concentration points taken throughout a particular area of interest, selecting one method within a range of mathematical and statistical functions for interpolation. In this thesis the georeferenced location of calculated concentration contributions, obtained from the air dispersion modeling, served as $\mathrm{SO}_{2}$ sample concentration contribution points to be interpolated over the study area. Calculated concentration contribution point data were examined for normality of distribution. A normal QQ Plot of these 1145 data points, for each of the 5 modeled worst case (highest $\mathrm{SO}_{2}$ concentration) days were generated. The normal QQ Plots for these 5 days showed the modeling data to be close to normally distributed.

Arc GIS's Geostatistical Analyst extension allows the use of some of the most widely used deterministic and geostatistical interpolation methods. Inverse Distance Weighted (IDW) is a deterministic interpolation method that uses basic mathematical functions to interpolate a surface by placing a weighted value to calculated concentration points, fitting planes to the calculated concentration points. First to third order global polynomial functions may be used to interpolate various types of surfaces. These families of mathematical formulas are used to account for influential trends, over time and distance, within a set of calculated concentration points. Examples of trends include slope or wind as was the case in this study. The closer the calculated concentration 
points to one another, the more heavily those calculated concentration points are weighed. Points spread farther apart are weighed less, resulting in a lower weighted sample value. A disadvantage of IDW is its tendency to exclude extreme outlying calculated concentration points from influencing in the interpolation. for example assuming that extreme outliers have insignificant relationships to those located close to one another.

Kriging is a geostatistical method. Calculated concentration points are not only weighted based on distance between one another but also weighted based on their overall spatial arrangement. All calculated concentration points within a data set were used for predicting values between known calculated concentration points. The distances, between all known value points, are statistically analyzed. The kirging method uses mathematical and statistical methods to interpolate its surface. Here, spatial autocorrelation between sample points are quantified, meaning closer sample points are assumed to be more alike than the points spread farther apart. ${ }^{69}$ Through ordinary kriging, calculated $\mathrm{SO}_{2}$ contribution concentration estimates were used interpolate concentration contributions for the entire study area of $30 \mathrm{~km}$ radius from stack.

Spatial autocorrelatoin evaluates the statistical relationship among measured concentration values. ${ }^{69}$ The quantification of such relationships are calculated using the semivariogram plot, a tool available in Geostatistical Analyst. In the semivariogram, trends within the calculated concentration values may be explored, and a prediction model fitted with some measure of certainty or accuracy. ${ }^{69}$ Wind direction was the trend analyzed for in this study. Trend analysis of dispersion modeled $\mathrm{SO}_{2}$ concentration point values indicated directionality corresponding to prevailing wind direction, as independently verified by the annual windrose for the site, for the year 2000, from meteorological monitoring stations. Therefore, it was judged unnecessary to temporarily remove 
the trend, for analysis of residuals indicating variance in the data.

Cross validation of calculated concentration values to predicted values provides the measure of certainty or accuracy. One by one, for each of the 1145 calculated $\mathrm{SO}_{2}$ concentrations at specific locations, the Geostatistical Analyst sequentially removes a known calculated concentration value, predicts a value for that exact location, compares the two values, and calculates statistical prediction errors based on the differences between the two values for each of these 1145 locations. For a model to provide accurate predictions, the mean prediction error should be close to 0 , the root-meansquare standardized prediction error should be close to 1, and the root-mean-square prediction error should be small if predictions are close the calculated $\mathrm{SO}_{2}$ concentration contribution at each of these 1145 locations. ${ }^{69}$ 


\section{Chapter 4 - Results}

This chapter is divided into the following sections: 1) results of the GIS spatial analysis, 2) site plan drawing of the CFPP as a foundation for direction specific building downwash, 3) results of the air dispersion modeling of $\mathrm{SO}_{2}$ concentration contributions from the subject CFPP, 4) $\mathrm{SO}_{2}$ concentration contributions summed with the background monitored concentrations. It is to be understood that the term concentration, used throughout this chapter, is referring to $\mathrm{SO}_{2}$ concentrations in in $\mu \mathrm{g} / \mathrm{m}^{3}$. Various maps, figures and tables are used to address the key results. Appendix A - C serve to fully document details of key results below.

\subsection{GIS Spatial Analysis}

In order to conduct spatial analysis of categorized sensitive receptor populations to the proposed CFPP emissions, their spatial density and locations within the study area first needed to be identified. This was completed searching Yellowpages.com per category of sensitive receptor for each zip code in the study area, and comparing search results to the populated places database file (DBF). All sensitive receptor locations were identified and mapped, see Figure 9 and Table 4.1 below, by matching the tabular data of each sensitive receptor's local addresses, obtained from Yellowpages.com searches, to the corresponding populated places point DBF table, provided by WV NRAC. The nationwide populated places data (both map and DBF table) was cropped to match 30 $\mathrm{km}$ radius study area (see $30 \mathrm{~km}$ radius results below under straight line distance calculation). Using Microsoft excel, each category of sensitive receptor used was placed in separate spreadsheets, per county. Columns of the spreadsheet include the name column from the populated places DBF table, as well as address information provided by Yellowpages.com. Table 4.2 below, is a spreadsheet 
example of tabular data matched between Yellowpages.com address results and the populated places DBF. See Appendix B for the complete list of Yellowpages.com results and populated places DBF name column matches. Where Yellowpages.com did not provide a street address, this cell in the table has been left blank. This matching was used to eliminate from the study area, those populated places that did not have any categorized sensitive receptors identified within them. 


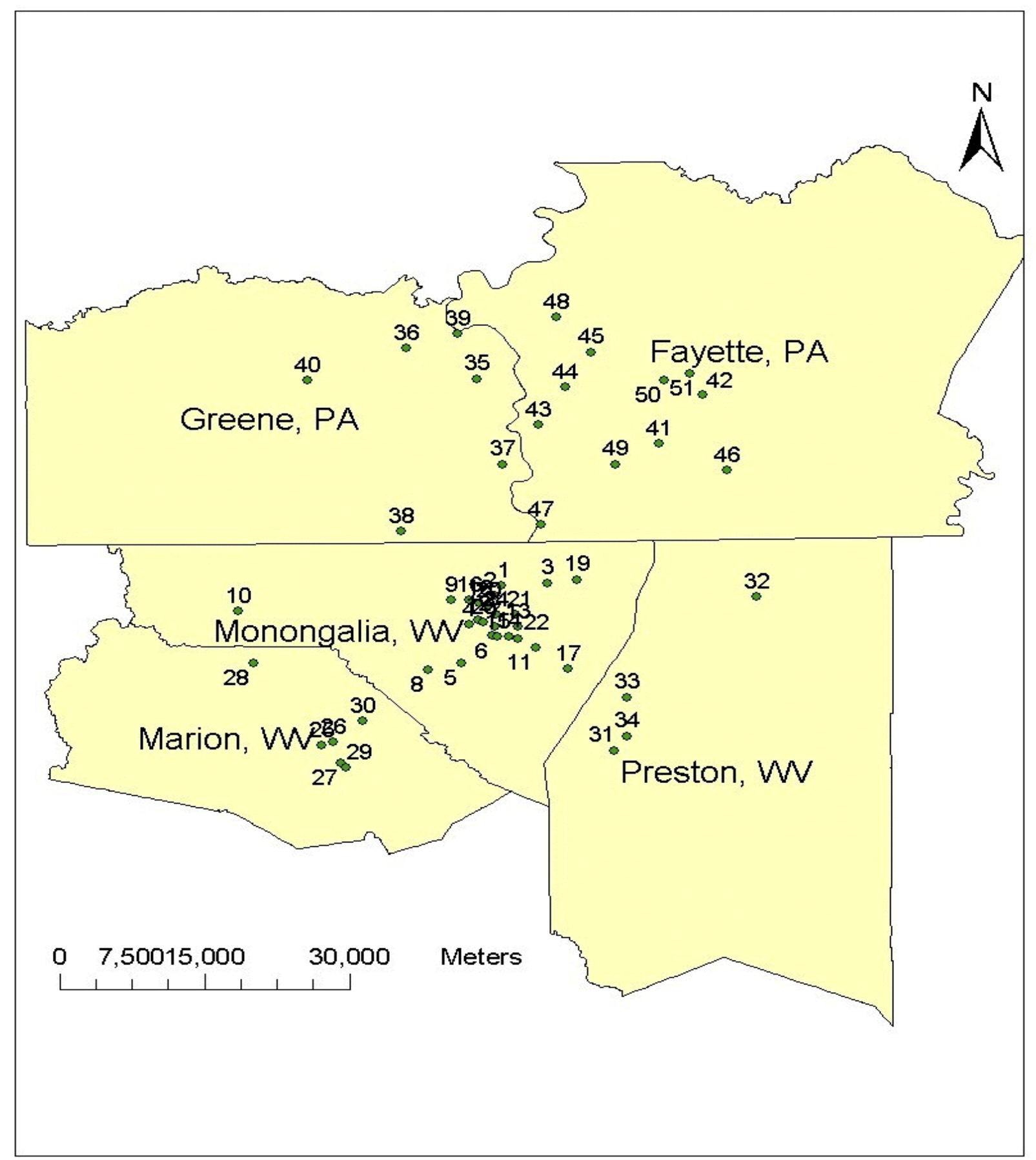

Figure 9: 51 populated places with sensitive receptor categories, out $30 \mathrm{~km}$ from source stack. There were 51 populated places identified with having one or more of the sensitive receptor categories. See Table 4.1 for corresponding names and numbers of populated places containing sensitive receptor categories. 
Table 4.1 Names of Populated Places Containing Sensitive Receptor Categories Used

\begin{tabular}{|c|c|c|c|}
\hline NUMBER & NAME & 44 & McClellandtown \\
\hline 1 & Baker Ridge & 45 & New Salem \\
\hline 2 & Braewick Woods & 46 & Point Breeze \\
\hline 3 & Canyon & 47 & Point Marion \\
\hline 4 & Fairmor & 48 & Republic \\
\hline 5 & Hilderbrand & 49 & Smithfield \\
\hline 6 & Hopecrest & 50 & South Uniontown \\
\hline 7 & Morgantown & 51 & Uniontown \\
\hline
\end{tabular}

\begin{tabular}{|c|c|}
\hline 8 & National \\
\hline 9 & Osage \\
\hline 10 & Ragtown \\
\hline 11 & Richard \\
\hline 12 & Riverside \\
\hline 13 & Sabraton \\
\hline 14 & South Hills \\
\hline 15 & South Park \\
\hline 16 & Star City \\
\hline 17 & Sturgisson \\
\hline 18 & Suncrest \\
\hline 19 & Sunset Beach \\
\hline 20 & The Flatts \\
\hline 21 & The Mileground \\
\hline 22 & West Sabraton \\
\hline 23 & Westover \\
\hline 24 & Wiles Hill \\
\hline 25 & Barrackville \\
\hline 26 & Chesapeake \\
\hline 27 & Fairmont \\
\hline 28 & Fairview \\
\hline 29 & Palatine \\
\hline 30 & Rivesville \\
\hline 31 & Arthurdale \\
\hline 32 & Bruceton Mills \\
\hline 33 & Masontown \\
\hline 34 & Reedsville \\
\hline 35 & Carmichaels \\
\hline 36 & Jefferson \\
\hline 37 & Mapletown \\
\hline 38 & Mount Morris \\
\hline 39 & Rices Landing \\
\hline 40 & Waynesburg \\
\hline 41 & Fairchance \\
\hline 42 & Hopwood \\
\hline 43 & Masontown \\
\hline
\end{tabular}


Table 4.2 Example Tabular Data Matched between Yellowpages.com and the Populated Places DBF Table, Year 2000

\begin{tabular}{|c|l|l|l|l|l|}
\hline Populated Place DBF & \multicolumn{4}{|c|}{ Yellowpages.com Results } \\
\hline Point Name & $\begin{array}{l}\text { Sensitive Recptor } \\
\text { Name }\end{array}$ & \multicolumn{1}{|c|}{ Address } & City/Town & State & Zip \\
\hline BRAEWICK WOODS & $\begin{array}{l}\text { MORGANTOWN } \\
\text { HOSPICE }\end{array}$ & $\begin{array}{l}989 \text { MAPLE } \\
\text { DR }\end{array}$ & MORGANTOWN & WV & 26505 \\
\hline SUNCREST & $\begin{array}{l}\text { TENDER } \\
\text { LOVING CARE } \\
\text { HOME CARE }\end{array}$ & $\begin{array}{l}3280 \\
\text { UNIVERSITY } \\
\text { AVE }\end{array}$ & MORGANTOWN & WV & 26505 \\
\hline THE FLATTS & THE MADISON & $\begin{array}{l}\text { 445 VAN } \\
\text { VOORHIS RD }\end{array}$ & MORGANTOWN & WV & 26505 \\
\hline
\end{tabular}

After establishing the density and location of sensitive receptor within populated place of the study area, spatial analysis of those point locations to the proposed CFPP main stack was conducted. This was done using the straight line distance calculation with ArcGIS 8.3 Spatial Analyst extension, previously discussed. Using the Spatial Analyst raster calculator, the radius, extending from the proposed CFPP out to $30 \mathrm{~km}$ was calculated, then divided into separate $5 \mathrm{~km}$ increments. The $5 \mathrm{~km}$ increments were arbitrarily chosen to improve the evaluating ability of sensitive receptors within the entire $30 \mathrm{~km}$ radius. To date, I have not located in the literature any data that suggests maximum or minimum radial increment levels to be established out from CFPP stacks and facilities. Figure 10 shows the distance to stack radial calculation and respective counties and states with in the study area. 


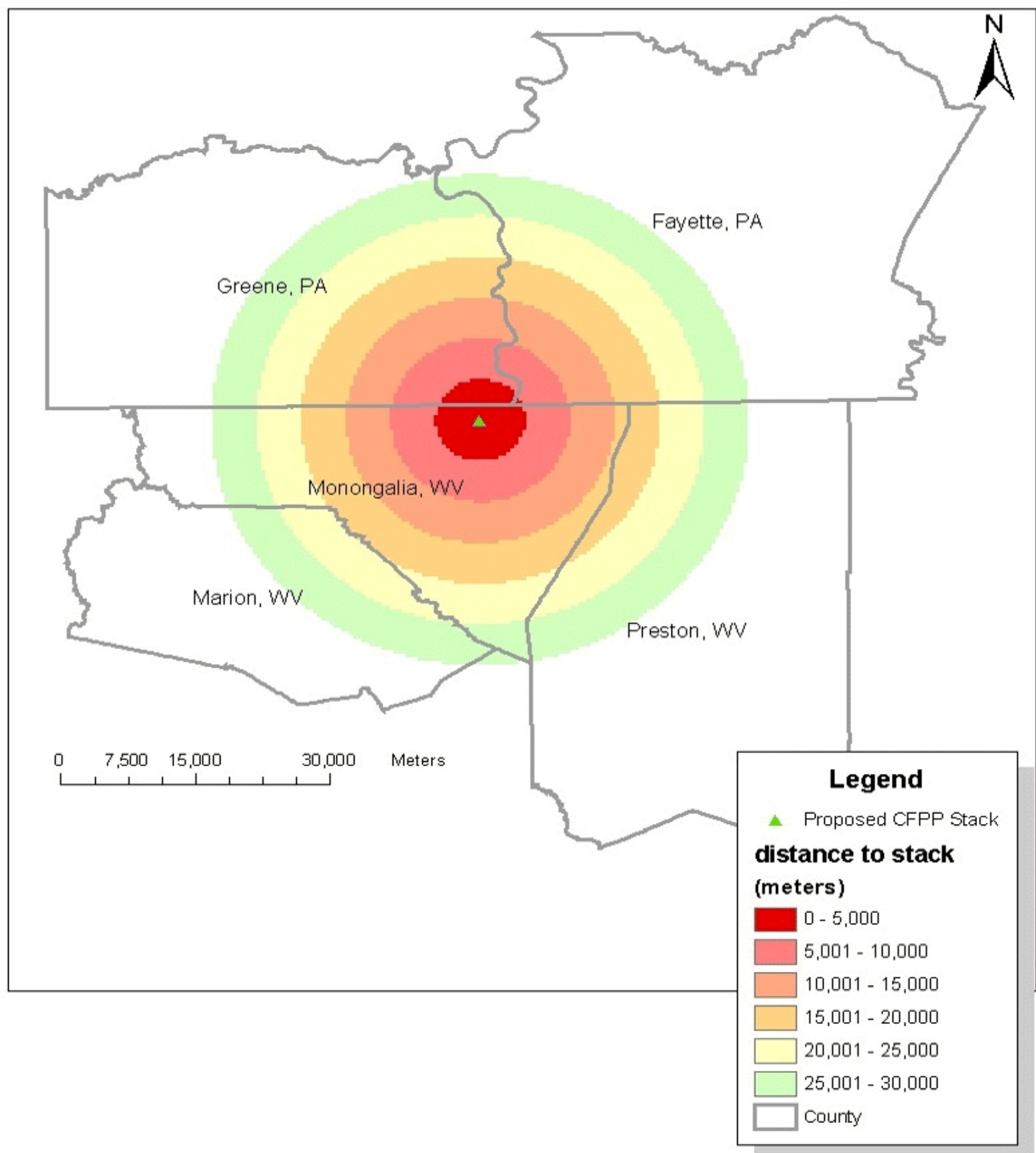

Figure 10: Increment of annular distance to stack calculation. It shows the distance to stack radial calculation and respective counties and states within the study area. The radius, extending from the proposed CFPP out to $30 \mathrm{~km}$ was calculated using spatial analysis tools in GIS software. It was arbitrarily divided into seperate $5 \mathrm{~km}$ increments to improve the evaluating ability of sensitive receptors within the entire $30 \mathrm{~km}$ radius. This annular distance calculation was used to identify straight line distances of populated places containing sensitive receptor categories. 
Figure 11 below shows those populated places within $0-5 \mathrm{~km}$ radius of the proposed stack. Table 4.3 is the DBF table associated with Figure 11. At this point, the DBF locations associated with the populated place shapefiles having sensitive receptors, were upgraded with spatial density information on sensitive receptors, and could be presented in conjunction with the various figures of incremental distance to stack. The particular DBF table below identifies that Baker Ridge has 1 child day care facility, and Braewick Woods has 1 hospital, 1 nursing home, 1 school, and 2 child day care facilities. Each point in the DBF table correlates to actual coordinate points (UTM; easting and northing), with FIPS number. The Federal Information Processing Standards (FIPS) number is the federal government coding system for identifying geographic locations. This particular code identifies location by state and county level and was provided in the populated places DBF. The first two numbers signify which state while the last three numbers signify a county within the state. Figures of populated places at $5-10 \mathrm{~km}, 10-15 \mathrm{~km}, 15-20 \mathrm{~km}, 20-25 \mathrm{~km}$, 25-30km and their associated DBF attribute names follow in Figures 12 - 19, and Tables $4.4-4.8$. In order to clearly read the names of all populated places at $25-30 \mathrm{~km}$ radius, nine different figures were developed for presentation. 


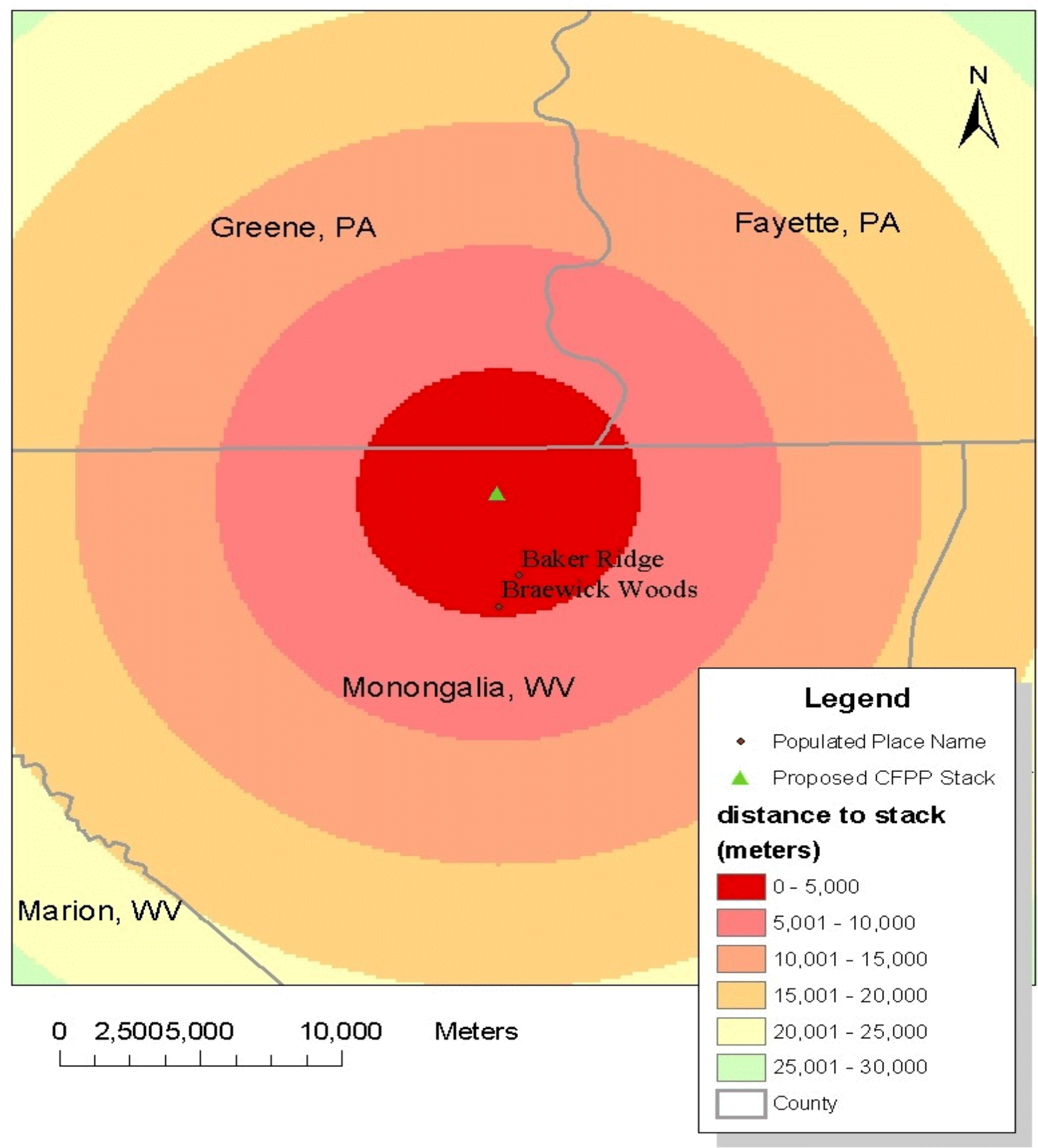

Figure 11: Counties and locations of sensitive receptor categories used within distance to stack calculation of 0 - $5 \mathrm{~km}$. Bakers Ridge and Braewick Woods are the only two populated places containing sensitive receptor categories within 0 - $5 \mathrm{~km}$ from the proposed stack. There is a hospital, nursing home, school, and $\mathbf{3}$ child day care facilities identified within this distance from the proposed stack. Table 4.3, page 78, identifies which populated place contains these sensitive receptors. 


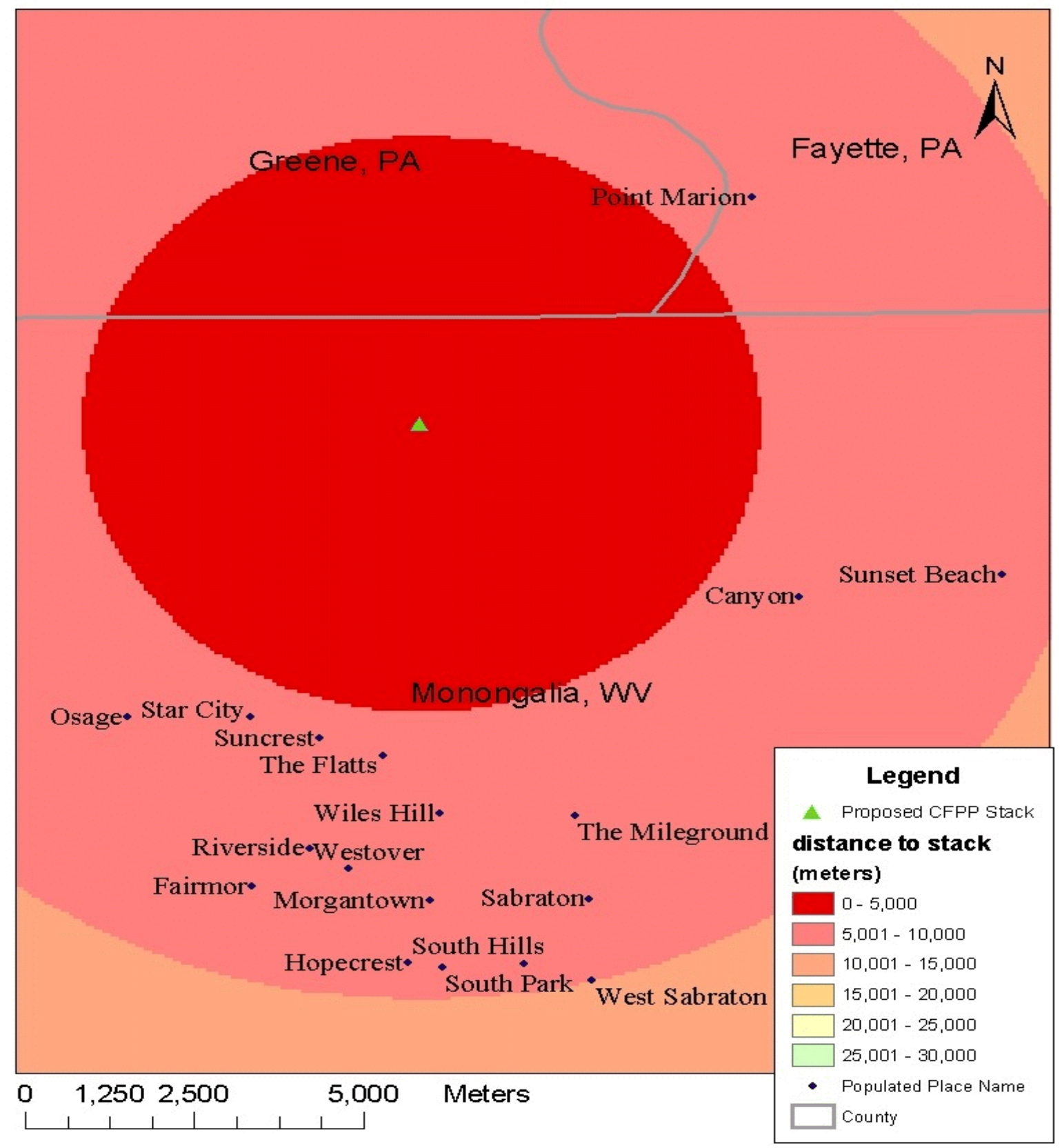

Figure 12: Counties and locations of sensitive receptor categories used within distance to stack calculation of $5-10 \mathrm{~km}$. Greater Morgantown, WV and neighboring populated places containing sensitive receptor categories are within 5 - $10 \mathrm{~km}$ from the proposed stack. Point Marion, PA is also within $5-10 \mathrm{~km}$ from the proposed stack. There are two hospitals, 2 nursing homes, 25 schools, and 17child day care facilities identified within this distance from the proposed stack. Table 4.4, page 78, identifies which populated place contains what sensitive receptor category. 


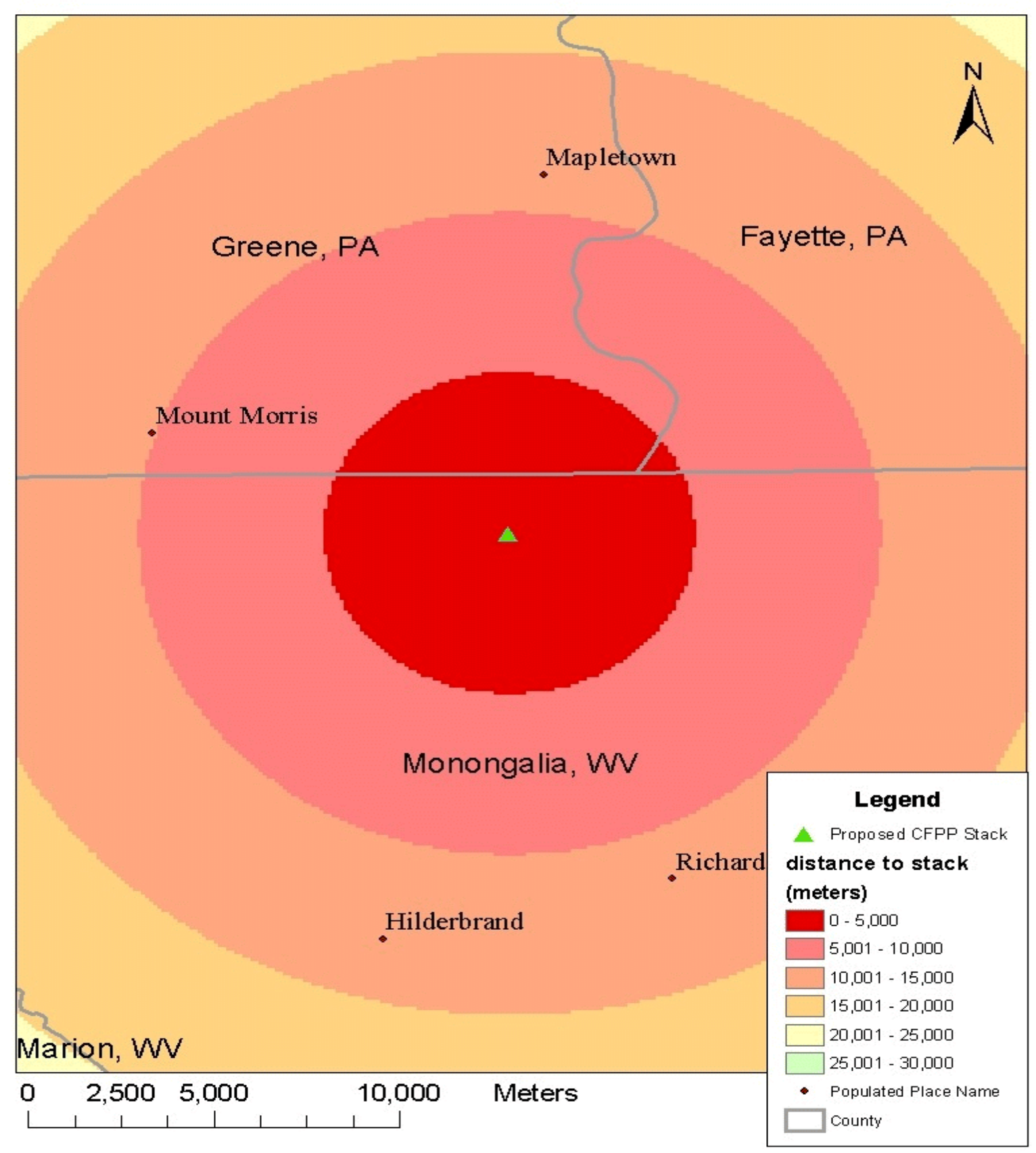

Figure 13: Counties and locations of sensitive receptor categories used within distance to stack calculation of 10 - $15 \mathrm{~km}$. Hilderbrand and Richard, WV, and Mount Morris and Mapletown, PA are the populated places containing sensitive receptor categories within 10 - $15 \mathrm{~km}$ from the proposed stack. There are 4 schools, and 2 child day care facilities identified within this distance from the proposed stack. Table 4.5, page 78, identifies which populated place contains what sensitive receptor category. 


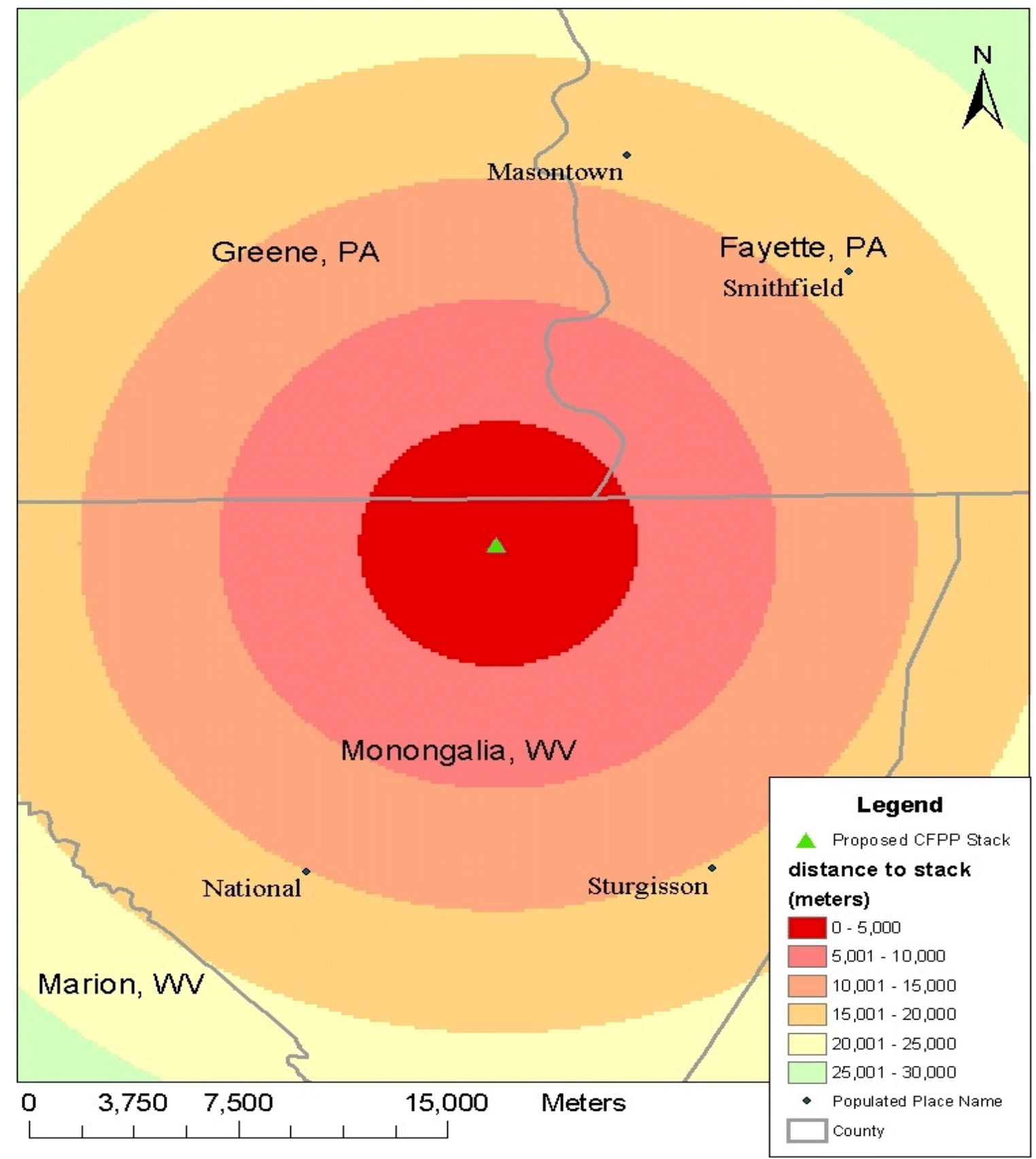

Figure 14: Counties and locations of sensitive receptor categories used within distance to stack calculation of $15-20 \mathrm{~km}$. National and Sturgisson, WV and Smithfield and Masontown, PA populated places containing sensitive receptor categories are within 15 $20 \mathrm{~km}$ from the proposed stack. There are two 4 schools, and 4 child day care facilities identified within this distance from the proposed stack. Table 4.6, page 79, identifies which populated place contains what sensitive receptor category. 


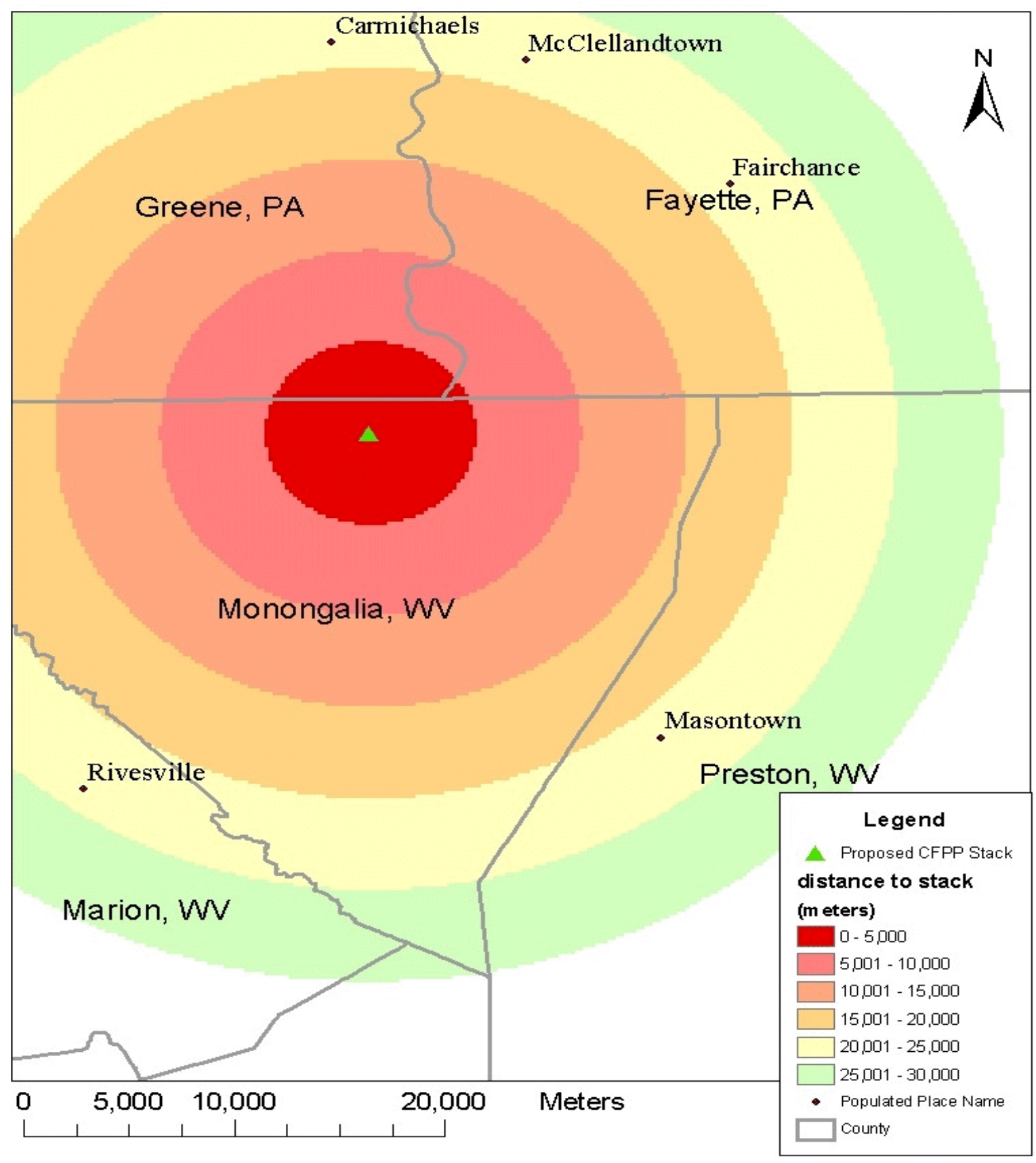

Figure 15: Counties and locations of sensitive receptor categories used within distance to stack calculation of 20 - $25 \mathrm{~km}$. Rivesville and Masontown, WV, and Fairchance, McClellantown, and Carmicheals, PA are the populated places containing sensitive receptor categories within $20-25 \mathrm{~km}$ from the proposed stack. There is a hospital, 5 schools, and 5 child day care facilities identified within this distance from the proposed stack. Table 4.7, page 79, identifies which populated place contains what sensitive receptor category. 


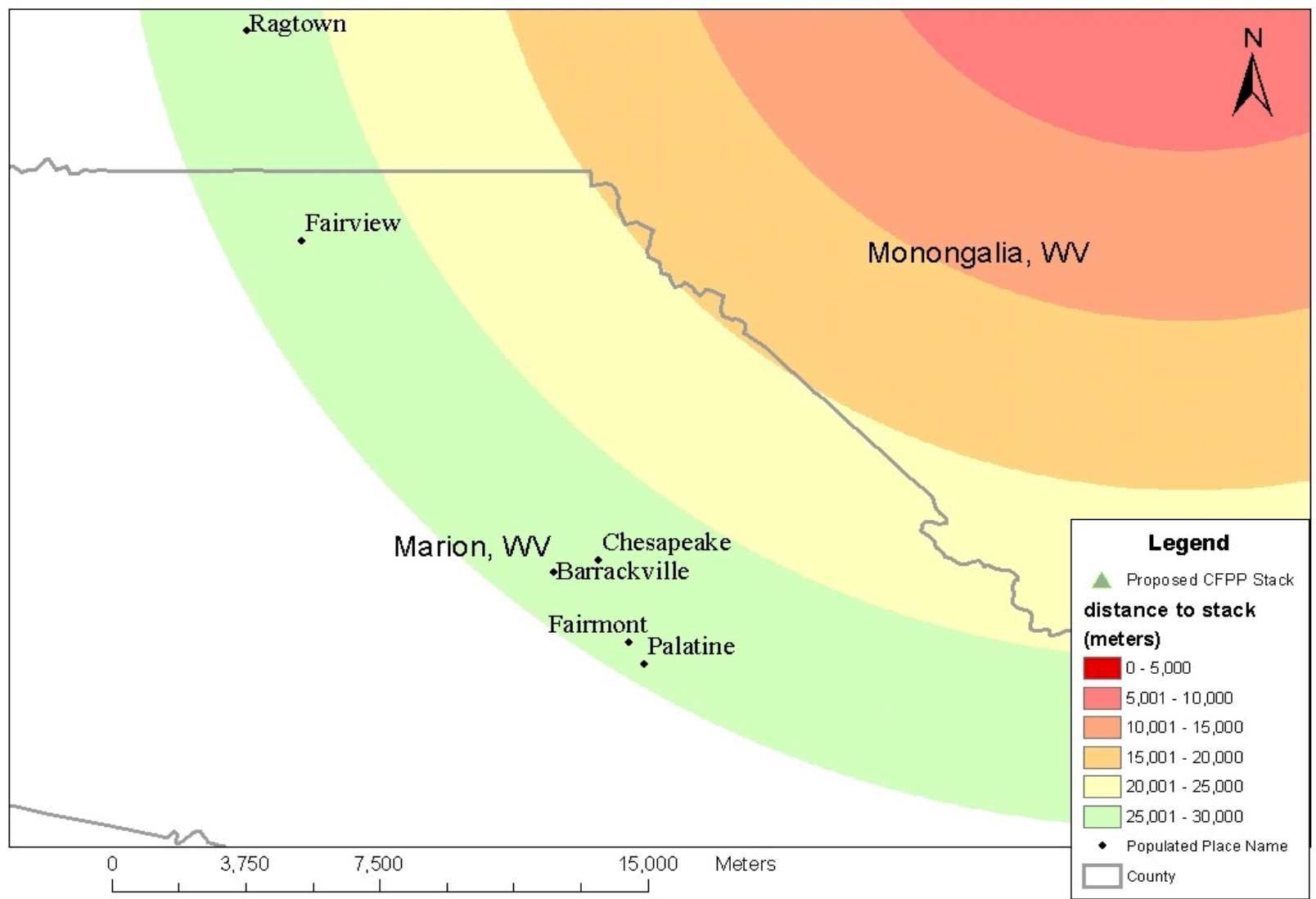

Figure 16: Southwest Counties and locations of sensitive receptor categories used within distance to stack calculation of $25-30 \mathrm{~km}$. This figure identifies Ragtown, Fairview and Fairmont, WV (and neighboring communities) as the populated places containing sensitive receptor categories within $25-30 \mathrm{~km}$ from the proposed stack. This is southwest from the proposed stack. There are 10 hospitals, 4 nursing homes, 35 schools, and 33 child day care facilities identified within this distance from the proposed stack; more than what is depicted in this figure. Table 4.8, page 79, identifies which populated place contains what sensitive receptor category. 


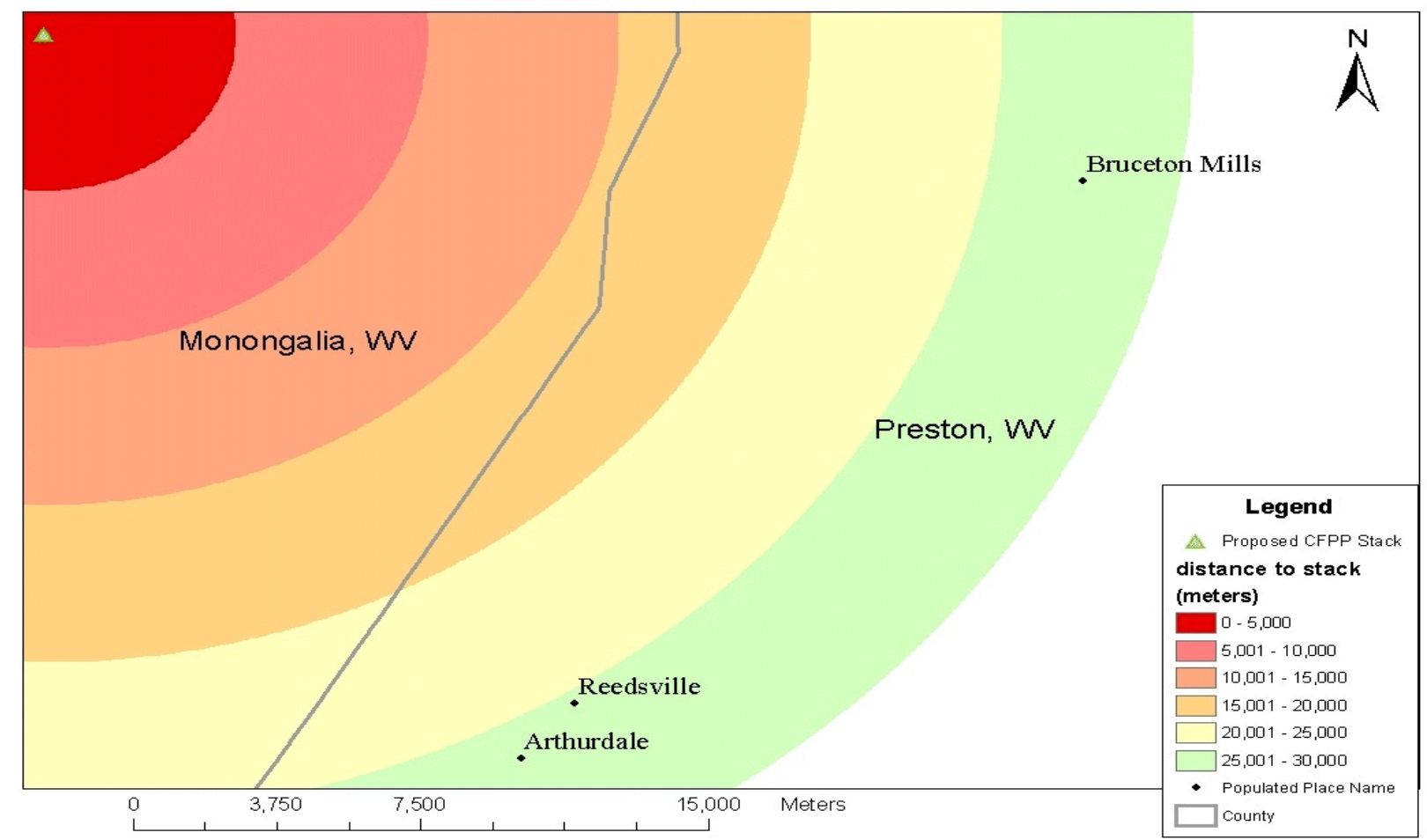

Figure 17: Southeast Counties and locations of sensitive receptor categories used within distance to stack calculation of 25 - $30 \mathrm{~km}$. This figure identifies Arthurdale, Reedsville and Bruceton Mills, WV as the populated places containing sensitive receptor categories within $25-30 \mathrm{~km}$ from the proposed stack. This is southeast from the proposed stack. There are 10 hospitals, 4 nursing homes, 35 schools, and 33 child day care facilities identified within this distance from the proposed stack; more than what is depicted in this figure. Table 4.8, page 79, identifies which populated place contains what sensitive receptor category. 


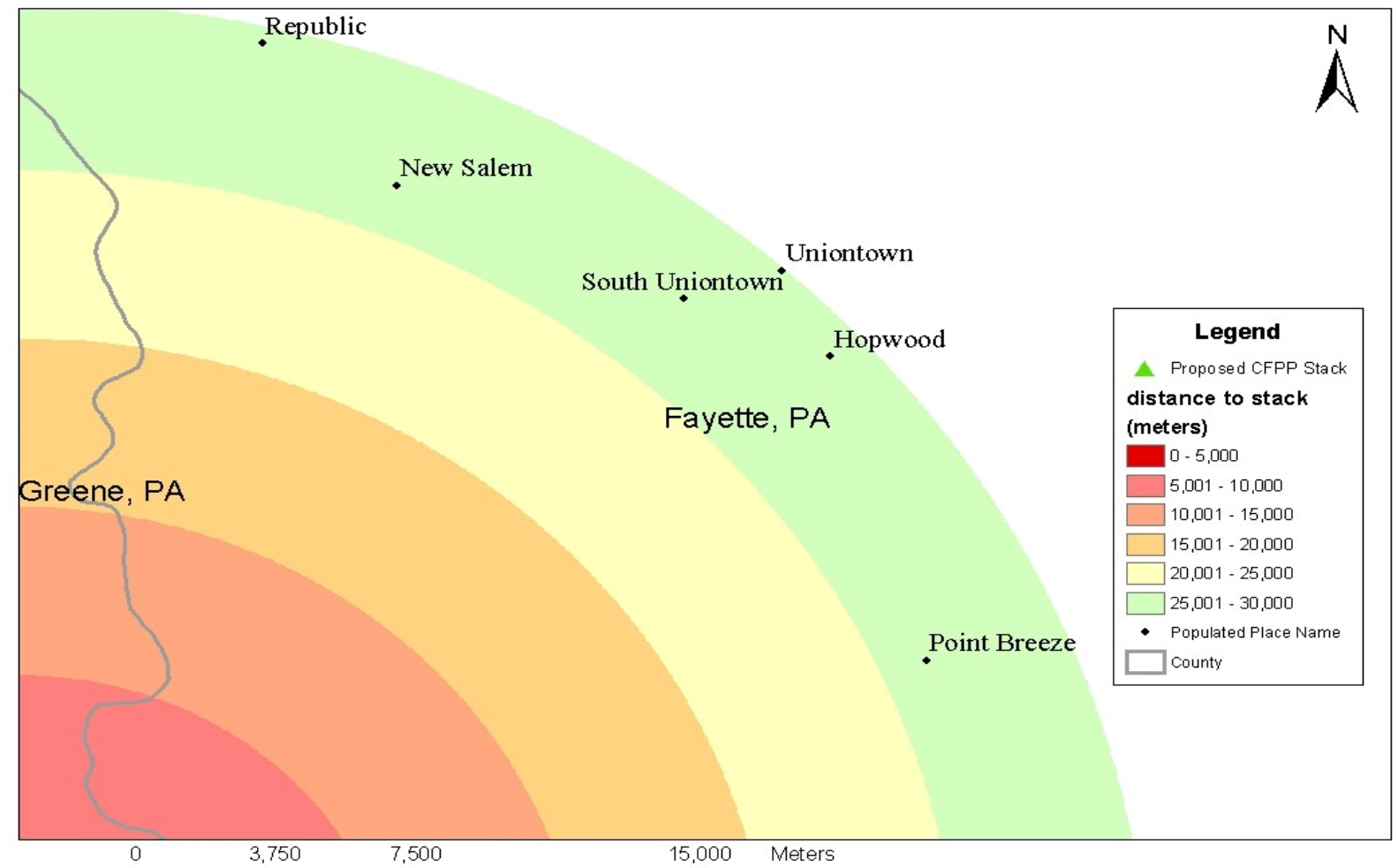

Figure 18: Northeast Counties and locations of sensitive receptor categories used within distance to stack calculation of $25-30 \mathrm{~km}$. This figure identifies Uniontown, PA (and neighboring communities) as the populated places containing sensitive receptor categories within $25-30 \mathrm{~km}$ from the proposed stack. This is northeast from the proposed stack. There are 10 hospitals, 4 nursing homes, 35 schools, and 33 child day care facilities identified within this distance from the proposed stack; more than what is depicted in this figure. Table 4.8, page 79, identifies which populated place contains what sensitive receptor category. 


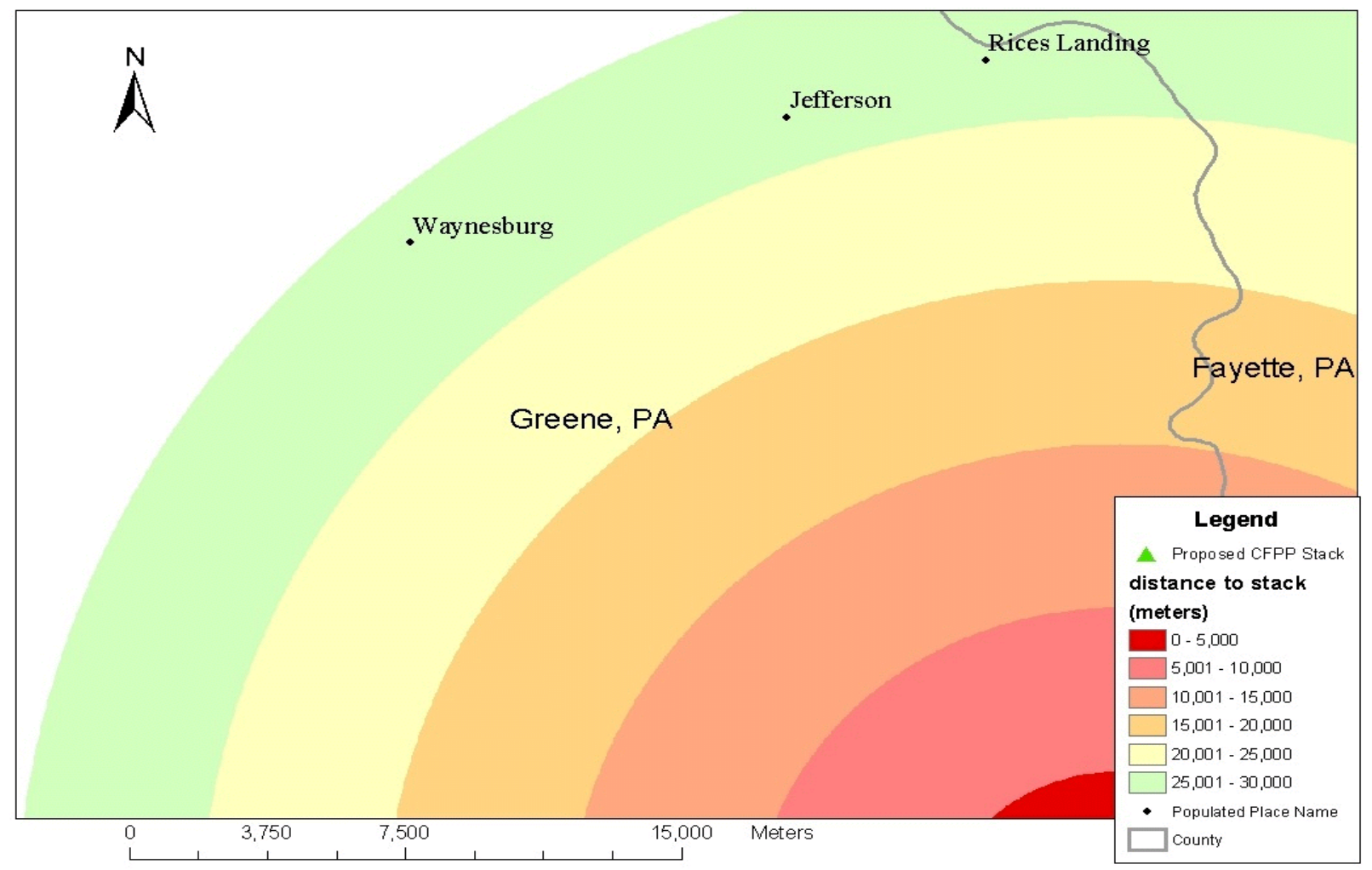

Figure 19: Northwest Counties and locations of sensitive receptor categories used within distance to stack calculation of 25 - $30 \mathrm{~km}$. This figure identifies Waynesburg, Jefferson, and Rices Landing, PA as the populated places containing sensitive receptor categories within $25-30 \mathrm{~km}$ from the proposed stack. This is northwest from the proposed stack. There are 10 hospitals, 4 nursing homes, 35 schools, and 33 child day care facilities identified within this distance from the proposed stack; more than what is depicted in this figure. Table 4.8, page 79, identifies which populated place contains what sensitive receptor category. 
Table 4.3 DBF Table: Sensitive Receptors at Populated Areas, Distance to Stack

Calculation - 0 - 5 km

\begin{tabular}{|c|c|c|c|c|c|c|c|}
\hline NAME & HOSPITALS & $\begin{array}{c}\text { NURSING } \\
\text { HOMES }\end{array}$ & SCHOOLS & $\begin{array}{c}\text { CHILD DAY } \\
\text { CARE }\end{array}$ & EASTING & NORTHING & FIPS \\
\hline Baker Ridge & 0 & 0 & 0 & 1 & 590168.10 & 4392253.90 & 54061 \\
\hline Braewick Woods & 1 & 1 & 1 & 2 & 589384.60 & 4390817.50 & 54061 \\
\hline
\end{tabular}

Table 4.4 DBF Table: Sensitive Receptors at Populated Areas, Distance to Stack Calculation -5 - $10 \mathrm{~km}$

\begin{tabular}{|c|c|c|c|c|c|c|c|}
\hline NAME & HOSPITALS & $\begin{array}{c}\text { NURSING } \\
\text { HOMES }\end{array}$ & SCHOOLS & $\begin{array}{c}\text { CHILD DAY } \\
\text { CARE }\end{array}$ & EASTING & NORTHING & FIPS \\
\hline Canyon & 0 & 0 & 0 & 1 & 595130.10 & 4392645.60 & 54061 \\
\hline Fairmor & 0 & 0 & 0 & 1 & 587034.20 & 4387422.50 & 54061 \\
\hline Hopecrest & 0 & 0 & 3 & 2 & 589223.60 & 4386070.40 & 54061 \\
\hline Morgantown & 0 & 0 & 4 & 4 & 589574.20 & 4387161.10 & 54061 \\
\hline Osage & 0 & 0 & 2 & 0 & 585055.70 & 4390433.20 & 54061 \\
\hline Riverside & 0 & 0 & 2 & 1 & 587788.30 & 4388137.40 & 54061 \\
\hline Sabraton & 0 & 0 & 2 & 0 & 591911.40 & 4387167.20 & 54061 \\
\hline South Hills & 0 & 0 & 2 & 0 & 590892.70 & 4386100.10 & 54061 \\
\hline South Park & 0 & 0 & 2 & 1 & 589728.60 & 4386100.10 & 54061 \\
\hline Star City & 0 & 0 & 0 & 2 & 586915.10 & 4390386.70 & 54061 \\
\hline Suncrest & 0 & 1 & 3 & 1 & 587933.80 & 4390029.20 & 54061 \\
\hline Sunset Beach & 0 & 0 & 2 & 0 & 598023.40 & 4392794.10 & 54061 \\
\hline The Flatts & 2 & 1 & 0 & 1 & 588903.90 & 4389738.10 & 54061 \\
\hline The Mileground & 0 & 0 & 0 & 2 & 591717.40 & 4388671.00 & 54061 \\
\hline West Sabraton & 0 & 0 & 0 & 1 & 592088.40 & 4385809.00 & 54061 \\
\hline Westover & 0 & 0 & 1 & 0 & 588370.30 & 4387797.80 & 54061 \\
\hline Wiles Hill & 0 & 0 & 1 & 0 & 589631.50 & 4388768.00 & 54061 \\
\hline Point Marion & 0 & 0 & 1 & 0 & 594336.80 & 4399439.70 & 42051 \\
\hline
\end{tabular}

Table 4.5 DBF Table: Sensitive Receptors at Populated Areas, Distance to Stack Calculation

\section{$-10-15 \mathrm{~km}$}

\begin{tabular}{|c|c|c|c|c|c|c|c|}
\hline NAME & HOSPITALS & $\begin{array}{c}\text { NURSING } \\
\text { HOMES }\end{array}$ & SCHOOLS & $\begin{array}{c}\text { CHILD DAY } \\
\text { CARE }\end{array}$ & EASTING & NORTHING & FIPS \\
\hline Hilderbrand & 0 & 0 & 0 & 1 & 586068.40 & 4382798.30 & 54061 \\
\hline Richard & 0 & 0 & 0 & 1 & 593900.20 & 4384693.30 & 54061 \\
\hline Mapletown & 0 & 0 & 2 & 0 & 590310.70 & 4406570.30 & 42059 \\
\hline Mount Morris & 0 & 0 & 2 & 0 & 579784.50 & 4398566.50 & 42059 \\
\hline
\end{tabular}


Table 4.6 DBF Table: Sensitive Receptors at Populated Areas, Distance to Stack Calculation -15 - $20 \mathrm{~km}$

\begin{tabular}{|c|c|c|c|c|c|c|c|}
\hline NAME & HOSPITALS & NURSING HOME & SCHOOLS & $\begin{array}{c}\text { CHILD } \\
\text { DAY CARE }\end{array}$ & EASTING & NORTHING & FIPS \\
\hline National & 0 & 0 & 2 & 0 & 582679.50 & 4381980.30 & 54061 \\
\hline Sturgisson & 0 & 0 & 0 & 1 & 597101.70 & 4382219.40 & 54061 \\
\hline Masontown & 0 & 0 & 1 & 1 & 594045.70 & 4411372.60 & 42051 \\
\hline Smithfield & 0 & 0 & 1 & 2 & 602049.50 & 4406570.30 & 42051 \\
\hline
\end{tabular}

Table 4.7 DBF Table: Sensitive Receptors at Populated Areas, Distance to Stack Calculation -20 - $25 \mathrm{~km}$

\begin{tabular}{|c|c|c|c|c|c|c|c|}
\hline NAME & HOSPITALS & NURSING HOMES & SCHOOLS & $\begin{array}{c}\text { CHILD } \\
\text { DAY CARE }\end{array}$ & EASTING & NORTHING & FIPS \\
\hline Rivesville & 0 & 0 & 1 & 1 & 575855.40 & 4375961.90 & 54049 \\
\hline Masontown & 0 & 0 & 1 & 1 & 603165.20 & 4378872.40 & 54077 \\
\hline Carmichaels & 0 & 0 & 1 & 3 & 587691.20 & 4416853.90 & 42059 \\
\hline Fairchance & 1 & 0 & 1 & 0 & 606560.70 & 4409092.70 & 42051 \\
\hline McClellandtown & 0 & 0 & 1 & 0 & 596762.20 & 4415838.30 & 42051 \\
\hline
\end{tabular}

Table 4.8 DBF Table: Sensitive Receptors at Populated Areas, Distance to Stack Calculation

\begin{tabular}{|c|c|c|c|c|c|c|c|}
\hline NAME & HOSPITALS & NURSING HOMES & SCHOOLS & $\begin{array}{c}\text { CHILD } \\
\text { DAY CARE }\end{array}$ & EASTING & NORTHING & FIPS \\
\hline Ragtown & 0 & 0 & 0 & 1 & 562877.10 & 4388989.40 & 54061 \\
\hline Barrackville & 0 & 0 & 2 & 0 & 571538.20 & 4373003.00 & 54049 \\
\hline Chesapeake & 0 & 0 & 1 & 0 & 572799.40 & 4373439.50 & 54049 \\
\hline Fairmont & 3 & 1 & 10 & 10 & 573672.50 & 4370965.60 & 54049 \\
\hline Fairview & 0 & 0 & 1 & 0 & 564553.10 & 4382801.50 & 54049 \\
\hline Palatine & 0 & 0 & 1 & 1 & 574109.10 & 4370383.60 & 54049 \\
\hline Arthurdale & 0 & 0 & 1 & 0 & 601806.90 & 4372420.90 & 54077 \\
\hline Bruceton Mills & 0 & 0 & 1 & 1 & 616504.80 & 4390805.30 & 54077 \\
\hline Reedsville & 1 & 0 & 0 & 2 & 603310.70 & 4374167.20 & 54077 \\
\hline Jefferson & 0 & 0 & 1 & 1 & 580318.10 & 4420443.50 & 42059 \\
\hline Rices Landing & 0 & 0 & 0 & 1 & 585750.90 & 4422189.80 & 42059 \\
\hline Waynesburg & 1 & 1 & 5 & 5 & 570082.90 & 4416708.40 & 42059 \\
\hline Hopwood & 0 & 0 & 0 & 1 & 610974.90 & 4414962.10 & 42051 \\
\hline New Salem & 0 & 0 & 1 & 0 & 599430.10 & 4420006.90 & 42051 \\
\hline Point Breeze & 0 & 0 & 2 & 1 & 613497.30 & 4405988.20 & 42051 \\
\hline Republic & 0 & 0 & 1 & 0 & 595937.50 & 4424227.10 & 42051 \\
\hline South Uniontown & 1 & 0 & 2 & 1 & 607094.30 & 4416659.90 & 42051 \\
\hline Uniontown & 4 & 2 & 6 & 8 & 609713.70 & 4417484.50 & 42051 \\
\hline
\end{tabular}


Upon completing the identification and spatial analysis, 51 populated place points have been which contain sensitive receptor categories used. There densities and distance to stack were depicted and listed in the figures and tables above. A total of 76 schools, 64 child day care facilities, 7 nursing homes and 8 hospitals are associated with the populated places mapped within the $30 \mathrm{~km}$ radius. Appendix $\mathrm{C}$ provides a complete list of facilities, per type of categorized sensitive receptor. Each table in Appendix C is divided into 7 columns: distance to stack range (km), populated place, name of sensitive receptor, state, FIPS, and county. Rows are divided into the $5 \mathrm{~km}$ increment level sections, counting the number of that particular type of sensitive receptor within that increment level.

\subsection{Plot Plan Drawing Results for Potential Building Downwash}

The layout of the proposed CFPP boundary and building profiles are very important when modeling the dispersion of on-site emissions off-site. As stated earlier, the direct impact of building downwash concentrations on neighboring surrounding communities, does sometimes occur. This is why I chose to construct a 2D digital drawing, Figure 20 below, of the proposed CFPP plot plan as a foundation for use in the air dispersion modeling software for modeling potential direction specific building downwash effects. Another drawing depicts building and stack dimensions, and their relative location to one another. See Figure 21 below. Both drawings were derived from the CFPP proposed plot plan provided by WV DAQ. 


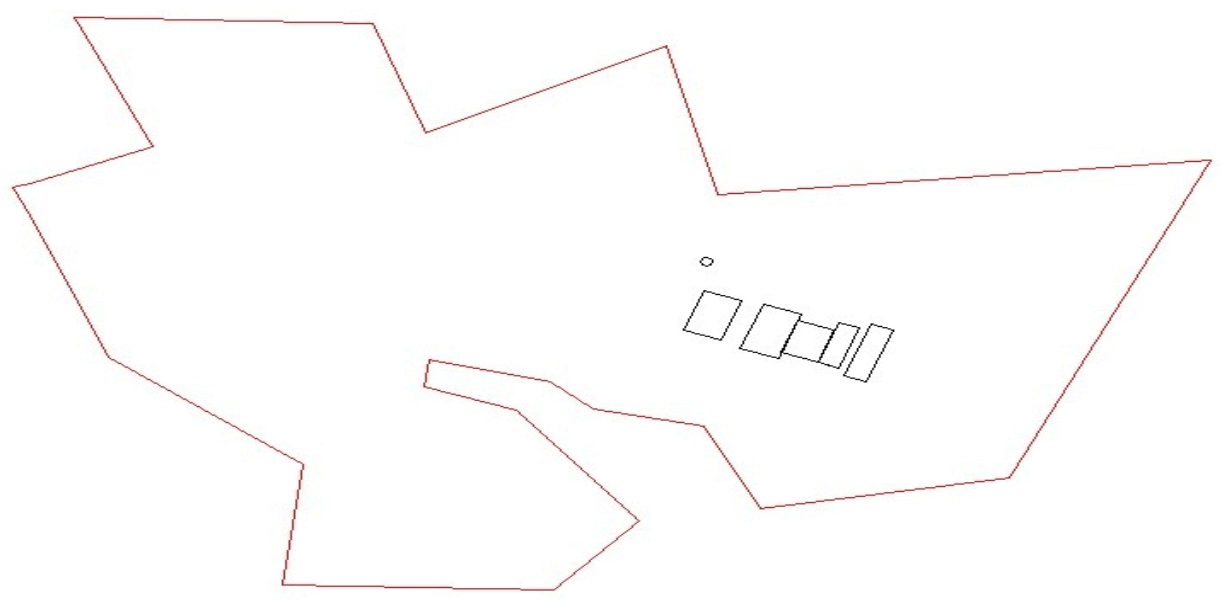

Figure 20: 2 dimensional drawing of proposed coal fired power plant plot plan. This digital drawing was used in the air dispersion modeling software for modeling potential direction specific building downwash effects discussed in chapter 2 . The air dispersion modeling software only imports 2D digital drawings. The dimensions of each building and the stack (See figure below) is added to the 2D drawing in the air dispersion model.

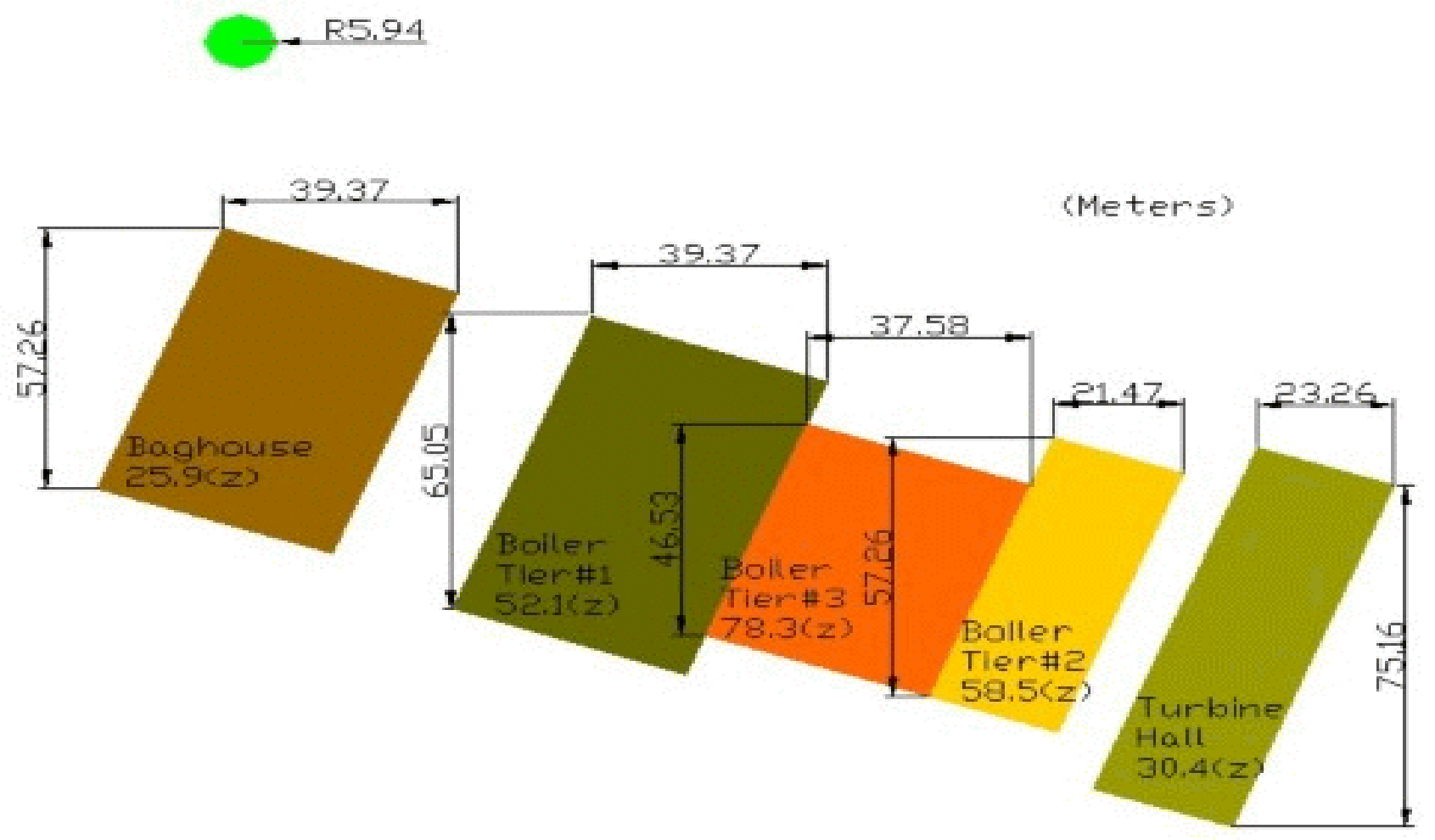

Figure 21: Plot plan dimensions of proposed coal fired power plant plot plan. This drawing depicts building and stack dimensions, and their relative location to one another. There are five different buildings. The dimensions of each building were added to the 2D drawing in the air dispersion model. 
To date, the proposed site is going to have 6 different building tiers. The simple $2 \mathrm{D}$ drawing above was drawn in the world coordinate system (WCS), over the proposed plot plan real world coordinates, as discussed sections 3.2 and 3.3.2 respectively. Drawing it in such a manner enables it to be imported and read by the air dispersion modeling software. The Bag House is 39.37 meters wide $\mathrm{x} 57.26$ meters long x 25.9 meters tall. Boiler Tier \# 1 is 39.37 meters wide $\mathrm{x} 65.05$ meters long $\mathrm{x} 52.1$ meters high. Boiler Tier \#3 is 37.58 meters wide $\mathrm{x} 46.53$ meters long $\mathrm{x} 78.3$ meters high. Boiler Tier \#2 is 21.47 meters wide x 57.26 meters long x 58.5 meters high. The Turbine Hall is 23.26 meters wide $\times 75.16$ meters long $\times 30.4$ meters high. The stack, as listed in Table 3.1, is 168.9 meters high with an internal stack exit diameter of 5.94 meters. The 3 dimensional profile, however, not depicted in the figures above, is what contributes to downwash effects. Calculation and evaluation of the third dimension contributions to direction specific building downwash takes place in AERMOD, as stated in Method 2. The results of 3D modeling, within AERMOD is below (Figure 22). This does not show wake, or cavity, for each direction per particular day 24 hour average. Figure 22 does however point out visually the relative sizes and locations of proposed stack and buildings withing the site plan, from an elevated vantage point, from south of the site, looking north. From this viewing direction, building downwash would conceivably occur on the east or south side of the buildings. 


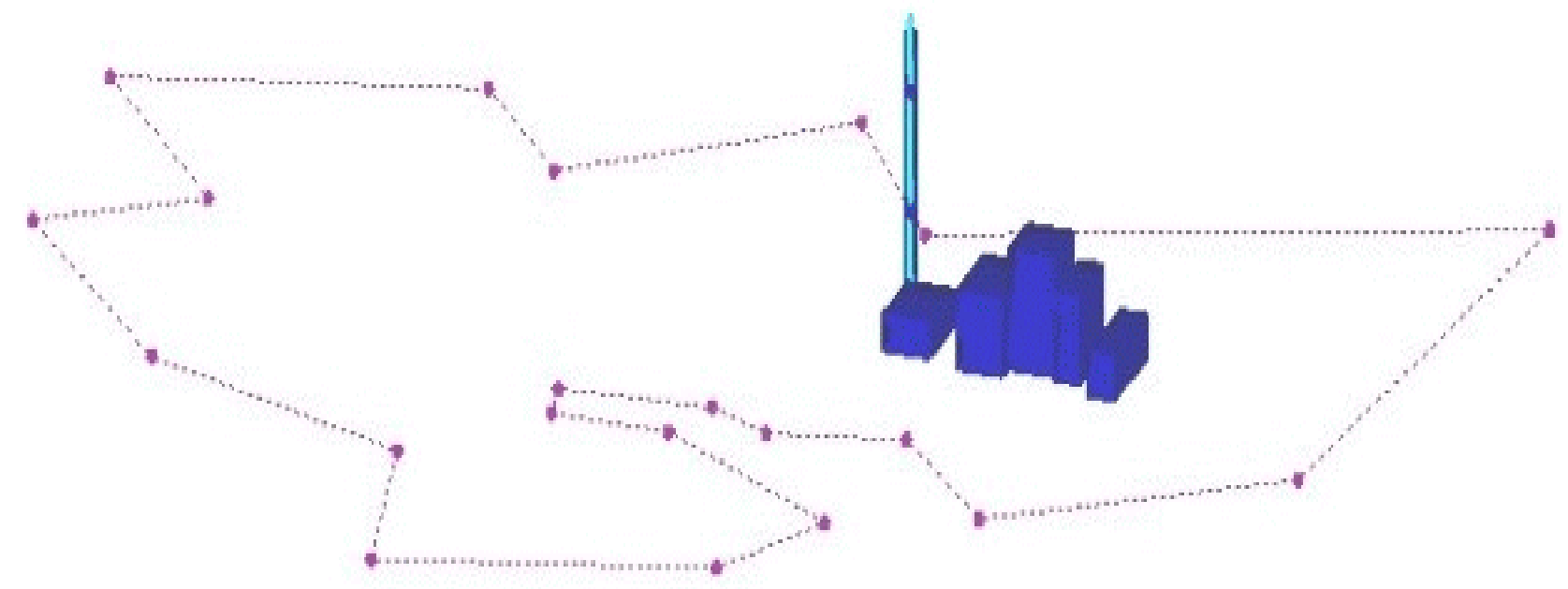

Figure 22: 3 dimensional modeling in the air dispersion modeling software, AERMOD. 3 dimensional profile, not depicted in the figures above, is what contributes to downwash effects discussed in chapter 2 . Calculation and evaluation of the third dimension takes place in air dispersion modeling software, and is depicted here.

Unfortunately, neither dimensions nor the building themselves can be labeled by the 3D view in AERMOD. Buildings and dimensions may be distinguished using Figure 21 above.

\subsection{Concentration Exposure Modeling Results}

Modeled concentration results, and concentration contour map results, with populated places included, are listed below. It was decided that modeling would be conducted for the maximum 24 hour averages, for the entire year of 2000. Choosing to model at this averaging period, matched that of the same averaging period for monitored background concentrations, that were provided to us by the EPA. Table 4.9 shows the highest 25 maximum 24 hour averaging concentrations, their real world coordinates in UTM (meters), and the dates they occurred, modeled for the year 2000. This table was extracted from the, extremely large, model run output file, and organized into an Excel 
spreadsheet to facilitate evaluation.

Table 4.9 25 Maximum, 24 Hour Averaging Concentrations $\left(\mu \mathrm{g} / \mathrm{m}^{3}\right)$ Contributions, for 2000

\begin{tabular}{|c|c|c|c|c|}
\hline RANK & CONC & DATE & XCOOR & YCOOR \\
\hline 1 & 1.07346 & June 11,2000 & 590763.31 & 4396379.00 \\
\hline 2 & 0.99433 & June 19,2000 & 588951.25 & 4394219.50 \\
\hline 3 & 0.98795 & June 16,2000 & 590428.50 & 4396778.00 \\
\hline 4 & 0.97003 & June 11,2000 & 590330.31 & 4396129.00 \\
\hline 5 & 0.95395 & July 23, 2000 & 588951.25 & 4394219.50 \\
\hline 6 & 0.92331 & June 19,2000 & 588780.25 & 4393749.50 \\
\hline 7 & 0.88237 & June 11,2000 & 591196.38 & 4396629.00 \\
\hline 8 & 0.86932 & July 23, 2000 & 588780.25 & 4393749.50 \\
\hline 9 & 0.86635 & May 31,2000 & 590428.50 & 4396778.00 \\
\hline 10 & 0.84513 & May 12,2000 & 590763.31 & 4396379.00 \\
\hline 11 & 0.82696 & July 23, 2000 & 589122.25 & 4394689.50 \\
\hline 12 & 0.81994 & June 16,2000 & 590749.88 & 4397161.00 \\
\hline 13 & 0.81748 & July 25, 2000 & 587987.06 & 4395889.50 \\
\hline 14 & 0.81437 & May 12,2000 & 590428.50 & 4396778.00 \\
\hline 15 & 0.80741 & May 31,2000 & 590107.06 & 4396395.00 \\
\hline 16 & 0.79782 & May 8, 2000 & 590763.31 & 4396379.00 \\
\hline 17 & 0.79255 & June 21,2000 & 590428.50 & 4396778.00 \\
\hline 18 & 0.77657 & May 8, 2000 & 590330.31 & 4396129.00 \\
\hline 19 & 0.76232 & May 18,2000 & 590428.50 & 4396778.00 \\
\hline 20 & 0.76187 & May 12,2000 & 590749.88 & 4397161.00 \\
\hline 21 & 0.74810 & June 25,2000 & 590428.50 & 4396778.00 \\
\hline 22 & 0.73689 & May 30, 2000 & 588165.25 & 4396379.00 \\
\hline 23 & 0.73676 & May 15,2000 & 590428.50 & 4396778.00 \\
\hline 24 & 0.72924 & May 12,2000 & 591196.38 & 4396629.00 \\
\hline 25 & 0.72848 & July 25,2000 & 588165.25 & 4396379.00 \\
\hline
\end{tabular}

The above table was used to assess in more detail the top five modeled highest concentration dates for the entire year. The highest modeled 24 hour average concentration date, at $1.073 \mu \mathrm{g} / \mathrm{m}^{3}$, occurred on June 11, 2000. The second highest modeled concentration date, at $0.994 \mu \mathrm{g} / \mathrm{m}^{3}$, occurred on June 19. The third highest modeled concentration date, at $0.987 \mu \mathrm{g} / \mathrm{m}^{3}$, occurred on June 16. The fourth highest modeled concentration date, at $0.953 \mu \mathrm{g} / \mathrm{m}^{3}$, occurred on July 23 . The 
fifth highest modeled concentration date, at $0.866 \mu \mathrm{g} / \mathrm{m}^{3}$, occurred on May 31. Each of these dates were chosen for individual modeling, and creation of contour map, in order to represent the 5 worst 24 hour averaging conditions for that year. A contour map of the first model run would only represent an annual average concentration, not worst conditions. Such a map would depict lower concentrations than what is of concern in this study.

The individual 24 hour model run of June 11, 2000, again modeled the same highest concentration value and it's location for that day, as the preceding annual model run. The same thing happened for the four other dates. For presentation purposes, only the top 25 modeled average 24 hour concentrations for each 24 hour period are listed in Table 4.10 - 4.14. UTM easting (X COOR) and northing (Y COORD) in meters, Zone 17 North. Latitude is here measured westward from zero meridian at Greenwich, England, which would make these Latitudes negative; however, by convention, in the Western Hemisphere, these are written as positive values of meters, as in this table. 
Table 4.10 Top 25, 24 Hour Concentration $\left(\mu \mathrm{g} / \mathrm{m}^{3}\right)$ Contributions for June 11, 2000

\begin{tabular}{|c|c|c|c|}
\hline RANK & CONC & XCOOR & YCOOR \\
\hline 1 & 1.07346 & 590763.31 & 4396379.00 \\
\hline 2 & 0.97003 & 590330.31 & 4396129.00 \\
\hline 3 & $\mathbf{0 . 8 8 2 3 7}$ & 591196.38 & 4396629.00 \\
\hline 4 & 0.69305 & 590449.12 & 4395802.50 \\
\hline 5 & 0.69279 & 591629.38 & 4396879.00 \\
\hline 6 & 0.65419 & 590941.50 & 4395889.50 \\
\hline 7 & 0.55408 & 591433.94 & 4395976.50 \\
\hline 8 & 0.50955 & 590428.50 & 4396778.00 \\
\hline 9 & 0.49644 & 592062.38 & 4397129.00 \\
\hline 10 & 0.46710 & 590749.88 & 4397161.00 \\
\hline 11 & 0.42773 & 592495.38 & 4397379.00 \\
\hline 12 & 0.37882 & 591926.31 & 4396063.00 \\
\hline 13 & 0.36992 & 591071.25 & 4397544.00 \\
\hline 14 & 0.33462 & \begin{tabular}{|l|l|}
592928.38 \\
\end{tabular} & 4397629.00 \\
\hline 15 & 0.31271 & 590107.06 & 4396395.00 \\
\hline 16 & 0.30200 & 592418.75 & 4396150.00 \\
\hline 17 & 0.29857 & 591392.69 & 4397927.00 \\
\hline 18 & 0.27711 & 593361.44 & 4397879.00 \\
\hline 19 & 0.26124 & 592911.12 & 4396237.00 \\
\hline 20 & 0.24557 & 591714.06 & 4398310.00 \\
\hline 21 & 0.23900 & 593794.44 & 4398129.00 \\
\hline 22 & 0.20872 & 594227.44 & 4398379.00 \\
\hline 23 & 0.20835 & 593403.50 & 4396323.50 \\
\hline 24 & 0.19939 & 592035.44 & 4398693.00 \\
\hline 25 & 0.18393 & 594660.44 & 4398629.00 \\
\hline
\end{tabular}

Table 4.11 Top 25, 24 Hour Concentration $\left(\mu \mathrm{g} / \mathrm{m}^{3}\right)$ Contributions for June 19, 2000

\begin{tabular}{|c|c|c|c|}
\hline RANK & CONC & XCOOR & YCOOR \\
\hline 1 & 0.99433 & 588951.25 & 4394219.50 \\
\hline 2 & 0.92331 & 588780.25 & 4393749.50 \\
\hline 3 & 0.72689 & 588609.25 & 4393280.00 \\
\hline 4 & 0.70224 & 589122.25 & 4394689.50 \\
\hline 5 & 0.57393 & 588438.25 & 4392810.00 \\
\hline 6 & 0.49761 & 588267.25 & 4392340.00 \\
\hline 7 & 0.44256 & 588096.25 & 4391870.00 \\
\hline 8 & 0.40031 & 587925.19 & 4391400.50 \\
\hline 9 & 0.36149 & 587754.19 & 4390930.50 \\
\hline 10 & 0.34376 & 587933.81 & 4390029.00 \\
\hline 11 & 0.33476 & 587583.19 & 4390460.50 \\
\hline 12 & 0.33416 & 588500.12 & 4394480.00 \\
\hline 13 & 0.31103 & 587412.19 & 4389991.00 \\
\hline 14 & 0.30965 & 588178.75 & 4394097.00 \\
\hline 15 & 0.29289 & 587241.19 & 4389521.00 \\
\hline 16 & 0.27507 & 587070.19 & 4389051.00 \\
\hline 17 & 0.27182 & $\begin{array}{l}587788.31 \\
\end{array}$ & 4388137.50 \\
\hline 18 & 0.26784 & 587034.19 & 4387422.50 \\
\hline 19 & 0.25459 & 586899.12 & 4388581.50 \\
\hline 20 & 0.25170 & 586915.12 & 4390386.50 \\
\hline 21 & 0.24737 & 587857.31 & 4393714.00 \\
\hline 22 & 0.24259 & 586728.12 & 4388111.50 \\
\hline 23 & 0.23244 & 586557.12 & 4387641.50 \\
\hline 24 & 0.22921 & 589464.31 & 4394129.00 \\
\hline 25 & 0.22696 & 586386.12 & 4387172.00 \\
\hline
\end{tabular}


Table 4.12 Top 25, 24 Hour Concentration $\left(\mu \mathrm{g} / \mathrm{m}^{3}\right)$ Contributions for June 16, 2000

\begin{tabular}{|c|c|c|c|}
\hline RANK & CONC & XCOOR & YCOOR \\
\hline 1 & 0.98795 & 590428.50 & 4396778.00 \\
\hline 2 & 0.81994 & 590749.88 & 4397161.00 \\
\hline 3 & 0.69709 & 590107.06 & 4396395.00 \\
\hline 4 & 0.62887 & 591071.25 & 4397544.00 \\
\hline 5 & 0.49976 & 591392.69 & 4397927.00 \\
\hline 6 & 0.41037 & 591714.06 & 4398310.00 \\
\hline 7 & 0.40261 & 590763.31 & 4396379.00 \\
\hline 8 & 0.34867 & 592035.44 & 4398693.00 \\
\hline 9 & 0.33054 & 589977.31 & 4397038.50 \\
\hline 10 & 0.32987 & 590330.31 & 4396129.00 \\
\hline 11 & 0.31894 & 591196.38 & 4396629.00 \\
\hline 12 & 0.29583 & 592356.81 & 4399076.00 \\
\hline 13 & 0.29096 & 589806.31 & 4396568.50 \\
\hline 14 & 0.28339 & 590148.31 & 4397508.50 \\
\hline 15 & 0.25327 & 592678.25 & 4399459.00 \\
\hline 16 & 0.24450 & 591629.38 & 4396879.00 \\
\hline 17 & 0.22440 & 590319.38 & 4397978.00 \\
\hline 18 & 0.22229 & 592999.62 & 4399842.00 \\
\hline 19 & 0.18299 & 593321.00 & 4400225.50 \\
\hline 20 & 0.17312 & 592062.38 & 4397129.00 \\
\hline 21 & 0.16957 & 590490.38 & 4398448.00 \\
\hline 22 & 0.16797 & 593642.44 & 4400608.50 \\
\hline 23 & 0.15833 & 593963.81 & 4400991.50 \\
\hline 24 & 0.14918 & 592495.38 & 4397379.00 \\
\hline 25 & 0.14454 & 594285.19 & 4401374.50 \\
\hline
\end{tabular}

Table 4.13 Top 25, 24 Hour Concentration $\left(\mu \mathrm{g} / \mathrm{m}^{3}\right)$ Contributions for July 23, 2000

\begin{tabular}{|c|c|c|c|}
\hline RANK & CONC & XCOOR & YCOOR \\
\hline 1 & 0.95395 & 588951.25 & 4394219.50 \\
\hline 2 & 0.86932 & $\mathbf{5 8 8 7 8 0 . 2 5}$ & 4393749.50 \\
\hline 3 & 0.82696 & 589122.25 & 4394689.50 \\
\hline 4 & 0.69965 & 588609.25 & 4393280.00 \\
\hline 5 & 0.56952 & $\mathbf{5 8 8 4 3 8 . 2 5}$ & 4392810.00 \\
\hline 6 & 0.50257 & 588267.25 & 4392340.00 \\
\hline 7 & 0.47804 & 589464.31 & 4394129.00 \\
\hline 8 & 0.44730 & 588096.25 & 4391870.00 \\
\hline 9 & 0.42466 & 589464.31 & 4393629.00 \\
\hline 10 & 0.42455 & 589464.31 & 4394629.00 \\
\hline 11 & 0.40386 & 587925.19 & 4391400.50 \\
\hline 12 & 0.38696 & 588500.12 & 4394480.00 \\
\hline 13 & 0.36354 & 587754.19 & 4390930.50 \\
\hline 14 & 0.35663 & $\mathbf{5 8 8 1 7 8 . 7 5}$ & 4394097.00 \\
\hline 15 & 0.33446 & 587583.19 & 4390460.50 \\
\hline 16 & 0.33311 & $\mathbf{5 8 8 8 2 1 . 5 0}$ & 4394863.00 \\
\hline 17 & 0.33275 & $\mathbf{5 8 7 9 3 3 . 8 1}$ & 4390029.00 \\
\hline 18 & 0.31393 & 589464.31 & 4393129.00 \\
\hline 19 & 0.30910 & 587412.19 & 4389991.00 \\
\hline 20 & 0.29009 & $\mathbf{5 8 7 8 5 7 . 3 1}$ & 4393714.00 \\
\hline 21 & 0.28971 & 587241.19 & 4389521.00 \\
\hline 22 & 0.28745 & 589464.31 & 4392629.00 \\
\hline 23 & 0.27081 & 587070.19 & 4389051.00 \\
\hline 24 & 0.26553 & 586915.12 & 4390386.50 \\
\hline 25 & 0.26022 & 589464.31 & 4392129.00 \\
\hline
\end{tabular}


Table 4.14 Top 25, 24 Hour Concentration $\left(\mu \mathrm{g} / \mathrm{m}^{3}\right)$ Contributions for May, 312000

\begin{tabular}{|c|c|c|c|}
\hline RANK & CONC & XCOOR & YCOOR \\
\hline 1 & 0.86635 & 590428.50 & 4396778.00 \\
\hline 2 & 0.80741 & 590107.06 & 4396395.00 \\
\hline 3 & 0.68635 & 589806.31 & 4396568.50 \\
\hline 4 & 0.68594 & 590749.88 & 4397161.00 \\
\hline 5 & 0.61240 & 589977.31 & 4397038.50 \\
\hline 6 & 0.51792 & 591071.25 & 4397544.00 \\
\hline 7 & 0.51316 & 590148.31 & 4397508.50 \\
\hline 8 & 0.40937 & 590319.38 & 4397978.00 \\
\hline 9 & 0.40732 & 591392.69 & 4397927.00 \\
\hline 10 & 0.39117 & 590763.31 & 4396379.00 \\
\hline 11 & 0.37211 & 590330.31 & 4396129.00 \\
\hline 12 & 0.33214 & 591714.06 & 4398310.00 \\
\hline 13 & 0.31934 & 590490.38 & 4398448.00 \\
\hline 14 & 0.30903 & 591196.38 & 4396629.00 \\
\hline 15 & 0.27463 & 592035.44 & 4398693.00 \\
\hline 16 & 0.25962 & 590661.38 & 4398918.00 \\
\hline 17 & 0.23631 & 591629.38 & 4396879.00 \\
\hline 18 & 0.23620 & 592356.81 & 4399076.00 \\
\hline 19 & 0.21528 & 589785.69 & 4396012.00 \\
\hline 20 & 0.21379 & 590832.38 & 4399388.00 \\
\hline 21 & 0.20283 & 592678.25 & 4399459.00 \\
\hline 22 & 0.18445 & $\mathbf{5 9 1 0 0 3 . 3 8}$ & 4399857.50 \\
\hline 23 & 0.17871 & 592999.62 & 4399842.00 \\
\hline 24 & 0.17027 & 589635.31 & 4396099.00 \\
\hline 25 & 0.16653 & 592062.38 & 4397129.00 \\
\hline
\end{tabular}

Analyzing Table 4.9 above, June 11 is the highest 24 hour average concentration day modeled. Provided EPA monitored background concentrations, Table 3.3, only lists the highest monitored 24 hour average concentration from the only four monitors within the study area. By combining, June 11 modeled concentration contribution to the highest monitored background concentration out of the four area monitors for the year 2000, ambient background concentration can be estimated at being $1.82 \mu \mathrm{g} / \mathrm{m}^{3}$. That is far below $260 \mu \mathrm{g} / \mathrm{m}^{3}$, the provisional maximum ambient $\mathrm{SO}_{2}$ concentratio of this study. Comparing this same estimation to the allotted PSD increment consumption of $91 \mu \mathrm{g} / \mathrm{m}^{3} 24$ hour averaging standard, only $2 \%$ is being consumed when 
using modeling techniques applied in this thesis. The WV DAQ modeling has estimated that $17 \%$ $\left(15.5 \mu \mathrm{g} / \mathrm{m}^{3}\right)$ of the PSD increment consumption of $91 \mu \mathrm{g} / \mathrm{m}^{3} 24$ hour averaging standard will be consumed using different modeling techniques. ${ }^{57} \mathrm{WV}$ DAQ summed all modeled contributing sources, creating a higher overall consumption of the PSD increment, by combining both nearby source contributions, using AERMOD, and distant sources, using CALPUFF models. The last historical PSD incremental modeling conducted of this area (PSD permit application to construct Beechurst Power Plant), by WV DAQ in 1988, estimated that $99.5 \%\left(90.5 \mu \mathrm{g} / \mathrm{m}^{3}\right)$ of the PSD increment consumption of $91 \mu \mathrm{g} / \mathrm{m}^{3} 24$ hour averaging standard would be consumed. ${ }^{70}$ See chapter 5 for a discussion of the differences between the PSD increment consumption of $91 \mu \mathrm{g} / \mathrm{m}^{3} 24$ hour averaging standard estimates modeled by WV DAQ in 1988, and the recently modeled estimates by WV DAQ in 2003, and the proposed CFPP contribution estimates modeled in this thesis.

Contour maps provide a means to present large quantities of spatial information in a condensed, easy to understand format. The output files for each modeled day are over 500 pages in length; each complete list is a significant amount of useful spatial information. The complete list of polar grid coordinate point and populated place concentrations from each model run output file was used to produce contour maps, using GIS Kriging methods discussed in Method 3, for each of the 5 days modeled. Calculated populated place concentrations and contour maps of each day modeled are presented in the tables 4.15- 4.19 and Figures 23- 27 below. 
Tables 4.15 June 11, 2000 Populated Place Concentration Contribution Calculations $\left(\mu \mathrm{g} / \mathrm{m}^{3}\right)$

\begin{tabular}{|c|c|c|c|c|}
\hline RANK & $\begin{array}{c}\text { POPULATED } \\
\text { PLACE }\end{array}$ & CONC & XCORD & YCOORD \\
\hline 1 & Point Marion & 0.15286 & $\mathbf{5 9 4 3 3 6 . 8 0}$ & 4399439.70 \\
\hline 2 & Smithfield & 0.03859 & 602049.50 & 4406570.30 \\
\hline 3 & Fairchance & 0.03252 & 606560.70 & 4409092.70 \\
\hline 4 & Point Breeze & 0.02760 & 613497.30 & 4405988.20 \\
\hline 5 & Hopwood & 0.02203 & 610974.90 & 4414962.10 \\
\hline 6 & Uniontown & 0.01649 & 609713.70 & 4417484.50 \\
\hline 7 & South Uniontown & 0.01547 & 607094.30 & 4416659.90 \\
\hline 8 & New Salem & 0.00766 & 599430.10 & 4420006.90 \\
\hline 9 & Baker Ridge & 0.00544 & 590168.10 & 4392253.90 \\
\hline 10 & McClellandtown & 0.00511 & 596762.20 & 4415838.30 \\
\hline 11 & Barrackville & 0.00495 & 571538.20 & 4373003.00 \\
\hline 12 & Chesapeake & 0.00304 & 572799.40 & $\mathbf{4 3 7 3 4 3 9 . 5 0}$ \\
\hline 13 & Masontown & 0.00299 & 594045.70 & 4411372.60 \\
\hline 14 & Suncrest & 0.00223 & $\mathbf{5 8 7 9 3 3 . 8 0}$ & 4390029.20 \\
\hline 15 & Star City & 0.00218 & 586915.10 & 4390386.70 \\
\hline 16 & The Flatts & 0.00215 & 588903.90 & 4389738.10 \\
\hline 17 & Osage & 0.00198 & 585055.70 & 4390433.20 \\
\hline 18 & Canyon & 0.00189 & 595130.10 & 4392645.60 \\
\hline 19 & Wiles Hill & 0.00166 & 589631.50 & 4388768.00 \\
\hline 20 & The Mileground & 0.00140 & 591717.40 & 4388671.00 \\
\hline 21 & Rivesville & 0.00139 & 575855.40 & 4375961.90 \\
\hline 22 & Riverside & 0.00137 & $\mathbf{5 8 7 7 8 8 . 3 0}$ & 4388137.40 \\
\hline 23 & Westover & 0.00133 & 588370.30 & 4387797.80 \\
\hline 24 & Sunset Beach & 0.00128 & 598023.40 & 4392794.10 \\
\hline 25 & Morgantown & 0.00119 & 589574.20 & 4387161.10 \\
\hline 26 & Fairmor & 0.00118 & 587034.20 & 4387422.50 \\
\hline 27 & Sabraton & 0.00113 & 591911.40 & 4387167.20 \\
\hline 28 & Hopecrest & 0.00101 & 589223.60 & 4386070.40 \\
\hline
\end{tabular}

\begin{tabular}{|c|c|c|c|c|}
\hline 29 & South Park & 0.00101 & 589728.60 & 4386100.10 \\
\hline 30 & South Hills & 0.00100 & 590892.70 & 4386100.10 \\
\hline 31 & West Sabraton & 0.00092 & 592088.40 & 4385809.00 \\
\hline 32 & Mount Morris & 0.00092 & $\mathbf{5 7 9 7 8 4 . 5 0}$ & 4398566.50 \\
\hline 33 & Mapletown & 0.00089 & 590310.70 & 4406570.30 \\
\hline 34 & Richard & 0.00077 & 593900.20 & 4384693.30 \\
\hline 35 & Hilderbrand & 0.00067 & 586068.40 & 4382798.30 \\
\hline 36 & Fairmont & 0.00066 & 573672.50 & 4370965.60 \\
\hline 37 & Republic & 0.00065 & $\mathbf{5 9 5 9 3 7 . 5 0}$ & 4424227.10 \\
\hline 38 & National & 0.00060 & 582679.50 & 4381980.30 \\
\hline 39 & Bruceton Mills & 0.00056 & 616504.80 & 4390805.30 \\
\hline 40 & Masontown & 0.00054 & 603165.20 & 4378872.40 \\
\hline 41 & Sturgisson & 0.00053 & 597101.70 & 4382219.40 \\
\hline 42 & Reedsville & 0.00053 & 603310.70 & 4374167.20 \\
\hline 43 & Palatine & 0.00050 & 574109.10 & 4370383.60 \\
\hline 44 & Carmichaels & 0.00049 & 587691.20 & 4416853.90 \\
\hline 45 & Arthurdale & 0.00047 & 601806.90 & 4372420.90 \\
\hline 46 & Fairview & 0.00045 & 564553.10 & 4382801.50 \\
\hline 47 & Ragtown & 0.00044 & 562877.10 & 4388989.40 \\
\hline 48 & Jefferson & 0.00044 & 580318.10 & 4420443.50 \\
\hline 49 & Rices Landing & 0.00043 & 585750.90 & 4422189.80 \\
\hline 50 & Waynesburg & 0.00043 & 570082.90 & 4416708.40 \\
\hline 51 & Braewick Woods & 0.00000 & 589384.60 & 4390817.50 \\
\hline
\end{tabular}


Tables 4.16 June 19, 2000 Populated Place Concentration Contribution Calculations $\left(\mu \mathrm{g} / \mathrm{m}^{3}\right)$

\begin{tabular}{|c|c|c|c|c|}
\hline RANK & POPULATED PLACE & CONC & XCOORD & YCOORD \\
\hline 1 & Suncrest & 0.36398 & 587933.80 & 4390029.20 \\
\hline 2 & Riverside & 0.28781 & \begin{tabular}{|l|}
587788.30 \\
\end{tabular} & 4388137.40 \\
\hline 3 & Fairmor & 0.28359 & 587034.20 & 4387422.50 \\
\hline 4 & Star City & 0.26650 & 586915.10 & 4390386.70 \\
\hline 5 & Westover & 0.23425 & 588370.30 & 4387797.80 \\
\hline 6 & Hilderbrand & 0.23321 & 586068.40 & 4382798.30 \\
\hline 7 & The Flatts & 0.21021 & 588903.90 & 4389738.10 \\
\hline 8 & Braewick Woods & 0.12964 & 589384.60 & 4390817.50 \\
\hline 9 & Hopecrest & 0.11593 & 589223.60 & 4386070.40 \\
\hline 10 & National & 0.10667 & 582679.50 & 4381980.30 \\
\hline 11 & Wiles Hill & 0.08152 & \begin{tabular}{|l|}
589631.50 \\
\end{tabular} & 4388768.00 \\
\hline 12 & Morgantown & 0.07955 & 589574.20 & 4387161.10 \\
\hline 13 & Osage & 0.07647 & 585055.70 & 4390433.20 \\
\hline 14 & South Park & 0.07192 & 589728.60 & 4386100.10 \\
\hline 15 & Palatine & 0.03332 & 574109.10 & 4370383.60 \\
\hline 16 & Rivesville & 0.03133 & 575855.40 & 4375961.90 \\
\hline 17 & Fairmont & 0.03004 & 573672.50 & 4370965.60 \\
\hline 18 & Chesapeake & $\mathbf{0 . 0 2 3 3 3}$ & 572799.40 & 4373439.50 \\
\hline 19 & Barrackville & 0.02076 & 571538.20 & 4373003.00 \\
\hline 20 & South Hills & 0.01376 & \begin{tabular}{|l|}
590892.70 \\
\end{tabular} & 4386100.10 \\
\hline 21 & Baker Ridge & 0.01261 & 590168.10 & 4392253.90 \\
\hline 22 & Canyon & 0.00254 & 595130.10 & 4392645.60 \\
\hline 23 & Point Marion & 0.00251 & 594336.80 & 4399439.70 \\
\hline 24 & West Sabraton & 0.00245 & 592088.40 & 4385809.00 \\
\hline 25 & Sabraton & 0.00233 & 591911.40 & 4387167.20 \\
\hline 26 & The Mileground & 0.00222 & $\mathbf{5 9 1 7 1 7 . 4 0}$ & 4388671.00 \\
\hline 27 & Sunset Beach & 0.00194 & 598023.40 & 4392794.10 \\
\hline 28 & Mount Morris & 0.00182 & \begin{tabular}{|l|}
579784.50 \\
\end{tabular} & 4398566.50 \\
\hline 29 & Richard & 0.00177 & \begin{tabular}{|l|}
593900.20 \\
\end{tabular} & 4384693.30 \\
\hline
\end{tabular}

\begin{tabular}{|c|c|c|c|c|}
\hline 30 & Mapletown & $\mathbf{0 . 0 0 1 7 7}$ & $\mathbf{5 9 0 3 1 0 . 7 0}$ & $\mathbf{4 4 0 6 5 7 0 . 3 0}$ \\
\hline 31 & Smithfield & $\mathbf{0 . 0 0 1 5 2}$ & $\mathbf{6 0 2 0 4 9 . 5 0}$ & $\mathbf{4 4 0 6 5 7 0 . 3 0}$ \\
\hline 32 & Masontown & $\mathbf{0 . 0 0 1 5 1}$ & $\mathbf{5 9 4 0 4 5 . 7 0}$ & $\mathbf{4 4 1 1 3 7 2 . 6 0}$ \\
\hline 33 & Fairview & $\mathbf{0 . 0 0 1 3 7}$ & $\mathbf{5 6 4 5 5 3 . 1 0}$ & $\mathbf{4 3 8 2 8 0 1 . 5 0}$ \\
\hline 34 & McClellandtown & $\mathbf{0 . 0 0 1 3 6}$ & $\mathbf{5 9 6 7 6 2 . 2 0}$ & $\mathbf{4 4 1 5 8 3 8 . 3 0}$ \\
\hline 35 & Fairchance & $\mathbf{0 . 0 0 1 3 4}$ & $\mathbf{6 0 6 5 6 0 . 7 0}$ & $\mathbf{4 4 0 9 0 9 2 . 7 0}$ \\
\hline 36 & Carmichaels & $\mathbf{0 . 0 0 1 3 3}$ & $\mathbf{5 8 7 6 9 1 . 2 0}$ & $\mathbf{4 4 1 6 8 5 3 . 9 0}$ \\
\hline 37 & Sturgisson & $\mathbf{0 . 0 0 1 2 7}$ & $\mathbf{5 9 7 1 0 1 . 7 0}$ & $\mathbf{4 3 8 2 2 1 9 . 4 0}$ \\
\hline 38 & New Salem & $\mathbf{0 . 0 0 1 2 4}$ & $\mathbf{5 9 9 4 3 0 . 1 0}$ & $\mathbf{4 4 2 0 0 0 6 . 9 0}$ \\
\hline 39 & Ragtown & $\mathbf{0 . 0 0 1 2 1}$ & $\mathbf{5 6 2 8 7 7 . 1 0}$ & $\mathbf{4 3 8 8 9 8 9 . 4 0}$ \\
\hline 40 & South Uniontown & $\mathbf{0 . 0 0 1 2 1}$ & $\mathbf{6 0 7 0 9 4 . 3 0}$ & $\mathbf{4 4 1 6 6 5 9 . 9 0}$ \\
\hline 41 & Jefferson & $\mathbf{0 . 0 0 1 2 0}$ & $\mathbf{5 8 0 3 1 8 . 1 0}$ & $\mathbf{4 4 2 0 4 4 3 . 5 0}$ \\
\hline 42 & Hopwood & $\mathbf{0 . 0 0 1 1 9}$ & 610974.90 & $\mathbf{4 4 1 4 9 6 2 . 1 0}$ \\
\hline 43 & Rices Landing & $\mathbf{0 . 0 0 1 1 7}$ & $\mathbf{5 8 5 7 5 0 . 9 0}$ & $\mathbf{4 4 2 2 1 8 9 . 8 0}$ \\
\hline 44 & Waynesburg & $\mathbf{0 . 0 0 1 1 7}$ & $\mathbf{5 7 0 0 8 2 . 9 0}$ & $\mathbf{4 4 1 6 7 0 8 . 4 0}$ \\
\hline 45 & Republic & $\mathbf{0 . 0 0 1 1 6}$ & $\mathbf{5 9 5 9 3 7 . 5 0}$ & $\mathbf{4 4 2 4 2 2 7 . 1 0}$ \\
\hline 46 & Uniontown & $\mathbf{0 . 0 0 1 1 6}$ & $\mathbf{6 0 9 7 1 3 . 7 0}$ & $\mathbf{4 4 1 7 4 8 4 . 5 0}$ \\
\hline 47 & Masontown & $\mathbf{0 . 0 0 1 0 3}$ & 603165.20 & $\mathbf{4 3 7 8 8 7 2 . 4 0}$ \\
\hline 48 & Bruceton Mills & $\mathbf{0 . 0 0 0 9 7}$ & $\mathbf{6 1 6 5 0 4 . 8 0}$ & $\mathbf{4 3 9 0 8 0 5 . 3 0}$ \\
\hline 49 & Reedsville & $\mathbf{0 . 0 0 0 9 6}$ & $\mathbf{6 0 3 3 1 0 . 7 0}$ & $\mathbf{4 3 7 4 1 6 7 . 2 0}$ \\
\hline 50 & Arthurdale & $\mathbf{0 . 0 0 0 9 5}$ & $\mathbf{6 0 1 8 0 6 . 9 0}$ & $\mathbf{4 3 7 2 4 2 0 . 9 0}$ \\
\hline 51 & Point Breeze & $\mathbf{0 . 0 0 0 8 6}$ & 613497.30 & $\mathbf{4 4 0 5 9 8 8 . 2 0}$ \\
\hline
\end{tabular}


Tables 4.17 July 23, 2000 Populated Place Concentration Contribution Calculations $\left(\mu \mathrm{g} / \mathrm{m}^{3}\right)$

\begin{tabular}{|c|c|c|c|c|}
\hline RANK & $\begin{array}{c}\text { POPULATED } \\
\text { PLACES }\end{array}$ & CONC & XCOORD & YCOORD \\
\hline 1 & Suncrest & 0.35232 & 587933.80 & 4390029.20 \\
\hline 2 & Star City & 0.28115 & 586915.10 & 4390386.70 \\
\hline 3 & Riverside & 0.26066 & 587788.30 & 4388137.40 \\
\hline 4 & Fairmor & 0.25712 & 587034.20 & 4387422.50 \\
\hline 5 & The Flatts & 0.24112 & 588903.90 & 4389738.10 \\
\hline 6 & Westover & 0.21725 & 588370.30 & 4387797.80 \\
\hline 7 & Braewick Woods & 0.21036 & 589384.60 & 4390817.50 \\
\hline 8 & Hilderbrand & 0.18336 & 586068.40 & 4382798.30 \\
\hline 9 & National & 0.12357 & 582679.50 & 4381980.30 \\
\hline 10 & Osage & 0.12176 & 585055.70 & 4390433.20 \\
\hline 11 & Wiles Hill & 0.11184 & 589631.50 & 4388768.00 \\
\hline 12 & Hopecrest & 0.11087 & 589223.60 & 4386070.40 \\
\hline 13 & Morgantown & 0.09511 & 589574.20 & 4387161.10 \\
\hline 14 & South Park & 0.07765 & 589728.60 & 4386100.10 \\
\hline 15 & Baker Ridge & 0.06173 & 590168.10 & 4392253.90 \\
\hline 16 & Palatine & 0.05968 & 574109.10 & 4370383.60 \\
\hline 17 & Rivesville & 0.05774 & 575855.40 & 4375961.90 \\
\hline 18 & Fairmont & 0.05586 & 573672.50 & 4370965.60 \\
\hline 19 & Chesapeake & 0.04707 & 572799.40 & 4373439.50 \\
\hline 20 & Barrackville & 0.04372 & 571538.20 & 4373003.00 \\
\hline 21 & South Hills & 0.02681 & 590892.70 & 4386100.10 \\
\hline 22 & Sabraton & 0.00791 & 591911.40 & 4387167.20 \\
\hline 23 & West Sabraton & 0.00789 & 592088.40 & 4385809.00 \\
\hline 24 & The Mileground & 0.00677 & 591717.40 & 4388671.00 \\
\hline 25 & Canyon & 0.00430 & 595130.10 & 4392645.60 \\
\hline 26 & Point Marion & 0.00422 & 594336.80 & 4399439.70 \\
\hline 27 & Fairview & 0.00371 & 564553.10 & 4382801.50 \\
\hline 28 & Sunset Beach & 0.00347 & 598023.40 & 4392794.10 \\
\hline
\end{tabular}

\begin{tabular}{|c|c|c|c|c|}
\hline 29 & Richard & 0.00345 & 593900.20 & 4384693.30 \\
\hline 30 & Mount Morris & 0.00327 & 579784.50 & 4398566.50 \\
\hline 31 & Mapletown & 0.00318 & 590310.70 & 4406570.30 \\
\hline 32 & Masontown & 0.00260 & 594045.70 & 4411372.60 \\
\hline 33 & Smithfield & 0.00260 & 602049.50 & 4406570.30 \\
\hline 34 & McClellandtown & 0.00228 & 596762.20 & 4415838.30 \\
\hline 35 & Sturgisson & 0.00226 & 597101.70 & 4382219.40 \\
\hline 36 & Fairchance & 0.00225 & 606560.70 & 4409092.70 \\
\hline 37 & Carmichaels & 0.00224 & 587691.20 & 4416853.90 \\
\hline 38 & New Salem & 0.00203 & 599430.10 & 4420006.90 \\
\hline 39 & Ragtown & 0.00199 & 562877.10 & 4388989.40 \\
\hline 40 & South Uniontown & 0.00199 & 607094.30 & 4416659.90 \\
\hline 41 & Jefferson & 0.00197 & 580318.10 & 4420443.50 \\
\hline 42 & Hopwood & 0.00194 & 610974.90 & 4414962.10 \\
\hline 43 & Rices Landing & 0.00193 & 585750.90 & 4422189.80 \\
\hline 44 & Waynesburg & 0.00192 & 570082.90 & 4416708.40 \\
\hline 45 & Republic & 0.00190 & 595937.50 & 4424227.10 \\
\hline 46 & Uniontown & 0.00190 & 609713.70 & 4417484.50 \\
\hline 47 & Masontown & 0.00183 & 603165.20 & 4378872.40 \\
\hline 48 & Reedsville & 0.00170 & 603310.70 & 4374167.20 \\
\hline 49 & Arthurdale & 0.00166 & 601806.90 & 4372420.90 \\
\hline 50 & Bruceton Mills & 0.00164 & 616504.80 & 4390805.30 \\
\hline 51 & Point Breeze & 0.00160 & 613497.30 & 4405988.20 \\
\hline
\end{tabular}


Tables 4.18 June 16, 2000 Populated Place Concentration Contribution Calculations $\left(\mu \mathrm{g} / \mathrm{m}^{3}\right)$

\begin{tabular}{|c|c|c|c|c|}
\hline RANK & POPULATED PLACE & CONC & XCOORD & YCOORD \\
\hline 1 & Point Marion & $\mathbf{0 . 1 3 7 9 2}$ & $\mathbf{5 9 4 3 3 6 . 8 0}$ & 4399439.70 \\
\hline 2 & New Salem & $\mathbf{0 . 0 6 2 9 2}$ & $\mathbf{5 9 9 4 3 0 . 1 0}$ & $\mathbf{4 4 2 0 0 0 6 . 9 0}$ \\
\hline 3 & McClellandtown & $\mathbf{0 . 0 5 6 3 4}$ & $\mathbf{5 9 6 7 6 2 . 2 0}$ & $\mathbf{4 4 1 5 8 3 8 . 3 0}$ \\
\hline 4 & Smithfield & $\mathbf{0 . 0 4 7 9 7}$ & $\mathbf{6 0 2 0 4 9 . 5 0}$ & $\mathbf{4 4 0 6 5 7 0 . 3 0}$ \\
\hline 5 & Masontown & $\mathbf{0 . 0 4 1 8 1}$ & $\mathbf{5 9 4 0 4 5 . 7 0}$ & 4411372.60 \\
\hline 6 & South Uniontown & $\mathbf{0 . 0 3 2 0 5}$ & $\mathbf{6 0 7 0 9 4 . 3 0}$ & $\mathbf{4 4 1 6 6 5 9 . 9 0}$ \\
\hline 7 & Fairchance & $\mathbf{0 . 0 2 9 9 0}$ & $\mathbf{6 0 6 5 6 0 . 7 0}$ & $\mathbf{4 4 0 9 0 9 2 . 7 0}$ \\
\hline 8 & Uniontown & $\mathbf{0 . 0 2 8 1 8}$ & $\mathbf{6 0 9 7 1 3 . 7 0}$ & $\mathbf{4 4 1 7 4 4 . 5 0}$ \\
\hline 9 & Hopwood & $\mathbf{0 . 0 2 5 6 5}$ & $\mathbf{6 1 0 9 7 4 . 9 0}$ & $\mathbf{4 4 1 4 9 6 2 . 1 0}$ \\
\hline 10 & Republic & $\mathbf{0 . 0 2 2 1 5}$ & $\mathbf{5 9 5 9 3 7 . 5 0}$ & $\mathbf{4 4 2 4 2 2 7 . 1 0}$ \\
\hline 11 & Mapletown & $\mathbf{0 . 0 1 7 1 8}$ & $\mathbf{5 9 0 3 1 0 . 7 0}$ & $\mathbf{4 4 0 6 5 7 0 . 3 0}$ \\
\hline 12 & Baker Ridge & $\mathbf{0 . 0 0 3 2 7}$ & $\mathbf{5 9 0 1 6 8 . 1 0}$ & $\mathbf{4 3 9 2 2 5 3 . 9 0}$ \\
\hline 13 & Point Breeze & $\mathbf{0 . 0 0 2 5 7}$ & $\mathbf{6 1 3 4 9 7 . 3 0}$ & $\mathbf{4 4 0 5 9 8 8 . 2 0}$ \\
\hline 14 & Braewick Woods & $\mathbf{0 . 0 0 1 9 5}$ & $\mathbf{5 8 9 3 8 4 . 6 0}$ & $\mathbf{4 3 9 0 8 1 7 . 5 0}$ \\
\hline 15 & Suncrest & $\mathbf{0 . 0 0 1 4 6}$ & $\mathbf{5 8 7 9 3 3 . 8 0}$ & $\mathbf{4 3 9 0 0 2 9 . 2 0}$ \\
\hline 16 & Star City & $\mathbf{0 . 0 0 1 4 1}$ & $\mathbf{5 8 6 9 1 5 . 1 0}$ & $\mathbf{4 3 9 0 3 8 6 . 7 0}$ \\
\hline 17 & The Flatts & $\mathbf{0 . 0 0 1 4 1}$ & $\mathbf{5 8 8 9 0 3 . 9 0}$ & $\mathbf{4 3 8 9 7 3 8 . 1 0}$ \\
\hline 18 & Canyon & $\mathbf{0 . 0 0 1 2 6}$ & $\mathbf{5 9 5 1 3 0 . 1 0}$ & $\mathbf{4 3 9 2 6 4 5 . 6 0}$ \\
\hline 19 & Wiles Hill & $\mathbf{0 . 0 0 1 1 7}$ & $\mathbf{5 8 9 6 3 1 . 5 0}$ & $\mathbf{4 3 8 8 7 6 8 . 0 0}$ \\
\hline 20 & Osage & $\mathbf{0 . 0 0 1 1 4}$ & $\mathbf{5 8 5 0 5 5 . 7 0}$ & $\mathbf{4 3 9 0 4 3 3 . 2 0}$ \\
\hline 21 & Carmichaels & $\mathbf{0 . 0 0 1 0 1}$ & $\mathbf{5 8 7 6 9 1 . 2 0}$ & $\mathbf{4 4 1 6 8 5 3 . 9 0}$ \\
\hline 22 & The Mileground & $\mathbf{0 . 0 0 1 0 0}$ & $\mathbf{5 9 1 7 1 7 . 4 0}$ & $\mathbf{4 3 8 8 6 7 1 . 0 0}$ \\
\hline 23 & Riverside & $\mathbf{0 . 0 0 0 9 8}$ & $\mathbf{5 8 7 7 8 8 . 3 0}$ & $\mathbf{4 3 8 8 1 3 7 . 4 0}$ \\
\hline 24 & Westover & $\mathbf{0 . 0 0 0 9 6}$ & $\mathbf{5 8 8 3 7 0 . 3 0}$ & $\mathbf{4 3 8 7 7 9 7 . 8 0}$ \\
\hline 25 & Fairmor & $\mathbf{0 . 0 0 0 8 9}$ & $\mathbf{5 8 7 0 3 4 . 2 0}$ & $\mathbf{4 3 8 7 4 2 2 . 5 0}$ \\
\hline 26 & Morgantown & $\mathbf{0 . 0 0 0 8 8}$ & $\mathbf{5 8 9 5 7 4 . 2 0}$ & $\mathbf{4 3 8 7 1 6 1 . 1 0}$ \\
\hline 27 & Sabraton & $\mathbf{0 . 0 0 0 8 5}$ & $\mathbf{5 9 1 9 1 1 . 4 0}$ & $\mathbf{4 3 8 7 1 6 7 . 2 0}$ \\
\hline 28 & Sunset Beach & $\mathbf{0 . 0 0 0 8 2}$ & $\mathbf{5 9 8 0 2 3 . 4 0}$ & $\mathbf{4 3 9 2 7 9 4 . 1 0}$ \\
\hline 29 & South Hills & $\mathbf{0 . 0 0 0 8 1}$ & $\mathbf{5 9 0 8 9 2 . 7 0}$ & $\mathbf{4 3 8 6 1 0 0 . 1 0}$ \\
\hline & & & & \\
\hline
\end{tabular}

\begin{tabular}{|l|c|c|c|c|}
\hline 30 & Hopecrest & $\mathbf{0 . 0 0 0 8 0}$ & $\mathbf{5 8 9 2 2 3 . 6 0}$ & $\mathbf{4 3 8 6 0 7 0 . 4 0}$ \\
\hline 31 & South Park & $\mathbf{0 . 0 0 0 8 0}$ & $\mathbf{5 8 9 7 2 8 . 6 0}$ & $\mathbf{4 3 8 6 1 0 0 . 1 0}$ \\
\hline 32 & West Sabraton & $\mathbf{0 . 0 0 0 7 3}$ & $\mathbf{5 9 2 0 8 8 . 4 0}$ & $\mathbf{4 3 8 5 8 0 9 . 0 0}$ \\
\hline 33 & Mount Morris & $\mathbf{0 . 0 0 0 7 3}$ & $\mathbf{5 7 9 7 8 4 . 5 0}$ & $\mathbf{4 3 9 8 5 6 6 . 5 0}$ \\
\hline 34 & Richard & $\mathbf{0 . 0 0 0 6 6}$ & $\mathbf{5 9 3 9 0 0 . 2 0}$ & $\mathbf{4 3 8 4 6 9 3 . 3 0}$ \\
\hline 35 & Hilderbrand & $\mathbf{0 . 0 0 0 5 7}$ & $\mathbf{5 8 6 0 6 8 . 4 0}$ & $\mathbf{4 3 8 2 7 9 8 . 3 0}$ \\
\hline 36 & National & $\mathbf{0 . 0 0 0 5 3}$ & $\mathbf{5 8 2 6 7 9 . 5 0}$ & $\mathbf{4 3 8 1 9 8 0 . 3 0}$ \\
\hline 37 & Rices Landing & $\mathbf{0 . 0 0 0 4 5}$ & $\mathbf{5 8 5 7 5 0 . 9 0}$ & $\mathbf{4 4 2 2 1 8 9 . 8 0}$ \\
\hline 38 & Sturgisson & $\mathbf{0 . 0 0 0 4 2}$ & $\mathbf{5 9 7 1 0 1 . 7 0}$ & $\mathbf{4 3 8 2 2 1 9 . 4 0}$ \\
\hline 39 & Rivesville & $\mathbf{0 . 0 0 0 4 0}$ & $\mathbf{5 7 5 8 5 5 . 4 0}$ & $\mathbf{4 3 7 5 9 6 1 . 9 0}$ \\
\hline 40 & Masontown & $\mathbf{0 . 0 0 0 4 0}$ & $\mathbf{6 0 3 1 6 5 . 2 0}$ & $\mathbf{4 3 7 8 8 7 2 . 4 0}$ \\
\hline 41 & Ragtown & $\mathbf{0 . 0 0 0 3 9}$ & $\mathbf{5 6 2 8 7 7 . 1 0}$ & $\mathbf{4 3 8 8 9 8 9 . 4 0}$ \\
\hline 42 & Fairview & $\mathbf{0 . 0 0 0 3 9}$ & $\mathbf{5 6 4 5 5 3 . 1 0}$ & $\mathbf{4 3 8 2 8 0 1 . 5 0}$ \\
\hline 43 & Reedsville & $\mathbf{0 . 0 0 0 3 9}$ & $\mathbf{6 0 3 3 1 0 . 7 0}$ & $\mathbf{4 3 7 4 1 6 7 . 2 0}$ \\
\hline 44 & Jefferson & $\mathbf{0 . 0 0 0 3 9}$ & $\mathbf{5 8 0 3 1 8 . 1 0}$ & $\mathbf{4 4 2 0 4 4 3 . 5 0}$ \\
\hline 45 & Waynesburg & $\mathbf{0 . 0 0 0 3 8}$ & $\mathbf{5 7 0 0 8 2 . 9 0}$ & $\mathbf{4 4 1 6 7 0 8 . 4 0}$ \\
\hline 46 & Chesapeake & $\mathbf{0 . 0 0 0 3 7}$ & $\mathbf{5 7 2 7 9 9 . 4 0}$ & $\mathbf{4 3 7 3 4 3 9 . 5 0}$ \\
\hline 47 & Fairmont & $\mathbf{0 . 0 0 0 3 7}$ & $\mathbf{5 7 3 6 7 2 . 5 0}$ & $\mathbf{4 3 7 0 9 6 5 . 6 0}$ \\
\hline 48 & Barrackville & $\mathbf{0 . 0 0 0 3 6}$ & $\mathbf{5 7 1 5 3 8 . 2 0}$ & $\mathbf{4 3 7 3 0 0 3 . 0 0}$ \\
\hline 49 & Palatine & $\mathbf{0 . 0 0 0 3 6}$ & $\mathbf{5 7 4 1 0 9 . 1 0}$ & $\mathbf{4 3 7 0 3 8 3 . 6 0}$ \\
\hline 50 & Arthurdale & $\mathbf{0 . 0 0 0 3 5}$ & $\mathbf{6 0 1 8 0 6 . 9 0}$ & $\mathbf{4 3 7 2 4 2 0 . 9 0}$ \\
\hline $\mathbf{5 1}$ & Bruceton Mills & $\mathbf{0 . 0 0 0 3 1}$ & $\mathbf{6 1 6 5 0 4 . 8 0}$ & $\mathbf{4 3 9 0 8 0 5 . 3 0}$ \\
\hline & & & & \\
\hline
\end{tabular}


Tables 4.19 May 31, 2000 Populated Place Concentration Contribution Calculations $\left(\mu \mathrm{g} / \mathrm{m}^{3}\right)$

\begin{tabular}{|c|c|c|c|c|}
\hline RANK & POPULATED PLACE & CONC & XCOORD & YCOORD \\
\hline 1 & Point Marion & 0.09380 & 594336.80 & 4399439.70 \\
\hline 2 & New Salem & 0.05280 & 599430.10 & 4420006.90 \\
\hline 3 & McClellandtown & 0.04243 & 596762.20 & 4415838.30 \\
\hline 4 & Smithfield & 0.03768 & 602049.50 & 4406570.30 \\
\hline 5 & South Uniontown & 0.03457 & 607094.30 & 4416659.90 \\
\hline 6 & Masontown & 0.02954 & 594045.70 & 4411372.60 \\
\hline 7 & Uniontown & 0.02751 & 609713.70 & 4417484.50 \\
\hline 8 & Jefferson & 0.02692 & 580318.10 & 4420443.50 \\
\hline 9 & Fairchance & 0.02458 & 606560.70 & 4409092.70 \\
\hline 10 & Hopwood & 0.02305 & 610974.90 & 4414962.10 \\
\hline 11 & Republic & 0.01163 & 595937.50 & 4424227.10 \\
\hline 12 & Point Breeze & 0.00808 & 613497.30 & 4405988.20 \\
\hline 13 & Rices Landing & 0.00686 & 585750.90 & 4422189.80 \\
\hline 14 & Mapletown & 0.00607 & 590310.70 & 4406570.30 \\
\hline 15 & Baker Ridge & 0.00599 & 590168.10 & 4392253.90 \\
\hline 16 & Suncrest & 0.00467 & 587933.80 & 4390029.20 \\
\hline 17 & Carmichaels & 0.00366 & 587691.20 & 4416853.90 \\
\hline 18 & Star City & 0.00272 & 586915.10 & 4390386.70 \\
\hline 19 & The Flatts & 0.00271 & 588903.90 & 4389738.10 \\
\hline 20 & Canyon & 0.00244 & 595130.10 & 4392645.60 \\
\hline 21 & Osage & 0.00225 & 585055.70 & 4390433.20 \\
\hline 22 & Wiles Hill & 0.00224 & 589631.50 & 4388768.00 \\
\hline 23 & The Mileground & 0.00198 & 591717.40 & 4388671.00 \\
\hline 24 & Riverside & 0.00196 & 587788.30 & 4388137.40 \\
\hline 25 & Westover & 0.00192 & 588370.30 & 4387797.80 \\
\hline 26 & Fairmor & 0.00179 & 587034.20 & 4387422.50 \\
\hline 27 & Morgantown & 0.00179 & 589574.20 & 4387161.10 \\
\hline 28 & Sabraton & 0.00174 & 591911.40 & 4387167.20 \\
\hline 29 & Sunset Beach & 0.00169 & 598023.40 & 4392794.10 \\
\hline
\end{tabular}

\begin{tabular}{|c|c|c|c|c|}
\hline 30 & Hopecrest & 0.00163 & 589223.60 & 4386070.40 \\
\hline 31 & South Hills & 0.00163 & 590892.70 & 4386100.10 \\
\hline 32 & South Park & 0.00163 & 589728.60 & 4386100.10 \\
\hline 33 & West Sabraton & 0.00153 & 592088.40 & 4385809.00 \\
\hline 34 & Mount Morris & 0.00153 & 579784.50 & 4398566.50 \\
\hline 35 & Richard & 0.00139 & 593900.20 & 4384693.30 \\
\hline 36 & Hilderbrand & 0.00125 & 586068.40 & 4382798.30 \\
\hline 37 & National & 0.00115 & 582679.50 & 4381980.30 \\
\hline 38 & Waynesburg & 0.00108 & 570082.90 & 4416708.40 \\
\hline 39 & Sturgisson & 0.00103 & 597101.70 & 4382219.40 \\
\hline 40 & Masontown & 0.00088 & 603165.20 & 4378872.40 \\
\hline 41 & Rivesville & 0.00087 & 575855.40 & 4375961.90 \\
\hline 42 & Ragtown & 0.00085 & 562877.10 & 4388989.40 \\
\hline 43 & Fairview & 0.00084 & 564553.10 & 4382801.50 \\
\hline 44 & Chesapeake & 0.00082 & 572799.40 & 4373439.50 \\
\hline 45 & Fairmont & 0.00081 & 573672.50 & 4370965.60 \\
\hline 46 & Reedsville & 0.00081 & 603310.70 & 4374167.20 \\
\hline 47 & Barrackville & 0.00080 & 571538.20 & 4373003.00 \\
\hline 48 & Palatine & 0.00080 & 574109.10 & 4370383.60 \\
\hline 49 & Arthurdale & 0.00079 & 601806.90 & 4372420.90 \\
\hline 50 & Bruceton Mills & 0.00075 & 616504.80 & 4390805.30 \\
\hline 51 & Braewick Woods & 0.00001 & 589384.60 & 4390817.50 \\
\hline
\end{tabular}




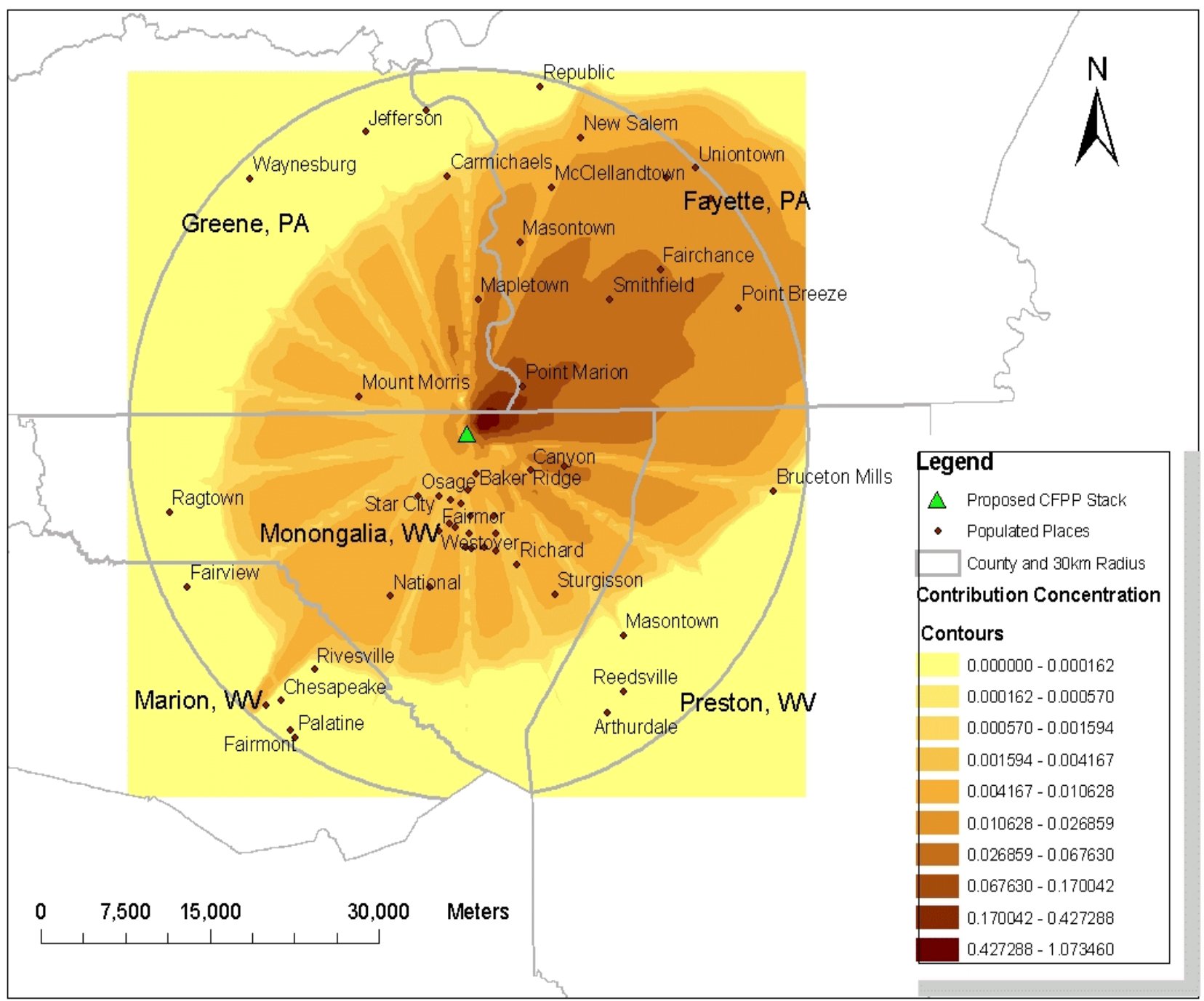

Figure 23: June 11, 2000 concentration contours from kriging $\left(\mu \mathrm{g} / \mathrm{m}^{3}\right)$ - highest 24 hour average values. June 11, 2000 was the highest concentration contribution day modeled from the proposed coal fired power plant. The highest 24 hour average concentration for June 11, 2000 was $1.07 \mu \mathrm{g} / \mathrm{m}^{3}$. It occurred northeast of the proposed stack on the West Virginia, Pennsylvania border. Point Marion, PA has the highest concentration contribution, at 0.15 $\mu \mathrm{g} / \mathrm{m}^{3}$ modeled that day. A majority of the contribution concentration moved toward the northeast on June 11, 2000. See chapter 5 for further discussion on kriging concentration predictions beyond the $30 \mathrm{~km}$ radius study area . 


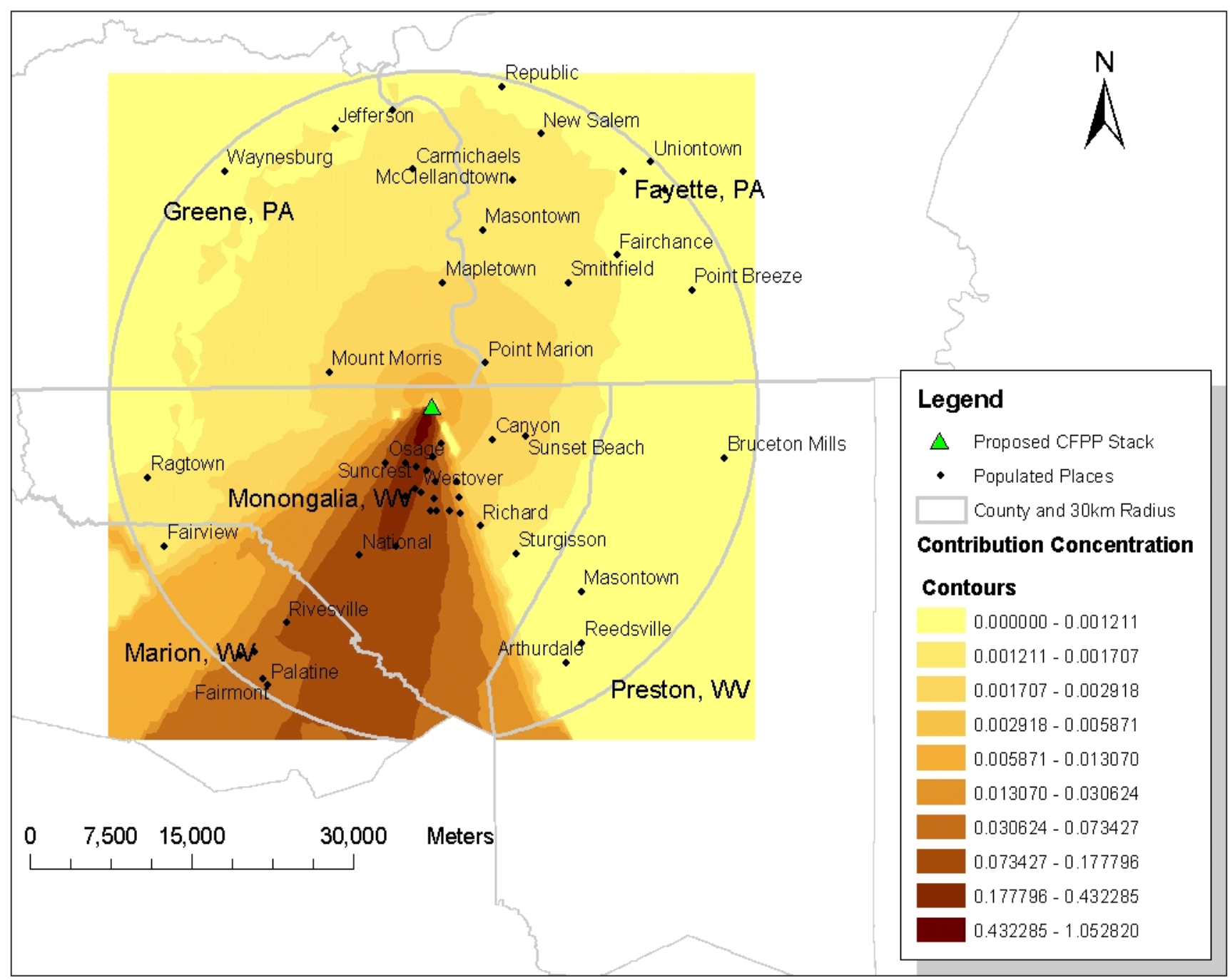

Figure 24: June 19, 2000 concentration contours from kriging $\left(\mu \mathrm{g} / \mathrm{m}^{3}\right)$ - highest 24 hour average values. June 19, 2000 was the second highest concentration contribution day modeled from the proposed coal fired power plant. The highest 24 hour average concentration for June 19, 2000 was $1.05 \mu \mathrm{g} / \mathrm{m}^{3}$. It occurred almost directly south of the proposed stack, northwest of Bakers Ridge. Suncrest, WV has the highest concentration contribution, at $0.36 \mu \mathrm{g} / \mathrm{m}^{3}$ modeled that day. A majority of the contribution concentration moved toward the southwest on June 19, 2000. See chapter 5 for further discussion on kriging concentration predictions beyond the $30 \mathrm{~km}$ radius study area . 


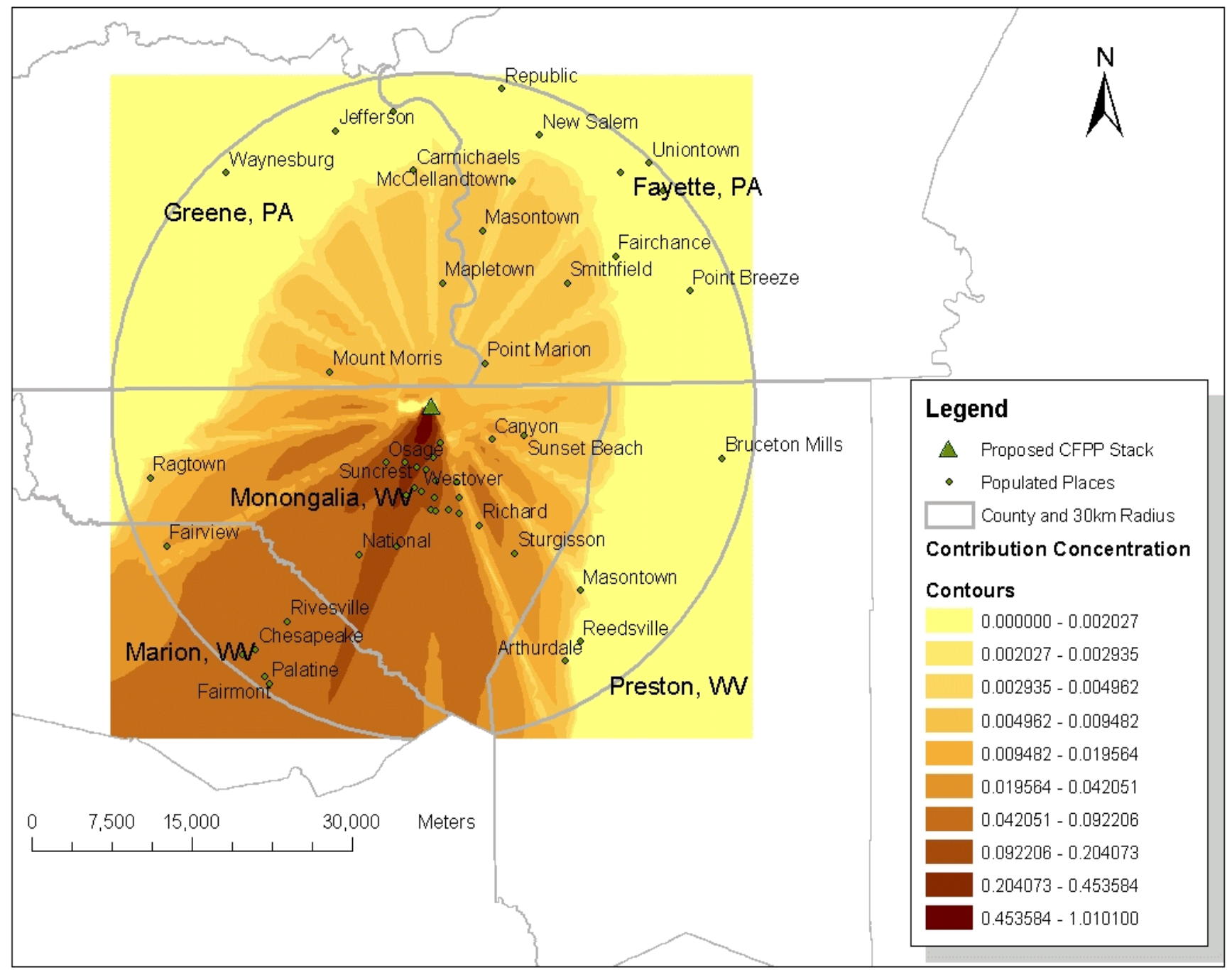

Figure 25: July 23, 2000 concentration contours from kriging $\left(\mu \mathrm{g} / \mathrm{m}^{3}\right)$ - highest 24 hour average values. June 23,2000 was the third highest concentration contribution day modeled from the proposed coal fired power plant. The highest 24 hour average concentration for June 23, 2000 was $0.101 \mu \mathrm{g} / \mathrm{m}^{3}$. It occurred southwest of the proposed stack, northwest of Bakers Ridge, WV. Suncrest, WV has the highest concentration contribution, at $0.35 \mu \mathrm{g} / \mathrm{m}^{3}$ modeled that day. A majority of the contribution concentration moved toward the southwest on June 23, 2000. See chapter 5 for further discussion on kriging concentration predictions beyond the $30 \mathrm{~km}$ radius study area . 


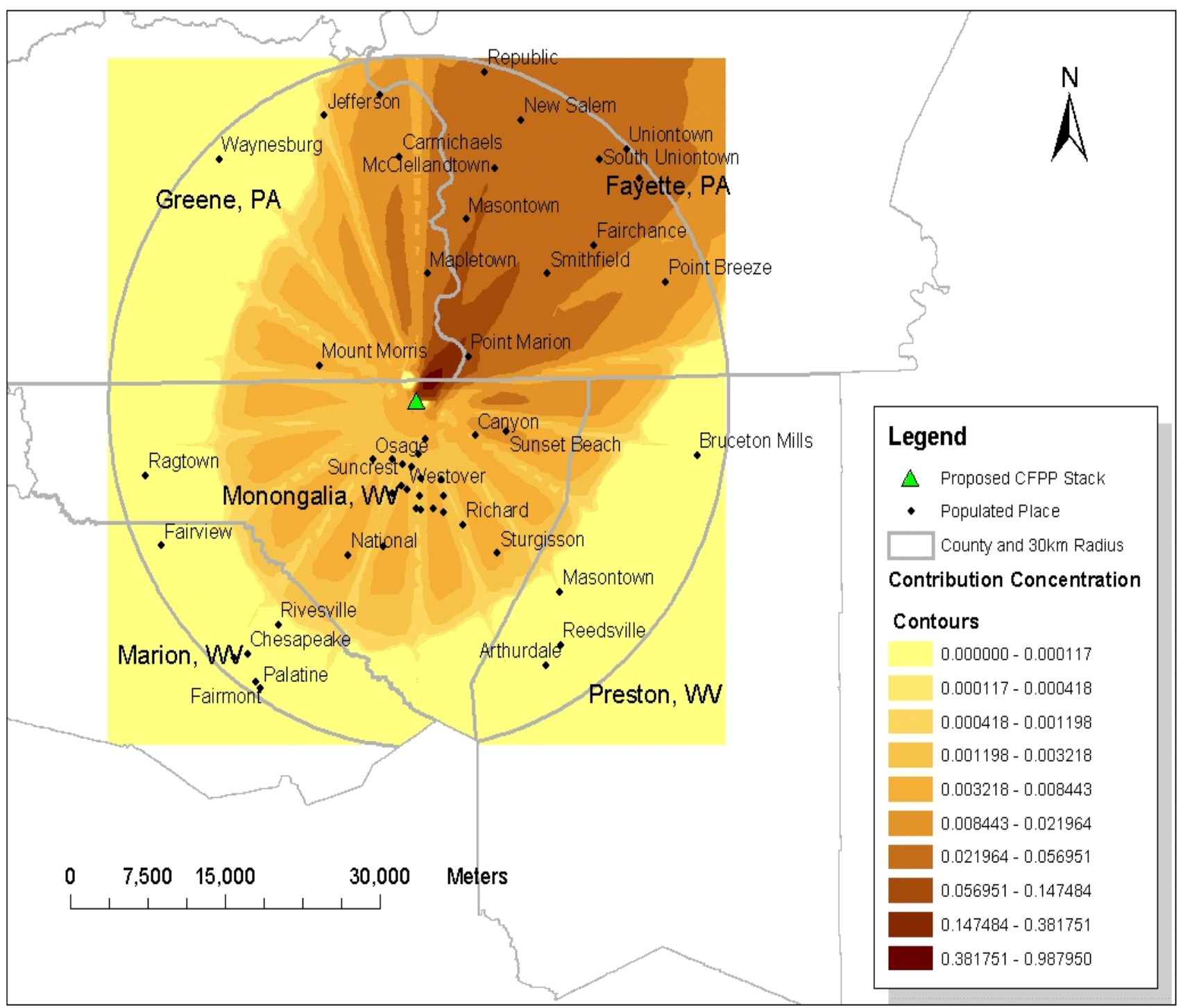

Figure 26 : June 16, 2000 concentration contours from $\mathrm{kriging}\left(\mu \mathrm{g} / \mathrm{m}^{3}\right)$ - highest 24 hour average values. June 16, 2000 was the fourth highest concentration contribution day modeled from the proposed coal fired power plant. The highest 24 hour average concentration for June 16, 2000 was $0.99 \mu \mathrm{g} / \mathrm{m}^{3}$. It occurred northeast of the proposed stack, southwest of Point Marion, PA. Point Marion, PA has the highest concentration contribution, at $0.14 \mu \mathrm{g} / \mathrm{m}^{3} \mathrm{modeled}$ that day. A majority of the contribution concentration moved toward the northeast on June 16, 2000. See chapter 5 for further discussion on kriging concentration predictions beyond the $30 \mathrm{~km}$ radius study area . 


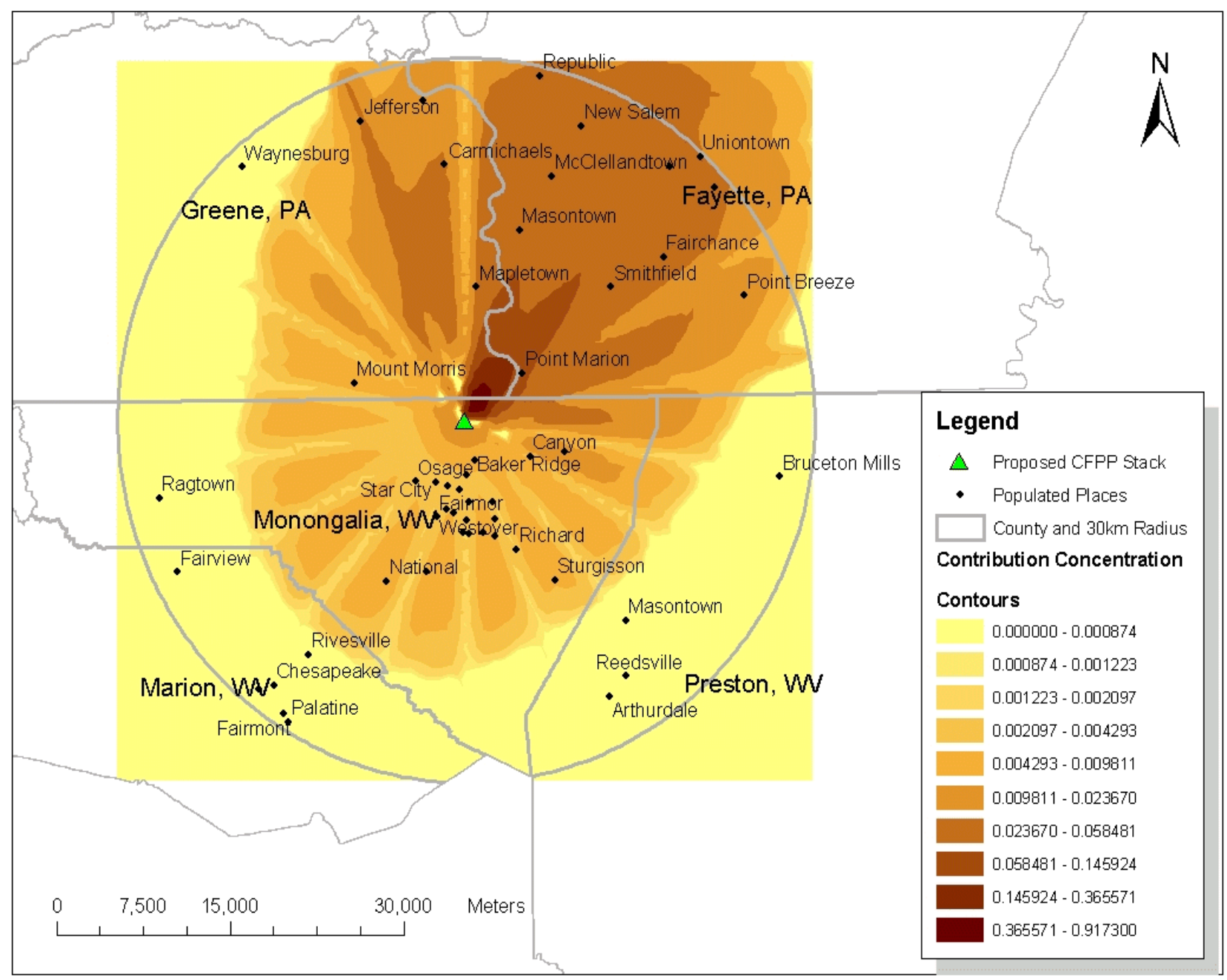

Figure 27 : May 31, 2000 concentration contours from kriging $\left(\mu \mathrm{g} / \mathrm{m}^{3}\right)$ - highest 24 hour average values. May 31, 2000 was the fifth highest concentration contribution day modeled from the proposed coal fired power plant. The highest 24 hour average concentration for May 31,2000 was $0.92 \mu \mathrm{g} / \mathrm{m}^{3}$. It occurred northeast of the proposed stack, southwest of Point Marion, PA. Point Marion, PA has the highest concentration contribution, at $0.09 \mu \mathrm{g} / \mathrm{m}^{3}$ modeled that day. A majority of the contribution concentration moved toward the northeast on May 31, 2000. See chapter 5 for further discussion on kriging concentration predictions beyond the $30 \mathrm{~km}$ radius study area . 
By analyzing the contour maps above and concentration calculations for each populated place, concentration contributions of the proposed CFPP can be estimated for each five days modeled. The highest modeled concentration contribution coordinate point on June 11 is $1.07 \mu \mathrm{g} / \mathrm{m}^{3}$. Populated places closest to this point, as well as other high modeled concentration contribution coordinate points, would assume to be exposed to a concentration represented by the contour interval level in which it is located, using these modeling methods. For example, modeled results (Figure 23, page 95) show that Point Marion was exposed to a 24 hour average concentration contribution of $0.15 \mu \mathrm{g} / \mathrm{m}^{3}$ (Table 4.15, page 90) on June 11 and is within the $0.067630-0.170042$ concentration contour interval. The highest calculated concentration of $1.07 \mu \mathrm{g} / \mathrm{m}^{3}$ was calculated a few meters south west of Point Marion. Point Marion and Suncrest alternated at being the highest populated place concentration contribution for each day modeled, falling in higher ranges of interpolated contour levels. On June 16, a concentration of $0.36 \mu \mathrm{g} / \mathrm{m}^{3}$ at Suncrest was the worst 24 hour average contribution condition modeled for any populated place, of any of the five days modeled using these methods. Similar types of analysis can be conducted on all five contour maps for each day.

The measure of certainty or accuracy of the interpolated concentration contour interval maps are listed in tables $4.20-4.24$ below. The prediction error value are pretty close to zero. The rootmean-square standardized prediction error is as it should be, close to 1, and the root-mean-square prediction error is pretty small. The spatial relationships of each calculated concentration value, for each day modeled, was explored in the semivariogram and fitted to a model receiving the best prediction error scores from the cross validation analysis conducted in the Geostatistical Analyst. 
Table 4.20 June 11, 2000 Cross Validation Results

\begin{tabular}{|l|l|}
\hline Mean & $\mathbf{0 . 0 0 0 3 9 0 1}$ \\
\hline Root-Mean-Square & $\mathbf{0 . 0 1 0 0 6}$ \\
\hline $\begin{array}{l}\text { Root-Mean-Square } \\
\text { Sandardized }\end{array}$ & $\mathbf{0 . 9 2 6 8}$ \\
\hline
\end{tabular}

Table 4.21 June 19, 2000 Cross Validation Results

\begin{tabular}{|l|l|}
\hline Mean & $\mathbf{0 . 0 0 0 1 2 7 2}$ \\
\hline Root-Mean-Square & $\mathbf{0 . 0 1 6 6 3}$ \\
\hline $\begin{array}{l}\text { Root-Mean-Square } \\
\text { Sandardized }\end{array}$ & $\mathbf{0 . 7 9 5 3}$ \\
\hline
\end{tabular}

Table 4.22 July 23, 2000 Cross Validation Results

\begin{tabular}{|l|l|}
\hline Mean & $\mathbf{0 . 0 0 0 3 1 3 3}$ \\
\hline Root-Mean-Square & $\mathbf{0 . 0 1 5 7 3}$ \\
\hline $\begin{array}{l}\text { Root-Mean-Square } \\
\text { Sandardized }\end{array}$ & $\mathbf{0 . 8 9 1 3}$ \\
\hline
\end{tabular}

Table 4.23 June 16, 2000 Cross Validation Results

\begin{tabular}{|l|l|}
\hline Mean & $\mathbf{0 . 0 0 0 3 3 6 2}$ \\
\hline
\end{tabular}

Root-Mean-Square 0.02372

Root-Mean-Square 0.841

Sandardized

Table 4.24 May 31, 2000 Cross Validation Results

\begin{tabular}{|l|l|}
\hline Mean & $\mathbf{0 . 0 0 0 1 1 5 2}$ \\
\hline Root-Mean-Square & $\mathbf{0 . 0 1 3 1 1}$ \\
\hline $\begin{array}{l}\text { Root-Mean-Square } \\
\text { Sandardized }\end{array}$ & $\mathbf{0 . 8 9 3 5}$ \\
\hline
\end{tabular}


It is of interest that for 2 of these 5 highest concentration contribution days, June 19 and July 23, 2000, the bulk of downwind exposure was toward the Greater Morgantown area, where the highest density of sensitive receptor categories were located (Figure 9), and that this general direction of dispersion is opposite that of prevailing wind direction for the study area. Figure 28 are the 2000 Windrows for Morgantown. As depicted in the figure, the majority of the wind was from the South-South-West, at velocities ranging from $<1.54 \mathrm{~m} / \mathrm{s}$ up to $8.23 \mathrm{~m} / \mathrm{s}$. The wind direction for June 19 and July 23, 2000 were nearly opposite.

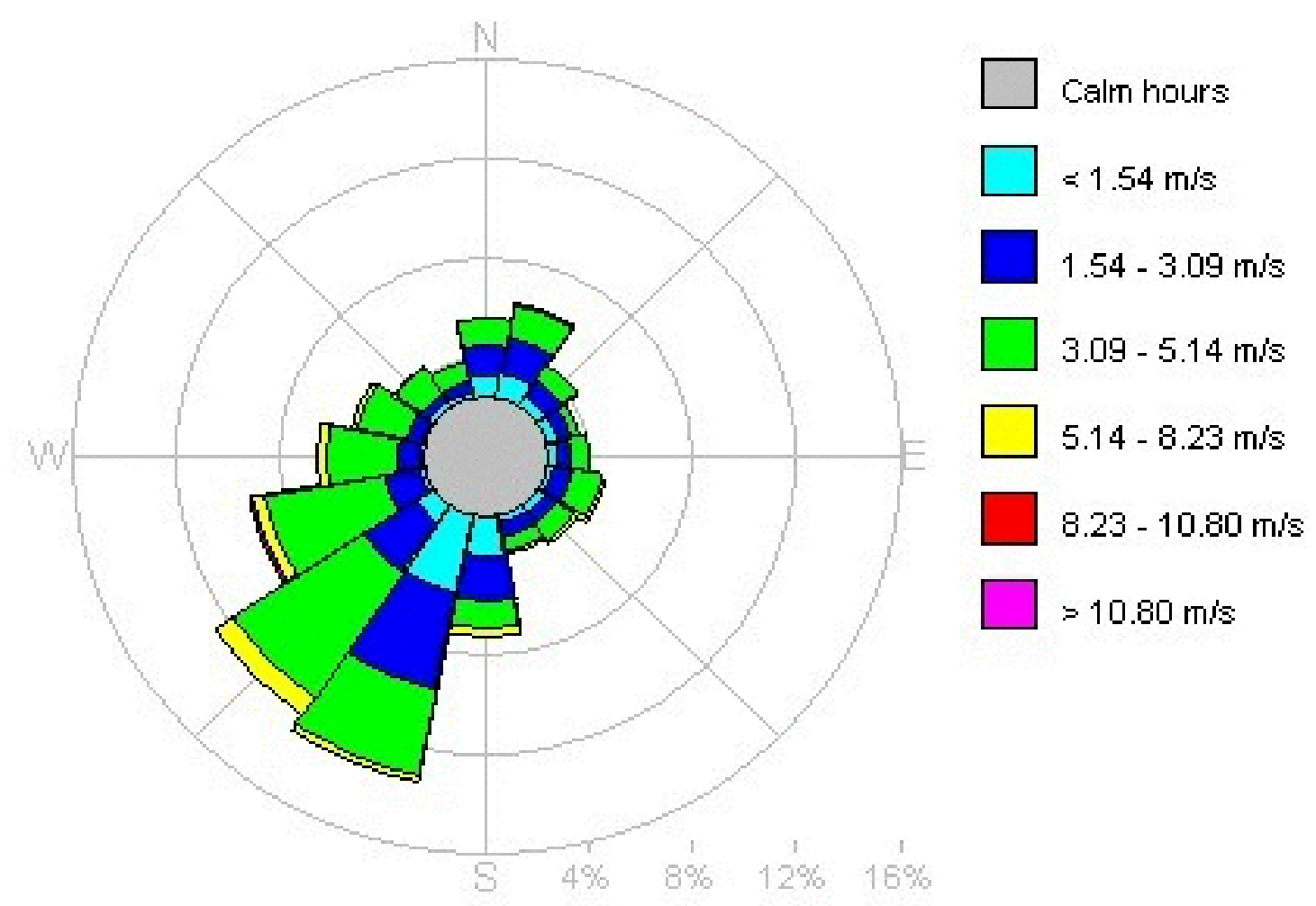

Figure 28: Morgantown, West Virginia windrose for the year 2000. The majority of the wind was from the South-South-West, at velocities ranging from $<1.54 \mathrm{~m} / \mathrm{s}$ up to $8.23 \mathrm{~m} / \mathrm{s}$. See Figures 23, 26 and 27. The wind direction for June 19 and July 23, 2000 were nearly opposite. See Figures 24 and 25. 
As it turns out, none of the modeled runs for the top five contribution days for the entire year of 2000, were as a result of direction specific building downwash. All of the highest calculated concentration contributions, for each modeled day, were off-site of the proposed CFPP. This may be contributed to two slightly different but related assumptions. One, is that the direction specific wind velocity, conducive to what would be necessary for building downwash to occur on the proposed CFPP site, never occurred on those days. The other assumption is that GEP height was consequently high enough to eliminate such direction specific building downwash within general area of the proposed site, as one would expect when implementing GEP practices. 


\section{Chapter 5 - Discussion and Summary}

Elderly, young and diseased populations, those most vulnerable to increased pollution emissions, are an integral part of our nations communities. Steadily rising industrial, economic, and population growth, resulting increasing air pollution, may episodically present serious public and environmental health threats those most vulnerable groups, as well as to the general population. Recognition of such issues has led private researchers, the government, and universities to conduct extensive research, looking for correlations between pollution levels to public and environmental health. This thesis was only concerned with an increased sulfur dioxide $\left(\mathrm{SO}_{2}\right)$ contribution from a proposes new coal fired power plant (CFPP). The study area of Greater Morgantown, WV, is comprised of diverse industry, including coal mining, coal fired electricity production, the chemical and other manufacturing industries, governmental research facilities, and universities. Any substantial regional increased in pollution emissions, including that of $\mathrm{SO}_{2}$, has the potential to increase ambient pollution levels in this area. This was the rational for a study of possible changes in exposure of these sensitive sub-populations.

Using Geographic Information Systems (GIS) technology, together with air pollutant dispersion modeling technology, within a particular study area, I have analyzed the potential for increased $\mathrm{SO}_{2}$ exposure to these local vulnerable groups. The goal of this thesis was to model, using these two technologies, the contribution of $\mathrm{SO}_{2}$ from a proposed new coal-fired electricity generating plant, which is now under review for construction permitting, to the potential for human exposure. Year 2000 emissions and weather data were used to be compatible with the decennial US Census data. Two distinct major objectives to accomplishing this goal included: 1) categorizing types of population locations that may contain people most vulnerable to increased ambient levels of 
$\left.\mathrm{SO}_{2} ; 2\right)$ modeling the worst case downwind dispersion of proposed $\mathrm{SO}_{2}$ contributions from this plant, added to monitored background ambient levels of $\mathrm{SO}_{2}$, toward those locations established in the first objective. The modeled increase in $\mathrm{SO}_{2}$ was then compared to the provisional maximum ambient air concentration as well as the 24 hour average $91 \mu \mathrm{g} / \mathrm{m}^{3}$ PSD increment level. This chapter discusses the results using the methodologies described in chapter 3 and that were used to accomplish the major objectives. Discussion of some of the limitations to using the GIS and air dispersion modeling concepts that have been presented here, are reviewed as well in this chapter.

\subsection{Summary of Categorized Sensitive Receptors Locations}

GIS analysis was conducted in this study to quantify the density of established sensitive receptor categories within a set distance of a proposed air pollution source. The results of the sensitive receptor category location density analysis quantitatively identifies schools as being the most spatially dense of categorized sensitive receptor groups within the study area, followed by progressively less dense day care, hospitals/medical centers, and nursing home facilities. See Figure 29. Out of the two different classes of categorized sensitive receptor types, those which have populations congregating intermittently appear to be more dense than those which contain populations of limited mobility. 


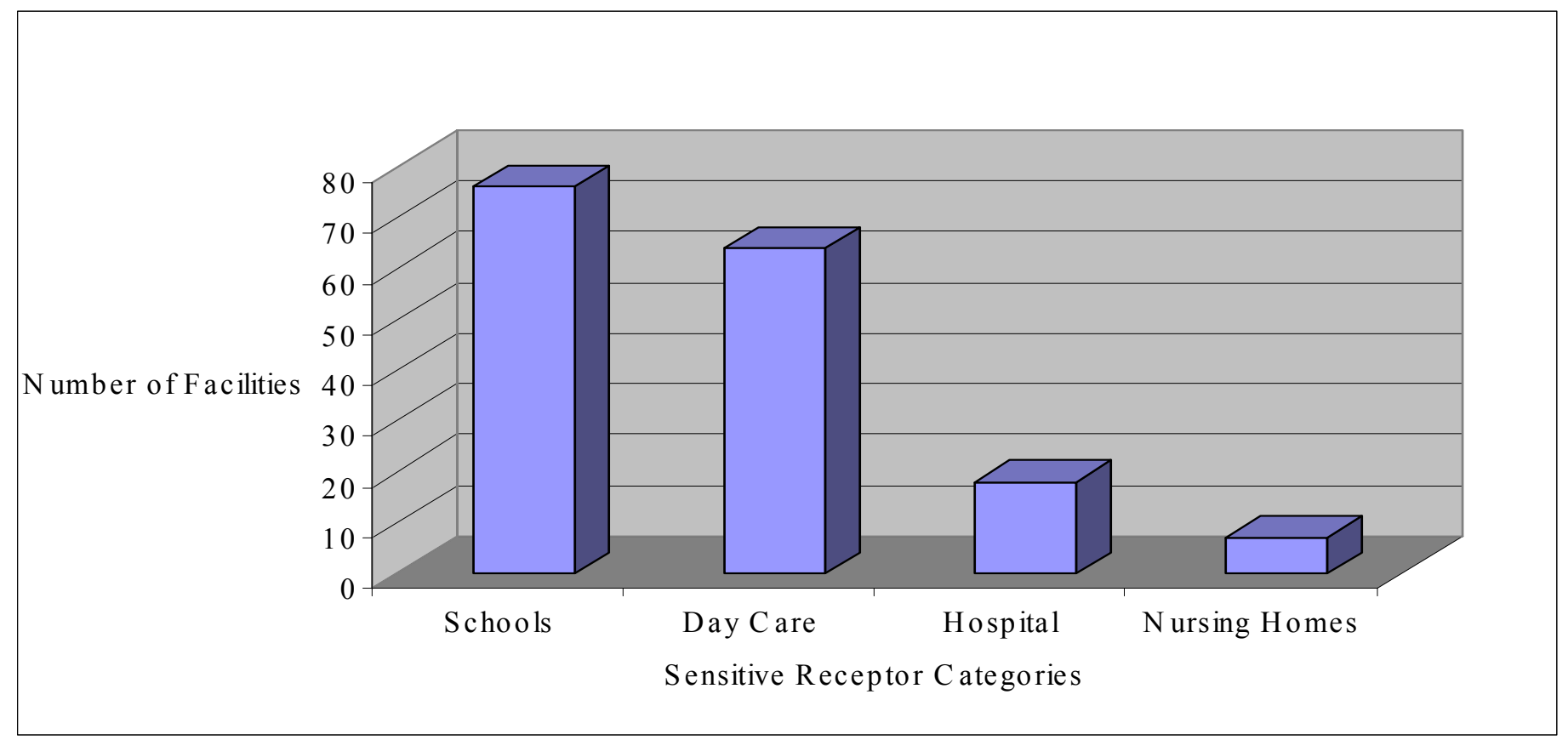

Figure 29: Sensitive receptor categories within $30 \mathrm{~km}$ of stack. The figure depicts the density of established sensitive receptor categories within the entire study area. There are 76 schools, 64 day care facilities, 13 hospitals, and 7 nursing homes.

It reasonable to expect that the most vulnerable sensitive receptor category, to local increased $\mathrm{SO}_{2}$ contributions, are the sensitive receptor categories with limited mobility, as seen by this type of analysis - due to longer time of a modeled exposure per 24 hours. This suggests that the most dense of sensitive receptor categories in this study area, may be the less vulnerable of the two categories, when considering spatial density only. We do not have data on the residential locations of the children in these day care or school facilities, so we cannot state with greater accuracy whether the overall exposure is less or greater than that of less mobile people in custodial facilities.

Another key factor of sensitive receptor category vulnerability is that of straight line distance to the proposed stack. Since the proposed CFPP is on a mountain ridge and proposes a very high stack, straight line plume dispersion was considered more likely in spite of the irregular topography. I conducted a straight line distance calculation, using GIS Spatial Analyst. It was assumed that 
those closer to the stack may be more heavily exposed and, therefore, more vulnerable than those farther away from the proposed source stack during weather conditions likely to impede dispersion. Discussion of modeled worst case episodes are to follow in the next section.

By comparing the density of sensitive receptor categories to their distances from the proposed stack, vulnerability to those sensitive groups discussed above may be addressed. Figure 30 presents the bimodal density of sensitive receptor category types at the increasing distances from the proposed stack. Over half, of both the most dense and less dense sensitive receptor category types, appear to be the farthest away from the proposed stack, therefore may be the least vulnerable to increased $\mathrm{SO}_{2}$ contributions. Note that the Greater Morgantown area occurs within the second highest dense distance increment, $5-10 \mathrm{~km}$ away from the proposed stack. Also at least one of each type of categorized sensitive receptor is located within $0-5 \mathrm{~km}$ of the proposed increasing $\mathrm{SO}_{2}$ contributing source, while the less dense collections are located toward the middle of the range of distances modeled. 


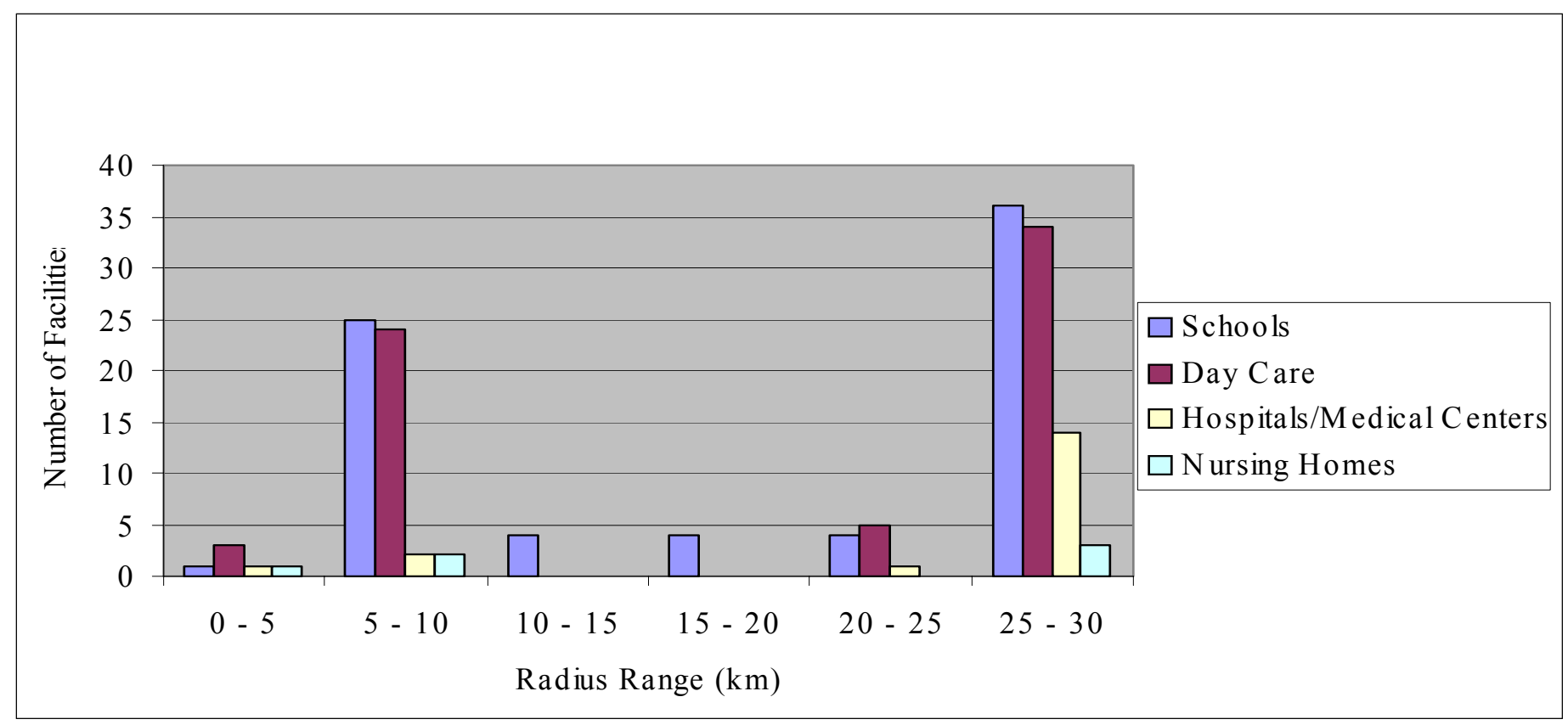

Figure 30: Density of sensitive receptors within distance to stack range. The highest dense area is the Greater Uniontown, PA. The second highest dense area is Greater Morgantown, WV. The least dense area is between Morgantown, WV and Uniontown, PA.

Geographically identifying locations and densities of categorized sensitive receptors to the proposed increased $\mathrm{SO}_{2}$ contributing source contributed to fulfilling one objective for this thesis. This method can be applied to any type of population vulnerability, to any pollution source, on any type of population group. John Boettner's method to assess population vulnerability to air pollution used some of these methods. His thesis, from the same laboratory as this one, is accessible on the Internet at http://etd.wvu.edu/.

In my judgement, future research extending to different types of categorized sensitive and non-sensitive receptor type populations exposed to air pollution, or proposed increases to air pollution is justifiable. Although beyond the scope of this thesis, location and density data on, these and other categories of sensitive receptors within the Greater Morgantown area now exists and can be used to assess vulnerability to other air pollution sources within the area. 


\subsection{Summary and Discussion of Worst Case Modeled $\mathrm{SO}_{2}$ Contribution Exposure}

The second objective of this thesis was to model worst case downwind exposure, from the proposed CFPP stack, of $\mathrm{SO}_{2}$ emissions for each day of the year 2000, and to add this plant contribution to the highest 24 - hour average monitored ambient background concentration for the same year. Air dispersion modeling and kriging of modeled calculated concentration points of the proposed CFPP contribution provided a way to analyze directional patterns of plume dispersion under highest modeled concentration days for that year. It was assumed that increasing $\mathrm{SO}_{2}$ pollution concentration can correlate to an increased public and environmental health threat. It is here argued that claiming a potential environmental public health threat for the proposed CFPP emissions is supported by modeling the movement of the highest $\mathrm{SO}_{2}$ concentration contributions, comparing them to the provisional maximum ambient air concentration recommended in this thesis, and to the 24 hour averaging PSD increment limit established by the EPA.

As expected, the highest modeled 24 - hour concentration contributions were relatively close in distance to proposed stack, but outside of the proposed CFPP property parameter (Figures 23 27). The highest worst case daily modeled concentration contribution for the entire year of 2000

was $1.82 \mu \mathrm{g} / \mathrm{m}^{3}$. This value is far below the established provisional maximum ambient air concentration recommended in this thesis of $260 \mu \mathrm{g} / \mathrm{m}^{3}$, established for this study; the minimum risk level established by the Agency for Toxic Substances and Disease Registry (ATSDR). By adding this highest modeled concentration value to the highest monitored 24 hour average ambient background concentration for the year 2000, the allotted 24 hour averaging $\mathrm{SO}_{2}$ Prevention of Significant Deterioration (PSD) increment consumption of $91 \mu \mathrm{g} / \mathrm{m}^{3}$ is consumed at $2 \%$. See Figure 31 . The 
highest $\mathrm{SO}_{2}$ monitored ambient background concentration value was chosen to represent a worst case ambient background concentration for the year 2000. This value represents all other $\mathrm{SO}_{2}$ air polluting sources in this air quality region, and was also added to the other four (second to fifth) highest days of 24 - hour average contributions modeled. All sources, including the proposed CFPP, contribute to levels that fell below the established provisional maximum ambient air concentration. They also share the consumption of the 24 hour average PSD increment of $91 \mu \mathrm{g} / \mathrm{m}^{3}$.

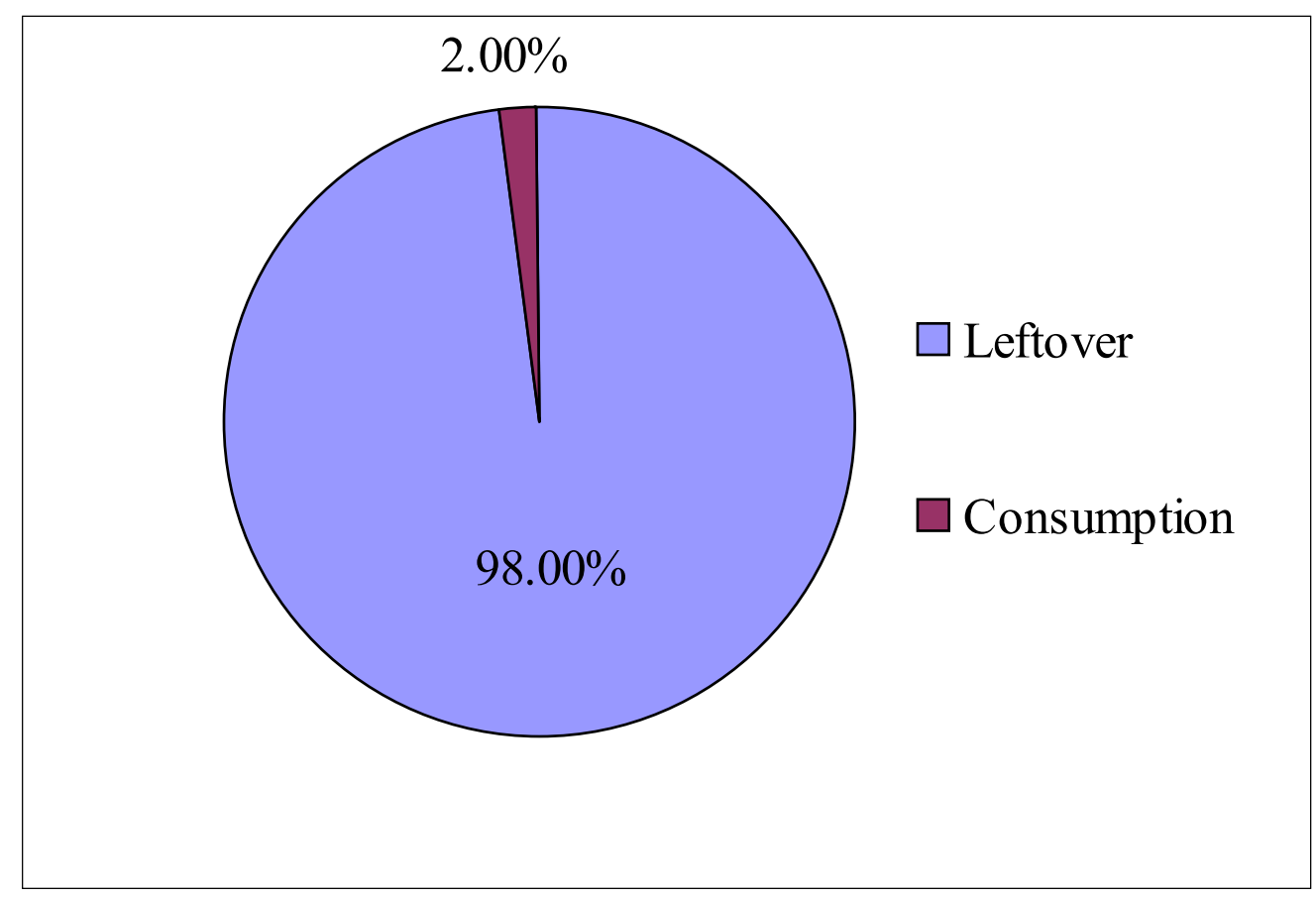

Figure 31 : Modeled increment consumption of prevention of significant deterioration (PSD), $91 \mu \mathrm{g} / \mathrm{m}^{3} 24$ hour averaging standard. Worst case proposed stack 24 hour average of $1.07 \mu \mathrm{g} / \mathrm{m}^{3}$ was added to worst case monitored background 24 hour average concentration of $0.75 \mu \mathrm{g} / \mathrm{m}^{3}$, totaling $1.82 \mu \mathrm{g} / \mathrm{m}^{3} .2 \%$ of $91 \mu \mathrm{g} / \mathrm{m}^{3}$ averaging standard was consumed using modeling methods in this thesis. 
Modeled values from this study did not exceed the provisional maximum ambient air concentration if the proposed CFPP were to be constructed and operated consistent with the current West Virginia Department of Air Quality (WV DAQ) draft permit. The body of epidemiological studies used for establishing the provisional maximum ambient air concentration in this study is growing. Extensive bodies of research coupled with public concern could conceivably lead to stricter in air quality standards (National Ambient Air Quality Standard or NAAQS, PSD increment standards). The modeled worst case exposure also shows very little deterioration in ambient $\mathrm{SO}_{2}$ air quality. However, this value marginally represents the expected PSD increment consumption and is discussed under the following discussion of limitations section. In the past, PSD modeled values of this incremental consumption, within this air quality region, have been conducted by other entities. Modeling values vary, as discussed in the following section.

Even though modeled concentration values fell below the provisional maximum ambient air concentration and estimated PSD increment consumption was extremely low, using this modeling technique, a directional influence to contribution of the 5 highest days modeled for the year 2000 was discovered. Directional changes in modeled $\mathrm{SO}_{2}$ concentration contributions, can be viewed in the results presented in Results, chapter 4. The contour concentration maps for these five highest contribution days show the majority of the highest $\mathrm{SO}_{2}$ concentration contribution dispersing towards a north-north-east or south-south-west (toward Greater Morgantown)direction. Directional influence may be attributed to the vector wind directional velocity per day modeled. The $\mathrm{SO}_{2}$ contribution modeling results indicate Point Marion (Fayette Co., PA) and Suncrest (Monongalia Co., WV) as being the most vulnerable populated places. Point Marion was the highest populated place concentration, for 3 out of the 5 (at $60 \%$ ) highest days modeled. Suncrest, a 
subdivision of Morgantown, WV, was the highest populated place concentration, for 2 out of the 5 (at $40 \%$ ) highest days modeled.

Point Marion and Suncrest share concentration contour intervals with other populated places modeled. Other populated places, neighboring either of the two locations, have high concentrations modeled as well. Overall, it was determined that those exposed, closest to the stack, under worst case scenario, are more exposed to higher $\mathrm{SO}_{2}$ contributions from the proposed CFPP. Sensitive receptor populations farther away, although exposed, were modeled as being less exposed than those closer to the stack.

As discussed in chapter 2, inhalation is the primary route of $\mathrm{SO}_{2}$ exposure. Susceptibility of sensitive populations to $\mathrm{SO}_{2}$, within the modeled exposed locations above is also likely to be influenced by genetic make-up, age, health and nutritional status, as well as the potential for exposure to other toxic pollutants. ${ }^{71}$ Elderly adults with preexisting respiratory and cardiovascular conditions appear to be more susceptible to increased respiratory illness following $\mathrm{SO}_{2}$ exposure than elderly populations lacking such conditions. The young appear to be more susceptible during the structural developing and maturing stages of their organ structure and functions. ${ }^{71}$ The young also breathe more air per body weight than adults and exercise more, leading to an increased potential for $\mathrm{SO}_{2}$ inhalation exposure.

Out of all the concerned sensitive populations addressed in this study, exercising mild asthmatics are recognized as the most sensitive receptor of humans to $\mathrm{SO}_{2}$ exposure. A human volunteer study of asthmatics exhibited the lowest threshold for bronchconstriction, which is the basis for the current ATSDR toxicological profile for $\mathrm{SO}_{2}$ recommended Minimum Risk Level (MRL) of $260 \mu \mathrm{g} / \mathrm{m}^{3}$. That MRL concentration is the lower provisional maximum ambient 
concentration recommended in this thesis. ${ }^{71}$ This research is further supported by the finding of doseresponse among such volunteers.

Beginning before birth and up through childhood, pre-teen, and teenage years, the human body goes through different developmental stages of structure and function. Susceptibility to $\mathrm{SO}_{2}$ and other xenobiotics may vary with developmental stage. ${ }^{71}$ Xenobiotics are foreign chemicals that can cause changes, often adverse, in biological systems. Children often display pharmacokinetics and metabolism different from adults. For example, enzymes that have the ability to activate a parent compound to its toxic form may only be present during certain developmental stages. ${ }^{71}$ One enzyme may be important: sulfite oxidase. On exposure of $\mathrm{SO}_{2}$ gas to the moist nasal mucosa, $\mathrm{SO}_{2}$ is converted to a mixture of sulfite, bisulfite and hydrogen ions. Sulfites are then oxidized to sulfates by sulfite oxidase. Rats show differences in sulfite oxidase activity with age. ${ }^{71}$ Sulfite oxidase activity, lower than that of the adult, may cause increased susceptibility to oxidative damage due to an increased presence of the sulfur trioxide radical intermediate. In animals, the lower the sulfite oxidase activity, the greater the susceptibility to mortality from introtracheally introduced bisulfite. ${ }^{71}$ Other examples include a more permeable immature blood-brain barrier and different excretion rates in the infant. Also, the newborn has a lower glomenular filtration rate than adults and has not developed efficient tubular secretion and resorption rates. ${ }^{71}$

The most important characteristic of children, making them more susceptible to $\mathrm{SO}_{2}$ exposure may be their more active lifestyles. Children exercise more frequently, increasing their breathing rate, enhancing their potential for increased $\mathrm{SO}_{2}$ exposure. However, this may be counterbalanced by less developed alveoli in infants resulting in a proportionally smaller gas exchange surface area per body weight from adults. Urban and industrialized area air levels tend to 
have higher $\mathrm{SO}_{2}$ levels. Non-Caucasian US populations have higher asthma mortality that

Caucasians. Prevalance of asthma in the US is highest in African American children of ages 8 to 11. Increased $\mathrm{SO}_{2}$ susceptibility is therefore expected in urban asthmatic minority children. ${ }^{71}$

In summary, children are different in behaviors, biological growth and maturity, making them more susceptible to increased inhalation exposure to $\mathrm{SO}_{2}$ than adults. Epidemiological studies show that the associated impacts of increased levels of $\mathrm{SO}_{2}$ in adults and the elderly appear to be due to pre-existing medical conditions, such as COPD. Regardless of the potential threshold concentration for a particular sensitive population's susceptibilities to $\mathrm{SO}_{2}$, the modeled $\mathrm{SO}_{2}$ concentration contribution from the proposed CFPP does show a potential for increased exposure at a range of sensitive receptor locations.

\subsection{Discussion of Limitations}

This section briefly addresses the limitations with the methods used to identify any $\mathrm{SO}_{2}$ contribution exposure, as a potential public and environmental health threat from the proposed CFPP. First the limitations of using GIS applications and data use will be addressed. Secondly, I will discuss limitations of the methods used to model worst case $\mathrm{SO}_{2}$ concentrations. Air dispersion modeling calculations, and geostatistical kriging methods used to map calculated concentration contribution surface contours, are reasonable yet somewhat limited estimates.

\subsubsection{Categorized Sensitive Receptor Location Identification}

The results of any GIS application is as accurate as the spatial data acquired, manipulated, and layered to produce desired visual images. It is important to acquire GIS data from reliable sources, reviewing the associated metadata provided upon receiving the data. Metadata may be 
referred to as background data on the data, validating its credibility. For example, good metadata will include the year assembled, from what sources, and who assembled it. Sources for all the GIS data used in this thesis are listed in Appendix A. All metadata for the GIS data used, were reviewed for use in this thesis.

Sensitive receptor density information, zip code area, and land cover used in the GIS spatial analysis are dynamic. Data such as this can change over time with population growth Ideally, having all the sampled spatial and population data for the same year would improve the accuracy of spatial analysis; however that is not always feasible. Where feasible, all data were within, or close to as possible to, the year 2000. This provided an optimally realistic insight into actual conditions for that year. The two sets of spatial analysis data farthest from 2000 were use of 1990 land cover data and 2003 Yellowpages.com. 1990 land cover was the United States Geological Survey’s (USGS) latest land cover data on the proposed study area available at the time of analysis. Information provided by Yellopages.com on each sensitive receptor category evaluated could be an under - or over estimation. Identification and location of some sensitive receptor facilities from Yellowpages.com may or may not be accurate today. I do not have any data indicating the frequency with which Yellowpages.com updates their listings. For example, search returns on categorized sensitive receptor facilities constructed since 2000 , or renovated for other uses, may not be accurately represented by Yellowpages.com listing. For example, the Madison Nursing Home building in Morgantown, WV, was transformed into a West Virginia University (WVU) dormitory since 2000.

The annular incremental distance to stack calculation maps, also, does not consider topology. That is the maps depict straight line distances from the source stack to populated places containing sensitive receptors, without considering the rolling hills to the west and higher mountains to the 
east.. As a result, some distortion between the actual real world straight line distance to the source stack and calculated distances, may exist. However, this type of distance calculation was chosen due to the height of the source stack being very high compared to surrounding elevations and populated places containing one or more of the sensitive receptors. It was assumed that the proposed height of the source stack would disperse $\mathrm{SO}_{2}$ concentrations more or less in a straight line.

\subsubsection{Modeled Worst Case $\mathrm{SO}_{2}$ Exposure}

Modeling is, by nature, an intentional simplification of actual conditions. The size and scope of a particular model, data use, terrain, among numerous other factors, all contribute complex variables difficult to model using current scientific knowledge and technology. So modeled results are reasonable quantitative estimates of reality. I elected, in this case, to model the likely worst case scenario for contributions to regional $\mathrm{SO}_{2}$ population exposure.

The procedure of adding worst case background monitored concentrations to modeled worst case contribution concentrations from the proposed CFPP, evaluating levels possibly exceeding a provisional maximum ambient air concentration as well as to estimate a PSD consumption, has limitations. To date, the body of epidemiological research on the health effects of $\mathrm{SO}_{2}$ have not been used to establish a more permanent toxicity level. The PSD incremental consumption predicted using the methods of this thesis differ greatly from other modeled results. The Gaussian dispersion theory used in the air dispersion modeling software has limited validity, when modeling under low wind speed conditions or within areas with drastically changing weather conditions occurring over short distances. Also, the quality of the weather data used in the air dispersion model per averaging time period, also contains technical limitations. Surface weather data is collected hourly across the year. Upper air data, tending to change less, is usually measured twice a day. Further, the three $\mathrm{SO}_{2}$ 
monitoring sites active in 2000 in Morgantown, WV, were at different elevations. Among these three measurements, the highest monitored 24 - hour average value was used. We would have expected this highest value to occur at the lowest elevation monitor at Knapp Hall, in the Monongahela River Valley, but the highest value actually occurred at the WVU Law School, on a small mountain ridge, 45 meters higher. Also, stack parameters used in these models may be changed at direction of WV DAQ, US Environmental Protection Agency (EPA), or the US Falderal Aviation Administration (US FAA), requiring these model contribution calculations to be redone. All these situations are addressed in detail in the following section.

\subsubsection{Modeled Provisional Maximum Ambient Air Concentration and PSD}

\section{Consumption Limitations}

There are only four $\mathrm{SO}_{2}$ monitoring sites located throughout the study area. Three in Monongalia county, West Virginia, and the other in Greene county, Pennsylvania. All three monitoring sites in Monongalia county are within the Greater Morgantown area. Two are located at roughly 305 meters (1000 feet) elevation above sea level, while the other is located within the Monongahela River valley at roughly 260 meters ( 850 feet) elevation. Out of the four monitoring sites, the highest recorded 24 hour average $\mathrm{SO}_{2}$ concentration, added together with modeled concentration contributions, was used to simulate worst case conditions. A ratio of 1:1145, single monitored concentration point to 1145 calculated concentration points was used in this procedure. The quantity of one monitoring point value to 1145 calculated contribution concentrations is quite a disproportion. Modeled concentration calculations from the proposed CFPP, far exceed those observations made at one monitoring site, here interpreted to represent all $\mathrm{SO}_{2}$ contribution from other (existing) sources. 
The highest annual 24 - hour average concentration monitored was $0.747 \mu \mathrm{g} / \mathrm{m}^{3}$. The second highest, in the valley, at WVU Knapp Hall was $0.723 \mu \mathrm{g} / \mathrm{m}^{3}$, slightly lower, and would give results close to my analysis based on the first highest. Third through fifth highest concentrations for that year were not available for monitored results.

The considerable gap between the much lower highest monitored concentration value and the modeled concentration contribution estimates may account for the value being below the provisional maximum ambient air concentration. A single monitored ambient background concentration point, used to represent existing $\mathrm{SO}_{2}$ concentrations extending across the study area, does not accurately represent ambient $\mathrm{SO}_{2}$ concentrations across the entire region. Ambient background concentrations of pollutants, at any particular time, fluctuate across changing land mass. Existing ambient concentrations could have been higher or lower, at different locations throughout the study area, than the concentration recorded at one monitoring station.

The same inadequate representation of existing $\mathrm{SO}_{2}$ monitored background concentrations may be attributed to low PSD incremental consumption results. Other $\mathrm{SO}_{2} \mathrm{PSD}$ incremental consumption modeling, by the WV DAQ, conducted on both this proposed CFPP, and the last CFPP addition (Beechurst Power Plant), to this region's air quality, included modeling worst case $\mathrm{SO}_{2}$ concentration contributions from all contributing CFPP and other industrial sources. Highest monitored ambient background concentrations were not used to interpret the results of such modeling. The WV DAQ method will more accurately estimate the cumulative worst case ambient level and PSD consumption due to a variety of sources, each modeled at worst case conditions. However, my results are probably closer to the actual exposure to be expected if the proposed CFPP goes into operation (looking at worst case contribution for only one source) 
The WV DAQ is currently responsible for modeling PSD incremental consumption. There is a large difference between PSD modeling results, conducted in 1988, prior to the construction of the Beechurst Power Station, to that conducted in 2003 for the construction of the new proposed CFPP. Modeling by the WV DAQ, or what was referred to then as the West Virginia Air Pollution Control Commission prior to issuing the permit for construction of the Beechurst Power Plant, showed an incremental consumption of $90.5 \mu \mathrm{g} / \mathrm{m}^{3}$ (i.e., a, or almost complete consumption at $99.5 \%$ of the allotted $91 \mu \mathrm{g} / \mathrm{m}^{3}$ PSD standard in a 24 hour averaging period). See Figure 32. Today, WV DAQ is modeling the same PSD standard consumption for all existing sources, plus the proposed CFPP, at $15.5 \mu \mathrm{g} / \mathrm{m}^{3}(17 \%)$. See Figure 33. These are not comparable estimates for what might otherwise be expected. PSD consumption values are fluid, meaning they change annually, although the $\mathrm{PSD}_{2}$ standard of $91 \mu \mathrm{g} / \mathrm{m}^{3}$ for this air quality region remains unchanged. The differences between the two modeled values, although beyond the scope of this thesis, may be attributed to advancements in modeling and emission control technology or changes in regional air polluting source emission contributions, for example due to source plant closures. 


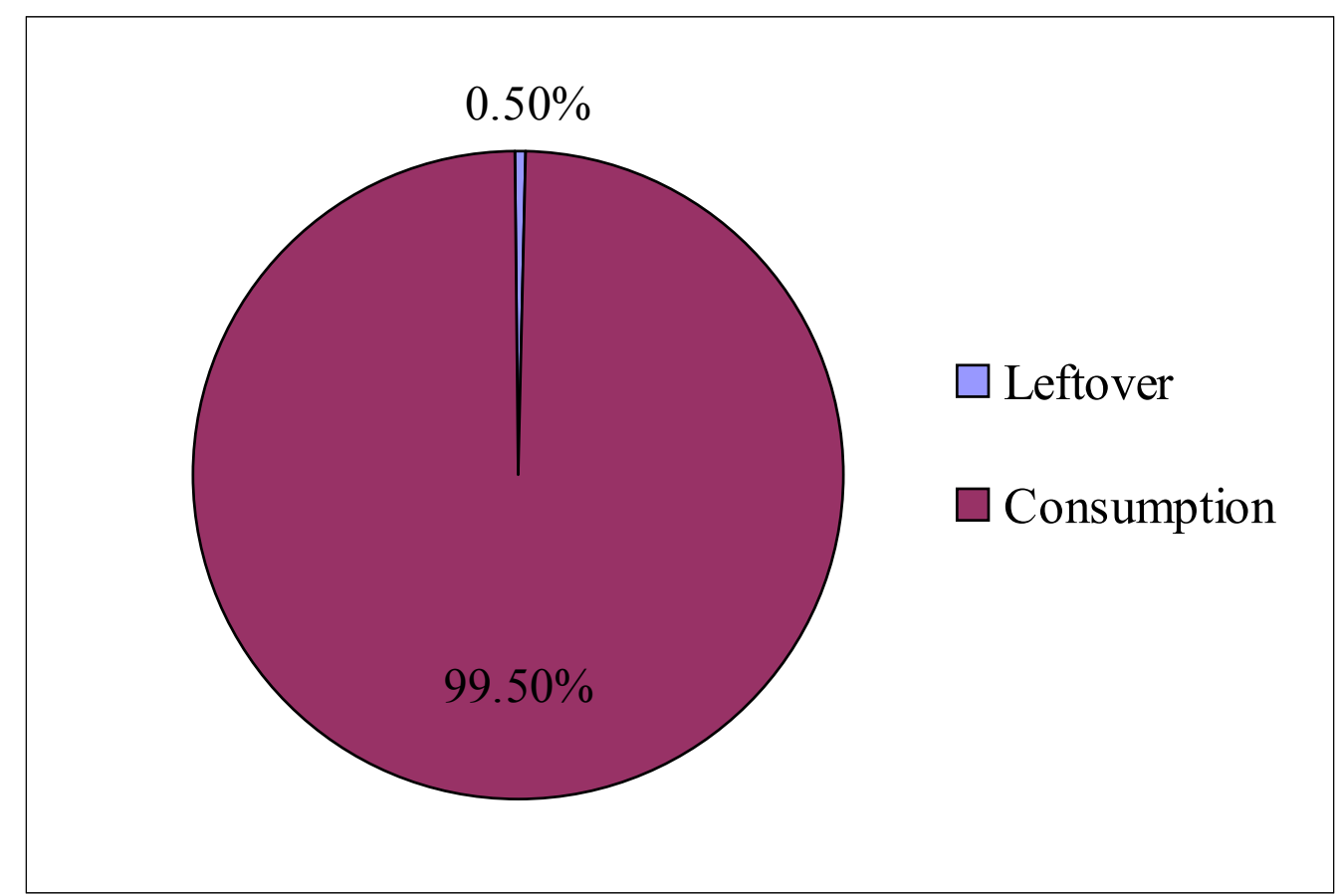

Figure 32 : Modeled increment consumption of prevention of significant deterioration (PSD), $91 \mu \mathrm{g} / \mathrm{m}^{3} 24$ hour averaging standard by West Virginia Air Pollution Control Commission prior to issuing the permit for construction of the Beechurst Power Plant in 1988. Model results, then, showed an incremental consumption of $90.5 \mu \mathrm{g} / \mathrm{m}^{3}$. This was almost complete consumption at $99.5 \%$ of the allotted $91 \mu \mathrm{g} / \mathrm{m}^{3}$ PSD standard in a 24 hour averaging period. 


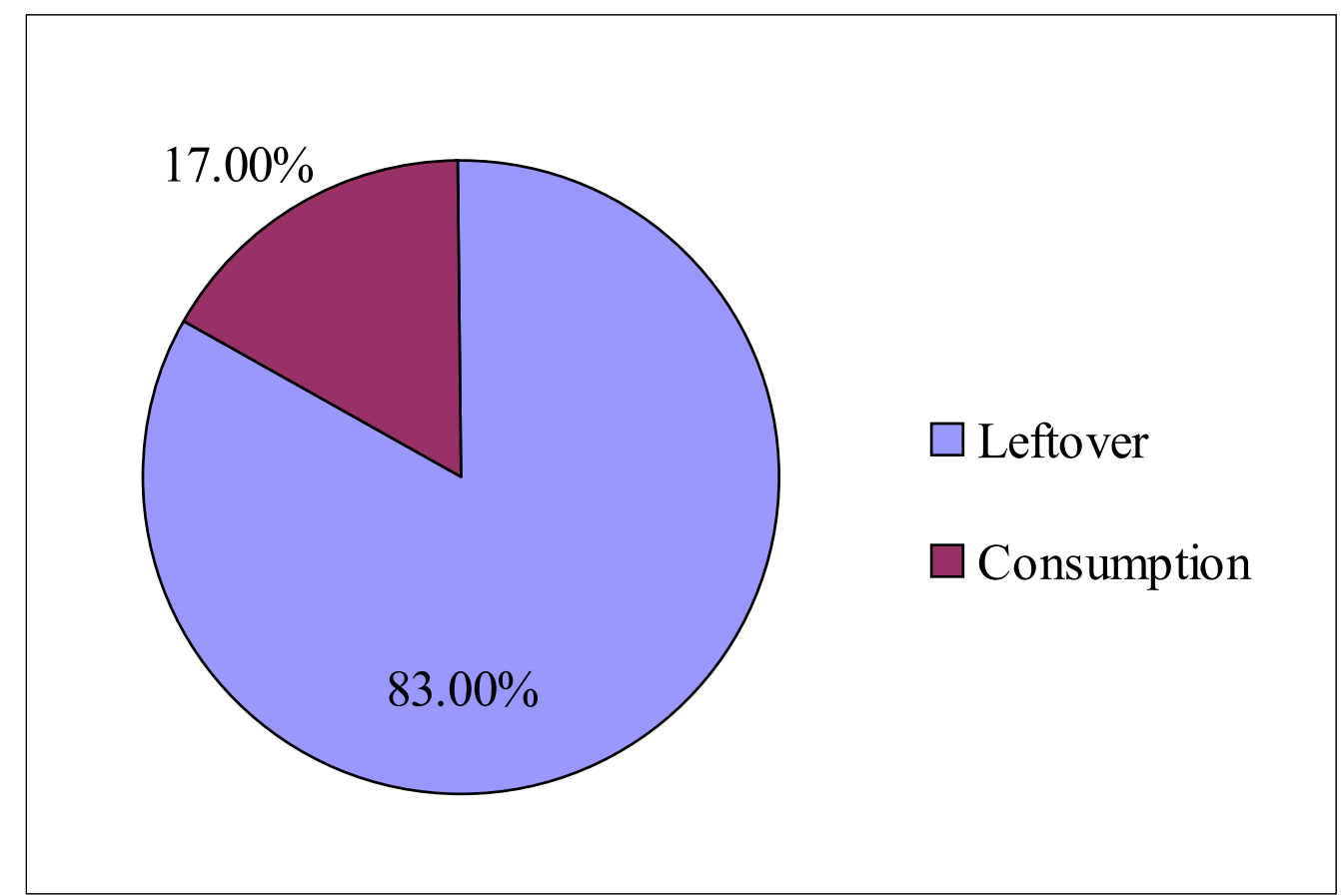

Figure 33: Modeled increment consumption of prevention of significant deterioration (PSD), $91 \mu \mathrm{g} / \mathrm{m}^{3} 24$ hour averaging standard by West Virginia Department of Air Quality prior to issuing the permit for construction of the proposed CFPP in 2003. The $91 \mu \mathrm{g} / \mathrm{m}^{3}$ PSD standard in a 24 hour averaging period was modeled by WV DAQ at $15.5 \mu \mathrm{g} / \mathrm{m}^{3}$, or $17 \%$ consumption.

\subsubsection{Gaussian Distribution Equation Limitations}

The Gaussian distribution equation relies on a "steady state" assumption and relatively higher wind speeds for accuracy in plume concentration calculations. The steady state assumption assumes that meteorology conditions (temperature profile and wind speed) between source emission and down wind receptor are spatially uniform and do not change. This is quite opposite of what is usually observed in nature. Also the Gaussian distribution equation can breakdown during low wind speed, or calm conditions, due to the inverse relationship between calculated ambient concentration and wind speed. ${ }^{31,63}$ Figure 34, shows the relationship of concentration predictions calculated over a range of common wind speeds. The lower the wind speed, the greater the concentration rapidly 
increases towards infinity, so that the results of calculated plume concentrations are no longer valid.

Such limitations prevent the Gaussian distribution equation from modeling concentrations during atmospheric stagnation episodes or that of radiation inversions, conditions proven to induce dangerously high levels of ambient air pollution concentrations.

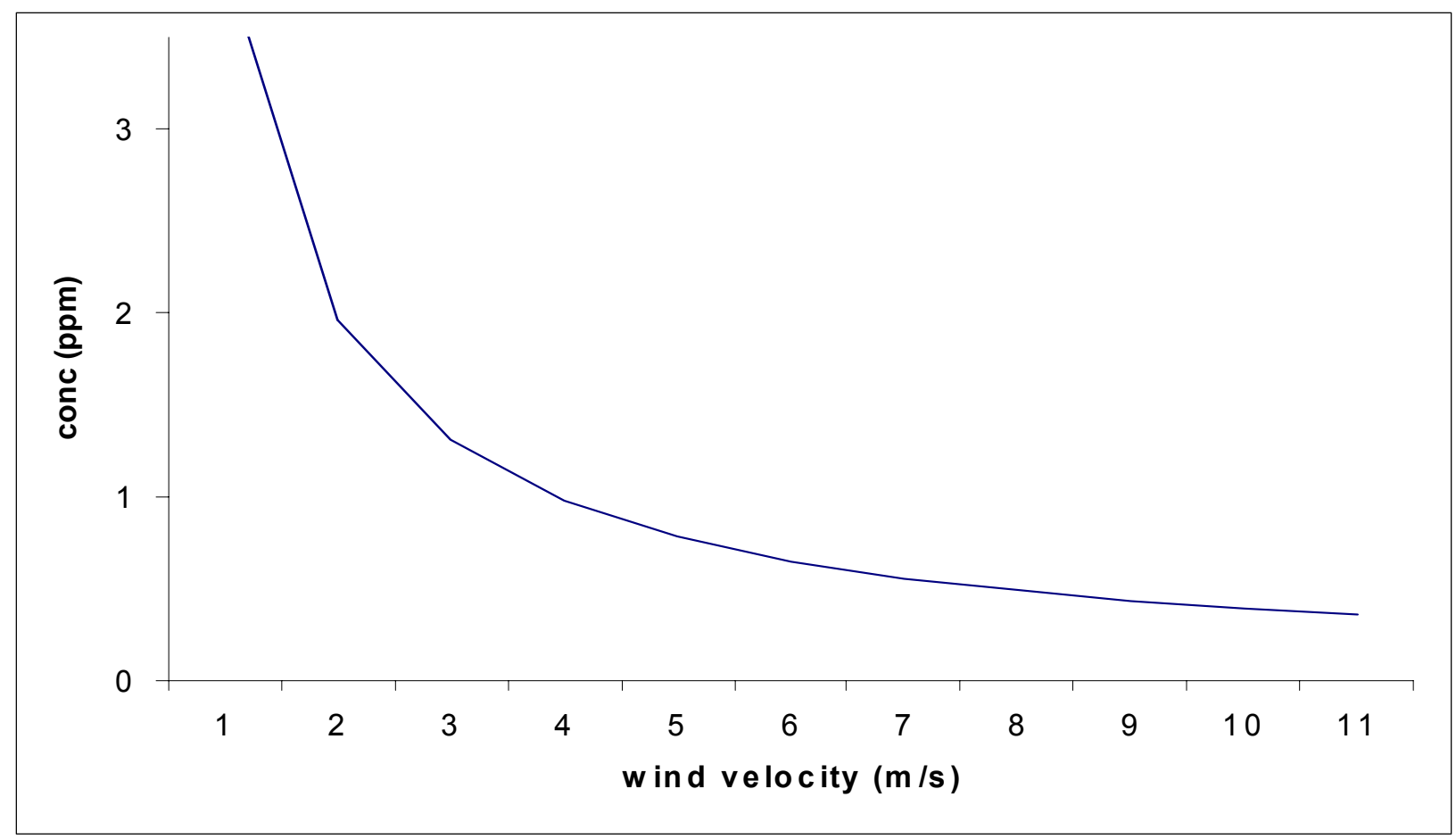

Figure 34: Inverse relationship between wind speed and $\mathrm{SO}_{2}$ calculated concentrations. Shows the relationship of concentration predictions calculated over a range of common wind speeds. The lower the wind speed, the greater the concentration rapidly increases towards infinity, making the results of calculated plume concentrations no longer valid. Concentrations approach unrealistic values.

Out of the 8784 hours of wind data recorded for the year 2000, 3350 were calm hours. That suggests that $38 \%$ of the year could not be modeled using the Gaussian distribution type model applied in this thesis. 


\subsubsection{Potential Stack Parameter Limitations}

Depending on the outcome of the proposed CFPP's PSD permit application, for emission of $\mathrm{SO}_{2}$ and other criteria pollutants, the proposed stack parameters (Table 3.1, page 41) may have to be altered to meet the West Virginia State Implementation Plan (SIP) monitoring and Environmental Protection Agency (EPA) requirements. Any alteration in stack parameters would directly effect the modeled results of this study. Alterations to stack parameters required by the SIP or any other federal agency may alter air dispersion modeled results, as well. For example, the proposed stack height may be a potential obstruction to air traffic, as designated by the Federal Aviation Administration (FAA). If this turns out to be the case, stack height may have to be decreased, altering this thesis model results as well as that of WV DAQ. Any future changes to stack parameters will limit current model results.

\subsubsection{Kriging Interpolation Limitations}

As a reminder, the simpler contour map created by the dispersion model uses inverse distance weighted for plume concentration contour mapping. Inverse distance means that interpolated concentrations of only the nearest data points are used to interpolate. Kriging is a more powerful process which takes into account all 1145 calculated concentration points to interpolate between calculated point concentrations which is, therefore, more accurate. Kriging predicts concentrations beyond the $30 \mathrm{~km}$ radius, but I cannot definded its spatial extrapolations beyond the study area, because I have no modeled concentrations to compare to the kriged extrapolations beyond the study area of $30 \mathrm{~km}$ radius. 


\section{Chapter 6 - Conclusions}

Historically, the air quality resulting from existing coal fired power plant (CFPP) emissions and the addition of new regional CFPP have been debated within Northern West Virginia. There are potential environmental and public health consequences associated with inhalation of sulfur dioxide $\left(\mathrm{SO}_{2}\right)$ from CFPP emissions. The proposed study area is steadily growing in economic activity and population. As such, it may be facing the need for serious pollution abatement. If pollution becomes too great, industrial economic growth could be forced to stop, due to enforcement of abatement regulations. Conclusion 1: A decision as to what type of economic growth would be best may be needed by the surrounding communities.

A growing economy and population surely has its positive outcomes; however, it may have negative impacts as well. Residents of this part of West Virginia, and potentially impacted border states, have a right to know the dangers associated with increased CFPP emissions and whether these are likely to affect local health. In this thesis, a sample of the literature on the possible public and environmental health threats associated with increased levels of $\mathrm{SO}_{2}$ exposure was reviewed. Conclusion 2: This study's modeling results show that the establishment of the proposed new CFPP within the region would have an insignificant impact on ambient $\mathrm{SO}_{2}$ concentrations. Conclusions on the possible public and environmental health threats associated with increased levels of other National Ambient Air Quality Standards (NAAQS) criteria pollutants were not reviewed in this study. However, the same methods used to model $\mathrm{SO}_{2}$ exposure in this study area may very well be used to individually model for ambient exposure to each of the NAAQS criteria pollutants.

By comparing Geographic Information Systems (GIS) spatial analysis to the air dispersion models produced using American Meteorological Society/Environmental Protection Agency 
Regulatory Model (AERMOD), a series of maps were developed showing the spatial relationship of categorized sensitive receptors to the downwind dispersion of the pollutant concentrations from the proposed stack. This information could be used by the state to make important public and environmental health decisions. Use of such maps can give authorities an idea of the public health threats associated with $\mathrm{SO}_{2}$ pollution in northern West Virginia and southwestern Pennsylvania, particularly in the urban area of greater Morgantown, which has recently been reclassified as a metropolitan area. Conclusion 3: Maps of sensitive (SR) spatial density together with modeled pollutant concentrations at SR are useful tools for public health and air quality decision making.

Furthermore, the results from modeling the dispersion of this criteria pollutant can be used to modify state air monitoring systems. Such modifications might include relocating the air monitoring systems in order to increase monitoring efficiency: to increase the number of pollutants monitored per station; to increase monitoring of more industrial, higher traffic areas; or to increase the number of air monitoring sites, in order to better measure compliance with air quality standards. Monitoring various criteria pollutants has been ongoing, and should continue throughout the study area. Future modeling of all the air polluting sources, in addition to that conducted by the state government, would be beneficial and could serve as reason to upgrade the ambient monitoring of all air pollution sources within the region. Conclusion 4: Regional compliance air monitoring could be expanded. Conclusion 5: Dispersion modeling can help decision making in upgrading monitoring systems.

This thesis demonstrates the spatial density of communities containing a sample of SR and modeled the worst case concentration contribution of $\mathrm{SO}_{2}$ to the ambient $\mathrm{SO}_{2}$ concentration within a 30 kilometer radius from the proposed stack. A kriged continuous concentration surface interpolation of this proposed CFPP $\mathrm{SO}_{2}$ contributions was developed for the 5 worst case 
distributions days in 2000. Conclusion 6: Based on a review of a sample of key epidemiologic studies and reviews, it is concluded that the primary 24 hour averaging NAAQS for $\mathrm{SO}_{2}$ should be lowered, in order to protect the SR in exposed populations, from $365 \mu \mathrm{g} / \mathrm{m}^{3}$ to $260 \mu \mathrm{g} / \mathrm{m}^{3}$. 


\section{Chapter 7 - Recommendations}

The complexity of modeling air pollution concentrations within the atmosphere has been discussed in this study. Complex meteorological conditions, different types of pollutant behavior in the atmosphere, and all other variables effecting pollutant concentration are not easily modeled given current levels of atmospheric science and technology and modeler(s) labor intensity. For this reason only one pollutant was chosen for modeling the addition of a proposed coal fired power plant (CFPP) to existing concentrations within the vicinity of Greater Morgantown, WV. There is a need for a clearer picture of regional meteorology that can affect air quality.

Results of this study can open the door to further air quality research within the Greater Morgantown area. Research beyond air dispersion modeling is certainly warranted. Current National Ambient Air Quality Standards (NAAQS), as well as other air quality standards, rely on research beyond that conducted in this thesis for promulgating current standards. Potential research areas include a better understanding of local micro-meteorological conditions, increased ambient air pollution monitoring or other sources of air pollution such as traffic, and local epidemiological studies on the health effects of existing concentrations of air pollution. Such information may subsequently lead to changes in air quality standards, which will improve air quality in the region. This chapter briefly addresses some of these potential research topics. Recommendation 1: Further research is warranted.

It is recommended that a provisional safe standard for sensitive receptors be established. Primary NAAQS are intended to protect public health, however epidemiological studies reveal $\mathrm{SO}_{2}$ standards are too high for protecting individuals most susceptible to air pollution. Currently, the primary $\mathrm{SO}_{2}$ NAAQS for a 24 hour averaging period is $365 \mu \mathrm{g} / \mathrm{m}^{3}$. The provisional maximum 
ambient $\mathrm{SO}_{2}$ concentration in this study, based on the Agency of Toxic Substances and Disease Registry (ATSDR), establishes a minimum risk level for $\mathrm{SO}_{2}$, at $260 \mu \mathrm{g} / \mathrm{m}^{3}$. Changes in lung function have been noticed in asthmatics at this concentration, which is $105 \mu \mathrm{g} / \mathrm{m}^{3}$ less than the current 24 hour averaging NAAQS for $\mathrm{SO}_{2}$. ATSDR establishes minimum risk levels of toxicity for various substances, reviewing substantial epidemiological studies that have been conducted on that particular substance. Established minimum toxicity levels are based on significant bodies of epidemiological research. A comparison between other primary NAAQS pollutants and their associated established minimum risk levels of toxicity by ATSDR for each pollutant is certainly justifiable. Recommendation 2: The primary 24 hour NAAQS for $\mathrm{SO}_{2}$. should be lowered to 260 $\mu \mathrm{g} / \mathrm{m}^{3}$.

Another important criteria pollutant of concern is particulate matter (PM). Given the current traffic conditions, existing regional CFPP, other industry, and local weather patterns, a strong need for researching potential PM exposure is suggested. In West Virginia the population in the northern part of the state has been growing due to steady growth of new businesses, university facilities and government research facilities. This is particularly true within Monongalia County, which contains Morgantown. The area is mountainous, limiting appropriate sites for roadways. As a result, traffic congestion has become a big problem. Pollution concentrations, mainly ambient particulate matter resulting from this traffic congestion, are likely to be a cause for concern. Further, with the steady area growth in population, Monongalia County and the surrounding region has seen an increasing demand for electric power. Consequently, the electric generating capacity has also had to keep expanding to meet rising demands. This area is within one of the primary coal-producing areas of the U.S., so naturally all nearby electric power plants are fueled by coal. Coal combustion for power 
generation is a major source of PM. Monitoring and modeling should be conducted not only of $\mathrm{PM}_{10}$ but also on $\mathrm{PM}_{2.5}$, which studies have shown is responsible for most of the health effects from inhalation of PM. ${ }^{41}$ Recommendation 3: NAAQS for other criteria pollutants should be reviewed again and perhaps revised to reflect research since they promulgated, particularly for PM, to include $\mathrm{PM}_{2.5}$.

CFPP are known to produce higher amounts of air pollutants than other forms of electric generation. There are 4 ambient air quality monitors, previously addressed in greater detail in chapter 5 , established throughout this thesis study area. These monitors have been strategically placed to monitor for NAAQS compliance. The ability of these monitors to adequately monitor for ambient concentrations accurately remains inconclusive. Given the current population growth and traffic density, the number of monitors, as well as their locations, may need to be reevaluated. To do so, all regional and distant air pollution sources need to be evaluated in great detail. Also, since air quality monitors lack the ability to distinguish between air pollution sources, increasing the number of monitors used, strategically located across ridge tops and valley floors, a more accurate insight as to the most significant polluters may be provided. Recommendation 4: Local monitoring for criteria pollutant ambient concentrations should be expanded to include more valley floor sites, particularly along inhabited areas containing congested traffic corridors.

In order to obtain more accurate insight, an increase in monitoring local micrometeorological conditions within the river valley is needed. With the growing population, increasing traffic density, numerous CFPP and other industry, there is a need for greater understanding on the effects of regional nocturnal radiation inversion frequency (see chapter 2) within the Monongahela River Valley. Currently, stagnation periods, or slow moving high pressure systems, gives some 
insight as to the frequency of potential air pollution episodes. However, these stagnation maps are large scale, constituting areas within West Virginia and surrounding states. As discussed in chapter 2 , local weather conditions are often different and change more frequently on smaller scales. Before that of large scale weather conditions, local weather conditions effect the immediate dispersion of air pollution.

National Weather Service (NWS) hourly temperature and wind speed data are also available, however at altitudes above the valley. Hourly temperature and wind speed within the Monongahela River Valley, often theoretically different than that on the valley ridge tops, are currently not being monitored by NWS. Collecting hourly temperature and wind speed data both within the valley and at valley ridge tops is recommended, in order to provide frequency of nocturnal radiation inversions within the river valley.

Valley inversion data could be used to produce maps for analyzing frequency and strength of air pollution episodes in conjunction with stagnation maps. The effects of nocturnal radiation inversions on the dispersion of air pollution have been recognized since the 1950's. Air pollution concentrations could be exceeding susceptible public health levels and established air quality standards within major industrial and urban areas located in river valleys across the United States. This thesis work suggests that a determination of public health impacts and air quality standards compliance within this type of topology would improve by introducing considerably more valley weather data, as well as using methods similar to those used in this study but modeling on a much smaller geographic scale. Recommendation 5: Ongoing local surface meteorological monitoring should be expanded to be more representative of industrial and traffic corridor areas in valley floors. 
Modeling the impact of a new regional CFPP only addresses a portion of the current air quality situation within Northern West Virginia. Local government and development authorities, within the study area of this thesis, are currently pushing economic growth that could result in significant impacts to public health and compliance with air quality standards. Air quality does not necessarily have to be sacrificed for economic growth. A broad-based community decision is needed as to the type and rate of economic growth desired within the surrounding region. Current rates of growth are straining local transportation infrastructure and possibly increasing the need for more electricity. In order to truly understand the effects of air pollution on public health and possibly promulgate more protective air quality standards, the body of air quality research needs to expand. Recommendation 6: Development of a mechanism to meaningfully involve the public is recommended in regional planning and in defining the degree and type of growth that is optimal for the region, including the issuance of commercial permits. 


\section{References}

1. Abramson, M, T Voigt. "Ambient air pollution and respiratory disease." The Medical Journal of Australia: v.154. August 1991. pp. 543-553.

2. American Lung Association: State of the Air 2002. http://www.lungusa.org/air2001/download/SOTA02_westvirginia5.pdf. Retrieved Nov. 12, 2002.

3. Bernhardsen, T. "Geographic Information Systems: An Introduction, 3nd Edition." John Wiley and Sons, Inc. 2002.

4. Blue Ridge Environmental Defense League. Roanoke Air Quality. http://www.bredl.org/transportation/I-73_comments/I-73airimpacts.htm. Retrieved May 15, 2003.

5. Boettner, J. Masters Thesis-Environmental Justice Through Pollution Prevetion: Development of a Quantitative Method to Assess Community Vulnerability and Air Emission Hazard for Optimal Impact. West Virginia University Electronic Thesis and Dissertation. http://www.wvu.edu/ thesis/. Retrieved May 13, 2003.

6. Breeze ISC and AERMOD User's Guide,Version 3.5. Trinity Consultants, 1991-2001.

7. Breeze AERMOD/ISC Pro Factsheet. Trinity Consultants, 1991-2003.

8. Burrough, P, R McDonnell. "Principles of Geographical Information Systems.” Oxford University Press. 1999.

9.CFR Title 40 Part 51.66. Protection of the Environment, Requirements for the Preparation, Adoption, and Submittal of Implementation Plans, Prevention of significant deterioration of air quality.

10. Cicero-Fernandez, P., V Torres and A Rosales, H Cesar and K Dorland, R Munoz and R Uribe, AP Martinez. "Evaluation of Human Exposure to Ambient PM10 in the Metropolitan Area of Mexico City Using GIS-Based Methodology." Journal of the AWMA: v.51. Nov. 2001. pp. 1586 - 1593.

11. Dickey, JH. "No Room to Breathe: Health Effects of Criteria Air Pollutants from Power Plants." Greater Boston Physician of Social Responsibility. 1999. http://psr.igc.org/nrtb-project.htm Retrieved Nov. 12, 2002.

12. Gauderman, WJ, GF Gilliland, H Vora, E Avol, D Stram, R McConnell, D Thomas, FLurmann, HG Margolis, EB Rappaport, K Berhane, JM Peters. "Association between air pollution and 
lung function growth in southern California children: Results from a second cohort.” American Journal of Respiratory and Critical Care Medicine: v.166, no.1. July 2002. pp. 76 84.

13. Glover, L. "Donora's Killer Smog Noted at 50." Tribune Review. October 25, 1998.

14. Godish, T. Air Quality - Second Edition. Lewis Publishers. 1991.

15. Gold DR, A Litonjua, J Schwartz, E Lovett, A Larson, B Nearing, G Allen, M Verrier, R Cherry, R Verrier. "Ambient pollution and heart rate variability." American Heart Association, Circulation: v.101, no.11. March 21, 2000. pp. 101 - 126.

16. Holgate, S, J Samet, H Koren, R Marynard. Air Pollution and Health. Academic Press.1999.

17. Hedley, AJ, CM Wong, TQ Thach, S Ma, TH Lam, HR Anderson. "Cardiorespiratory and all-cause mortality after restrictions on sulphur content of fuel in Hong Kong:an intervention study.” Lancet: v.60,no.9346. November 23, 2003. pp. 1646 - 1652.

19. Jacobson, MZ. Atmospheric Pollution: History, Science, and Regulation. Cambridge University Press, 2002.

20. Jaffe, DH, ME Singer, AA Rimm. "Air pollution and emergency department visits for asthma among Ohio Medicaid recipients, 1991-1996." Environmental Health Research: v.91,no.1. January 2003. pp. 21 - 28.

21. Kiester E. “A Darkness in Donora.” Smithsonian Magazine. November 1999.

22. Kilic, D. "The effects of ageing and sulfur dioxide inhalation exposure on visual-evoked potentials, antioxidant enzyme systems, and lipid peroxidation levels of the brain and eye." Neurotoxicology Teratology: v.25,no.5. September-October 2003. pp. 587 - 598.

23. Koken, PJ, WT Piver, F Ye, A Elixhauser, LM Olsen, CJ Portier. "Temperature, air pollution, and hospitalization for cardiovascular diseases among elderly people in Denver." Environmental Health Perspectives: v.111,no.10. August 2003. pp. 1312 - 1317.

24. Lippmann, M, RB Schlesinger. "Toxicological bases for the setting of health-related air Pollution standards.” Annual Review of Public Health: v.21. 2000. pp. 309 - 333.

25. Maryland Department of the Environment, Air and Radiation Management Administration. Air Quality Data Report.

26. McCoy, J, K Johnston. Using ArcGIS Spatial Analyst. Environmental Systems Research Institute, 2001-2002. 
27. McMurry, J, R Fay. Chemistry. Prentice-Hall International. 1995.

28. Meng, Z, B Zhang, J Bai, H Geng, C Liu. "Oxidative damage of sulfur dioxide inhalation on stomachs and intestines of mice." Inhalation Toxicology: v.15,no.4. April 2003. pp. 397 410.

29. National Aeronautic and Space Administration. "Lidar Atmospheric Sensing Experiment(LASE): Measuring Water Vapor, Aerosols and Clouds." NASA Langley Research Center Office of Public Affairs. November 2003.

30. National Oceanic and Atmospheric Administration. Olympics, Salt Lake City: Factsheet.www.wrh.noaa.gov/Saltlake/olympics/fact9.htm. Retrieved May 15, 2003.

31. Nevers, N. Air Pollution Control Engineering - Second Edition. McGraw-Hill Company. 2000.

32. Norris, G, T Larson, J Koenig, C Claiborn, L Sheppard, D Finn. "Asthma aggravation, combustion, and stagnant air.” Thorax: v.55, no.6. June 2000. pp. 466 - 470.

33. Nowak, D, R Jorres, J Berger, M Claussen, H Magnussen. "Airway responsiveness to sulfur dioxide in an adult population sample." American Journal of Respiratory and Critical Care Medicine: v.156, no.4. October 1997. pp. 1151 - 1156.

34. Ormsby T, E Napoleon, R Burke, C Groessl, L Feaster. "Getting to Know ArcGIS ." ESRI Press. 2001.

35. Pasquill, F, F Smith. Atmospheric Diffusion - Third Edition: study of the dispersion of windborne material from industrial and other sources.” Ellis Horwood Limited. 1983.

36. Pearson, F. Map Projection Methods. Sigma Scientific, Inc., 1984.

37. Pennsylvania Department of Environmental Protection, Bureau of Air Quality. Air Quality Annual Report.

38. Perera, FP, SM Illman, PL Kinney, RM Whyat, EA Kelvin, P Shepard, D Evans, M Fullilove, J Ford, RL Miller, IH Meyer, VA Rauh. "The challenge of preventing Environmentally related disease in young children: community-based research in New York City." Environmental Health Perspectives: v. 110, no.2. February 2002. pp. 197 - 204.

39. Peter, R, R Adler. For Geodesists, Cartographers and Geographers: Map Projections. North-Holland Publishing Company-Amsterdam, 1972.

40. Peters, W, R Wilson, A Cimorelli, S Perry, J Weil, A Venkatram. "Comparison of Regulatory Design Concentrations: AERMOD versus ISCST3 and CTDMPLUS.” US Environmental 
Protection Agency - Office of Air Quality Planning and Standards. April 1999.

41. Pope, A. "Respiratory Disease Asscociated with Community Air Pollution and a

Steel Mill, Utah Valley." Americnan Journal of Public Health: v.79,no.2. May 1989. Pp. 623 -628 .

42. Reese, A. "Blue Skies: A High-Stakes Fight Over New Pollution Rules Threatens America's Already Toxic Air." The Environmental Magazine: v.10, no. 6. November-December 1999.

43. Rushton, G. Public Health, GIS, and Spatial Analytical Tools. Annual Review of Public Health:v.24. 2003.

44. Saron, M. Problem Report - Air Dispersion Analysis of Particulate Pollutants. West Virginia University. May 1992.

45. Schnelle, K, R Partha. Atmospheric Dispersion Modelling Compliance Guide. McGraw-Hill, 1999.

46. Schrenk, HH, H Heimann, GD Clayton, WM Gafafer, H Wexler. "Air Pollution in Donora, Pa. Epidemiology of the Unusual Smog Episode of October 1948, Preliminary Report." Public Health Bulletin: no.306. 1949.

47. Singh, V, R Khandelwal, AB Gupta. "Effect of air pollution on peak expiratory flow rate variability." Journal of Asthma: v.40,no.1. February 2003. pp. 81 - 86.

48. Snyder, W, R Thompson, R Eskridge, R Lawson, I Castro, J Lee, J Hunt, Y Ogawa. "The structure of strongly stratified flow over hills: dividing-streamline concept." Journal of Fluid Mechanics: v. 152. 1985. pp. 249 - 288.

49. Southern Appalachian Mountains Initiative. www.saminet.org. May 15, 2003.

50. Stern, AC, HC Wohlers, RW Boubel, WP Lowry. "Fundamentals of Air Pollution." Academic Press, 1973.

51. Strager, Michael. Power Point Presentation. "Intro to Geographic Information Systems." NRAC at West Virginia University. http://www.nrac.wvu.edu/. Nov. 2, 2002.

52. Sunyer, J, F Ballester, AL Tertre, R Atkinson, JG Ayres, F Forastiere, B Forsberg, JM Vonk, L Bisanti, JM Tenias, S Medina, J Schwartz, K Katsouyanni. "The association of daily sulfur dioxide air pollution levels with hospital admissions for cardiovascular diseases in Europe (The Aphea-II study)." European Heart Journal:v.24,no.8. April 2003. pp. 752 - 760.

53. Sunyer, J, R Atkinson, F Ballester, A Le Tertre, JG Ayres, F Forastiere, B Forsberg, JM Vonk, 
L Bisanti, RH Anderson, J Schwartz, K Katsouanni. "Respiratory effects of sulphur dioxide: a hierarchical multicity analysis in the APHEA 2 study." Occupational and Environmental Medicine: v.60,no.8. August 2003. e2.

54. Tunnicliffe WS, MF Hilton, RM Harrison, JG Ayres. "The effect of sulphur dioxide exposure of indices of heart rate variability in normal asthmatic adults." European Respiratory Journal: v.17,no.4. April 2001. pp. $604-608$.

55. Tunnicliffe, WS, RM Harrsion, FJ Kelly, C Dunster, JG Ayres. "The effect of sulphurous air pollutant exposures on symptoms, lung function, exhaled nitric oxide, and nasal epithelial lining fluid antioxidant concentrations in normal and asthmatic adults." Occupational and Environmental Medicine: v.60,no.11. November 2003. e15.

56. Turner, D. "Workbook of Atmospheric Dispersion Estimates." U.S. Department of Health, Education, and Welfare. 1967.

57. UAI, Environmental, Inc. Prevention of Significant Deterioration Permit Application for the Longview Power Project. West Virginia Department of Environmental Protection, Division of Air Quality. August 2002.

58. U.S. Census Bureau. Zip Code Tabulation Areas. http://www.census.gov/geo/ZCTA/zcta.html. Retrieved November, 2003.

59. US EPA: 2001 Toxic Release Inventory State Fact Sheets. http://www.epa.gov/tri/tridata/tri01/state/index.htm. Retrieved October 18, 2003.

60. US EPA: Air Quality Standards and Planning. http://www.epa.gov/oar/oaqps.htm. Retrieved Nov. 12, 2002.

61. US EPA: Geographic Information Systems and Information Resources Section. http://www.epa.gov/region4/gis/index.html. Retrieved Nov. 15, 2002.

62. US EPA: Greenbook. http://www.epa.gov/oar/oaqps/greenbk/ Retrieved January 23, 2003.

63. Weiss, A, D Schaub, P Hofer. "Modelling the spreading of air pollution with weather models." Swiss Federal Laboratories for Material Testing and Research.

64.West Virginia Department of Environmental Protection, Division of Air Quality. West Virginia Air Quality Report, 2002.

65. West Virginia GIS Technical Center. http://wvgis.wvu.edu/. Retrieved November, 2003.

66. Willis, A, M Jerrett, RT Burnett, K Krewski. "The association between sulfate air pollution and 
mortality at the county scale: an exploration of the impact of scale on a long term exposure study." Journal of Toxicology and Environmental Health Association: v.66,no.16. August 2003. pp. $1605-1624$.

67. Buzzelli, M, J Michael, R Burnett. "Saptiotemporal Perspectives on Air Pollution and Envrionemental Justice in Hamilton, Canada, 1985-1996." Analysis of the Association of American Geographers: v.93, is. 3. September 2003. pp. 557 - 573.

68. Inserra, S, B Phifer, R Pierson. "Community-based exposure estimate for hydrogen sulfide." Journal of Exposure Analysis and Environmental Epidemiology: v. 12, is. 2. March 2002. pp. $124-129$.

69. Johnston, K, J Ver Hoef, K Krivoruchko, and N Lucas. Using ArcGIS Geostatistical Analyst. Environment Systems Research Institute, 2001-2002.

70. West Virginia Air Pollution Control Commission. Regulation XIV (PSD). Preliminary Determination, Morgantown Energy Associates. Application No. 1085. 1988.

71. U.S Department of Health and Human Services, Agency for Toxic Substances and Disease Registry. Sciences International. December 1998. 
Appendix 


\section{Appendix A - GIS Data Used}

Provided Data Sets:

\begin{tabular}{|c|c|c|c|}
\hline Data Layer & Source & Scale & File Type \\
\hline 1990 County Boundaries (WV and PA) & WV GIS Technical Center and PASDA & $1: 100 \mathrm{k}$ & Shape-file \\
\hline 2000 USGS GNIS Populated Places & NRAC & $\mathrm{N} / \mathrm{A}$ & $\begin{array}{l}\text { Shape- and } \\
\text { Database- } \\
\text { file }\end{array}$ \\
\hline 2000 U. S. Zip Code Tabulation Area & US Census Bureau & $1: 100 \mathrm{k}$ & Shape-file \\
\hline 1990 U.S Land Cover & USGS National Map Viewer & $1: 50 \mathrm{k}$ & ArcInfo Grid \\
\hline
\end{tabular}

Created Data Sets:

\begin{tabular}{|c|c|c|c|}
\hline Data Layer & Source & Scale & File Type \\
\hline 1990 Study Area County Boundaries & WV GIS Technical Center and PASDA & $1: 24 \mathrm{k}$ & Shape-file \\
\hline 2000 Study Area Populated Places with Sensitive Receptors & NRAC & $1: 24 \mathrm{k}$ & $\begin{array}{l}\text { Shape- and } \\
\text { Database- } \\
\text { file }\end{array}$ \\
\hline 2000 U.S. Zip Code Tabulation Area of Study Area & US Census Bureau & $1: 50 \mathrm{k}$ & Shape-file \\
\hline 30 Kilometer Distance to Stack Calculation & Spatial Analyst Raster Calculator & $1: 24 \mathrm{k}$ & ArcInfo Grid \\
\hline Contribution Concentration Contours & Geostatistical Analyst & $1: 24 \mathrm{k}$ & $\begin{array}{c}\text { ArcInfo } \\
\text { Grid }\end{array}$ \\
\hline
\end{tabular}

*NOTE: All GIS data was projected to North American Datum 1983 UTM zone 17 for this thesis. 
The Technical Center is a division of the Department of Geology and Geography at West Virginia University that provides technical support services to support the development and operation of GIS in West Virginia. PASDA is sponsored by Pennsylvania State University, the Pennsylvania Geospatial Information Council, and the Pennsylvania Department of Environmental Protection. The Pennsylvania Geospatial Information Council, consisting of state-wide associations and nonprofit organizations, facilitate the sharing of geospatial data, cooperatively, across different agency jurisdictions.

Yellowpages.com provided the name of each category of sensitive receptor within each city/community/area, searchable per zip code area within the study area. Zip code boundaries within each county studied, were obtained from the US Census Bureau's Zipcode Tabulation Area database via their website. The community/town/city names provided by Yellowpages.com were matched with those names found in a nationwide points shapefile of cities, towns, townships, community areas, and subdivisions, provided by Michael Strager and the WV Natural Resources Analysis (WV NRAC).

Metadata are data about quality of data, including such information as where the data came from, who collected it and where. County shapefile boundaries and their respective metadata were downloaded from two WVU resource websites, the WVU NRAC, in the Davis College of Agricultural, Forestry and Consumer Sciences, from the WVU GIS Technology Center, run by the Department of Geography and Geology in the Eberley College of Arts and Sciences, and from Pennsylvania Spatial Data Access compiled by Pennsylvania State University. 
Appendix B - Complete List: Yellowpages Sensitive Receptor Category Mathched to Populated Places Table Schools, Monongalia Co. WV

\begin{tabular}{|c|c|c|c|c|c|}
\hline \multirow{2}{*}{\begin{tabular}{|l|} 
Populated Place DBF \\
Point Name \\
\end{tabular}} & \multicolumn{5}{|c|}{ Yellowpages.com Results } \\
\hline & Sensitive Receptor Name & Address & City/Town & State & Zip \\
\hline BRAEWICK WOODS & $\begin{array}{l}\text { CHRISTIAN SCHOOLS } \\
\text { INCORPORATED }\end{array}$ & 1189 PINEVIEW DR & MORGANTOWN & WV & 26505 \\
\hline HOPECRESRT & $\begin{array}{l}\text { AREA SCHOOLS } \\
\text { MONANGALIA COUNTY }\end{array}$ & 661 GREENBAG RD & MORGANTOWN & WV & 26508 \\
\hline HOPECRESRT & MORGANTOWN SCHOOL & 109 WILSON AVE & MORGANTOWN & WV & 26501 \\
\hline HOPECRESRT & MORGANTOWN SCHOOL & 263 PRAIRIE AVE & MORGANTOWN & WV & 26501 \\
\hline MORGANTOWN & MORGANTOWN SCHOOL & 475 BAIRD ST & MORGANTOWN & WV & 26505 \\
\hline MORGANTOWN & $\begin{array}{l}\text { PRESSLEY RIDGE SCHOOLS } \\
\text { OF W V MORGANTOWN SITE }\end{array}$ & $\begin{array}{l}1431 \text { UNIVERSITY } \\
\text { AVE }\end{array}$ & MORGANTOWN & WV & 26505 \\
\hline MORGANTOWN & $\begin{array}{l}\text { SCHOOLS CLAY BATTELLE } \\
\text { HIGH \& JR HIGH } \\
\text { BLACKSVILLE }\end{array}$ & 13 S HIGH ST & MORGANTOWN & WV & 26501 \\
\hline MORGANTOWN & UNIVERSITY HIGH SCHOOL & 991 PRICE ST & MORGANTOWN & WV & 26505 \\
\hline NATIONAL & $\begin{array}{l}\text { AREA SCHOOLS } \\
\text { MONANGALIA COUNTY }\end{array}$ & 1702 RIVER RD & MORGANTOWN & WV & 26501 \\
\hline NATIONAL & $\begin{array}{l}\text { AREA SCHOOLS } \\
\text { MONANGALIA COUNTY }\end{array}$ & 670 RIVER RD & MORGANTOWN & WV & 26501 \\
\hline OSAGE & ADVENTURE HIGH SCHOOL & & MORGANTOWN & WV & 26501 \\
\hline OSAGE & MORGANTOWN SCHOOL & & OSAGE & WV & 26543 \\
\hline RIVERSIDE & MORGANTOWN SCHOOL & 417 HOLLAND AVE & MORGANTOWN & WV & 26501 \\
\hline RIVERSIDE & MORGANTOWN SCHOOL & 403 SCHLEY ST & MORGANTOWN & WV & 26501 \\
\hline SABRATON & TRINITY HIGH SCHOOL & 30 HARNER RUN RD & MORGANTOWN & WV & 26508 \\
\hline SABRATON & $\begin{array}{l}\text { AREA SCHOOLS } \\
\text { MONANGALIA COUNTY }\end{array}$ & 1837 LISTRAVIA AVE & MORGANTOWN & WV & 26505 \\
\hline SOUTHHILLS & MORGANTOWN SCHOOL & 533 BROCKWAY AVE & MORGANTOWN & WV & 26501 \\
\hline SOUTHHILLS & $\begin{array}{l}\text { SCHOOLS WAITMAN BARBE } \\
\text { ELEMENTARY }\end{array}$ & 109 WILSON AVE & MORGANTOWN & WV & 26501 \\
\hline
\end{tabular}




\begin{tabular}{|l|l|l|l|l|l|}
\hline SOUTHPARK & MORGANTOWN SCHOOL & 500 E PARKWAY DR & MORGANTOWN & WV & 26501 \\
\hline SOUTHPARK & $\begin{array}{l}\text { MORGANTOWN CHRISTIAN } \\
\text { ACADEMY }\end{array}$ & 64 GREENBAG RD & MORGANTOWN & WV & 26501 \\
\hline SUNCREST & $\begin{array}{l}\text { AREA SCHOOLS } \\
\text { MONANGALIA COUNTY }\end{array}$ & 360 BALDWIN ST & MORGANTOWN & WV & 26505 \\
\hline SUNCREST & $\begin{array}{l}\text { AREA SCHOOLS } \\
\text { MONANGALIA COUNTY }\end{array}$ & 523 JUNIOR AVE & MORGANTOWN & WV & 26505 \\
\hline SUNCREST & $\begin{array}{l}\text { ADVENTIST CHRISTIAN } \\
\text { SCHOOL FOR NCENTRAL W } \\
\text { VA }\end{array}$ & 437 DRUMMOND ST & MORGANTOWN & WV & 26505 \\
\hline SUNSET BEACH & $\begin{array}{l}\text { AREA SCHOOLS } \\
\text { MONANGALIA COUNTY }\end{array}$ & 160 CROSBY RD & MORGANTOWN & WV & 26508 \\
\hline SUNSET BEACH & SHAFFRON PETE \& DONNA & $\begin{array}{l}3135 \text { N GREYSTONE } \\
\text { DR }\end{array}$ & MORGANTOWN & WV & 26508 \\
\hline WESTOVER & MORGANTOWN SCHOOL & 200 W PARK AVE & MORGANTOWN & WV & 26501 \\
\hline WILES HILL & MORGANTOWN SCHOOL & 287 EUREKA DR & MORGANTOWN & WV & 26505 \\
\hline
\end{tabular}

Child Day Care Facilities, Monongalia Co. WV

\begin{tabular}{|c|c|c|c|c|c|}
\hline Populated Place DBF & Yellowpages.com Results & & & & \\
\hline Point Name & Sensitive Receptor Name & Address & City/Town & State & Zip \\
\hline BAKER RIDGE & $\begin{array}{l}\text { CONTINUOUS LEARNING } \\
\text { CENTER }\end{array}$ & 201 BAKERS RIDGE RD & MORGANTOWN & WV & 26508 \\
\hline BRAEWICK WOODS & $\begin{array}{cc}\text { LIFE } & \text { CARE LEARNING } \\
\text { CENTER } & \\
\end{array}$ & 99 J D ANDERSON DR & MORGANTOWN & WV & 26505 \\
\hline BRAEWICK WOODS & $\begin{array}{l}\text { CHYLEENS 2S \& 3S DAYCARE } \\
\text { LLC }\end{array}$ & 116 ELLEN LN & MORGANTOWN & WV & 26505 \\
\hline CANYON & $\begin{array}{c}\text { CHOICE CHILDRENS } \\
\text { CENTERS LLC }\end{array}$ & 246 LAKESIDE DR & MORGANTOWN & WV & 26508 \\
\hline FAIRMOR & SHEPHERDS CARE & 6 EDWIN ST & MORGANTOWN & WV & 26501 \\
\hline FAIRMOR & BUNDLES OF JOY & 16 COMMERCE DR & MORGANTOWN & WV & 26501 \\
\hline HILDERBRAND & $\begin{array}{l}\text { CHILD DEVELOPMENT } \\
\text { RESOURCE }\end{array}$ & 1045 RIVER RD & MORGANTOWN & WV & 26501 \\
\hline
\end{tabular}




\begin{tabular}{|c|c|c|c|c|c|}
\hline HOPECREST & \begin{tabular}{rrr|} 
CHILD & CARE RESOURCE \\
CENTER & & \\
\end{tabular} & 235 S HIGH ST & MORGANTOWN & WV & 26501 \\
\hline HOPECREST & $\begin{array}{l}\text { KINDER HAUS CHILD CARE } \\
\text { CENTER }\end{array}$ & 129 GREENBAG RD & MORGANTOWN & WV & 26501 \\
\hline MORGANTOWN & HEAD START & & MORGANTOWN & WV & 26501 \\
\hline MORGANTOWN & $\begin{array}{ccc}\text { HIGH STREETS A PLUS } \\
\text { LEARNING CENTER }\end{array}$ & 54 HIGH ST & MORGANTOWN & WV & 26505 \\
\hline MORGANTOWN & $\begin{array}{l}\text { KLINGBERG CENTER FOR } \\
\text { CHILD DEVELOPMENT }\end{array}$ & & MORGANTOWN & WV & 26501 \\
\hline MORGANTOWN & $\begin{array}{l}\text { PRESBYTERIAN CHILD } \\
\text { DEVELOPMENT CENTER }\end{array}$ & & MORGANTOWN & WV & 26501 \\
\hline RAGTOWN & COUNTRY ANGEL DAY CARE & $\begin{array}{l}224 \text { DUNKARD VALLEY } \\
\text { BLVD }\end{array}$ & CORE & WV & 26529 \\
\hline RICHARD & $\begin{array}{l}\text { SMALL WONDERS CHILD } \\
\text { CARE SERVICE }\end{array}$ & 3174 EARL L CORE RD & MORGANTOWN & WV & 26508 \\
\hline RIVERSIDE & $\begin{array}{l}\text { SCHOOLS ALTERNATIVE } \\
\text { LEARNING CENTER }\end{array}$ & 417 HOLLAND AVE & MORGANTOWN & WV & 26501 \\
\hline SOUTHPARK & $\begin{array}{l}\text { HEAD START PROGRAM } \\
\text { DORSEY CENTER }\end{array}$ & 1433 DORSEY AVE & MORGANTOWN & WV & 26501 \\
\hline STAR CITY & DUSEYLAND & 375 BOYERS AVE & MORGANTOWN & WV & 26505 \\
\hline STAR CITY & $\begin{array}{l}\text { SERENDIPITY PRE SCHOOL } \\
\text { \& KINDERGARTEN }\end{array}$ & 3529 UNIVERSITY AVE & MORGANTOWN & WV & 26505 \\
\hline STURGISSON & $\begin{array}{l}\text { CHILD CARE RESOURCE } \\
\text { CENTER }\end{array}$ & 14 MARVINS GDNS & MORGANTOWN & WV & 26508 \\
\hline SUNCREST & ST MARYS PRE SCHOOL & 3344 UNIVERSITY AVE & MORGANTOWN & WV & 26505 \\
\hline THE FLATTS & KIDS KORNER DAY CARE & 464 INGLEWOOD BLVD & MORGANTOWN & WV & 26505 \\
\hline THE MILEGROUND & PLEASANT DAY SCHOOLS & 1315 AIRPORT BLVD & MORGANTOWN & WV & 26505 \\
\hline THE MILEGROUND & SERENDIPITY PRESCHOOL & 1850 MILEGROUND RD & MORGANTOWN & WV & 26505 \\
\hline WEST SABRATON & PEEK A BOO DAYCARE & 2005 LISTRAVIA AVE & MORGANTOWN & WV & 26505 \\
\hline
\end{tabular}


Hospitals/Medical Centers, Monogalia Co. WV

\begin{tabular}{|c|c|c|c|c|c|}
\hline Populated Place DBF & Yellowpages.com Results & & & & \\
\hline Point Name & Sensitive Receptor Name & Address & City/Town & State & Zip \\
\hline BRAEWICK WOODS & $\begin{array}{l}\text { MONONGALIA GEN HOSP } \\
\text { THE COMMUNITY } \\
\text { RELATIONS }\end{array}$ & & MORGANTOWN & WV & 26501 \\
\hline THE FLATTS & $\begin{array}{l}\text { RUBY MEMORIAL HOSPITAL } \\
\text { PATIENT INFORMATION }\end{array}$ & & MORGANTOWN & WV & 26501 \\
\hline THE FLATTS & $\begin{array}{l}\text { UNIVERSITY HEALTH } \\
\text { ASSOCIATES } \\
\text { ADMINISTRATION }\end{array}$ & & MORGANTOWN & WV & 26501 \\
\hline
\end{tabular}

Nursing Homes, Monogalia Co. WV

\begin{tabular}{|c|c|c|c|c|c|}
\hline Populated Place DBF & Yellowpages.com Results & & & & \\
\hline Point Name & Sensitive Receptor Name & Address & City/Town & State & Zip \\
\hline$\overline{\text { BRAEWICK WOODS }}$ & MORGANTOWN HOSPICE & 989 MAPLE DR & MORGANTOWN & $\mathrm{WV}$ & 26505 \\
\hline SUNCREST & $\begin{array}{l}\text { TENDER LOVING CARE } \\
\text { HOME CARE }\end{array}$ & 3280 UNIVERSITY AVE & MORGANTOWN & $\mathrm{WV}$ & 26505 \\
\hline THE FLATTS & THE MADISON & 445 VAN VOORHIS RD & MORGANTOWN & WV & 26505 \\
\hline
\end{tabular}

\section{Schools, Marion Co. WV}

\begin{tabular}{|l|l|l|l|l|l|}
\hline $\begin{array}{l}\text { Populated Place } \\
\text { DBF }\end{array}$ & \multicolumn{2}{|l|}{ Yellowpages.com Results } \\
\hline Point Name & Sensitive Receptor Name & Address & City/Town & State & Zip \\
\hline BARRACKVILLE & $\begin{array}{l}\text { MARION COUNTY AREA } \\
\text { SCHOOLS }\end{array}$ & 101 HIGH ST & FAIRMONT & WV & 26554 \\
\hline BARRACKVILLE & $\begin{array}{l}\text { MARION COUNTY AREA } \\
\text { SCHOOLS }\end{array}$ & & BARRACKVILLE & WV & 26559 \\
\hline
\end{tabular}




\begin{tabular}{|c|c|c|c|c|c|}
\hline CHESAPEAKE & \begin{tabular}{|l|} 
BARNES ELEMENTARY TITLE I \\
PARENT RESOURCE CENTER \\
\end{tabular} & 100 NAOMI ST & FAIRMONT & WV & 26554 \\
\hline FAIRMONT & $\begin{array}{l}\text { AREA SCHOOLS MARION } \\
\text { COUNTY EAST DALE } \\
\text { ELEMENTARY }\end{array}$ & RR 3 & FAIRMONT & $\mathrm{WV}$ & 26554 \\
\hline FAIRMONT & $\begin{array}{l}\text { MARION COUNTY AREA } \\
\text { SCHOOLS }\end{array}$ & 601 LOCUST AVE & FAIRMONT & WV & 26554 \\
\hline FAIRMONT & $\begin{array}{l}\text { MARION COUNTY AREA } \\
\text { SCHOOLS }\end{array}$ & 1025 FAIRFAX ST & FAIRMONT & WV & 26554 \\
\hline FAIRMONT & $\begin{array}{l}\text { MARION COUNTY AREA } \\
\text { SCHOOLS }\end{array}$ & 2 PENNSYLVANIA AVE & FAIRMONT & WV & 26554 \\
\hline FAIRMONT & $\begin{array}{l}\text { MARION COUNTY AREA } \\
\text { SCHOOLS }\end{array}$ & 1119 MINOR AVE & FAIRMONT & WV & 26554 \\
\hline FAIRMONT & SCHOOLS PUBLIC SCHOOLS & 200 GASTON AVE & FAIRMONT & WV & 26554 \\
\hline FAIRMONT & $\begin{array}{l}\text { AREA SCHOOLS MARION } \\
\text { COUNTY }\end{array}$ & PO BOX 65 & FAIRMONT & $\mathrm{WV}$ & 26554 \\
\hline FAIRMONT & $\begin{array}{l}\text { CALVARY CHRISTIAN } \\
\text { SCHOOLS }\end{array}$ & & FAIRMONT & WV & 26554 \\
\hline FAIRMONT & EAST FAIRMONT JUNIOR HIGH & 1 ORION LN & FAIRMONT & WV & 26554 \\
\hline FAIRMONT & $\begin{array}{l}\text { MARION COUNTY AREA } \\
\text { SCHOOLS }\end{array}$ & 215 7TH ST & FAIRMONT & WV & 26554 \\
\hline FAIRVIEW & $\begin{array}{l}\text { DAYBROOK ELEM SCHOOL } \\
\text { TITLE ONE READING } \\
\text { PROGRAM }\end{array}$ & & FAIRVIEW & WV & 26570 \\
\hline PALATINE & $\begin{array}{l}\text { MARION COUNTY AREA } \\
\text { SCHOOLS }\end{array}$ & & FAIRMONT & WV & 26554 \\
\hline RIVESVILLE & $\begin{array}{l}\text { MARION COUNTY AREA } \\
\text { SCHOOLS }\end{array}$ & & RIVESVILLE & WV & 26588 \\
\hline
\end{tabular}

\section{Child Day Care Facilities, Marion Co. WV}

\begin{tabular}{|l|l|l|l|l|l|}
\hline Populated Place DBF & \multicolumn{4}{|c|}{ Yellowpages.com Results } \\
\hline Point Name & Sensitive Receptor Name & Address & City/Town & State & Zip \\
\hline FAIRMONT & BAPTIST TEMPLE PRE & 430 MORGANTOWN & FAIRMONT & WV & 26554 \\
\hline
\end{tabular}




\begin{tabular}{|c|c|c|c|c|c|}
\hline & SCHOOL & AVE & & & \\
\hline FAIRMONT & $\begin{array}{l}\text { CHILDRENS LEARNING } \\
\text { CENTER }\end{array}$ & 424 MONROE ST & FAIRMONT & WV & 26554 \\
\hline FAIRMONT & HEAD START & 107 MAPLE AVE & FAIRMONT & WV & 26554 \\
\hline FAIRMONT & HEAD START & $\begin{array}{l}1000 \text { COUNTRY CLUB } \\
\text { RD }\end{array}$ & FAIRMONT & WV & 26554 \\
\hline FAIRMONT & HEAD START & 213 JACKSON ST & FAIRMONT & $\mathrm{WV}$ & 26554 \\
\hline FAIRMONT & \begin{tabular}{|l} 
METHODIST DAY CARE \\
CENTER
\end{tabular} & & FAIRMONT & WV & 26554 \\
\hline FAIRMONT & $\begin{array}{l}\text { NOAHS ARK NURSERY } \\
\text { SCHOOL }\end{array}$ & & FAIRMONT & WV & 26554 \\
\hline FAIRMONT & $\begin{array}{l}\text { SMALL WORLD CENTER } \\
\text { INCORPORATED }\end{array}$ & 303 COLUMBIA ST & FAIRMONT & WV & 26554 \\
\hline FAIRMONT & $\begin{array}{l}\text { SUNBEAM CHILD CARE } \\
\text { CENTER }\end{array}$ & $\begin{array}{l}1654 \text { MARY LOU } \\
\text { RETTON DR }\end{array}$ & FAIRMONT & WV & 26554 \\
\hline FAIRMONT & $\begin{array}{l}\text { CHILD CARE RESOURCES } \\
\text { CENTER }\end{array}$ & 309 CLEVELAND AVE & FAIRMONT & WV & 26554 \\
\hline PALATINE & $\begin{array}{l}\text { VALLEY CHAPEL CHILD } \\
\text { DEVELOPMENT CENTER }\end{array}$ & \begin{tabular}{|l}
1511 PLEASANT \\
VALLEY RD
\end{tabular} & FAIRMONT & WV & 26554 \\
\hline RIVESVILLE & HEAD START & & RIVESVILLE & WV & 26588 \\
\hline
\end{tabular}

Hospitals/Medical Centers, Marion Co. WV

\begin{tabular}{|l|l|l|l|l|l|}
\hline Populated Place DBF & \multicolumn{3}{|c|}{ Yellowpages.com Results } & State & Zip \\
\hline Point Name & Sensitive Receptor Name & Address & City/Town & WV & 26554 \\
\hline FAIRMONT & $\begin{array}{l}\text { FAIRMONT GENERAL } \\
\text { HOSPITAL }\end{array}$ & 214 MERCHANT ST & FAIRMONT & WV & 26554 \\
\hline FAIRMONT & GENERAL HOSPITAL & 1325 LOCUST AVE & FAIRMONT & WV & 26554 \\
\hline FAIRMONT & $\begin{array}{l}\text { WOUND HEALING } \\
\text { CENTER OF FAIRMONT } \\
\text { GENERAL HOSPITAL }\end{array}$ & $\begin{array}{l}1224 \text { CLUB RD O U R Y } \\
\text { FAIRMONT }\end{array}$ & & & \\
\hline FAIRVIEW & FAIRVIEW EMERGENCY & & FAIRVIEW & WV & 26570 \\
\hline
\end{tabular}


Nursing Homes, Marion Co. WV

\begin{tabular}{|l|l|l|l|l|l|}
\hline Populated Place DBF & \multicolumn{3}{|c|}{ Yellowpages.com Results } \\
\hline Point Name & Sensitive Receptor Name & Address & City/Town & State & Zip \\
\hline FAIRMONT & FAIRMONT CLINIC & 132 LOCUST AVE & FAIRMONT & WV & 26554 \\
\hline
\end{tabular}

\section{Schools, Preston Co. WV}

\begin{tabular}{|l|l|l|l|l|l|}
\hline $\begin{array}{l}\text { Populated Place } \\
\text { DBF }\end{array}$ & \multicolumn{4}{|c|}{ Yellowpages.com Results } \\
\hline Point Name & Sensitive Receptor Name & Address & City/Town & State & Zip \\
\hline ARTHURDALE & $\begin{array}{l}\text { VALLEY ELEMENTARY } \\
\text { SCHOOL }\end{array}$ & & ARTHURDALE & WV & 26520 \\
\hline BRUCETON MILLS & $\begin{array}{l}\text { PRESTON COUNTY OF } \\
\text { SCHOOLS BRCTN SCH K } 8 \\
\text { CTRL PRSTN }\end{array}$ & & BRUCETON MILLS & WV & 26525 \\
\hline MASONTOWN & $\begin{array}{l}\text { AREA SCHOOLS PRESTON } \\
\text { COUNTY }\end{array}$ & & MASONTOWN & WV & 26542 \\
\hline
\end{tabular}

\section{Child Day Care Facilities, Preston Co. WV}

\begin{tabular}{|l|l|l|l|l|l|}
\hline Populated Place DBF & \multicolumn{4}{|c|}{ Yellowpages.com Results } \\
\hline Point Name & Sensitive Receptor Name & Address & City/Town & State & Zip \\
\hline BRUCETON MILLS & $\begin{array}{l}\text { GUARDIAN ANGEL CHILD } \\
\text { CARE CENTE }\end{array}$ & PO BOX 26 & BRUCETON MILLS & WV & 26525 \\
\hline MASONTOWN & HEAD START & & MASONTOWN & WV & 26542 \\
\hline REEDSVILLE & DAYCARE HUGS AND KISSES & & REEDSVILLE & WV & 26547 \\
\hline REEDSVILLE & $\begin{array}{l}\text { PRECIOUS HUGS CHILDRENS } \\
\text { CENTER }\end{array}$ & & REEDSVILLE & WV & 26547 \\
\hline
\end{tabular}


Hospitals/Medical Centers, Preston Co. WV

\begin{tabular}{|l|l|l|l|l|l|}
\hline Populated Place DBF & \multicolumn{4}{|c|}{ Yellowpages.com Results } \\
\hline Point Name & Sensitive Receptor Name & Address & City/Town & State & Zip \\
\hline BRUCETON MILLS & $\begin{array}{l}\text { HARNED MEMORIAL } \\
\text { MEDICAL CLINIC }\end{array}$ & & $\begin{array}{l}\text { BRUCETON } \\
\text { MILLS }\end{array}$ & WV & 26525 \\
\hline REEDSVILLE & $\begin{array}{l}\text { WEST PRESTON MEDICAL } \\
\text { CLINIC }\end{array}$ & & REEDSVILLE & WV & 26547 \\
\hline
\end{tabular}

Schools, Greene Co. PA

\begin{tabular}{|c|c|c|c|c|c|}
\hline Populated Place DBF & \multicolumn{5}{|c|}{ Yellowpages.com Results } \\
\hline Point Name & Sensitive Receptor Name & Address & City/Town & State & Zip \\
\hline CARMICHAELS & $\begin{array}{l}\text { CARMICHAELS AREA } \\
\text { SCHOOL DISTRICT } \\
\text { CARMICHAELS AREA ELEM }\end{array}$ & 225 N VINE ST & CARMICHAELS & PA & 15320 \\
\hline JEFFERSON & $\begin{array}{l}\text { SCHOOLS PUB SCHOOLS } \\
\text { ACADEMIC ELEM } \\
\text { SECONDARY }\end{array}$ & & JEFFERSON & $\mathrm{PA}$ & 15344 \\
\hline MAPLETOWN & $\begin{array}{l}\text { PUB SCHOOLS - ACADEMIC - } \\
\text { ELEM - SECONDARY GREENE } \\
\text { CNT }\end{array}$ & & GREENSBORO & PA & 15338 \\
\hline MAPLETOWN & $\begin{array}{l}\text { SOUTHESTRN GRNE SCHOOL } \\
\text { DISTRICT BUS MGR PENN } \\
\text { PITT ELEM } \\
\end{array}$ & & GREENSBORO & $\mathrm{PA}$ & 15338 \\
\hline MOUNT MORRIS & $\begin{array}{l}\text { CENTRAL GREENE SCHOOL } \\
\text { DISTRICT PERRY } \\
\text { ELEMENTARY }\end{array}$ & & MOUNT MORRIS & $\mathrm{PA}$ & 15349 \\
\hline MOUNT MORRIS & $\begin{array}{l}\text { SCHOOLS PUB SCHOOLS } \\
\text { ACADEMIC ELEM } \\
\text { SECONDARY }\end{array}$ & & MOUNT MORRIS & $\mathrm{PA}$ & 15349 \\
\hline WAYNESBURG & CENTRAL GREENE SCHOOL & RR 2 & WAYNESBURG & PA & 15370 \\
\hline
\end{tabular}




\begin{tabular}{|l|l|l|l|l|l|}
\hline & $\begin{array}{l}\text { WAYNESBURG CENTRAL } \\
\text { HIGH SCHOOL }\end{array}$ & & & \\
\hline WAYNESBURG & $\begin{array}{l}\text { CTRL GREENE SCHOOL } \\
\text { DISTRICT MARGARET BELL } \\
\text { MILLER MID }\end{array}$ & 126 E LINCOLN ST & WAYNESBURG & PA & 15370 \\
\hline WAYNESBURG & $\begin{array}{l}\text { OPEN DOOR CHRISTIAN } \\
\text { SCHOOL }\end{array}$ & 793 LIPPENCOTT RD & WAYNESBURG & PA & 15370 \\
\hline WAYNESBURG & WARRIOR TRAIL SCHOOL & 30 E WAYNE ST & WAYNESBURG & PA & 15370 \\
\hline WAYNESBURG & $\begin{array}{l}\text { CENTRAL GREENE SCHOOL } \\
\text { WAYNESBURG CIMMERMAN DR } \\
\text { ELEMENTARY SCHOOL }\end{array}$ & WAYNESBURG & PA & 15370 \\
\hline
\end{tabular}

\section{Child Day Care Facilities, Greene Co. PA}

\begin{tabular}{|c|c|c|c|c|c|}
\hline Populated Place DBF & & Yellowpages.com & & & \\
\hline Point Name & Sensitive Receptor Name & Address & City/Town & State & Zip \\
\hline CARMICHAELS & HEAD START & & CARMICHAELS & $\mathrm{PA}$ & 15320 \\
\hline CARMICHAELS & $\begin{array}{l}\text { LIGHTHOUSE CHRISTIAN } \\
\text { DAY SCHOOL }\end{array}$ & 508 E GEORGE ST & CARMICHAELS & $\mathrm{PA}$ & 15320 \\
\hline CARMICHAELS & DONNAS DAY CARE & & CARMICHAELS & $\mathrm{PA}$ & 15320 \\
\hline JEFFERSON & HEAD START & & JEFFERSON & $\mathrm{PA}$ & 15344 \\
\hline RICES LANDING & HEAD START & & RICES LANDING & $\mathrm{PA}$ & 15357 \\
\hline WAYNESBURG & HEAD START & 300 NORTH ST & WAYNESBURG & $\mathrm{PA}$ & 15370 \\
\hline WAYNESBURG & $\begin{array}{l}\text { NANNYS CREATIVE } \\
\text { LEARNING CENTER } \\
\end{array}$ & RR 5 & WAYNESBURG & PA & 15370 \\
\hline WAYNESBURG & $\begin{array}{l}\text { RAINBOWS END LEARNING } \\
\text { CENTER }\end{array}$ & 300 NORTH ST & WAYNESBURG & PA & 15370 \\
\hline WAYNESBURG & $\begin{array}{l}\text { DAY CARE CHILDREN } \\
\text { GREENE COUNTY VO TECH } \\
\text { SCHOOL }\end{array}$ & & WAYNESBURG & PA & 15370 \\
\hline WAYNESBURG & \begin{tabular}{|l} 
INTERMEDIATE UNIT 1 \\
PRESCHOOL PROGRAM
\end{tabular} & 90 ZIMMERMAN DR & WAYNESBURG & $\mathrm{PA}$ & 15370 \\
\hline
\end{tabular}


Hospitals/Medical Centers, Greene Co. PA

\begin{tabular}{|c|c|c|c|c|c|}
\hline Populated Place DBF & \multicolumn{5}{|c|}{ Yellowpages.com Results } \\
\hline Point Name & Sensitive Receptor Name & Address & City/Town & State & Zip \\
\hline WAYNESBURG & $\begin{array}{l}\text { OCCUPTNL MEDCN CENTER } \\
\text { WASHINGTON HOSP }\end{array}$ & 343 E ROY FURMAN HWY & WAYNESBURG & PA & 15370 \\
\hline
\end{tabular}

Nursing Homes, Greene Co. PA

\begin{tabular}{|l|l|l|l|l|l|}
\hline $\begin{array}{l}\text { Populated Place } \\
\text { DBF }\end{array}$ & \multicolumn{3}{|c|}{ Yellowpages.com Results } \\
\hline Point Name & Sensitive Receptor Name & Address & City/Town & State & Zip \\
\hline WAYNESBURG & $\begin{array}{l}\text { HOSPICE CARE } \\
\text { INCORPORATED }\end{array}$ & 58 E GREENE ST & WAYNESBURG & PA & 15370 \\
\hline
\end{tabular}

Schools, Fayette Co. PA

\begin{tabular}{|c|c|c|c|c|c|}
\hline Populated Place DBF & \multicolumn{5}{|c|}{ Yellowpages.com Results } \\
\hline Point Name & Sensitive Receptor Name & Address & City/Town & State & Zip \\
\hline FAIRCHANCE & $\begin{array}{l}\text { ALBERT GALLATIN AREA } \\
\text { SCHOOL DISTRICT TRI VLY SR } \\
\text { HIGH A }\end{array}$ & & FAIRCHANCE & $\mathrm{PA}$ & 15436 \\
\hline MASONTOWN & $\begin{array}{l}\text { ALBERT GALLATIN AREA } \\
\text { SCHOOL DISTRICT FOOD } \\
\text { SERVICE SUPVSR }\end{array}$ & & MASONTOWN & $\mathrm{PA}$ & 15461 \\
\hline MC CLELLANDTOWN & $\begin{array}{l}\text { ALBERT GALLATIN AREA } \\
\text { SCHOOL } \\
\text { DISTRICTSECONDARY } \\
\text { SCHOOLS }\end{array}$ & & $\begin{array}{l}\text { MC } \\
\text { CLELLANDTOW } \\
\mathrm{N}\end{array}$ & $\mathrm{PA}$ & 15458 \\
\hline NEW SALEM & $\begin{array}{l}\text { BROWNSVILLE AREA SCHOOL } \\
\text { DIST INTERMEDIATE UNIT } \\
\text { CLASSROOM }\end{array}$ & 239 ROYAL RD & NEW SALEM & PA & 15468 \\
\hline POINT BREEZE & WHARTON SCHOOL & & FARMINGTON & PA & 15437 \\
\hline
\end{tabular}




\begin{tabular}{|c|c|c|c|c|c|}
\hline POINT BREEZE & $\begin{array}{l}\text { LIGHTHOUSE CHRISTIAN } \\
\text { ACADEMY }\end{array}$ & RR 1 & FARMINGTON & $\mathrm{PA}$ & 15437 \\
\hline POINT MARION & $\begin{array}{l}\text { ALBERT GALLATIN AREA } \\
\text { SCHOOL DIST ELEM SCHOOLS }\end{array}$ & & POINT MARION & PA & 15474 \\
\hline REPUBLIC & $\begin{array}{l}\text { BROWNSVILLE AREA } \\
\text { SCHOOL DIST REDSTONE MID } \\
\text { SCHOOL }\end{array}$ & & REPUBLIC & PA & 15475 \\
\hline SMITHFIELD & $\begin{array}{l}\text { ALBERT GALLATIN AREA } \\
\text { SCHOOL DISTRICT SMITHFLD } \\
\text { ELEM SCH }\end{array}$ & & SMITHFIELD & PA & 15478 \\
\hline SOUTH UNIONTOWN & $\begin{array}{l}\text { FAYETTE COUNTY AREA } \\
\text { VOCATIONAL TECHNICAL } \\
\text { SCHOOL }\end{array}$ & $\begin{array}{l}175 \text { GEORGES } \\
\text { FAIRCHANCE RD }\end{array}$ & UNIONTOWN & PA & 15401 \\
\hline SOUTH UNIONTOWN & $\begin{array}{l}\text { LAUREL HGLNDS SCHOOL } \\
\text { DISTRICT LAUREL } \\
\text { HIGHLANDS JR HIGH }\end{array}$ & & UNIONTOWN & $\mathrm{PA}$ & 15401 \\
\hline UNIONTOWN & COMMUNITIES IN SCHOOLS & 137 N BEESON AVE & UNIONTOWN & $\mathrm{PA}$ & 15401 \\
\hline UNIONTOWN & $\begin{array}{l}\text { LAUREL HGLNDS SCHOOL } \\
\text { DISTRICT GEN GEORGE C } \\
\text { MRSHLL ELEM }\end{array}$ & & UNIONTOWN & $\mathrm{PA}$ & 15401 \\
\hline UNIONTOWN & \begin{tabular}{|l} 
LAUREL HIGHLANDS \\
SCHOOL DIST R W CLARK \\
ELEMENTARY
\end{tabular} & 304 BAILEY AVE & UNIONTOWN & PA & 15401 \\
\hline UNIONTOWN & $\begin{array}{l}\text { LAUREL HIGHLANDS } \\
\text { SCHOOL DISTRICT R W } \\
\text { CLARK ELEMENTARY }\end{array}$ & $\begin{array}{l}200 \text { WATER ST, } \\
\text { UNIONTOWN, PA }\end{array}$ & UNIONTOWN & PA & 15401 \\
\hline UNIONTOWN & PRESSLEY RIDGE SCHOOL & UNIONTOWN, PA & UNIONTOWN & PA & 15401 \\
\hline UNIONTOWN & ABC SCHOOL HOUSE & 144 N GALLATIN AVE & UNIONTOWN & $\mathrm{PA}$ & 15401 \\
\hline
\end{tabular}


Child Day Care Facilities, Fayette Co. PA

\begin{tabular}{|c|c|c|c|c|c|}
\hline Populated Place DBF & & Yellowpages.com Resu & & & \\
\hline Point Name & Sensitive Receptor Name & Address & City/Town & State & Zip \\
\hline HOPWOOD & $\begin{array}{l}\text { HOPWOOD UNITED } \\
\text { METHODIST PRE SCHOOL }\end{array}$ & & HOPWOOD & $\mathrm{PA}$ & 15445 \\
\hline MASONTOWN & $\begin{array}{l}\text { ECHO CHILD DEVELOPMENT } \\
\text { CENTER }\end{array}$ & 10 S MAIN ST & MASONTOWN & $\mathrm{PA}$ & 15461 \\
\hline POINT BREEZE & $\begin{array}{l}\text { COUNTRY KIDS LEARNING } \\
\text { CENTER }\end{array}$ & RR 2 & FARMINGTON & PA & 15437 \\
\hline SMITHFIELD & $\begin{array}{l}\text { SMITHFIELD LEARNING } \\
\text { CENTER }\end{array}$ & & SMITHFIELD & $\mathrm{PA}$ & 15478 \\
\hline SMITHFIELD & HEAD START & 25 MAIN ST & SMITHFIELD & $\mathrm{PA}$ & 15478 \\
\hline SOUTH UNIONTOWN & CHESTNUT RIDGE DAY CARE & $\begin{array}{l}308 \text { MCCLELLANDTOWN } \\
\text { RD }\end{array}$ & UNIONTOWN & $\mathrm{PA}$ & 15401 \\
\hline UNIONTOWN & $\begin{array}{l}\text { CHILD DEVELOPMENT } \\
\text { CENTER }\end{array}$ & & UNIONTOWN & $\mathrm{PA}$ & 15401 \\
\hline UNIONTOWN & COORDINATED CHILD CARE & 137 N BEESON AVE & UNIONTOWN & $\mathrm{PA}$ & 15401 \\
\hline UNIONTOWN & $\begin{array}{l}\text { ECHO CHILD DEVELOPMENT } \\
\text { CENTER }\end{array}$ & 23 S GALLATIN AVE & UNIONTOWN & $\mathrm{PA}$ & 15401 \\
\hline UNIONTOWN & HEAD START & 21 WEST PL & UNIONTOWN & $\mathrm{PA}$ & 15401 \\
\hline UNIONTOWN & HEAD START & 80 OLD NEW SALEM RD & UNIONTOWN & $\mathrm{PA}$ & 15401 \\
\hline UNIONTOWN & $\begin{array}{l}\text { PRIVATE INDUSTRY } \\
\text { COUNSEL CHILD CARE }\end{array}$ & PO BOX W & UNIONTOWN & PA & 15401 \\
\hline UNIONTOWN & $\begin{array}{l}\text { TRESSLERS FAITH LEARNING } \\
\text { CENTER }\end{array}$ & 665 CHERRY TREE LN & UNIONTOWN & $\mathrm{PA}$ & 15401 \\
\hline UNIONTOWN & $\begin{array}{l}\text { BETHS CHILD DAY CARE } \\
\text { CENTER }\end{array}$ & 226 N GALLATIN AVE & UNIONTOWN & $\mathrm{PA}$ & 15401 \\
\hline
\end{tabular}


Hospitals/Medical Centers, Fayette Co. PA

\begin{tabular}{|l|l|l|l|l|l|}
\hline Populated Place DBF & \multicolumn{3}{|c|}{ Yellowpages.com Results } \\
\hline Point Name & Sensitive Receptor Name & Address & City/Town & State & Zip \\
\hline FAIRCHANCE & $\begin{array}{l}\text { SEWICKLEY VALLEY } \\
\text { HOSPITAL CREDIT }\end{array}$ & & GEORGES TWNSHP & PA & 15436 \\
\hline NEW SALEM & $\begin{array}{l}\text { FAYETTE EMERGENCY } \\
\text { MEDICAL SERVICE } \\
\text { INCORPORATED }\end{array}$ & & NEW SALEM & PA & 15468 \\
\hline REPUBLIC & $\begin{array}{l}\text { FAYETTE EMERGENCY } \\
\text { MEDICAL SERVICE } \\
\text { INCORPORATED }\end{array}$ & & REPUBLIC & PA & 15475 \\
\hline SOUTH UNIONTOWN & $\begin{array}{l}\text { SOUTHWEST WOMENS } \\
\text { HEALTH CARE INC }\end{array}$ & $\begin{array}{l}\text { 104 DELAWARE } \\
\text { AVE STE 244, } \\
\text { UNIONTOWN, PA }\end{array}$ & UNIONTOWN & PA & 15401 \\
\hline UNIONTOWN & LAUREL RIDGE CENTER & 75 HICKLE ST & UNIONTOWN & PA & 15401 \\
\hline UNIONTOWN & $\begin{array}{l}\text { UNIONTOWN HOSPITAL } \\
\text { PRIORITY CARE }\end{array}$ & & UNIONTOWN & PA & 15401 \\
\hline UNIONTOWN & $\begin{array}{l}\text { UNIONTOWN HOSPITAL } \\
\text { UNIONTOWN HOSPITAL } \\
\text { FOUNDATION }\end{array}$ & $\begin{array}{l}500 \text { W BERKELEY } \\
\text { ST UNIONTOWN }\end{array}$ & PA & 15401 \\
\hline UNIONTOWN & $\begin{array}{l}\text { SENTRAL MEDICAL } \\
\text { CENTER AND HOSPITAL }\end{array}$ & & UNIONTOWN & PA & 15401 \\
\hline
\end{tabular}

Nursing Homes, Fayette Co. PA

\begin{tabular}{|l|l|l|l|l|l|}
\hline Populated Place DBF & \multicolumn{4}{|l|}{ Yellowpages.com Results } \\
\hline Point Name & Sensitive Receptor Name & Address & City/Town & State & Zip \\
\hline UNIONTOWN & $\begin{array}{l}\text { MABELS PERSONAL CARE } \\
\text { HOME }\end{array}$ & 54 WILSON AVE & UNIONTOWN & PA & 15401 \\
\hline UNIONTOWN & $\begin{array}{l}\text { PERSONAL CARE } \\
\text { SERVICES }\end{array}$ & $\begin{array}{l}100 \text { NEW SALEM } \\
\text { RD }\end{array}$ & UNIONTOWN & PA & 15401 \\
\hline
\end{tabular}




\section{Appendix C - Complete List of Facilities per Category of Sensitive Receptors within Study Area}

\section{Child Day Care Facilities}

\begin{tabular}{|c|c|c|c|c|c|}
\hline $\begin{array}{c}\text { Density } \\
\text { within } \\
\text { Distance to } \\
\text { Stack } \\
\text { Range }(\mathbf{k m})\end{array}$ & $\begin{array}{c}\text { Populated Places } \\
\text { Name }\end{array}$ & Sensitive Receptor Name & State & FIPS & County \\
\hline \multicolumn{6}{|l|}{3 in $0-5$} \\
\hline 1 & BAKER RIDGE & CONTINUOUS LEARNING CENTER & WV & 54061 & MONONGALIA \\
\hline 2 & BRAEWICK WOODS & LIFE CARE LEARNING CENTER & WV & 54061 & MONONGALIA \\
\hline 3 & BRAEWICK WOODS & CHYLEENS 2S \& 3S DAYCARE LLC & WV & 54061 & MONONGALIA \\
\hline \multicolumn{6}{|l|}{24 in $5-10$} \\
\hline 1 & MASONTOWN & ECHO CHILD DEVELOPMENT CENTER & PA & 42051 & FAYETTE \\
\hline 2 & SMITHFIELD & SMITHFIELD LEARNING CENTER & $\mathrm{PA}$ & 42051 & FAYETTE \\
\hline 3 & SMITHFIELD & HEAD START & $\mathrm{PA}$ & 42051 & FAYETTE \\
\hline 4 & CANYON & CHOICE CHILDRENS CENTERS LLC & WV & 54061 & MONONGALIA \\
\hline 5 & FAIRMOR & SHEPHERDS CARE & WV & 54061 & MONONGALIA \\
\hline 6 & FAIRMOR & BUNDLES OF JOY & WV & 54061 & MONONGALIA \\
\hline 7 & HILDERBRAND & CHILD DEVELOPMENT RESOURCE & WV & 54061 & MONONGALIA \\
\hline 8 & HOPECREST & CHILD CARE RESOURCE CENTER & WV & 54061 & MONONGALIA \\
\hline 9 & HOPECREST & KINDER HAUS CHILD CARE CENTER & WV & 54061 & MONONGALIA \\
\hline 10 & MORGANTOWN & HEAD START & WV & 54061 & MONONGALIA \\
\hline 11 & MORGANTOWN & HIGH STREETS A PLUS LEARNING CENTER & WV & 54061 & MONONGALIA \\
\hline 12 & MORGANTOWN & KLINGBERG CENTER FOR CHILD DEVELOPMENT & WV & 54061 & MONONGALIA \\
\hline 13 & MORGANTOWN & PRESBYTERIAN CHILD DEVELOPMENT CENTER & WV & 54061 & MONONGALIA \\
\hline 14 & RICHARD & SMALL WONDERS CHILD CARE SERVICE & $\mathrm{WV}$ & 54061 & MONONGALIA \\
\hline 15 & RIVERSIDE & SCHOOLS ALTERNATIVE LEARNING CENTER & WV & 54061 & MONONGALIA \\
\hline 16 & SOUTHPARK & HEAD START PROGRAM DORSEY CENTER & WV & 54061 & MONONGALIA \\
\hline 17 & STAR CITY & DUSEYLAND & WV & 54061 & MONONGALIA \\
\hline
\end{tabular}




\begin{tabular}{|c|c|c|c|c|c|}
\hline 18 & STAR CITY & SERENDIPITY PRE SCHOOL \& KINDERGARTEN & WV & 54061 & MONONGALIA \\
\hline 19 & STURGISSON & CHILD CARE RESOURCE CENTER & WV & 54061 & MONONGALIA \\
\hline 20 & SUNCREST & ST MARYS PRE SCHOOL & WV & 54061 & MONONGALIA \\
\hline 21 & THE FLATTS & KIDS KORNER DAY CARE & WV & 54061 & MONONGALIA \\
\hline 22 & THE MILEGROUND & PLEASANT DAY SCHOOLS & WV & 54061 & MONONGALIA \\
\hline 23 & THE MILEGROUND & SERENDIPITY PRESCHOOL & WV & 54061 & MONONGALIA \\
\hline 24 & WEST SABRATON & PEEK A BOO DAYCARE & WV & 54061 & MONONGALIA \\
\hline \multicolumn{6}{|c|}{5 in $20-25$} \\
\hline 1 & CARMICHAELS & HEAD START & PA & 42059 & GREENE \\
\hline 2 & CARMICHAELS & LIGHTHOUSE CHRISTIAN DAY SCHOOL & $\mathrm{PA}$ & 42059 & GREENE \\
\hline 3 & CARMICHAELS & DONNAS DAY CARE & $\mathrm{PA}$ & 42059 & GREENE \\
\hline 4 & RIVESVILLE & HEAD START & WV & 54049 & MARION \\
\hline 5 & MASONTOWN & HEAD START & WV & 54077 & PRESTON \\
\hline \multicolumn{6}{|c|}{34 in $25-30$} \\
\hline 1 & HOPWOOD & HOPWOOD UNITED METHODIST PRE SCHOOL & $\mathrm{PA}$ & 42051 & FAYETTE \\
\hline 2 & POINT BREEZE & COUNTRY KIDS LEARNING CENTER & $\mathrm{PA}$ & 42051 & FAYETTE \\
\hline 3 & SOUTH UNIONTOWN & CHESTNUT RIDGE DAY CARE & $\mathrm{PA}$ & 42051 & FAYETTE \\
\hline 4 & UNIONTOWN & CHILD DEVELOPMENT CENTER & PA & 42051 & FAYETTE \\
\hline 5 & UNIONTOWN & COORDINATED CHILD CARE & $\mathrm{PA}$ & 42051 & FAYETTE \\
\hline 6 & UNIONTOWN & ECHO CHILD DEVELOPMENT CENTER & $\mathrm{PA}$ & 42051 & FAYETTE \\
\hline 7 & UNIONTOWN & HEAD START & $\mathrm{PA}$ & 42051 & FAYETTE \\
\hline 8 & UNIONTOWN & HEAD START & $\mathrm{PA}$ & 42051 & FAYETTE \\
\hline 9 & UNIONTOWN & PRIVATE INDUSTRY COUNSEL CHILD CARE & $\mathrm{PA}$ & 42051 & FAYETTE \\
\hline 10 & UNIONTOWN & TRESSLERS FAITH LEARNING CENTER & $\mathrm{PA}$ & 42051 & FAYETTE \\
\hline 11 & UNIONTOWN & BETHS CHILD DAY CARE CENTER & $\mathrm{PA}$ & 42051 & FAYETTE \\
\hline 12 & JEFFERSON & HEAD START & $\mathrm{PA}$ & 42059 & GREENE \\
\hline 13 & RICES LANDING & HEAD START & $\mathrm{PA}$ & 42059 & GREENE \\
\hline 14 & WAYNESBURG & HEAD START & $\mathrm{PA}$ & 42059 & GREENE \\
\hline 15 & WAYNESBURG & NANNYS CREATIVE LEARNING CENTER & $\mathrm{PA}$ & 42059 & GREENE \\
\hline 16 & WAYNESBURG & RAINBOWS END LEARNING CENTER & PA & 42059 & GREENE \\
\hline 17 & WAYNESBURG & DAY CARE CHILDREN GREENE COUNTY VO TECH & $\mathrm{PA}$ & 42059 & GREENE \\
\hline
\end{tabular}




\begin{tabular}{|c|c|c|c|c|c|}
\hline & & SCHOOL & & \\
\hline 18 & WAYNESBURG & INTERMEDIATE UNIT 1 PRESCHOOL PROGRAM & PA & 42059 & GREENE \\
\hline 19 & FAIRMONT & BAPTIST TEMPLE PRE SCHOOL & WV & 54049 & MARION \\
\hline 20 & FAIRMONT & CHILDRENS LEARNING CENTER & WV & 54049 & MARION \\
\hline 22 & FAIRMONT & HEAD START & WV & 54049 & MARION \\
\hline 23 & HAIRMONT & HEAD START & WV & 54049 & MARION \\
\hline 24 & FAIRMONT & METHODIST DAY CARE CENTER & WV & 54049 & MARION \\
\hline 25 & FAIRMONT & NOAHS ARK NURSERY SCHOOL & WV & 54049 & MARION \\
\hline 26 & FAIRMONT & WM & 54049 & MARION \\
\hline 27 & FAIRMONT & SUNBEAM CHILD CARE CENTER & WV & 54049 & MARION \\
\hline 28 & FAIRMONT & CHILD CARE RESOURCES CENTER & 54049 & MARION \\
\hline 29 & FAIRMONT & COUNTRY ANGEL DAY CARE & WV & 54049 & MARION \\
\hline 30 & PALATINE & VALLEY CHAPEL CHILD DEVELOPMENT CENTER & WV & 54049 & MARION \\
\hline 31 & RAGTOWN & WV & 54061 & MONONGALIA \\
\hline 32 & BRUCETON MILLS & GUARDIAN ANGEL CHILD CARE CENTE & WV & 54077 & PRESTON \\
\hline 33 & REEDSVILLE & DAYCARE HUGS AND KISSES & WV & 54077 & PRESTON \\
\hline 34 & REEDSVILLE & PRECIOUS HUGS CHILDRENS CENTER & WV & 54077 & PRESTON \\
\hline
\end{tabular}

\section{Schools}

\begin{tabular}{|c|c|c|c|c|c|}
\hline $\begin{array}{c}\text { Density } \\
\text { within } \\
\text { Distance to } \\
\text { Stack } \\
\text { Range } \\
\text { (km) }\end{array}$ & $\begin{array}{c}\text { Populated Places } \\
\text { Name }\end{array}$ & Sensitive Receptor Name & State & FIPS & County \\
\hline \multicolumn{6}{|l|}{1 in $0-5$} \\
\hline 1 & BRAEWICK WOODS & CHRISTIAN SCHOOLS INCORPORATED & WV & 54061 & MONONGALIA \\
\hline \multicolumn{6}{|l|}{25 in 5-10 } \\
\hline 1 & POINT MARION & $\begin{array}{l}\text { ALBERT GALLATIN AREA SCHOOL DIST ELEM } \\
\text { SCHOOLS }\end{array}$ & PA & 42051 & FAYETTE \\
\hline 2 & HOPECRESRT & AREA SCHOOLS MONANGALIA COUNTY & WV & 54061 & MONONGALIA \\
\hline 3 & HOPECRESRT & MORGANTOWN SCHOOL & WV & 54061 & MONONGALIA \\
\hline
\end{tabular}




\begin{tabular}{|c|c|c|c|c|c|}
\hline 4 & HOPECRESRT & MORGANTOWN SCHOOL & WV & 54061 & MONONGALIA \\
\hline 5 & MORGANTOWN & MORGANTOWN SCHOOL & WV & 54061 & MONONGALIA \\
\hline 6 & MORGANTOWN & $\begin{array}{l}\text { PRESSLEY RIDGE SCHOOLS OF W V MORGANTOWN } \\
\text { SITE }\end{array}$ & WV & 54061 & MONONGALIA \\
\hline 7 & MORGANTOWN & $\begin{array}{c}\text { SCHOOLS CLAY BATTELLE HIGH \& JR HIGH } \\
\text { BLACKSVILLE }\end{array}$ & WV & 54061 & MONONGALIA \\
\hline 8 & MORGANTOWN & UNIVERSITY HIGH SCHOOL & WV & 54061 & MONONGALIA \\
\hline 9 & OSAGE & ADVENTURE HIGH SCHOOL & WV & 54061 & MONONGALIA \\
\hline 10 & OSAGE & MORGANTOWN SCHOOL & WV & 54061 & MONONGALIA \\
\hline 11 & RIVERSIDE & MORGANTOWN SCHOOL & WV & 54061 & MONONGALIA \\
\hline 12 & RIVERSIDE & MORGANTOWN SCHOOL & WV & 54061 & MONONGALIA \\
\hline 13 & SABRATON & TRINITY HIGH SCHOOL & WV & 54061 & MONONGALIA \\
\hline 14 & SABRATON & AREA SCHOOLS MONANGALIA COUNTY & WV & 54061 & MONONGALIA \\
\hline 15 & SOUTHHILLS & MORGANTOWN SCHOOL & WV & 54061 & MONONGALIA \\
\hline 16 & SOUTHHILLS & SCHOOLS WAITMAN BARBE ELEMENTARY & WV & 54061 & MONONGALIA \\
\hline 17 & SOUTHPARK & MORGANTOWN SCHOOL & WV & 54061 & MONONGALIA \\
\hline 18 & SOUTHPARK & MORGANTOWN CHRISTIAN ACADEMY & WV & 54061 & MONONGALIA \\
\hline 19 & SUNCREST & AREA SCHOOLS MONANGALIA COUNTY & WV & 54061 & MONONGALIA \\
\hline 20 & SUNCREST & AREA SCHOOLS MONANGALIA COUNTY & WV & 54061 & MONONGALIA \\
\hline 21 & SUNCREST & ADVENTIST CHRISTIAN SCHOOL FOR NCENTRAL W VA & WV & 54061 & MONONGALIA \\
\hline 22 & SUNSET BEACH & AREA SCHOOLS MONANGALIA COUNTY & WV & 54061 & MONONGALIA \\
\hline 23 & SUNSET BEACH & SHAFFRON PETE \& DONNA & WV & 54061 & MONONGALIA \\
\hline 24 & WESTOVER & MORGANTOWN SCHOOL & WV & 54061 & MONONGALIA \\
\hline 25 & WILES HILL & MORGANTOWN SCHOOL & WV & 54061 & MONONGALIA \\
\hline \multicolumn{6}{|c|}{4 in $10-15$} \\
\hline 1 & MAPLETOWN & $\begin{array}{c}\text { PUB SCHOOLS - ACADEMIC - ELEM - SECONDARY } \\
\text { GREENE CNT }\end{array}$ & $\mathrm{PA}$ & 42059 & GREENE \\
\hline 2 & MAPLETOWN & $\begin{array}{c}\text { SOUTHESTRN GRNE SCHOOL DISTRICT BUS MGR PENN } \\
\text { PITT ELEM }\end{array}$ & PA & 42059 & GREENE \\
\hline 3 & MOUNT MORRIS & $\begin{array}{l}\text { CENTRAL GREENE SCHOOL DISTRICT PERRY } \\
\text { ELEMENTARY }\end{array}$ & PA & 42059 & GREENE \\
\hline 4 & MOUNT MORRIS & SCHOOLS PUB SCHOOLS ACADEMIC ELEM & $\mathrm{PA}$ & 42059 & GREENE \\
\hline
\end{tabular}




\begin{tabular}{|c|c|c|c|c|c|}
\hline & & SECONDARY & & & \\
\hline \multicolumn{6}{|l|}{4 in $15-20$} \\
\hline 1 & FAIRCHANCE & $\begin{array}{l}\text { ALBERT GALLATIN AREA SCHOOL DISTRICT TRI VLY } \\
\text { SR HIGH A }\end{array}$ & $\mathrm{PA}$ & 42051 & FAYETTE \\
\hline 2 & MASONTOWN & $\begin{array}{l}\text { ALBERT GALLATIN AREA SCHOOL DISTRICT FOOD } \\
\text { SERVICE SUPVSR }\end{array}$ & $\mathrm{PA}$ & 42051 & FAYETTE \\
\hline 3 & MC CLELLANDTOWN & $\begin{array}{l}\text { ALBERT GALLATIN AREA SCHOOL } \\
\text { DISTRICTSECONDARY SCHOOLS }\end{array}$ & $\mathrm{PA}$ & 42051 & FAYETTE \\
\hline 4 & SMITHFIELD & $\begin{array}{l}\text { ALBERT GALLATIN AREA SCHOOL DISTRICT } \\
\text { SMITHFLD ELEM SCH }\end{array}$ & PA & 42051 & FAYETTE \\
\hline 4 in $20-25$ & CARMICHAELS & $\begin{array}{l}\text { CARMICHAELS AREA SCHOOL DISTRICT } \\
\text { CARMICHAELS AREA ELEM }\end{array}$ & PA & 42059 & GREENE \\
\hline 1 & NATIONAL & AREA SCHOOLS MONANGALIA COUNTY & WV & 54061 & MONONGALIA \\
\hline 2 & NATIONAL & AREA SCHOOLS MONANGALIA COUNTY & WV & 54061 & MONONGALIA \\
\hline 3 & MASONTOWN & AREA SCHOOLS PRESTON COUNTY & WV & 54077 & PRESTON \\
\hline 4 & & & & & \\
\hline \multicolumn{6}{|l|}{36 in $25-30$} \\
\hline 1 & NEW SALEM & $\begin{array}{c}\text { BROWNSVILLE AREA SCHOOL DIST INTERMEDIATE } \\
\text { UNIT CLASSROOM }\end{array}$ & PA & 42051 & FAYETTE \\
\hline 2 & POINT BREEZE & WHARTON SCHOOL & PA & 42051 & FAYETTE \\
\hline 3 & POINT BREEZE & LIGHTHOUSE CHRISTIAN ACADEMY & $\mathrm{PA}$ & 42051 & FAYETTE \\
\hline 4 & REPUBLIC & $\begin{array}{l}\text { BROWNSVILLE AREA SCHOOL DIST REDSTONE MID } \\
\text { SCHOOL }\end{array}$ & $\mathrm{PA}$ & 42051 & $\overline{\text { FAYETTE }}$ \\
\hline 5 & SOUTH UNIONTOWN & $\begin{array}{l}\text { FAYETTE COUNTY AREA VOCATIONAL TECHNICAL } \\
\text { SCHOOL }\end{array}$ & PA & 42051 & FAYETTE \\
\hline 6 & SOUTH UNIONTOWN & $\begin{array}{c}\text { LAUREL HGLNDS SCHOOL DISTRICT LAUREL } \\
\text { HIGHLANDS JR HIGH }\end{array}$ & PA & 42051 & FAYETTE \\
\hline 7 & UNIONTOWN & COMMUNITIES IN SCHOOLS & $\mathrm{PA}$ & 42051 & FAYETTE \\
\hline 8 & UNIONTOWN & $\begin{array}{c}\text { LAUREL HGLNDS SCHOOL DISTRICT GEN GEORGE C } \\
\text { MRSHLL ELEM }\end{array}$ & PA & 42051 & FAYETTE \\
\hline 9 & UNIONTOWN & $\begin{array}{l}\text { LAUREL HIGHLANDS SCHOOL DIST R W CLARK } \\
\text { ELEMENTARY } \\
\end{array}$ & PA & 42051 & FAYETTE \\
\hline 10 & UNIONTOWN & LAUREL HIGHLANDS SCHOOL DISTRICT R W CLARK & PA & 42051 & FAYETTE \\
\hline
\end{tabular}




\begin{tabular}{|c|c|c|c|c|c|}
\hline & & ELEMENTARY & & & \\
\hline 11 & UNIONTOWN & PRESSLEY RIDGE SCHOOL & $\mathrm{PA}$ & 42051 & FAYETTE \\
\hline 12 & UNIONTOWN & ABC SCHOOL HOUSE & $\mathrm{PA}$ & 42051 & FAYETTE \\
\hline 13 & JEFFERSON & $\begin{array}{c}\text { SCHOOLS PUB SCHOOLS ACADEMIC ELEM } \\
\text { SECONDARY } \\
\end{array}$ & PA & 42059 & GREENE \\
\hline 14 & WAYNESBURG & $\begin{array}{l}\text { CENTRAL GREENE SCHOOL WAYNESBURG CENTRAL } \\
\text { HIGH SCHOOL }\end{array}$ & PA & 42059 & GREENE \\
\hline 15 & WAYNESBURG & $\begin{array}{l}\text { CTRL GREENE SCHOOL DISTRICT MARGARET BELL } \\
\text { MILLER MID }\end{array}$ & $\mathrm{PA}$ & 42059 & GREENE \\
\hline 16 & WAYNESBURG & OPEN DOOR CHRISTIAN SCHOOL & $\mathrm{PA}$ & 42059 & GREENE \\
\hline 17 & WAYNESBURG & WARRIOR TRAIL SCHOOL & $\mathrm{PA}$ & 42059 & GREENE \\
\hline 18 & WAYNESBURG & $\begin{array}{c}\text { CENTRAL GREENE SCHOOL WAYNESBURG CENTRAL } \\
\text { ELEMENTARY SCHOOL }\end{array}$ & PA & 42059 & GREENE \\
\hline 19 & BARRACKVILLE & MARION COUNTY AREA SCHOOLS & WV & 54049 & MARION \\
\hline 20 & BARRACKVILLE & MARION COUNTY AREA SCHOOLS & WV & 54049 & MARION \\
\hline 21 & CHESAPEAKE & $\begin{array}{c}\text { BARNES ELEMENTARY TITLE I PARENT RESOURCE } \\
\text { CENTER }\end{array}$ & $\overline{\mathrm{WV}}$ & 54049 & MARION \\
\hline 22 & FAIRMONT & $\begin{array}{l}\text { AREA SCHOOLS MARION COUNTY EAST DALE } \\
\text { ELEMENTARY }\end{array}$ & $\overline{\mathrm{WV}}$ & 54049 & MARION \\
\hline 23 & FAIRMONT & MARION COUNTY AREA SCHOOLS & WV & 54049 & MARION \\
\hline 24 & FAIRMONT & MARION COUNTY AREA SCHOOLS & WV & 54049 & MARION \\
\hline 25 & FAIRMONT & MARION COUNTY AREA SCHOOLS & WV & 54049 & MARION \\
\hline 26 & FAIRMONT & MARION COUNTY AREA SCHOOLS & WV & 54049 & MARION \\
\hline 27 & FAIRMONT & SCHOOLS PUBLIC SCHOOLS & WV & 54049 & MARION \\
\hline 28 & FAIRMONT & AREA SCHOOLS MARION COUNTY & WV & 54049 & MARION \\
\hline 29 & FAIRMONT & CALVARY CHRISTIAN SCHOOLS & WV & 54049 & MARION \\
\hline 30 & FAIRMONT & EAST FAIRMONT JUNIOR HIGH & WV & 54049 & MARION \\
\hline 31 & FAIRMONT & MARION COUNTY AREA SCHOOLS & WV & 54049 & MARION \\
\hline 32 & FAIRVIEW & $\begin{array}{c}\text { DAYBROOK ELEM SCHOOL TITLE ONE READING } \\
\text { PROGRAM }\end{array}$ & $\mathrm{WV}$ & 54049 & MARION \\
\hline 33 & PALATINE & MARION COUNTY AREA SCHOOLS & $\mathrm{WV}$ & 54049 & MARION \\
\hline 34 & RIVESVILLE & MARION COUNTY AREA SCHOOLS & WV & 54049 & MARION \\
\hline 35 & ARTHURDALE & VALLEY ELEMENTARY SCHOOL & WV & 54077 & PRESTON \\
\hline
\end{tabular}




\begin{tabular}{|l|c|c|c|c|c|}
\hline 36 & BRUCETON MILLS & PRESTON COUNTY OF SCHOOLS BRCTN SCH K 8 CTRL & WV & 54077 & PRESTON \\
\hline
\end{tabular}

\section{Hospitals/Medical Centers}

\begin{tabular}{|c|c|c|c|c|c|}
\hline \begin{tabular}{|c|} 
Density \\
within \\
Distance to \\
Stack \\
Range \\
(km) \\
\end{tabular} & $\begin{array}{c}\text { Populated Places } \\
\text { Name }\end{array}$ & Sensitive Receptor Name & State & FIPS & County \\
\hline \multicolumn{6}{|l|}{1 in $0-5$} \\
\hline 1 & BRAEWICK WOODS & MONONGALIA GEN HOSP & WV & 54061 & MONONGALIA \\
\hline \multicolumn{6}{|l|}{2 in 5-10 } \\
\hline 1 & THE FLATTS & RUBY MEMORIAL HOSPITAL & WV & 54061 & MONONGALIA \\
\hline 2 & THE FLATTS & UNIVERSITY HEALTH ASSOCIATES & WV & 54061 & MONONGALIA \\
\hline \multicolumn{6}{|l|}{0 in 10-15 } \\
\hline \multicolumn{6}{|l|}{0 in $15-20$} \\
\hline \multicolumn{6}{|l|}{1 in $20-25$} \\
\hline 1 & FAIRCHANCE & SEWICKLEY VALLEY HOSPITAL CREDIT & PA & 42051 & FAYETTE \\
\hline \multicolumn{6}{|l|}{14 in $25-30$} \\
\hline 1 & NEW SALEM & $\begin{array}{l}\text { FAYETTE EMERGENCY MEDICAL SERVICE } \\
\text { INCORPORATED }\end{array}$ & PA & 42051 & FAYETTE \\
\hline 2 & REPUBLIC & $\begin{array}{l}\text { FAYETTE EMERGENCY MEDICAL SERVICE } \\
\text { INCORPORATED }\end{array}$ & PA & 42051 & FAYETTE \\
\hline 3 & SOUTH UNIONTOWN & SOUTHWEST WOMENS HEALTH CARE INC & PA & 42051 & FAYETTE \\
\hline 4 & UNIONTOWN & LAUREL RIDGE CENTER & $\mathrm{PA}$ & 42051 & FAYETTE \\
\hline 5 & UNIONTOWN & UNIONTOWN HOSPITAL PRIORITY CARE & PA & 42051 & FAYETTE \\
\hline 6 & UNIONTOWN & $\begin{array}{l}\text { UNIONTOWN HOSPITAL UNIONTOWN HOSPITAL } \\
\text { FOUNDATION }\end{array}$ & $\mathrm{PA}$ & 42051 & FAYETTE \\
\hline 7 & UNIONTOWN & CENTRAL MEDICAL CENTER AND HOSPITAL & $\overline{\mathrm{PA}}$ & 42051 & FAYETTE \\
\hline
\end{tabular}




\begin{tabular}{|c|c|c|c|c|c|}
\hline 8 & WAYNESBURG & OCCUPTNL MEDCN CENTER WASHINGTON HOSP & PA & 42059 & GREENE \\
\hline 9 & BRUCETON MILLS & HARNED MEMORIAL MEDICAL CLINIC & WV & 54077 & PRESTON \\
\hline 10 & FAIRMONT & FAIRMONT GENERAL HOSPITAL & WV & 54049 & MARION \\
\hline 11 & FAIRMONT & GENERAL HOSPITAL & WV & 54049 & MARION \\
\hline 12 & FAIRMONT & WOUND HEALING CENTER OF FAIRMONT & WV & 54049 & MARION \\
\hline 13 & FAIRVIEW & FAIRVIEW EMERGENCY MEDICAL SERVICES & WV & 54049 & MARION \\
\hline 14 & REEDSVILLE & WEST PRESTON MEDICAL CLINIC & WV & 54077 & PRESTON \\
\hline
\end{tabular}

\section{Nursing Homes}

\begin{tabular}{|c|c|c|c|c|c|}
\hline $\begin{array}{c}\text { Density } \\
\text { withing } \\
\text { Distance to } \\
\text { Stack } \\
\text { Range } \\
(\mathbf{k m}) \\
\end{array}$ & $\begin{array}{c}\text { Populated Place } \\
\text { Name }\end{array}$ & Sensitive Receptor Name & State & FIPS & County \\
\hline \multicolumn{6}{|l|}{1 in $0-5$} \\
\hline 1 & BRAEWICK WOODS & MORGANTOWN HOSPICE & WV & 54061 & MONONGALIA \\
\hline \multicolumn{6}{|l|}{2 in $5-10$} \\
\hline 1 & SUNCREST & TENDER LOVING CARE HOME CARE & $\mathrm{WV}$ & 54061 & MONONGALIA \\
\hline 2 & THE FLATTS & THE MADISON & $\mathrm{WV}$ & 54061 & MONONGALIA \\
\hline \multicolumn{6}{|l|}{0 in $10-15$} \\
\hline \multicolumn{6}{|l|}{0 in $15-20$} \\
\hline \multicolumn{6}{|l|}{0 in $20-25$} \\
\hline \multicolumn{6}{|l|}{3 in $25-30$} \\
\hline 1 & UNIONTOWN & MABELS PERSONAL CARE HOME & $\mathrm{PA}$ & 42051 & FAYETTE \\
\hline 2 & WAYNESBURG & HOSPICE CARE INCORPORATED & $\mathrm{PA}$ & 42059 & GREENE \\
\hline 3 & FAIRMONT & FAIRMONT CLINIC & $\mathrm{WV}$ & 54049 & MARION \\
\hline
\end{tabular}

